\title{
RESPONSIBLE CONSOLIDATION OF CUSTOMARY
}

LANDS 



\title{
RESPONSIBLE CONSOLIDATION OF CUSTOMARY LANDS
}

\author{
DISSERTATION
}

to obtain

the degree of doctor at the University of Twente, on the authority of the rector magnificus,

prof.dr. T.T.M. Palstra,

on account of the decision of the doctorate board, to be publicly defended

on Wednesday 17 April 2019 at 16.45 hrs

by

Kwabena Obeng Asiama

born on 28 November, 1989

in Kumasi, Ghana 
This thesis has been approved by

Prof.mr.dr.ir. J.A. Zevenbergen, supervisor

Dr. R.M. Bennett, co-supervisor

ITC dissertation number 350

ITC, P.O. Box 217, 7500 AE Enschede, The Netherlands

ISBN 978-90-365-4754-3

DOI $10.3990 / 1.9789036547543$

Cover designed by Benno Masselink

Printed by ITC Printing Department

Copyright (c) 2019 by Kwabena Asiama

\section{UNIVERSITY OF TWENTE.}

T1C FACULTY OF GEO-INFORMATION SCIENCE AND EARTH OBSERVATION 
Graduation committee:

\section{Chairman/Secretary}

Prof.dr.ir. A. Veldkamp University of Twente

\section{Supervisor}

Prof.mr.dr.ir. J.A. Zevenbergen University of Twente

\section{Co-supervisor}

Dr. R.M. Bennett

Swinburne University of Technology

\section{Members}

Prof.dr.ir. C.H.J. Lemmen

Prof.ir. P. van der Molen

niversity of Twente

Prof.dr.ir. A. van den Brink

University of Twente

Dr. T. van Dijk

Wageningen University

Dr. R.T. Abdulai

University of Groningen

Newcastle University 

For Seth and Clara 



\section{Acknowledgements}

This thesis is the product of the help and contributions from a lot of people who made themselves available in many capacities in particular, Jaap Zevenbergen and Rohan Bennett. Jaap's inspiring guidance and foresight as the promoter got this work started and greatly helped in shaping it into its robust form. After pestering Jaap from the first day I met him during my MSc period that I want to do a PhD, it was through his encouragement that I applied for and received the Twente Graduate School (TGS) grant. Unfortunately, when I couldn't access the grant, he was very instrumental in me getting funded for a four year AiO/PhD candidate contract with University of Twente, to start this work. Whilst I was applying for the TGS grant, Rohan became my daily supervisor. Rohan is both a superb supervisor and teacher, who challenges his students to think outside their preconceived notions and look at the different sides of an issue. Together they formed an exceptional and complementary team, and I am very appreciative of their efforts.

On fieldwork in Ghana, my first encounter in Nanton was with a very jovial man by the name of Adam Abdullai Osman, who took me around the community to introduce me and explained traditional norms, and courtesies as well as nuances that underpinned the culture. I am also grateful to the late Nanton-Na, Naa Alhaji Alhassan Sulemana, who allowed the work to start in his community, and to his son, Sulley Seidu, the Head of the Nanton Customary Land Secretariat for opening his office allowing his staff to assist with the fieldwork. And also to the Regent of Nanton, Naa Abdullai Mahama, who allowed the work to continue in Nanton.

In Tongo, I arrived without any contacts, but I was led to Maurice Korah, who was very instrumental in the data collection, going as far as running me around on his motorcycle. I am also grateful to the Paramount Chief of Talensi, Tongraan Kugblisong Nalebteng and his court as well as the late Tindana of Talensi, Baare Tindan Mayalik and his court, both of whom took the time to have several discussions with me about the area, and also allowing me to work in their jurisdictions. I am also grateful to the people of Nanton, Tongo, and Agbakofe for the warm reception they extended to me during my stay in their communities. Also to several people at the Dutch Kadaster such as Chrit Lemmen (whose lectures during my MSc got me interested in land consolidation in the first place), Marije Louwsma, Dave Bruyning, and ErnstPeter Oosterbroek. Big thanks also to the two MSc. students from Rwanda who were instrumental in my data from Rwanda, Innocent Rubanye (of blessed memory), and Oscar Gasuku.

I would also like to acknowledge the roles played by Justice Rebecca Sittie, Dr. Wilfred Anim-Odame, Jones Ofori-Boadu, Yaa Boadu, Abdul Hanan, and Mark 
Kakraba Ampeh in the data collection. They made themselves available for interviews, and small talks afterwards when I needed more information. And several people in Ghana of whom I bounced ideas at various stages of this research including Prof. Kasim Kasanga, Dr. Anthony Arko-Adjei, and Jonathan Zinzi Ayitey. And to the DigitalGlobe Foundation for providing the satellite imagery used for this research.

Special thanks also goes to Andre da Silva Mano who advised on parts of this work to aid in its completion. Also to my former officemate, Dimo Todorovski, who kept his door open from my first day, ready to dispense advice about how to navigate the $\mathrm{PhD}$ life, and the university bureaucracy. Lots of thanks also to Abhishek Nair, with whom I shared close quarters for the last four years. To Javier Morales, who took the time to introduce me to the use of ESRI's Collector for ArcGIS. I would also like to thank my colleagues and friends in ITC for the support and encouragement especially Monica Lengoiboni, Christine Richter, Divyani Kohli, Mila Koeva, Monika Kuffer, Paul van Asperen (who translated the summary of this thesis into Dutch), Liza Groenendijk, Peter Laarakker, Claudia Stoker, Fenna Hoefsloot, Andres Morales, Alice Nikuze, Flavia de Souza and many other ITC colleagues and friends. Furthermore to the professional and administrative staff of ITC who made my PhD period both smooth and a delight. In particular to Petra Weber, Jacqueline Mol, Marlies Nijhuis and Loes Colenbrander, who steered me through the complex university bureaucracy. And to Benno Masselink and Job Duim who were always quick to help with all printing needs. Also to Roelof Schoppers, whose smile greeted me at the front desk when I walked in through ITC's doors every morning for the past six years - one of the small gestures that make a good start to a day in ITC. Oh of course, with my love for food, I can't leave out the ITC Restaurant staff for the sumptuous meals daily. Heel lekker!

The Ghanaian community in Enschede has also been very supportive, and a shoulder to lean on, including Kwame Aviane, Frank Osei, Zaid Abubakari, Kingsley Kumah, Baslyd Nara, Muntaka Kamaro, Uncle Lord and Auntie Gladys. Also to the International Christian Fellowship (ICF-Enschede), for being a home away from home. And to several other friends in Enschede - Arun, Bart, Sheila, Sanne, Desiree, and many others.

And finally to my family and friends. To my friends who provided support in many capacities throughout this period, especially Frank Kuffour, Afia Boakye, Kwame Obeng, and Ebenezer and Cynthia Incoom. To my parents, Seth and Clara, for their most affectionate love and encouragement, teaching me the value of hard work, believing in me even when I didn't see myself able, and most of all never sparing the rod. It is that discipline that has kept my eye on the ball. To my siblings - Lady, Kay, and Maame, for cheering your little brother on! And to my adorable nieces and nephews - Kukua, Mamboa, Eno, Bryan, 
Mimi, and Kofi, for making their favourite uncle's trips home something to always look forward to!

If I can see far, it is because I stand on the shoulders of giants (Bernard of Chartres) 


\section{Table of Contents}

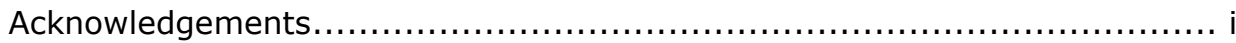

List of Figures........................................................................ vii

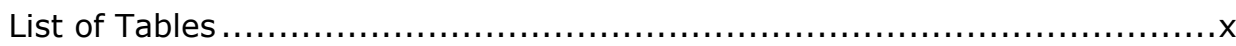

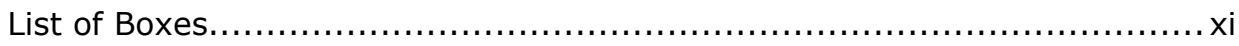

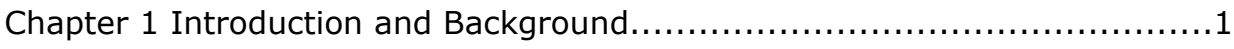

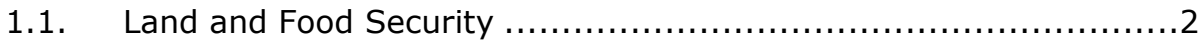

1.2. Land Fragmentation .....................................................

1.3. Customary Land Tenure, Agricultural System and

Land Fragmentation .....................................................

1.4. Land Consolidation: The Problem Statement ..........................6

1.5. Responsible Land Consolidation.......................................9

1.6. Research Formulation; General and Specific Objectives ..............11

1.7. Methodology .......................................................... 11

1.8. Overview of Study Areas .......................................... 13

1.9. Outline of Thesis....................................................... 16

Chapter 2 Land Consolidation on Customary Lands: Learning from

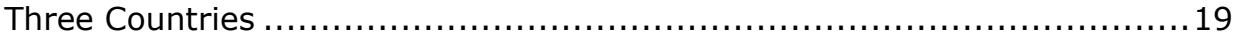

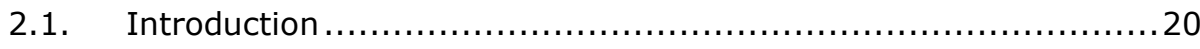

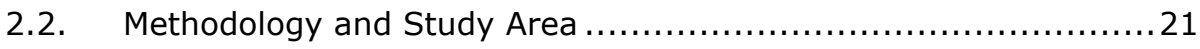

2.3. An analytical framework for understanding the choice of

land consolidation strategies...........................................24

2.3.1. Technological and Legal Issues...................................24

2.3.2. Political Issues...................................................... 26

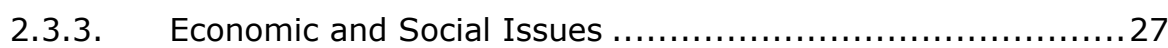

2.3.4. Environmental Issues ....................................... 28

2.4. Land Consolidation Influences in the Netherlands, Lithuania,

Rwanda, and Ghana - A Comparative Analysis .......................29

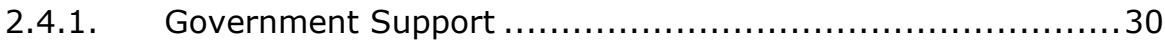

2.4.2. Land Market and Land Mobility ............................... 31

2.4.3. Land Tenure, Land Fragmentation, and Farming Technology. 32

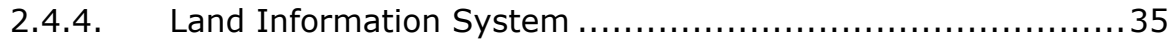

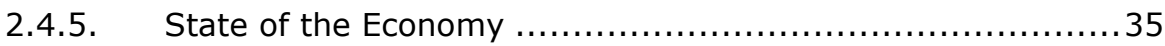

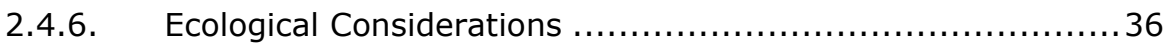

2.5. Discussion .............................................................. 38

2.5.1. Customary Authorities as the Land Consolidation Authority .. 39

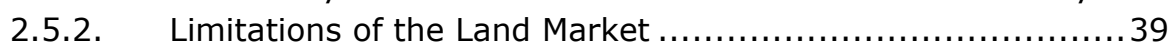

2.5.3. Low Farming Technology, and High Physical and Land Tenure Land Fragmentation ........................................ 40

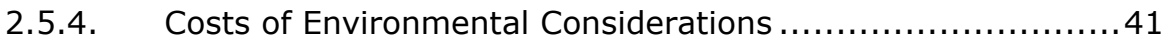

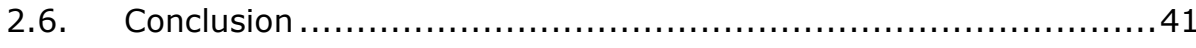

Chapter 3 Participatory Land Administration for Responsible Land

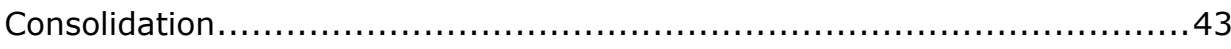


3.1. Introduction ....................................................... 44

3.2. Participatory Land Administration: A Theoretical Background.......45

3.2.1. From Voluntary Geographic Information to Participatory Land Administration................................................ 46

3.2.2. Aspects of Participatory Land Administration ................... 48

3.3. The Experiment ................................................... 51

3.3.1. Innovative Approaches to Customary Land Administration in Ghana............................................................ 51

3.3.2. The Area of Interest ........................................... 52

3.3.3. Land Consolidation's Information Needs on Customary

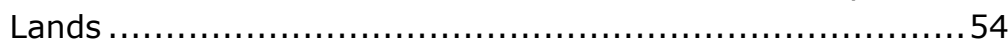

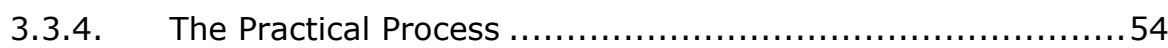

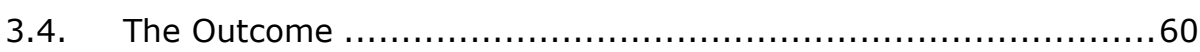

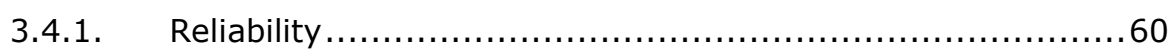

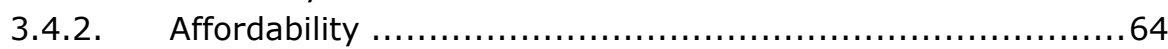

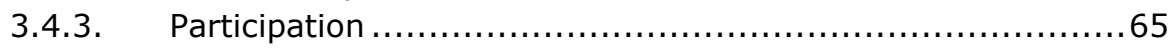

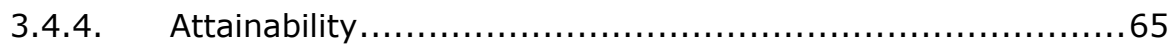

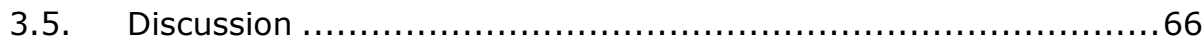

3.5.1. Technological Innovation Push: Mobile App vs. Satellite Images ............................................................... 67

3.5.2. Bottom-Up Citizen Contribution: CLS, TIs and Quality

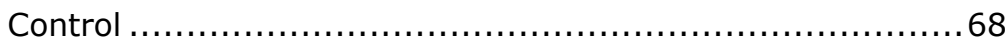

3.5.3. Societal Needs and Pull: Land Consolidation in Support of

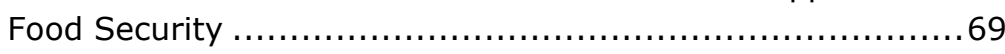

3.5.4. Top-Down Institutional Influence: Professional Standards and Legal Requirements........................................... 70

3.6. Conclusions............................................................. 70

Chapter 4 Land Valuation on Rural Customary Farmlands...................... 73

4.1. Introduction ....................................................... 74

4.2. Background on Land Valuation for Land Consolidation ................75

4.3. Valuation of Customary Lands in Ghana ...............................77

4.4. The Framework for a Valuation Approach for Customary Lands .... .78

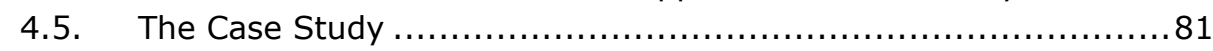

4.5.1. The Area of Interest ........................................ 82

4.5.2. The Land Valuation Factors .................................. 84

4.5.3. Scenario Analysis: The Impact of the Weights on the Land Value Index........................................................ 90

4.5.4. Sensitivity Analysis: The Effect of Individual Weight Changes in the Land Value Indices..................................992

4.5.5. The influence of Automatic Valuation Models (AVMs) ...........93

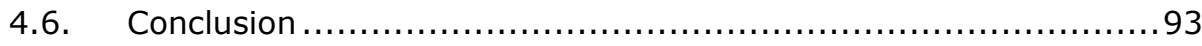

Chapter 5 Customary Land Reallocation........................................ 95

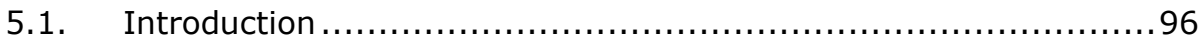

5.2. Research Approach and Methodology ................................ 99 
5.3. Model Design and Development .................................. 100

5.3.1. General Requirements for Land Reallocation.................... 100

5.3.2. Customary Lands: A Background and General Characteristics ................................................... 103

5.3.3. Framework for General Land reallocation Process on Customary Lands .................................................... 105

5.4. Applying the Model: Case and Findings ............................. 109

5.4.1. Overview of the Area of Interest............................... 109

5.4.2. The Land Fragmentation Situation and Farming System ..... 111

5.4.3. Mediating Authority ............................................. 114

5.4.4. The Land Tenure Situation, Local Customs and Land Mobility ......................................................... 115

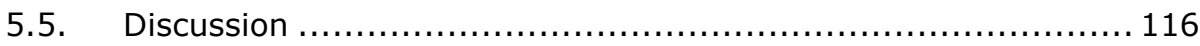

5.6. Conclusion ........................................................ 118

Chapter 6 Towards Responsible Land Consolidation: Summary and

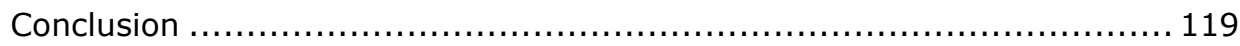

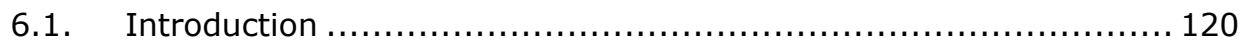

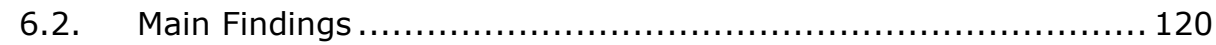

6.2.1. To explore how the factors, need to be addressed to develop a responsible land consolidation approach for customary lands.......................................... 121

6.2.2. To develop and assess an approach for collecting land information to support responsible land consolidation . 122

6.2.3. To develop and assess a land valuation approach to support responsible land consolidation on customary lands. 123

6.2.4. To develop the framework for a reallocation approach to support land consolidation on customary lands ................ 124

6.3. Implications of Results........................................... 125

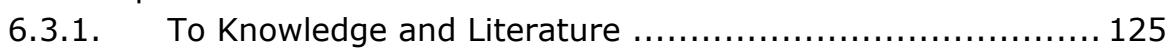

6.3.2. To Policy Formulation and Implementation...................... 126

6.3.3. To Meeting Other Societal Challenges and Needs ............. 128

6.3.4. To the Areas of Interest in Ghana ............................ 128

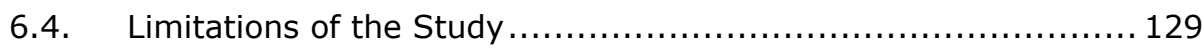

6.5. Future Research Prospects ......................................... 129

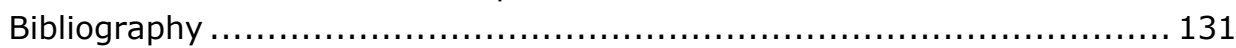

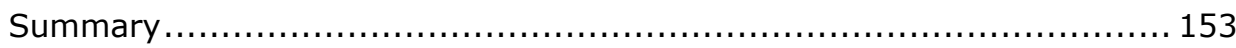

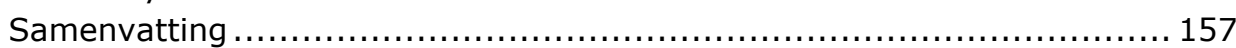

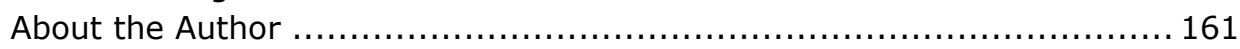




\section{List of Figures}

Figure 1: Conceptual Framework for the Problem Statement....................9 Figure 2: Map of Ghana showing the locations and Agro-Ecological Zones of the Study Areas .................................................................. 15

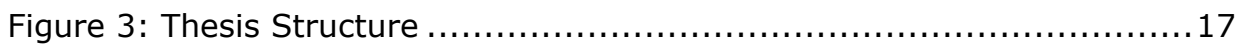

Figure 4: The Research Design................................................. 21

Figure 5: Framework for the selection or development of a land consolidation

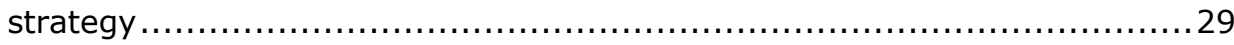

Figure 6: Hierarchy of Rural Customary Land Tenure in Ghana................. 33 Figure 7: General Representation of the predominant types of land fragmentation in the Netherlands, Lithuania, Rwanda, and Ghana .............34 Figure 8: Continuum of Land Consolidation Strategies ............................. 39 Figure 9. Structure of Participatory Land Administration..........................50 Figure 10. Map showing the area of interest in the Nanton Traditional Area and

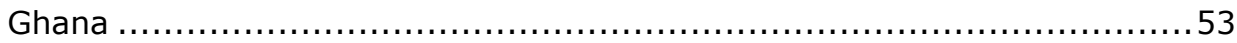

Figure 11: A Farmer walking the boundary of his farm ..........................55

Figure 12: Interface of the Mobile App, Collector for ArcGIS ...................56

Figure 13: Farmers and Trusted Intermediaries (TIs) identifying their farmland

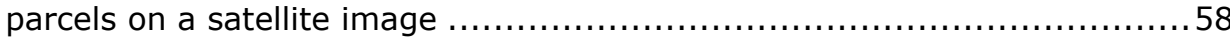

Figure 14: A Farmer and Trusted Intermediaries happy with their results ...59 Figure 15. Part of the satellite image from the farm parcel identification showing Red Lines that are parcels identified by farmers and Black lines being parcels verified by the Trusted Intermediaries. ...................................61 Figure 16. Parcels boundaries collected by Satellite Image (Blue) and Mobile

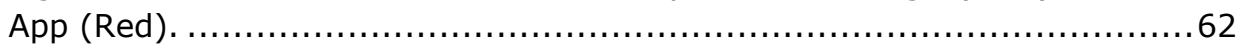

Figure 17. Family Lands in the Area of Interest..................................63

Figure 18: Flowchart of the Farmland Parcel Valuation Process..................8 80

Figure 19: Map of Ghana showing the Study Area and other areas relevant to

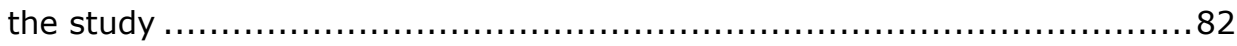

Figure 20: The Area of Interest (with farm boundaries denoted by blue lines)

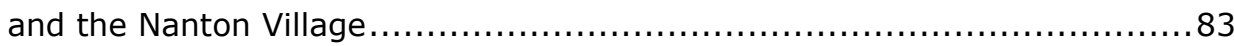
Figure 21: Summary of Land Value Factors (Adapted from (Wyatt, 1996)...85 Figure 22: The Physical Attributes and Legal Conditions in the Area of Interest

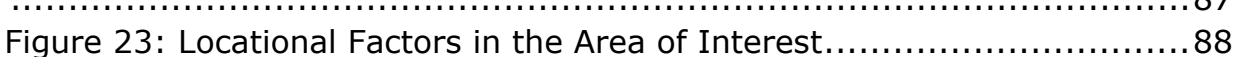

Figure 24:Land Value Indices of the Farmland Parcels....................... 89

Figure 25: The comparison of the four scenarios ......................... 91

Figure 26: The sensitivity of the overall LVI for either an increase or decrease

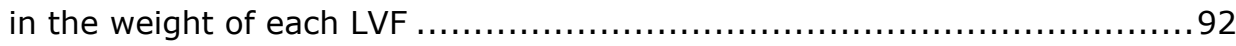

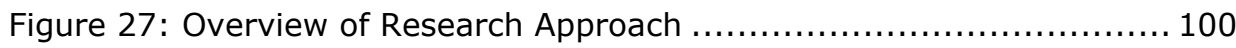

Figure 28: Summary of the General Requirements for Land reallocation ... 102

Figure 29: Flowchart of the Land reallocation Framework for Customary Lands 
Figure 30: Map of Ghana Showing the Location of the Area of Interest.... 108

Figure 31: Map Showing the Farmland Parcels in the Area of Interest ...... 110

Figure 32: New Farmland Parcel Arrangements............................. 111

Figure 33: Change Detection Map for Original and New Farmland Parcel

Arrangements....................................................... 113

Figure 34: Summary of findings connecting the gaps in concepts identified in

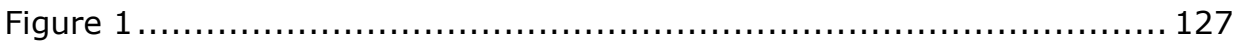




\section{List of Tables}

Table 1: Summary of the Influences of the Factors in three countries with existing Land Consolidation strategies and Customary Lands. ...................37

Table 2. Summary of Assessment Elements and Indicators.....................60

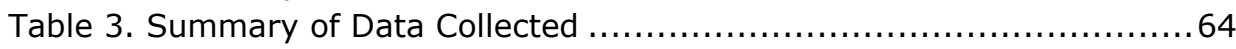

Table 4. Breakdown of the Cost of the Mapping Process ..........................65

Table 5. The Experiment Process and the Role of the Actors ....................66

Table 6: Land Value Indices Table for Farmland Parcels ..........................81

Table 7: Weights assigned to the LVFs according to the scenarios .............90

Table 8: Summary of the Farms in the Area of Interest....................... 109

Table 9: Summary of the Effect of the Approach of the Physical Land

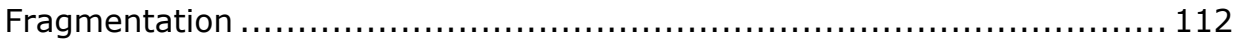




\section{List of Boxes}

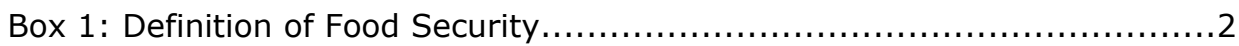

Box 2: Farmland Parcel and Farm Holding........................................ 3

Box 3: Definition of Land Fragmentation ..........................................

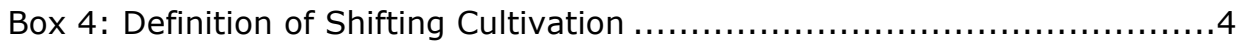

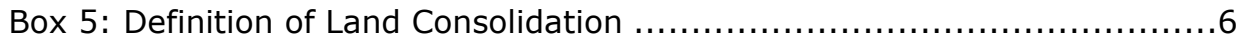

Box 6: Definition of Responsible Land Consolidation .......................... 10

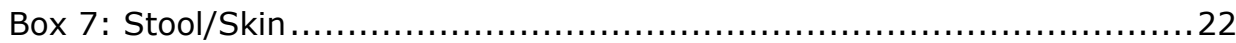

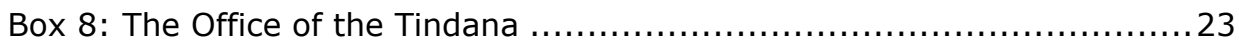

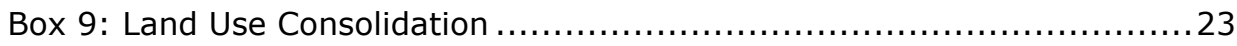

Box 10: Voluntary Land Consolidation ........................................... 26

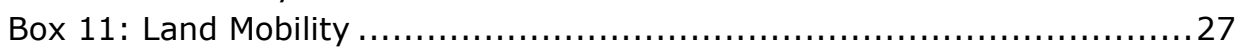

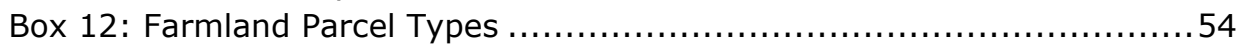

Box 13: Customary Share Cropping ......................................... 104 


\section{Chapter 1 Introduction and Background*}

* This chapter is the extended version of an international peer reviewed journal paper published as:

Asiama, K. O., Bennett, R. M., \& Zevenbergen, J. A. (2017a). Land Consolidation for Sub-Saharan Africa's Customary Lands - The Need for Responsible Approaches. American Journal of Rural Development, Vol. 5, 2017, Pages 39-45, 5(2), 39-45. https://doi.org/10.12691/AJRD-5-2-2 


\subsection{Land and Food Security}

Food security is a crucial global challenge that has received much attention over the past two decades from international bodies, particularly in relation to sub-Saharan Africa. The importance of food security is highlighted by its elevation from a target of one of the Millennium Development Goals (MDG 1c) to a Sustainable Development Goal (SDG 2). Food security is a multi-faceted agenda with several dimensions. Achieving food security means tackling its four dimensions - food availability, food accessibility, food utilisation, and food stability (Pinstrup-Andersen, 2009). Food availability is the physical existence of adequate food of the appropriate quality for a population, encompassing the food supply, food production, and food aid. Food access entails the physical, economic/financial, and social

Box 1: Definition of Food Security Food security exists when all people, at all times, have physical and economic access to sufficient, safe and nutritious food to meet their dietary needs and food preferences for an active and healthy life (FAO, 1996).

abilities and barriers of a population to acquire a requisite amount of food regularly. Food utilization refers to the process through which the body utilises various nutrients in food, through proper food preparation, hygienic practices, and a balanced diet. Food stability refers to the ability to maintain the other three dimensions over time. The achievement of these four dimensions requires policies and processes that cover two key areas - nutrition transition and security, and food and agricultural production (Van der Molen, 2016). Nutritional transition covers the need for the growing population, increased urbanisation and rising incomes to be accompanied by a shift in food consumption patterns that favour resource intensive foods, animal products, fat and sugar. This study uses agricultural productivity as the primary motivator.

The link between food security and agricultural productivity on the one hand and, land and land administration on the other hand has been explored practically and theoretically. Theoretically, Bennett et al. (2015) shows land administration as one of the support systems that lead to increased food security, though it undermines it in some cases. Van der Molen (2016) concludes that provision of food security requires the growth of agricultural productivity. Statistically about 821 million people in the world $(10.9 \%$ of the world population) are undernourished (FAO, 2018). To provide food for the estimated 9.5 billion in 2050a $70 \%$ increase in global food productivity is needed. It is estimated that globally, 1.5 billion out of the 4.2 billion hectares of arable land is being used for agricultural production. These numbers are more pronounced in the Sub-Saharan African (SSA) region, with $22.7 \%$ of the population (224.3 million people) being undernourished (FAO, 2017). 
However, even though Africa is estimated to contain $60 \%$ of the world's uncultivated land, it is estimated that $65 \%$ of Africa's arable land is too damaged to sustain viable food production (The Montpellier Panel, 2014). This problem points to the need to effectively manage the remainder of the arable land. The institutional and technical approaches to increasing agricultural productivity include, but are not limited to land and water access, access to markets, land tenure security, better roads, mechanisation, and use of fertilizers. However, one factor that is found to impede these institutional and technical approaches to increase agricultural productivity, among others, is the fragmented structure of farms (Bentley, 1990; King \& Burton, 1982; Van Dijk, 2003a). In many cases land consolidation has been touted as an effective solution to land fragmentation (Bullard, 2007; Jürgenson, 2016; Niroula \& Thapa, 2005). This thesis aims to develop a responsible approach to land consolidation on customary lands, using Ghana as a case.

\subsection{Land Fragmentation}

Land fragmentation is often seen as a serious hindrance to agricultural development as it obstructs mechanisation and reduces productivity, resulting in large costs in assuaging these effects. Studies identify two main forms of land fragmentation; physical and tenure fragmentation. Physical fragmentation is described as the spatial dispersion of farm parcels over a large area of land (also known as scattering) and the division of farm parcels into small near-unproductive parcels (sub-division) (Bullard,

Box 2: Definition of Land
Fragmentation
Land Fragmentation is the dispersion of a
single farm-holding into several distinct
farmland parcels, as well as a discrepancy
between land use and ownership (Binns,
1950; King and Burton, 1982; Van Dijk,
2003).
2007; King \& Burton, 1982). The second, land tenure fragmentation, is described by Van Dijk (2003) as a discrepancy between land use and ownership. Land fragmentation has also been shown to have some positive impacts on farm productivity as evidenced by Blarel et al. (1992) and Netting (1972) in studies focused on Ghana, Rwanda, and Switzerland. As such, McPherson (1982) groups the causes of land fragmentation into two causes supply-side and demand-side. The supply-side causes suggest land

Box 3: Farmland Parcel and Farm Holding

Farmland Parcel is a single contiguous expanse of farmland.

Farm holding is a collection of farm parcels farmed by one (or a group of) farmer(s). fragmentation is a result of external forces such as population growth and cultural systems which may result in partible inheritance and land scarcity, as has been the case in most of 
Western Europe (Van Dijk, 2003a); and a change in government policy that results in a breakdown of common or communal property systems, as happened in Central and Eastern Europe and Eastern Nigeria (Hartvigsen, 2015c; Udo, 1965). In general, areas with land fragmentation caused by external forces have resulted in negative social, economic, and environmental impacts and outcomes. However, demand-side causes result from farmers' choices, due to the positive impacts and benefits they reap from land fragmentation. These benefits include the spreading of risk, especially in volatile areas, spreading of land parcels to take advantage of different types of soil for crop diversification, the level of technology available to them, the practice of shifting cultivation, and enabling better allocation of labour over the seasons as happens in the Swiss mountainous regions (Blarel et al., 1992; Netting, 1972).

Land fragmentation has always been prevalent in the agricultural system of customary lands, however its articulation as a problem is a recent occurrence (Eastwood et al, 2010; Headey \& Jayne, 2014; Pingali et al., 1987). Despite this, recent studies examining food productivity in customary lands rather focus on the mechanisation of farms and fertilizer use than dealing with land fragmentation (Baudron et al., 2015; Binswanger \& Pingali, 1989; Houmy et al., 2013; Nothale, 1986; Thurston, 1987).

\subsection{Customary Land Tenure, Agricultural System and Land Fragmentation}

Land fragmentation on customary lands has two key causes - the customary land tenure (a supply-side cause), and the agricultural system (a demand-side cause). Customary land is defined in several ways depending on the origins. However, there are three fundamental elements. The first is that land is held on the basis

\section{Box 4: Definition of Shifting} Cultivation

Shifting cultivation, which thrives on land fragmentation, involves farming a parcel of land for a period and then leaving it to fallow whilst another area is farmed. of locally evolved native land tenure; secondly, the basis of the land holding is both group and individual rights, with the former superseding the later; and thirdly, the mechanisms for obtaining, using, distributing and disseminating these rights arise from accepted practices based on the group's customs and traditions (Arko-Adjei, 2011; Kalabamu, 2014; van Gils et al., 2014). Customary lands may also be referred to as community lands, communal lands, indigenous lands, traditional lands, among others (S. O. Asiama, 2004; Migot-Adholla et al., 1991; Quiggin, 1995; van Gils et al., 2014). Customary land tenure reflects the socio-cultural and spiritual bonds among generations - the many who have passed on, the 
living few, and the countless generation yet unborn. The basic tenet of customary land administration is that the current generation is a mere caretaker of the land meant to protect it as the legacy of their ancestors and safeguard it for the future generation.

The nature of customary land tenure systems, together with the changing agricultural system of customary lands, also presents another key cause of land fragmentation (Migot-Adholla et al., 1991; Pingali et al., 1987). Shifting cultivation, the predominant agricultural system of customary lands, favours the acquisition of land by forest clearance as it uses the natural fertility of land, and small farming equipment on small parcels, resulting in low productivity (Headey \& Jayne, 2014; Pingali et al., 1987). Shifting cultivation allows for the tilling of the farms one after the other, gradually causing land fragmentation, as the customary land tenure allows the farmer to keep his land use rights in perpetuity. The fragmentation of parcels is not a problem when population and demand for food is low: the farmer is able to take advantage of the fragmented parcels to deal with seasonal labour bottlenecks (Fenoaltea, 1976; OheneYankyera, 2004). The increase in demand for food in urban areas, in tandem with the supply of fertilizer, causes the adoption of more intensive agricultural systems such as the annual cultivation and the multiple cropping farming systems which require simultaneous cultivation of the farm parcels, intensive weeding and ploughing (Abunyewa et al., 2007; Kuusaana \& Bukari, 2015; Pingali, 2007). Higher returns to labour offered by the industrial and service sectors, as against the farming sector, also substantially reduce the available pool of labour that can be hired, resulting in the farm labour being determined by the household size (Ohene-Yankyera, 2004). The labour shortage necessitates the adoption of large farm machinery, to keep up with the urban food demand, which is difficult with small, scattered farms. The simultaneous farming of the fragmented parcels, use of rudimentary farming equipment, and application of fertilizer, still results in a less optimum productivity than experienced with the shifting cultivation (Abunyewa et al., 2007; Heisey \& Mwangi, 1996). This makes it necessary to deal with the land fragmentation situation. 


\subsection{Land Consolidation: The Problem Statement}

Land consolidation, in various forms, has been successfully used in Europe to curb land fragmentation and increase food productivity, and further develop

\begin{tabular}{l} 
Box 5: Definition of Land \\
Consolidation \\
Land consolidation is a land \\
management activity that involves all \\
the procedures for exchanging farmland \\
parcel rights, rearranging, realigning, \\
and expanding farmland parcels. \\
\hline
\end{tabular}
rural areas. However the majority of land consolidation attempts in customary lands in sub-Saharan Africa have either failed or broken down the customary land tenure in the areas (Coldham, 1978; Nothale, 1986; Takane, 2008; Taylor, 1964). These attempts at land consolidation were predicated on the assumption that land consolidation was needed as an approach to developing the agricultural sector, even though land tenure and agricultural systems did not favour it (Makana, 2009; Swynnerton, 1955; Thurston, 1987). Makana (2009) however notes that land consolidation in some customary lands rather yielded positive results in terms of increase in food production, despite the breakdown of the customary land tenure. Various reasons have been advanced for the successes and the failures of these land consolidation schemes. One group attributes the fortunes of the process to the participation of all the parties involved, whilst another is the failure to adapt the land consolidation scheme to the conditions of the customary area (Abubakari, 2015; Taylor, 1964). In Malawi, land consolidation was started in the 1940's, and although the government was successful in consolidating 81,000 hectares of farmlands, complete with infrastructural improvements, the programme still failed because it was solely run by the colonial government, after being prematurely rolled out without consideration for local factors and conditions (Nothale, 1986). Kenya's land consolidation was also started by the colonial government; however, a major objective was a complete overhaul of the land tenure system that was to do away with the customary land tenure and replace it with individual titles, as customary rules were seen to be a militating factor against the benefits of land consolidation and a wellfunctioning land market (Coldham, 1978). Here the land consolidation planning was participatory, with the plans being drawn by the government officials together with the clan elders. However, the last step of the plan was to grant individual titles, thus effectively ending the coverage of customary land in these areas.

The most recent of the land consolidation activities in Sub-Saharan Africa is from Rwanda, which undertook a new form of land use consolidation. Land use consolidation is the procedure of putting together small plots of land in order to manage the land use in an efficient manner so the land is more productive (Republic of Rwanda, 2005). With the prime objective of increasing agricultural 
production, the reasoning behind this is to be able to undertake a land consolidation programme that does not alter the land tenure relations (Musahara, Nyamulinda, Bizimana, \& Niyonzima, 2014).

Land consolidation, as a land development tool, has the goal of reducing the number of farmland parcels per farm land holding. This is achieved by exchanging, rearranging, and realigning the farmland parcels. Land consolidation procedures can be generally grouped into three main stages the administrative preparatory stage, inventory and planning (technical) preparation stage, and the implementation stage (Demetriou, 2014; Vitikainen, 2004). The preparatory stage involves the application for land consolidation, the education of the stakeholders about the processes and the costs vs benefits analysis of the project. The inventory and planning stage involve the collection and/or updating of land tenure and spatial information, the valuation of the farms and ancillary lands, and the preparation of the land reallocation and other land consolidation works as well as the appeals from stakeholders for the plans. The last stage, the implementation stage involves the demarcation of new boundaries, complementary construction works; calculation and payment of compensation to landowners/holders and the corresponding cost of the project to each landowner, registration of the new parcels, and the issuing of the land certificates. This thesis focuses on the implementation stage.

Land consolidation requires a substantial amount of land information to be able to identify who owns what, and to which extent (Vitikainen, 2004). Furthermore, land value is needed to ensure equity in the process of exchange, rearrangement, and realignment. A basic requirement for land consolidation is therefore a well-functioning land administration system with an up-to-date land information system. Although many Western countries began contemporary registration of their lands in at least 1808 (based on Napoleon's Cadastre) and have covered the entire countries with an effective land administration system, this is not the same for Sub-Saharan African countries (UN-Habitat, 2012; Williamson, 1985; Zevenbergen et al., 2013). However, most sub-Saharan African countries with customary lands undertake land administration processes in order to improve land transactions, and create a market economy (Binns, 1953; Zevenbergen, 2004). They attempt to replicate the conventional style of land registration that favours individual rights, leading to the exclusion of secondary rights holders. The conventional land administration processes are also slow and expensive and do not serve the goal of aiding land management activities. Furthermore, customary land holders, having a strong cultural and spiritual bond with their lands, are unlikely to trade in their lands. This limits the operation of a land market on customary lands, hence it impedes land consolidation. There is therefore the 
need for innovative processes, approaches, and technologies to remedy the situation.

Western European countries, when embarking on land consolidation, did not focus on the collection of land information much. This is because in these regions, there were well functioning land administration systems to support the process. The same cannot be said of customary lands. The undertaking of projects that have to deal with parcel changes are looked upon with great precaution, particularly by the poor, and marginalized, who are usually powerless (Abubakari, 2015). For such a project to be acceptable to them, the plan should either ensure that their access to land is not altered, or their land tenure is not altered. With respect to the altering of land access, there must be an absolute certainty that they will not lose their access to land; in other words, the project will not alter any aspect their lands, physically and legally. These concerns are valid as land consolidation has already been demonstrated by the Swynnerton Plan as a tool capable of being used to dispossess owners of customary lands (Thurston, 1987). In terms of the altering of the land tenure, this brings focus to the Rwandan Land Use Consolidation (LUC). The LUC as a policy is aimed to place the focus solely on agricultural production rather than looking at the legal and spatial arrangements of the farms in removing the effects of land fragmentation. This is seen by the objective of its umbrella programme, Crop Intensification Programme (CIP). The LUC and CIP have the goal of raising agricultural production of high potential food crops in order to provide food security (Musahara et al., 2014). The LUC allows farmers to increase productivity, but it has also enabled the expansion of farm parcels, and its coupling with the villagization programme - a resettlement programme to aid the development projects, shows the potential role of land administration in the policy, however, no study has so far been conducted to determine whether the LUC had any effect on the land tenure security and arrangements in the area, and whether this would in any way improve the situation. 


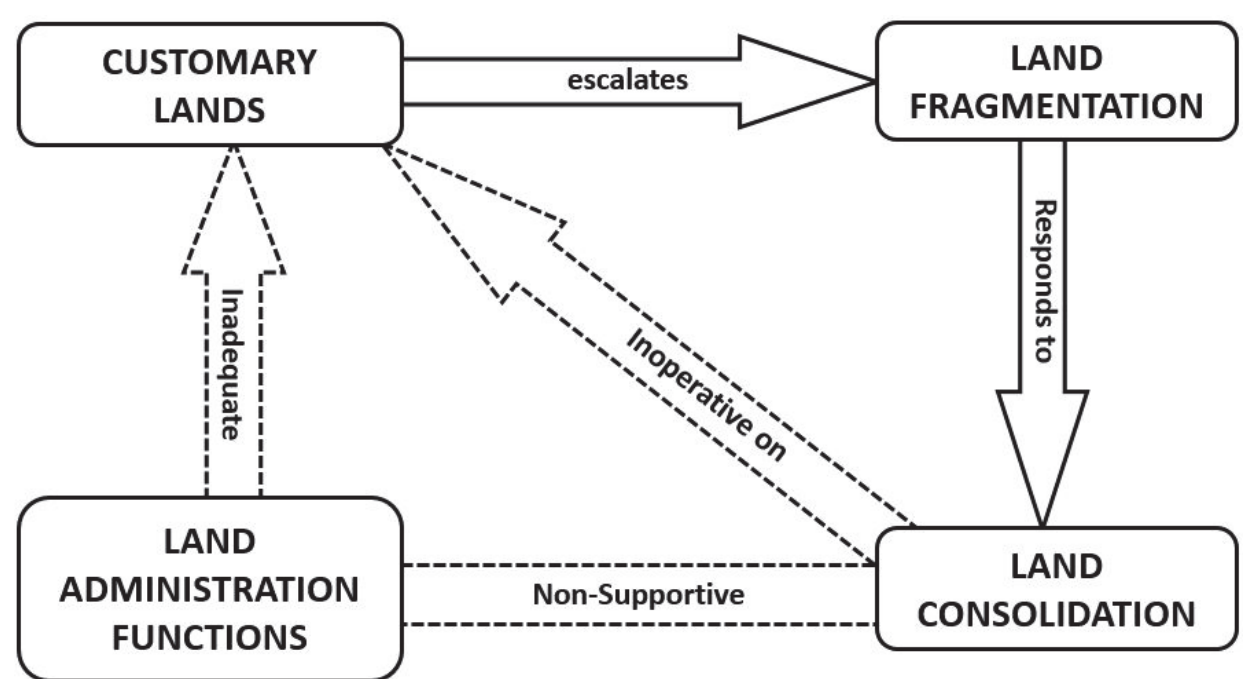

Figure 1: Conceptual Framework for the Problem Statement

(Land Administration Functions here include Land Tenure and Land Value in the context of customary lands, and the dotted lines indicate the gaps to be researched)

The success of the Rwandan Land Use Consolidation, and the failure of the land consolidation approaches in Malawi and Kenya, coupled with the general sentiment towards some requirement for consolidating lands across sub Saharan Africa, shows the need to investigate the knowledge gap between the development of land consolidation and customary lands with consideration for the local societal context through using a responsible approach.

Figure 1 displays the concepts related to the problem and the associated gaps in knowledge. In summary, it is known that the conditions on customary lands (land tenure and the farming system) escalate the occurrence of land fragmentation. It is also known that land fragmentation is responded to by land consolidation. However, it is also seen that land consolidation has not been inoperative on customary lands. Therefore, to connect land consolidation with customary lands, it is necessary to improve the inadequate land administration functions on customary lands that cannot support land consolidation.

\subsection{Responsible Land Consolidation}

Responsible approaches and policies apply broadly to a paradigm shift from traditional, and general approaches and policies to solving problems, to more societally and contextually based approaches and policies. The term "responsible" was mostly used in government and public administration circles to describe the system of accountability. However, Bourgon (2007) looks at a new perspective of responsible from the New Public Management policy, with respect to its important issues, including citizen-centred services. Responsible 
here goes beyond the fundamental accountability relationship, where public administrators are responsive to the needs of the citizens. It extends to up to, among other things, building collaborative government activities. This need for these collaborative approaches has had the goal of producing societally acceptable results. To this end, the term responsible has surfaced in the areas of research and innovation (Genus \& Iskandarova, 2018), education (Arruda Filho, 2017), and marketing strategies (Yadlapalli, Rahman, \& Gunasekaran, 2018).

In the context of land and land administration, De Vries et al. (2015) describe responsible land administration to encompass a multi stakeholder focus that acknowledges and valorises the representation of stakeholders in the development of land policies; a connection between technical and information sciences on the one hand, and social sciences and humanities on the other hand; and the incorporation of ethical and societal aspects in the design process. Responsible land administration here seeks to align policies and administration much more fundamentally to the ever-changing needs of the individual, government, and society. In the context of food security, FAO (2012) introduced the Voluntary Guidelines on Responsible Governance of Tenure of land, fisheries, and forests in the context of national food security. In the guidelines, responsible is viewed not just in the collaborative governance sense of the New Public Management policy, but further describes its goals. The goals here being that the resulting policies and approaches should fit into the broader political, social, cultural, religious, economic, and legal contexts. Further from this, these policies and approaches need to be responsive to the changes within the broader context.

Land consolidation as a land development tool similarly dwells within a broader context. The adoption of responsible approaches to land consolidation is needed to be able to align the land consolidation approaches to the conditions that exist on customary lands. There is therefore the need to comparatively study the areas that have already undertaken land consolidation on customary lands, to be able to identify their commonalities and peculiarities before a responsible land consolidation approach for customary lands can be developed.

Box 6: Definition of Responsible Land Consolidation

Responsible land consolidation uses practices that continuously align the technical and administrative requirements, and the internal processes of land consolidation to the dynamic local societal demands, economic conditions, and cultural and legal requirements.
The technological advances in land administration that have paved the way for land administration to be aligned to customary lands and used as an aid to combat the problem of inadequate land information and the absence of land value. It is acknowledged that certain 
characteristics of customary lands cause land fragmentation and that land fragmentation can be reduced by land consolidation. However, attempts to undertake land consolidation on customary lands have largely failed in the face of inadequate land administration processes on customary lands. There is therefore the need to adapt responsible approaches to land consolidation.

In summary, whilst the conditions on customary lands cause land fragmentation, and land consolidation is found to curb land fragmentation, the conditions on customary lands do not allow for the success of land consolidation (Figure 1). Meanwhile, the land administration requirements of land consolidation are not fully ascertained because the countries that are currently undertaking land consolidation had a well-functioning land administration system in place before implementing land consolidation. Furthermore, land administration coverage is low and inadequate on customary lands. Therefore, these gaps must be filled in order to develop a responsible approach to land consolidation for customary lands.

\subsection{Research Formulation; General and Specific Objectives}

The general research objective for this work is to develop a responsible land consolidation approach for customary lands.

To achieve the general research objective, the following specific objectives will be achieved;

1. To explore the factors that need to be addressed to develop a responsible land consolidation approach for customary lands.

2. To develop and assess an approach for collecting land information to support responsible land consolidation on customary lands.

3. To develop and assess a land valuation approach to support responsible land consolidation on customary lands.

4. To develop a process model for a land reallocation approach to support land consolidation on customary lands.

\subsection{Methodology}

This thesis does not have an overarching chapter for the research methodology, however, there is a research methodology used to achieve each specific objective. This section provides the overview and the rationale behind the choices for the methodologies adopted to reach each specific objective. Details for each methodology are provided in each chapter. 
The first objective requires the exploration of how land consolidation's factors need to be addressed on customary lands. To reach this objective, a comparative case study approach is used to draw on the experiences of other countries with existing responsible land consolidation approaches. Crossnational comparison is a prerequisite in the export of planning knowledge across national borders (Van Dijk, 2002). In chapter Two, Van Dijk's (2002) model of comparative analysis is adapted to compare the local conditions in three countries with existing land consolidation strategies, the Netherlands, Rwanda, and Lithuania, with Ghana's rural customary lands.

The second objective is reached using the experimental case study with a Living Lab approach in Chapter Three. The Living Lab is able to create an environment for the experiment to analyse product service systems as well as technical, and social innovations whilst promoting the conditions of sustainable development. This objective requires the bridging of societal needs and technological innovations as well as institutional influences and citizen contributions. The involvement of the local people in the living lab approach encourages trust, allows access to adequate knowledge regarding the problem environment, and gives the users a sense of ownership of the product.

The third objective seeks to develop a valuation approach for land consolidation. Here the Multiple Attribute Decision-Making (MADM) method is used based on the general land valuation approach. MADM methods are flexible and can be adapted with ease to the development of indices being represented by a set of parameters, where the aim is to evaluate an object compared to a standard for which the application is concerned. In the case of this thesis, the standard is the most appropriate land parcel for farming. This approach is used because it is about to achieve quid pro quo values that can be used for land consolidation.

The fourth objective is achieved using the process modelling method that details the steps of the approach taking into consideration the social, economic, cultural, technical, and political considerations on customary lands. The process model developed in this paper is a meso-micro-level procedural model. The meso-micro-level procedural model conveys best practices intended to guide real-world situations by providing prescriptive guidelines for a design and/or problem-solving activity with a focus on individual steps as well as end to end flows of the activity, where each step establishes objectives, and constraints for the next, with feedback loops between the steps for the possibility to re-work undesirable outcomes. 


\subsection{Overview of Study Areas}

The study focuses on Ghana, an agriculturally dominant country. The choice of Ghana is made because it is one of the two countries that undertook the efforts adopt customary land tenure laws that were derived from an African angle, expend state influence out into the customary domain and strengthening the governance structures already in place right after independence (Cotula, Chauveau, Cissé, \& Colin, 2007; Knight, 2010). The other country is Botswana. However, compared to Ghana, Botswana has a low land productivity that can still be improved and is one of Africa's smallest agricultural economies (Benin \& Nin-Pratt, 2016). About $49 \%$ of the population of Ghana lives in the rural areas, with $45 \%$ of the country's labour population (15 years and above) being engaged in agriculture (MoFA-SRID, 2016). Agriculture contributes to $54 \%$ of the Ghana's Gross Domestic Product, and accounts for over $40 \%$ of its export earnings, whilst at the same time providing over $90 \%$ of the food needs of the country. Out of the $258,539 \mathrm{~km}$ sq. area that Ghana covers, $57 \%$ is classified as agricultural land area.

Customary lands are recognized by the 1992 Constitution of Ghana (Article 38) and cover $80 \%$ of the lands in Ghana with the remaining $20 \%$ being public lands vested in the President in trust for the people of Ghana (Kasanga \& Kotey, 2001). The main interests in customary land tenure that relate to farming are the Allodial Title, the Customary Law Freehold or Usufructuary interest, and Tenancy (Figure 6) (Arko-Adjei, 2011; Chimhowu \& Woodhouse, 2006; Land Title Registration Law, 1986). The allodial title is held by the community and managed by its leaders under customary law, free from any restrictions and obligations, except such imposed by the laws of Ghana. The allodial interest cannot be transferred as this is restricted by the 1992 Constitution of Ghana and the customs, and it is exclusive to the community or tribe that holds the rights. The Usufructuary interest is exercised by individual members of a community to take possession of vacant land of which the community is the allodial owner subject to certain restrictions and obligations, upon payment of nominal consideration or free of charge (Ollennu, 1962). The Usufructuary interest is transferable within the allodial land owning group under certain strict circumstances. The Tenancy can be acquired by any person, indigene or otherwise, based on specific prior agreed terms, usually share cropping or an annual payment, usually for a term of one farming season. The tenant holds the land for the term exclusively, but subject to rules of the allodial title holder and/or the usufruct and cannot transfer his rights without the consent and concurrence of the landlord. Although the modes of acquiring the Usufructuary interest include the clearing of an unencumbered land followed by uninterrupted settlement, or as a gift or purchase; inheritance is currently the most common means of land acquisition (Arko-Adjei, 2011). The Usufructuary interest is held in perpetuity except for situations of abandonment, forfeiture, 
or want of successor; in which case, the land reverts to the allodial title holder (Kalabamu, 2000; Ollennu, 1962). The nature of the Usufructuary interest restricts farmers from expanding, as contiguous parcels' holders are unwilling to sell their parcels in order to hold the land for the future generations. This causes land fragmentation because to expand their operations, farmers move to parcels further away from their primary parcels.

Past approaches to increase food productivity in Ghana have largely focused on intensive cropping of farms, use of fertilizers, and mechanized farming (Houmy et al., 2013; NDPC, 2014; Pingali, 2007). These attempts were central to the development agenda of the governments of many developing countries, including Ghana, in the 1970's and 1980's through subsidies, direct importation and distribution to smallholder farmers (Dadson, 1971; Houmy et al., 2013). However, during this period of state-led pushes towards mechanization, there was low demand for the farm machinery. This led to the failure of the programmes despite the desire of farmers to increase farm productivity. On this, Pingali (2007) concedes that mechanization is not necessarily a driver for intensifying agriculture. The withdrawal of subsidies for fertilizer following the liberalization of the economy in the 1980's also led to low fertilizer use, causing farmers to turn to the combined use of fertilizer and manure to increase productivity (Abunyewa et al., 2007; Heisey \& Mwangi, 1996; Minot \& Benson, 2009). Recently, there has been an increase in the demand for mechanized farming equipment leading the government to set up Agricultural Mechanisation and Service Centres, at the district level across the country, to support farmers (NDPC, 2014; Sims \& Kienzle, 2016). Diao et al. (2014) assign the key reason for this to be the widespread labour constraints, which are mostly due to rural-urban drifts and the demand for labour from nonagricultural sectors in the economy. Mechanization is linked to expansion of farmlands as in other parts of the world (Ansoms, Verdoodt, \& Ranst, 2008; Heltberg, 1998; Ohene-Yankyera, 2004). However, because the expansion of land to a contiguous parcel on customary lands is not easy, the farmers have no option but to find land further away from the farm parcels to increase farm operations, thus worsening the land fragmentation situation.

Understanding the nature of the farming and land tenure systems is essential in the design of land consolidation strategies: they can facilitate or militate against the decision to consolidate land and land reallocation (Demetriou, 2014; Van Dijk, 2007). Since these systems evolve slowly, attempts at land consolidation needs to either adapt an existing land consolidation strategy or develop a new strategy that better aligns with the customary system. 


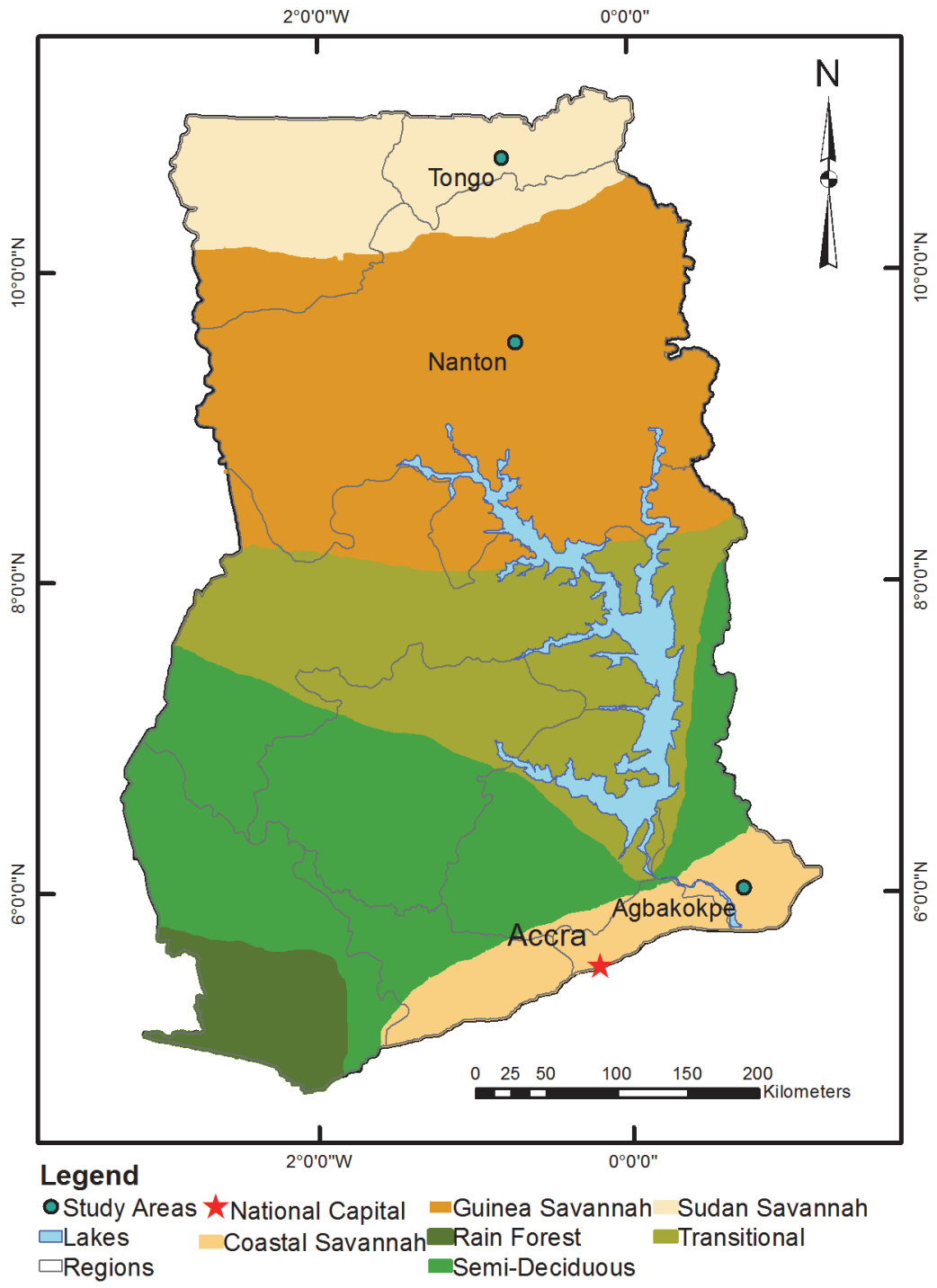

Figure 2: Map of Ghana showing the locations and Agro-Ecological Zones of the Study Areas

Farming in Ghana varies according to the seven agro-ecological zones - the rainforest, deciduous forest, semi-deciduous, transition, and the savannah zones (Guinea, Sudan, and Coastal) (Figure 2). In the forest zones, plantation and tree crops such as cocoa, oil palm, coffee and rubber are pre-dominant. The savannah and transition zones are characterized mostly by annual crops such as maize, roots, sorghum, and cowpea. In terms of rain, the forest and coastal savannah areas have bimodal rainy season, giving rise to two farming 
seasons per year - a major and a minor farming season. In the Guinea and Sudan savannah, and transition zones, there is one rainy season.

This study is conducted in three farming communities, one each in the three savannah zones of Ghana. These areas were chosen for two reasons. The first relates to the agro-ecological characteristics of the area. The savannah areas are characterized by tall grasses and a few trees (mostly shea, acacia, baobab, and mango) dotting the landscape. These conditions are favourable for the use of GNSS in this study, as the absence of tree cover will reduce the likelihood of multipath errors when using GNSS. The second reason relates to the tree crops grown. The growing of annual crops allows a certain amount of flexibility when dealing with the manipulation of farmland parcel arrangements. The third reason relates to the land tenure system. There are three main bases of landholding in Ghana - stool/skin lands, clan lands, and Tindana lands (Box 7 Box 8). One of these three basis exist in each of study area. The diversity in the systems of landholding provides an ideal footing to explore land consolidation in relation to the land tenure system. The three study areas are Nanton, Tongo, and Agbakokpe. Nanton is located in the Guinea savannah agro-ecological zone, with the land tenure being held on the basis of the skin lands. Tongo is located in the Sudan Savannah agro-ecological zone, with the lands being held by the Tindana. Agbakokpe is located in the coastal savannah zone with the lands being held by the clan. The dominant land use on all these communities is farming.

\subsection{Outline of Thesis}

The thesis is organised in chapters, based on the sub-objectives, towards achieving the overall objective. Chapters two to five form the core of this thesis, with each achieving one sub-objective. The chapters are derived from a series of published ISI journal papers. Each chapter provides a background to that sub-objective, the methodology used to achieve the objective, results and discussion of the results, and ends with a short conclusion. The research is undertaken in three stages - problem analysis, data collection and analysis, and the solution phases. The first stage, the analysis of the problem, uncovers and interrogates the miscarriage between land consolidation and customary lands (see Figure 1). Here the reasons why land consolidation has not worked on customary lands are further examined and the land consolidation needs are analysed. The first stage is embodied in Chapter Two. Chapters Three and Four cover the data collection and analysis stage - addressing the inadequacy of land administration functions' support on customary lands and the support of land administration functions on customary lands for land consolidation. In Chapter Three, the process for collecting land information on customary lands to support responsible land consolidation is explored. 


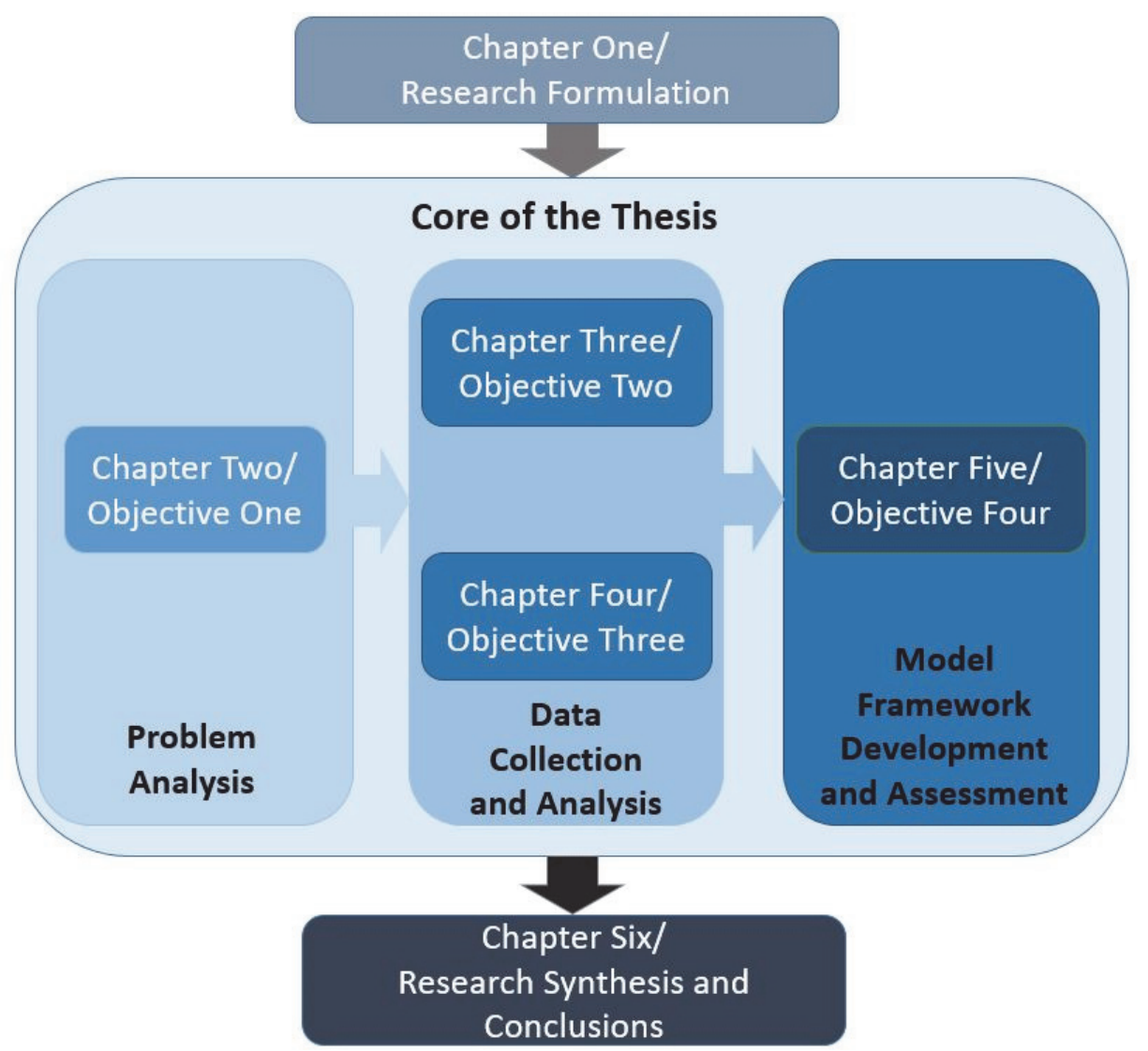

Figure 3: Thesis Structure

Chapter Four looks at developing a land valuation approach to form a basis for land consolidation on customary lands. The last stage is the solution stage, where a modal framework is developed for land reallocation - the crux of a land consolidation approach, drawing from the results of Chapters Three and Four. This deals with the non-alignment of customary land consolidation and responsible approaches. Chapter Six summarises the key findings of the previous chapters, reflecting on the main results and their implications on knowledge and literature, policy formulation and implementation, and the tackling of other contemporary challenges. It also recommends avenues for further research. 


\section{Chapter 2 Land Consolidation on Customary Lands: Learning from Three Countries*}

* This chapter is based on an ISI journal paper published as;

Asiama, K. O., Bennett, R. M., \& Zevenbergen, J. A. (2017b). Land consolidation on Ghana's rural customary lands: Drawing from The Dutch, Lithuanian and Rwandan experiences. Journal of Rural Studies, 56, 87-99.

https://doi.org/10.1016/j.jrurstud.2017.09.007 


\subsection{Introduction}

Whilst land consolidation has been shown to increase food productivity in several European, Asian and African countries (Muhinda \& Dusengemungu, 2013; Tang, et al., 2015; Van Dijk, 2003a), its use in Sub-Saharan Africa's rural customary lands has been limited (Makana, 2009): Application has largely failed to support delivery of increased food productivity, or has tended to disrupt the pre-existing customary land tenure system (Blarel et al., 1992; Muhinda \& Dusengemungu, 2013; Swynnerton, 1955; Takane, 2008; Thurston, 1987). This study explores whether and how experiences from the Dutch, Lithuanian and Rwandan land consolidation strategies can be adapted to Ghana's rural customary lands.

Studies agree that land fragmentation exists on Ghana's rural customary lands and that this undermines food productivity: $90 \%$ of farm parcels are held by smallholder farmers with less than 2 hectares (Abubakari et al., 2016; Blarel et al., 1992; MoFA-SRID, 2013). However, how best to increase food productivity has been a point of debate contention for several decades (Ansoms et al., 2008; Holden \& Otsuka, 2014; Migot-Adholla et al., 1991; Thurston, 1987). Land consolidation sits amongst soil improvement programs, fertilizer schemes, and mechanisation as one of many options. Previous studies by Abubakari et al. (2016) and Blarel et al., (1992) find that land consolidation experiences in Europe are not applicable to customary lands. Two key reasons are found to undermine the application of land consolidation on customary lands. First, land fragmentation was often not seen as a problem among the local farmers: fragmented land holdings favour the traditional agricultural system - shifting cultivation - and also offer for better risk management for smallholders (Bizimana at al. 2004; Blarel et al., 1992). Second, and perhaps more importantly, previous attempts at land consolidation in sub-Saharan Africa have failed as they directly transplanted Western European-style land consolidation methods - ignoring the underlying customary land tenure systems - during implementation (Abubakari et al., 2016; Coldham, 1978; Nothale, 1986; Ostrom, 1990). Meanwhile, land consolidation experiences outside Western Europe, such as in Lithuania and Rwanda demonstrate the ability to adapt conventional land consolidation approaches to areas outside Western Europe - with good results. A knowledge gap is therefore evident: what were the conditions that made land consolidation applications in other areas suitable, and how do those conditions manifest on Ghana's rural customary lands?

In response, this paper aims to identify the factors that need to be addressed to develop a land consolidation strategy that fits the local demands and requirements of customary lands to increase food productivity. The next section describes the methodology adopted in the study, as well as the profile 
of the study areas. Section three lays out an analytical framework for assessing the factors that influence the development of a land consolidation strategy. In this regard, in Section four, the current land consolidation strategies in the Netherlands, Lithuania, and Rwanda are set against Ghana with respect to the analytical framework. The implications of the comparison are discussed in section five. Section six concludes the paper with an acknowledgement of the factors that need attention in the case of Ghana, suggesting future research areas.

\subsection{Methodology and Study Area}

This section describes the methodology adopted to identify the factors to be addressed in order to develop an appropriate land consolidation strategy for Ghana's rural customary lands. A comparative case study approach is adopted. An underlying goal of a comparative case study approach is to search for similarities and variances between/among countries in order to undertake export of knowledge across nations (Hantrais, 1996; Mills et al., 2006). In this vein, this work develops an analytical framework for understanding the reasons different land consolidation strategies are adopted or adapted in different contexts, from existing literature, to form a scientific basis for the comparison.

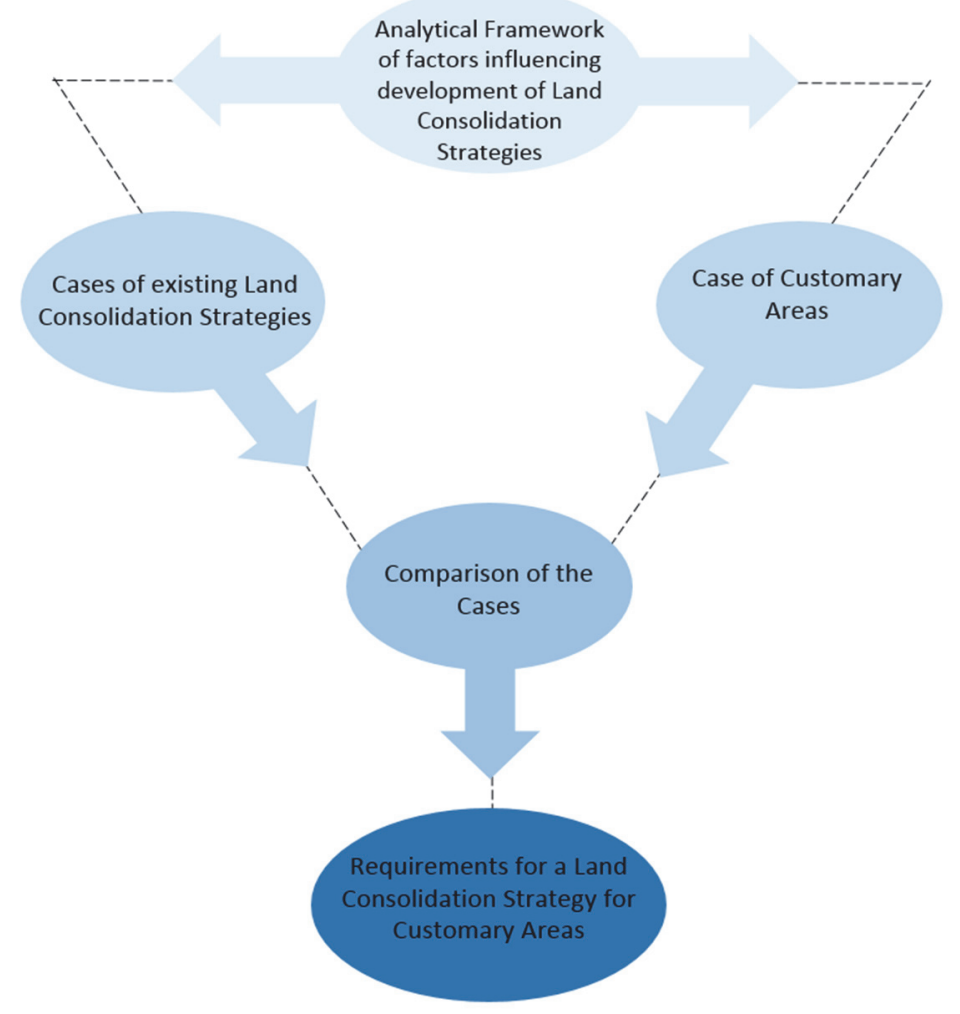

Figure 4: The Research Design 
Using Van Dijk's (2002) model of comparative analysis for cross-country exporting of knowledge, three countries with existing land consolidation strategies are selected, observed, and compared to Ghana's rural customary lands (Figure 4). This model is grounded in the reasoning that in transferring development and planning approaches across international borders, it is necessary to understand how and why the approach was developed in the original context. Understanding this will make it possible to relate and adapt the approach to the target context. The goal of using this model is to first understand the local contexts, and then to examine land consolidation factors and how they influenced the selection of the land consolidation strategy. The selected countries included the Netherlands, Lithuania, and Rwanda. The Netherlands is chosen because of its long-standing land consolidation strategies that have evolved over the years in response to the local traditional market oriented agricultural production's conditions and demands (Van Dijk, 2003a). This is coupled with the extensive English literature on their approach. It should be noted that unlike other European countries that followed similar historical trajectories with respect to land fragmentation and subsequent land consolidation, a comparatively large body of English literature exists on the Netherlands approach. Lithuania's land consolidation, the most recent in the Baltic region, was developed through a series of pilots in the country to allow it to fit with the local conditions (Hartvigsen, 2015a). This was necessitated by the agrarian and land reforms from the 1990s onwards as the transition into a market economy, from a centrally planned economy, was undertaken. Rwanda is so far, the only sub-Saharan African country to develop a unique land consolidation approach (Box 9) aligned with local conditions, and implements it nationwide (Kathiresan, 2012; Musahara et al., 2014). Rwanda's land use consolidation programme is a locally developed land consolidation programme in an SSA country according to its local conditions (Muhinda \& Dusengemungu, 2013; Rubanje, 2016).

\section{Box 7: Stool/Skin}

The stool/skin is a "shrine containing the soul and spirit of the community (the family, the tribe of the nation/kingdom)" and is therefore the embodiment of the collective authority of all members of the community. The occupant of the stool/skin is a trustee holding the land for and on behalf of the
Though the dominant land tenure system in these three countries is state ownership and individual private freehold, the Netherlands and Rwanda had customary lands in their past, which contributed to land fragmentation through land reclamation and inheritance.

However at the time of undertaking land consolidation, the communal lands in the Netherlands had evolved and Rwanda's the customary lands were converted into private individual lands (Grossman \& Brussard, 1988; Rubanje, 2016). 


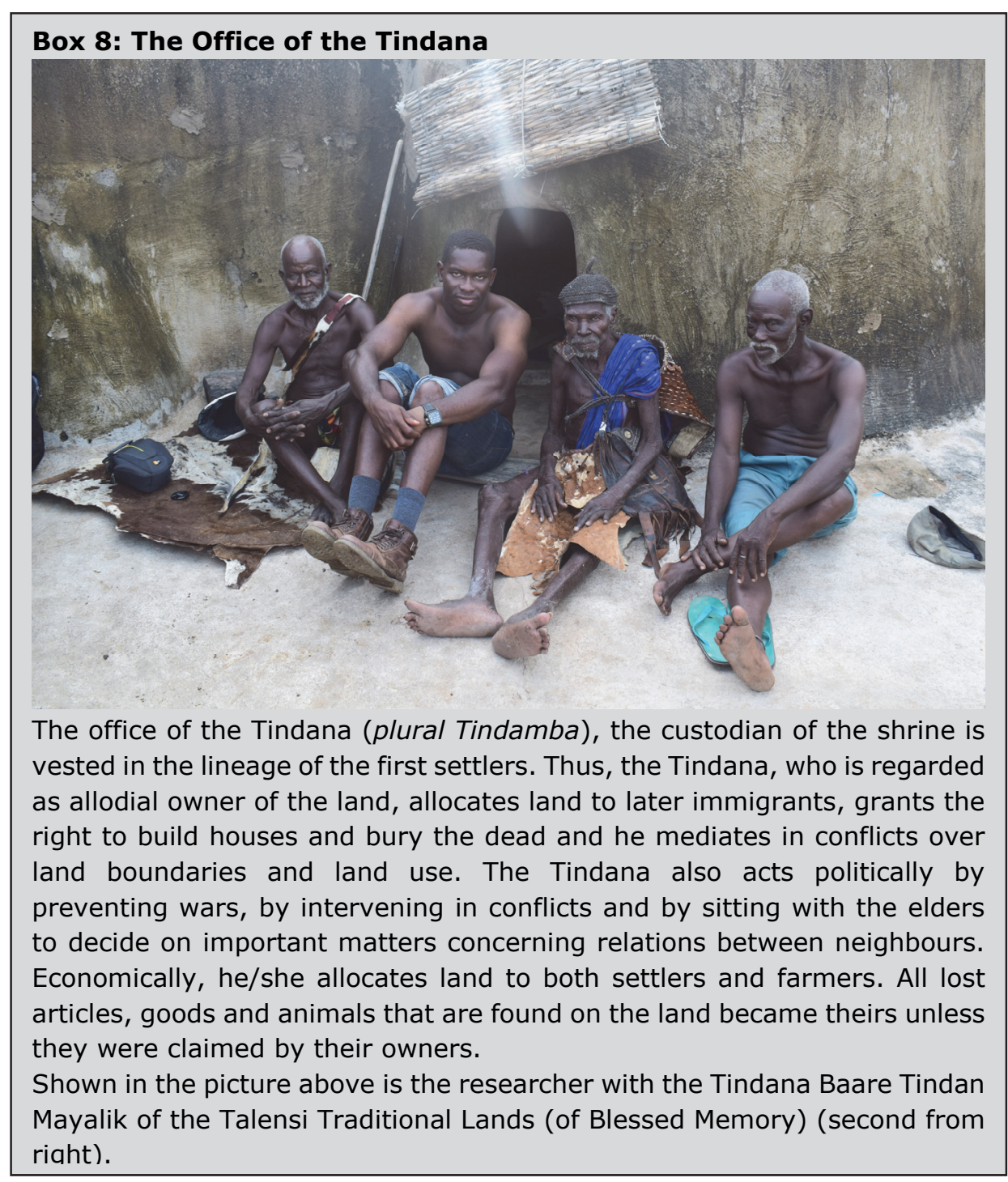

Data from the Netherlands, Lithuania, Rwanda and Ghana was collected through a document review - scientific literature, government policies, laws, and technical reports; and supplemented with interviews with land and agricultural sector officials, and farmers. In Ghana, further interviews were conducted with the traditional authorities and local government leaders in three areas in the country, Nantong, Agbakofe, and Tongo (Figure 2), that represent the three main forms of customary lands in Ghana - stool/skin lands, family/clan lands, and Tindana lands (Box 8) respectively (Figure 6) (ArkoAdjei, 2011; Imam, 2015; Kasanga \& Kotey, 2001). The Dutch, Lithuanian, and Rwandan cases did not require further data collection methods as the 
literature available was seen to already adequately capture the factors under investigation.

\subsection{An analytical framework for understanding the choice of land consolidation strategies}

The choice of land consolidation strategy is based on the existence, absence, or nature of certain factors, usually based on country or regional characteristics, including technological and legal, political, economic and social, and environmental issues. Being a land management activity, the influences on land consolidation encompass both the formal and informal institutional framework (Ekbäck, 2013; Lisec et al., 2014). Past studies have looked at these factors individually. Many earlier studies such as Binns (1950), Brotherhood (1964), and Jacoby (1959), tended to look at the technological and legal issues in land consolidation - these two issues being the most contentious issues at the time in Western Europe. Later studies pushed the boundaries of land consolidation beyond Western Europe and also broadened their scope, in the realisation that the areas of interest were fundamentally different from Western Europe with regards to: political issues related to the role of the government and the relationship between the government and the people (Haldrup, 2015; Thomas, 2006); economic issues that are peculiar to the country or region (Hiironen \& Riekkinen, 2016; Van Dijk, 2007); the social, cultural and historical trends (Coelho et al., 1996; Fang et al, 2016; Vitikainen, 2004), and environmental considerations (Muchova \& Petrovic, 2010). The following describes how these issues influence development of a land consolidation strategy and summarised in Figure 5.

\subsubsection{Technological and Legal Issues}

The technological and legal issues in the selection of a land consolidation strategy cover factors including the nature of land fragmentation, the farming system, the available technology, as well as the land tenure situation and the coverage of an enabling land information system. The nature of land fragmentation is seen in two forms - physical or spatial - characterised by the number of land parcels and the distance between the parcels; and tenure land fragmentation - characterised by the number of owners and users of land, and the number of leased lands (Van Dijk, 2003a). Land fragmentation does not always reduce the efficiency and productivity of farms. Following the neoclassical theory of the firm, a farm is seen to be technically efficient when it attains the maximum yield given the amount of inputs and technology (Culas, 2012; Verma \& Churchman, 1997; Young et al., 2014). The effort to increase yield is usually approached in the short term, either by the increase of familiar factors such as intensity of weeding and the application of fertilizer, or the introduction of new technology. Whereas the increase of these factors may 
increase productivity in the short term, the use of technologies that do not fit the size, scale, and the nature of the farming system may reduce the yield or produce negative returns. This is termed as inverse relationship between farm parcel size and productivity (Ansoms et al., 2008; Eastwood et al., 2010). Binswanger \& Pingali (1989) demonstrate how three factors - the farming system, desired productivity level, and the profit margins - affect the technology adopted. In the manner of classical development theory, they show how farming systems evolve from the forest fallow system, with low farm technology, small farm parcels, low productivity, and low profits; to the multiple cropping system, with its demand for mechanisation, large farm parcels, high productivity, and high profits. Consequently, whether land fragmentation is a problem depends on whether the available technology and farming system can take advantage of an increase in the parcel sizes to increase efficiency.

The form of tenure held in land as well as its security informs the amount of investment likely to be attracted, from both the government and the individual, with respect to the number of years that farming is certain on the land parcel (ILRI, 1960). Farmers who are tenure insecure will be sceptical about entering into such arrangements: tenure security is dependent on the long-held knowledge of their land rights. This means that a form of land registration should take place before any attempt to deal with land fragmentation is made. However, the prospect of land registration also nudges some authors into viewing land consolidation as an opportunity to reform land tenure arrangements by eliminating "outdated" rights of use such as access and grazing rights (Coldham, 1979; FAO, 2003; Parsova \& Kapostins, 2012). This approach considers individual tenure will fare better with land consolidation, as the communal land tenure requires the consent of several persons, usually at various levels of authority before such a decision can be made. Land tenure therefore plays a significant role in the land reallocation stage of land consolidation.

In summary, the technological and legal issues that affect the development of a land consolidation strategy are also likely to have determined the nature of land fragmentation in terms of tenure or physical fragmentation, the nature of the land tenure system in terms of individual or customary land tenure, and the coverage of a supportive land information system (Figure 5). 


\subsubsection{Political Issues}

The political issues in the selection or development of a land consolidation strategy cover the government's role in land management activities. Governments have mostly taken a central responsibility in land consolidation activities. This is a result of the view of the government as a provider, a leader, and an enabler of land management activities (Bennett \& Alemie, 2016; Bennett et al., 2012; Tang et al., 2015; Van Huylenbroeck et al., 1996). The new paradigm of land governance over the past two decades has introduced a second influential player into emerging land consolidation strategies, the market (comprising the people and the civil society) (Bell, 2007; FAO, 2012). This has caused a shift in the balance of power between the government and the market, with the latter taking a bigger role. Louwsma et al (2014) and Haldrup (2015) further suggest that the funding of existing Western European land consolidation

\section{Box 10: Voluntary Land Consolidation}

Voluntary land consolidation is where participation in the process is an offer to the local participants, and they will only participate if they are convinced of the benefits they will receive from the project (Bennett and Alemie, 2016). strategies also affects this balance of power, with the market also taking a larger role where funding is divided. However, supranational unions' also influence the selection of land consolidation strategies; an example being the European Union whose Rural Development Programme (RDP) has land consolidation as an explicit measure for improving farm agrarian structures among other goals. This has mostly resulted in many Eastern and Central European countries benefiting from the land consolidation influences of Western European countries, such as the Dutch influence on Estonia and the Danish on Latvia (FAO, 2008; Hartvigsen, 2015c). These initiatives followed the land reform the Eastern and Central European countries underwent as part of the transition to the market economy. Within the country, the levels of government in relation to land management also determines how land consolidation will be undertaken, especially in relation to federal systems of government, as is identified in Ethiopia by Bennett and Alemie (2016) in terms of the relationship between the Federal Government and the Amahara Regional government, where the former tentatively favours a comprehensive land consolidation approach and the latter, which tends to exercise management of land and controls land consolidation practices, prefers a piecemeal voluntary land consolidation approach (Box 10).

In summary, the government control over land management activities in areas where there is no land consolidation can give an idea of which body will drive land consolidation, in terms of a local, regional, national, or a supranational 
governmental body. Since this study concerns one country without a land consolidation strategy, the potential government support is ascertained from the government's control over and funding for current land management activities, with respect to the levels of government (Figure 5).

\subsubsection{Economic and Social Issues}

The economic and social issues in selecting a land consolidation strategy relates to the nature of the land market, the state of the economy and land mobility (Box 11), as well as the financing options for the land consolidation project.

Land consolidation thrives in a competitive economy with a vibrant land market, the underlying principle being the enabling of exchange/trading of land (Bullard, 2007; FAO, 2003; Liu et al., 2016). The existence of a land market is dependent on the decision of individual farmers to buy and sell their lands together with the national land policy regarding the ownership and trading of land. Although the existence of land fragmentation as a problem increases the demand for land for expansion, the decision to sell land goes beyond rational economic decision-making, bordering on the nature of social relations (Akudugu et al., 2012; Van Dijk \& Kopeva, 2006; Van Dijk, 2007).

The level of the purchasing power determining the demand for land relies on an interplay between government policies and the market. General economic growth also determines the government's preparedness and ability to finance the land consolidation programme. The expansion of land parcels and increased productivity, being objectives of land consolidation, means that there is the need for farmers to get credit facilities that will enable them to expand their farm operations (Binns, 1950; Bullard, 2007; Demetriou, 2014). Where the risks of borrowing money are high for farmers, expansion is not attractive. Government support to the agricultural sector lowers the risks involved in both agricultural investment and engaging in large-scale agriculture (SabatesWheeler, 2002).

Social issues are seen as the prime militating factors against a land market. In many areas, notwithstanding the utility value, the psychic ties to the land, especially those related to the status, tradition, and ancestral bonds to the land, determine land mobility. The notion that the present

Box 11: Land Mobility

The willingness and ability of the farmers and landowners to exchange their lands in a land consolidation (Hartvigsen, 2014). generation acts as a trustee for the future generation is held onto strictly, as is tied to landed resources especially in unstable economies (Bullard, 2007; Hartvigsen, 2015c; Ollennu, 
1962; Van Dijk, 2007). Despite this seemingly important role played by the social factors, strategies for dealing with land fragmentation mostly focused on the technological and economic factors (Benthem, 1969; Binns, 1950; ILRI, 1960; King \& Burton, 1989). More recent studies underscore the importance of social structure and systems in dealing with land fragmentation as farms function in a social system. The social system influences the sustainability of land consolidation, especially when it is considered in the reallocation stage. (Cay et al., 2010; Coelho et al., 1996).

In summary, the economic issues that influence the development of a land consolidation strategy include the presence of a land market, its effectiveness in terms of land mobility, as well as the state of the economy, dealing with macro-economic conditions and the farmers' ability to fund the land consolidation (Figure 5).

\subsubsection{Environmental Issues}

Land consolidation is influenced by and affects the environmental conditions such as the topography, nature of the soil, the natural habitat of fauna and flora in the area, biodiversity, and the water access. In some cases, these natural environmental conditions need to be altered to accommodate the land consolidation strategy adopted. In that case, land consolidation then influences the geo and bio-ecological characteristics of the land. On one hand, the topography and soil distribution of the land can limit the ability to exchange land in a particular area, and creating natural boundaries that limit expansion of the farm parcels (Demetriou, 2014; Sonnenberg, 2002). On the other hand, as land consolidation may include development works, it may also affect the environment negatively or positively (Muchova \& Petrovic, 2010). 


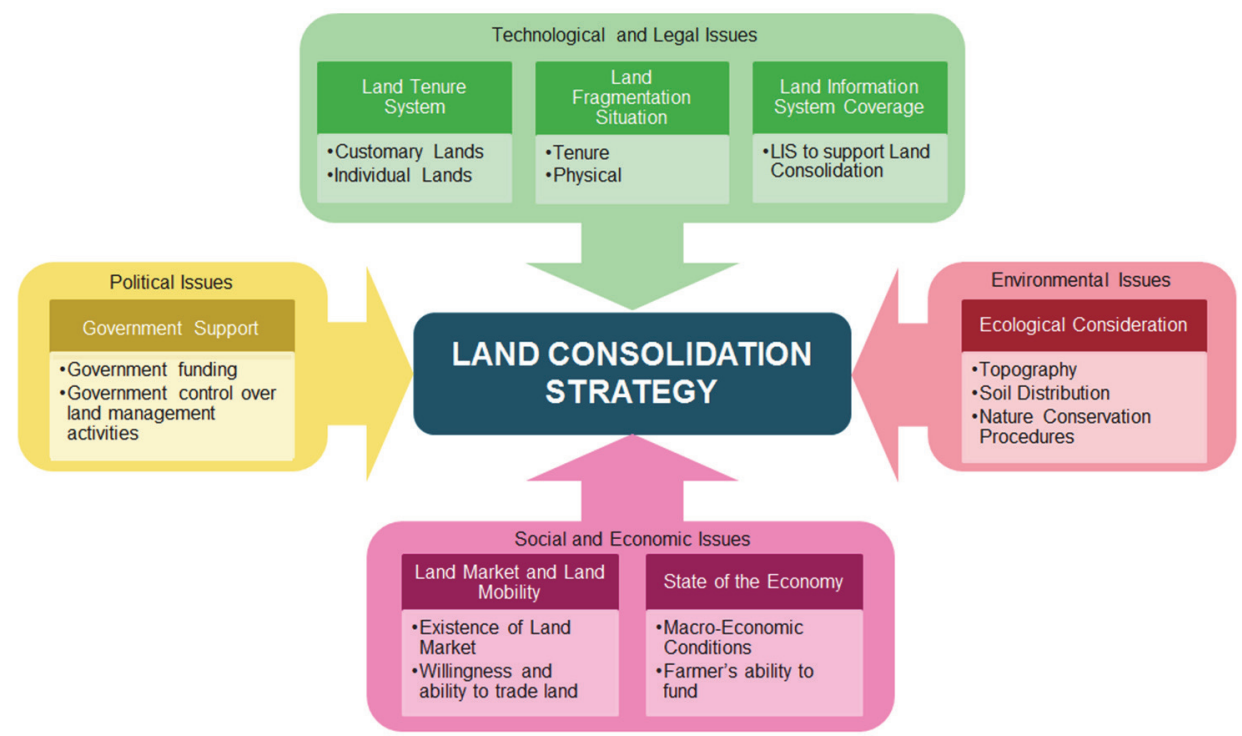

Figure 5: Framework for the selection or development of a land consolidation strategy

However, the effects of land consolidation on the environment have not always been considered as a priority. Many studies rather offer ex-post suggestions on how to recover and maintain the landscape after land consolidation, but the environmental conditions should play a role in the initial land reallocation process (Anna \& Adrianna, 2009; Dudzińska \& Kocur-Bera, 2014; Muchova \& Petrovic, 2010). The effects of land consolidation on the environment can be positive or negative, there is therefore the need to keep track of and conserve the flora and landscape when using land consolidation (Shuai et al., 2011; Yu et al., 2010). The environmental issues can therefore limit the extra lands that can be used as a land bank for land expansion in land consolidation.

In summary, the environmental conditions that affect land consolidation may be ex-ante factors that influence the undertaking of the project such topography, soil cover and water access; or ex-post factors that affected by the land consolidation such forest cover and the landscape influencing nature conservation (Figure 5).

\subsection{Land Consolidation Influences in the Netherlands, Lithuania, Rwanda, and Ghana - A Comparative Analysis}

Using the analytical framework established in Section 2.3, the comparison of the three country results to that of Ghana is presented in this section, based on the factors influencing the selection of a land consolidation strategy identified in Section 2.3 (Figure 5). Four existing land consolidation strategies 
were identified in the three countries - the Netherlands has the Land Development and the Land Consolidation by Agreement, Lithuania has the Voluntary and Simple Land Consolidation, and Rwanda has the Land Use Consolidation. Land development is the assembly and distribution of rural land parcels belonging to different people, led by the government. Land development results in a new distribution of the quality and quantity contributed with the aim of achieving a rational and economically justifiable agrarian management; a socially acceptable living, working, and housing climate in the country; a maximum shared use of the country by the entire non-agrarian population; and the preservation of the natural environment that is as varied as possible. Land consolidation by agreement is the procedure through which a small number of land owners voluntarily exchange land to achieve better parcelling. Simple and voluntary land consolidation is a process where land owners voluntarily exchange and realign their land parcels and undertake structural development to create economically viable farms. Land Use Consolidation here refers to the cultivation of same crops by different owners in order to combine their farms operations to create larger farm parcels without an exchange of farm parcel ownership.

\subsubsection{Government Support}

The comparison finds that the Dutch, Lithuanian, and Rwandan governments play a significant role in land management and land consolidation in terms of institutional, financial, and professional support; whilst in Ghana, the government's role in land management is low, with the traditional authorities taking the major role (Grossman \& Brussard, 1988; Hartvigsen, 2015a; Kathiresan, 2012; Ubink \& Quan, 2008) (

Table 1). Whilst in all cases land consolidation policies are set by the central government, the Dutch land consolidation by agreement rather relies on a partnership between the local people and the government for regulation and implementation (Grossman \& Brussard, 1988; Louwsma et al., 2014). Partly because of the shared control, in the Dutch case, the costs are shared between the government and the participating farmers. However, this shared control does not necessarily result in shared costs. This is seen in Lithuania's financial perspective from 2007 to 2013, where despite a shared control and voluntary process, the costs of land consolidation are borne by the EU, as a result of its quest to make its new members competitive against the original members (Hartvigsen, 2015c). This has been changed in the financial perspective 20142020. Land consolidation projects are now financed in a limited fashion within RDPs, with environmental issues being more important. In Rwanda, land consolidation is fully financed and controlled by the government as part of its Crop Intensification Programme (CIP), a centrally planned government programme (USAID, 2013). 
In the case of Ghana, the management of customary lands is in the hands of the traditional authorities who regulate and control land management activities in their traditional areas, in some cases through their Customary Land Secretariats (CLS), subject to the legislative oversight. This "hands off" approach (Ubink \& Quan, 2008), adopted by the government, is due to the revered position of the traditional authorities as spiritual leaders of the people. The low influence of the government in land management activities is opposed to the situations in the Netherlands, Lithuania, and Rwanda, where the lands in the country are either state or individual private lands, giving the government a strong role in land management activities such as land consolidation.

In summary, the Dutch, Lithuanian, and Rwandan governments have a strong role in land management activities; whereas in Ghana, the government plays a minor role, with the traditional authorities playing a significant role (Table 1).

\subsubsection{Land Market and Land Mobility}

Although it is found that all four countries allow for the operation of a land market, for different reasons, land mobility is high in the Netherlands, but low in Lithuania, Rwanda, and Ghana (Ali, Deininger, \& Ronchi, 2015; Grossman \& Brussard, 1988; Pašakarnis, Morley, \& Maliene, 2012) (Table 1). Grossman \& Brussard (1988) and Heide et al., (2011) describe the Dutch view of land in the $19^{\text {th }}$ century as sacred, which limited the voluntary exchange of land and the operation of a land market. This is like the current situation on customary lands, as people view land as a heritage for the future generation to be kept at all costs. The completion of a successful land consolidation project will likely result in the land owners and farmers holding and tilling a different parcel from the one they had before the consolidation. The evolution of the Dutch land consolidation strategies shows a shift from the sacred view of land to that of an economic commodity, with productivity and efficiency of the land outweighing the emotional attachment and the family traditions. The same cannot be said of Lithuania, Rwanda and Ghana. Though all the three countries have land policies that support the operation of a land market, land mobility in the three is still low because of the emotional attachment to and social and spiritual view of the land. The reasons for these views are however different in each country. In Lithuania, Van Dijk (2004) attributes this to farmers cherishing the idea of being able to hold their own lands after years of collective farming and ownership. Land, after restitution, became a source of familial pride, making exchange or sale of small unproductive parcels unlikely. Similarly, in Rwanda, Musahara and Huggins (2005) find that the years of conflict made several land owners wary of actions that would change their land titles and parcels. In both countries, many land owners do not trust the land 
certificates and register, but would rather prefer the testimony of witnesses to prove their ownership claims (Goodfellow, 2014; Hartvigsen, 2014). This militates against the ability to undertake a programme that will put their land parcels in a pool to be reallocated. With Ghana's customary lands, land mobility that restricts the land market is more institutionalized in the customary land tenure system. Notwithstanding the modes of acquiring the land, the unavailability lands means that inheritance is the most common means of land acquisition. The primogeniture inheritance system is practiced in the study areas, where the brother, oldest son or other male relative "assumes the position" of the deceased with a few exceptions where the deceased may make a gift inter vivo to his children in order to divide his properties among them. Short of this, the other relatives, especially the children, farm a portion of the farm allocated to them by the successor, or acquire their own farms in another area through purchase. The purchase and sale of land is limited, as there is a goal to keep the lands within the group as much as possible. The sale of land to a fellow member of the land-owning group is discouraged, but it is still allowed. Sale to non-member of the group is however not possible, unless with the express permission of the group, as this may deprive the future generations of their heritage.

In summary, the comparison shows that although land markets exist across all cases, land mobility is low in Lithuania, Rwanda, and Ghana - limiting the operation of a land market (Table 1 ).

\subsubsection{Land Tenure, Land Fragmentation, and Farming Technology}

The land fragmentation situation in the Netherlands and Rwanda took the form of physical fragmentation with the average Dutch farm parcel size being 2 hectares with an average of 6 parcels per holding in 1924, and an average Rwandan farm parcel size being 0.11 hectares with 5 parcels per holding in 2008 (Grossman \& Brussard, 1988; Kathiresan, 2012). Lithuania takes the form of tenure fragmentation with the average farm parcel size being 4.96 hectares (Daugaliene, 2004). All three countries have individual ownership of land. However, land fragmentation on customary lands is both physical and tenure fragmentation, with a communal ownership in land (Table 1). Though the farming system in Nanton, Tongo, and Agbakofe used to be shifting cultivation that favoured land fragmentation, with population increase and the need to increase food productivity, farms are now being cultivated simultaneously and intensively, together with the use of mechanised farming equipment and fertilizers. 


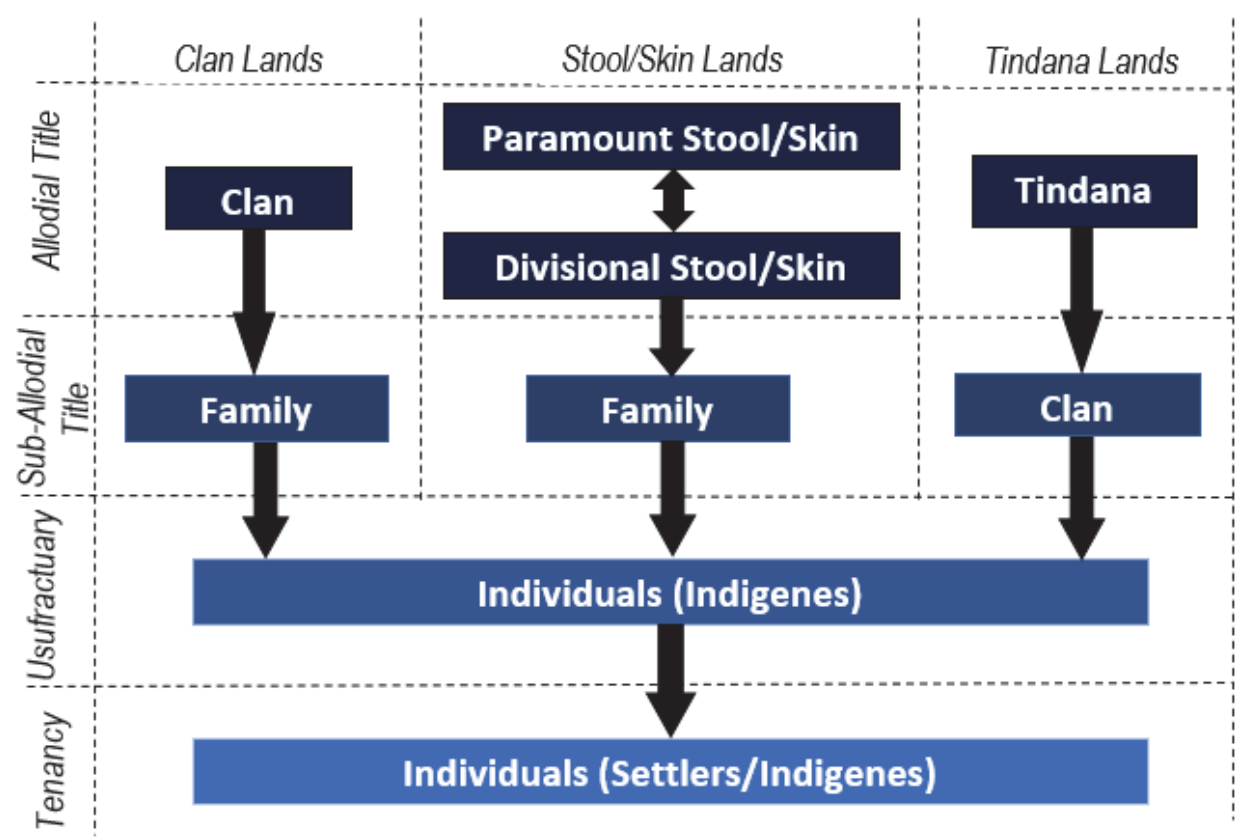

Figure 6: Hierarchy of Rural Customary Land Tenure in Ghana (Author's own construct)

A farmer who wants to expand therefore must move further away from his primary parcel in order to do so. With the customary freehold tenure, the farmer holds the land under either the landowning group or the Tindana, causing land tenure fragmentation (Figure 6). Land tenure in Nanton (Skin Lands) is organized around the skin, a body corporate headed by the paramount chief of Nanton (the Nanton-Na), holding the land intrust for the people. In Tongo (Tindana Lands), the Tindana sits at the top of the land holding hierarchy as the land owner, who then allocates the lands to the clans in the area. In Agbakofe (Clan Lands), the land is vested in the clans and managed by the clan head on their behalf. The lands held by or allocated to the clans are then vested in localised segments of the clans, families, whose members enjoy the rights of a usufruct. 


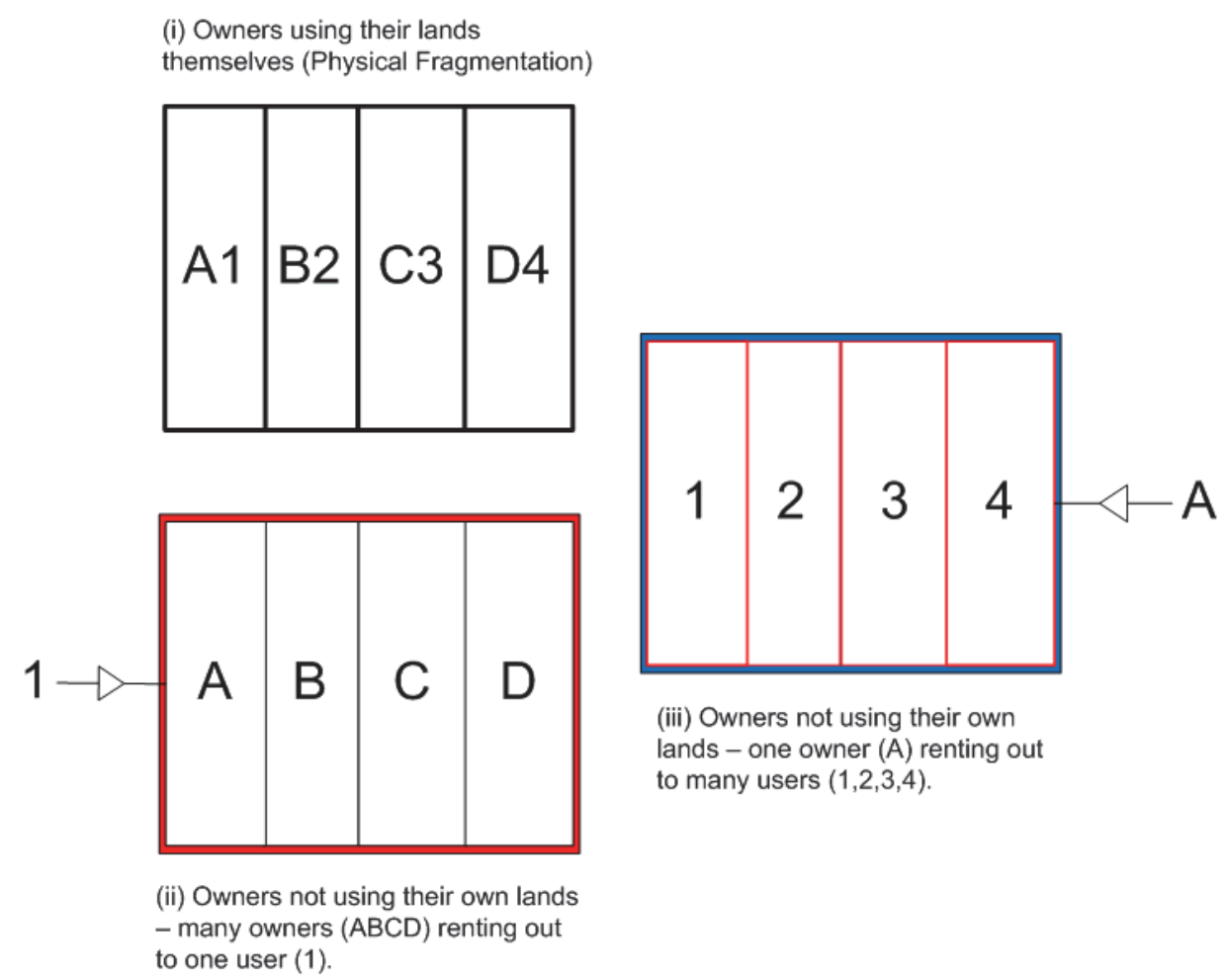

Figure 7: General Representation of the predominant types of land fragmentation in the Netherlands, Lithuania, Rwanda, and Ghana

Although the customary freeholder is tenure secure, he is still limited in the decisions he can make with respect to the land such as long term investment decisions and using the land as security for a loan (Ollennu, 1962; Udo, 1965). Unlike the Dutch, Lithuanian, and Rwandan cases, these decisions have to be made by the group, and not the customary freeholder, because of the land tenure arrangements as shown in Figure 6 and Figure 7. The differences are shown, in a more generalized manner, among the three contexts, where $A, B$, $\mathrm{C}$, and $\mathrm{D}$, are land owners and 1, 2, 3, and 4, are tenants/users. In Figure 7 , three current dominant forms of relationships between parcel ownership and use are presented. The first situation (i) shows where owners use the lands themselves. This is a situation identified in the Netherlands and Rwanda. The second situation (ii) is seen in Lithuania and also increasingly in the Netherlands where the farmlands are leased out. The third situation (iii) is found on Ghana's rural customary lands.

In summary, the land tenure system and the form of land fragmentation on customary lands differ from the other three cases. Customary land tenure displays a multi-layered decision-making process which is not seen in the other three cases with individual land tenure. The land fragmentation situation also 
differs among the cases with customary lands having both tenure and physical fragmentation (Table 1).

\subsubsection{Land Information System}

The Netherlands, Lithuania, and Rwanda have a form of functioning and up to date land information system supportive of land consolidation, whilst Ghana's rural customary lands have none (

Table 1). The difference is that the Netherlands and Lithuania had their LIS in place before land consolidation was started, but Rwanda developed its LIS after starting land consolidation. The current Dutch LIS was started in at least 1808, with roots in the Napoleonic Cadastre (Williamson, 1985). Lithuania and Rwanda's current LIS were however started in 1992 and 2008 respectively (Bagdonavicius \& Kasperavicius, 2003; Goodfellow, 2014). The Land Information System (LIS) coverage of customary lands is very limited, covering only certain urban areas. The coverage of the Land Register in Ghana as at 2011 was $30 \%$ of the land parcels in the country, mostly under deed registry. The Land Administration Project (LAP) funded by the World Bank made attempts to cover the country but was able to register 15,000 parcels in ten years (Biitir \& Nara, 2016; MASDAR, 2011). The Project further attempted to ease the collection of land information using Customary Land Secretariats (CLS), however few of these could be made operational to adequately collect and manage information relating to their lands. Nantong has a CLS that manages the lands in the township, not the farmlands. It gets complicated with Tongo: the Tindana does not exercise his land management powers as extensively as the Nantong chief, with most of his authority being religious and judicial. The chief of Agbakofe also does not hold the land in trust for the people. The clans hold and manage the lands, making the establishment of a CLS difficult as they only manage small pockets of land. Their primary method of recording land information is by memory of witnesses, with the Nantong CLS using a Microsoft Excel spreadsheet and a notebook with no spatial information.

\subsubsection{State of the Economy}

The state of the economy of the Netherlands at the time it started land consolidation, enabled its citizens to fund the bulk of the process. However, Lithuania, and Rwanda at the start of their land consolidation, had a low state of economy: high inflation was evident despite the availability of off-farm employment (

Table 1). In these countries, land consolidation costs therefore had to be absorbed by their government. The costs involved in land consolidation usually involves the hiring of lawyers, surveyors, and other professionals to aid with 
the process. In the Netherlands, most of these costs were absorbed by the government, especially for land development, as the foreign aid reconstruction following the WWII allowed the government to fund such projects. With land consolidation by agreement, the inflation rate in the commencement year was at $0.2 \%$ (1986): farmers could fund their own land consolidation projects (Heide et al., 2011; Kuhlman et al., 2003; The World Bank, 2016). For Lithuania and Rwanda, the high inflation rates, 6.7\% (2006) and 15.4\% (2008) respectively in the years of commencement meant reduced the purchasing power of consumers (The World Bank, 2016). Lithuania's government also lacked the resources to support farmers. With little government support and a volatile economy, the risks involved in investing in agriculture increased substantially: farmers in Lithuania and Rwanda had neither the capacity nor the resources and drive to invest in land consolidation. Funding was left to respective central governments and, in the case of Lithuania, the European Union. A comparable situation is found in Ghana; with an inflation rate of $17 \%$ in 2015 , the inability of farmers to produce a lot of food crops affects the level of their income. Therefore, short of external funding, the Ghanaian farmers would not be able to foot a share of the expenses as was done in the Netherlands.

The availability of alternate employment to farming also frees up land to be taken up by more efficient farmers. The years following the WW II saw an increase in the number of land consolidation in the Netherlands, as the reconstruction aided in making the Netherlands an industrial country, creating alternate employment opportunities outside farming (Heide et al., 2011; Kuhlman et al., 2003). In Rwanda, a similar process is underway with the Vision 2020 that aims at making it a middle-income country by the year 2020 . This policy seeks to offer employment to many Rwandan farmers in the industrial and service sectors. This philosophy was also found in Ghana where many young people opt out of farming in favour of white collar jobs in the cities, raising the demand for mechanized farming.

In summary, it is seen that the Netherlands had a robust economy at the time its land consolidation strategies were started, enabling the people to fund their projects. However, like Ghana; Lithuania and Rwanda have a volatile economy, therefore the farmers need support to undertake land consolidation (Table 1).

\subsubsection{Ecological Considerations}

The environmental influences on Dutch land consolidation were not considered until after the passage of the 1954 Land Consolidation Act, but the 1985 Land Development Act put environmental consideration as a high priority: the largescale and comprehensive nature of the strategy, as well as the agitation of the environmentalists to be part of the process drove the refocus. Though the 
Dutch land consolidation by agreement did not have environmental consideration high on its agenda in its initial stages, environmental considerations are slowly being incorporated in line with the 1985 Land Development Act. Lithuania's entry into the EU required it to pay more attention to the environmental effect of its land management activities. The involvement of the Natura 2000 network, created to protect and maintain the natural habitat of plants and animals in the Union, covers $11 \%$ of Lithuania's rural areas: use of these areas as land banks for the expansion of farms is restricted. Rwanda over the past forty years, due to its farming practices has experienced a high rate of environmental degradation (Musahara, et al., 2014; Odhiambo, 2013). The environmental influences on the development of land use consolidation were mostly due to the nature of the topography. The hilly nature of the country means that the clearing of the hill sides for farming is a significant concern and cause of soil erosion. Whilst soil erosion is more easily controlled on small parcels, large parcels need high-cost soil conservation methods for erosion control. Despite this, environmental conservation is not a part of the land use consolidation objectives, although it is an aim of the Vision 2020.

Table 1: Summary of the Influences of the Factors in three countries with existing Land Consolidation strategies and Customary Lands.

(The Netherlands from 1984 to present day has two concurrent land consolidation strategies for different needs and goals)

\begin{tabular}{|c|c|c|c|c|c|c|c|c|c|}
\hline- & Case & $\begin{array}{l}\text { Gov't } \\
\text { Support }\end{array}$ & $\begin{array}{l}\text { Land } \\
\text { Mobility }\end{array}$ & $\begin{array}{l}\text { State of } \\
\text { the } \\
\text { Economy }\end{array}$ & \begin{tabular}{|l} 
LIS \\
Coverage
\end{tabular} & $\begin{array}{l}\text { Land } \\
\text { Tenure }\end{array}$ & $\begin{array}{l}\text { Land } \\
\text { Frag. } \\
\text { Type }\end{array}$ & $\begin{array}{l}\text { Ecological } \\
\text { Considera } \\
\text { tion }\end{array}$ & \begin{tabular}{|l} 
Land \\
consolidation \\
Strategy
\end{tabular} \\
\hline \multirow{5}{*}{ 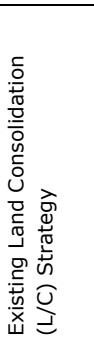 } & $\begin{array}{l}\text { Netherlands } \\
(1435-1924)\end{array}$ & Low & Low & Low & High & Ind. & Physical & Low & $\begin{array}{l}\text { Voluntary Land } \\
\text { Exchange }\end{array}$ \\
\hline & $\begin{array}{l}\text { Netherlands } \\
\text { (1924-Today) }\end{array}$ & High & High & High & High & Ind. & Physical & High & \begin{tabular}{|l} 
Land \\
Development \\
\end{tabular} \\
\hline & $\begin{array}{l}\text { Netherlands } \\
\text { (1986-Today) }\end{array}$ & High & High & High & High & Ind. & Physical & High & $\begin{array}{l}\text { Land } \\
\text { consolidation by } \\
\text { agreement }\end{array}$ \\
\hline & Lithuania & High & High & Low & High & Ind. & Tenure & High & \begin{tabular}{|l|} 
Voluntary and \\
Simple Land \\
Consolidation
\end{tabular} \\
\hline & Rwanda & High & Low & Low & High & Ind. & Physical & Low & $\begin{array}{l}\text { Land Use } \\
\text { Consolidation }\end{array}$ \\
\hline $\begin{array}{l}\text { No L/C } \\
\text { Strategy }\end{array}$ & Ghana & Low & Low & Low & Low & Cust. & $\begin{array}{l}\text { Physical } \\
\& \\
\text { Tenure }\end{array}$ & Low & - \\
\hline
\end{tabular}

Customary lands in Ghana, however, do not incorporate sustainable farming into their agricultural system. This is mainly because of their unfamiliarity with these methods, and those who are familiar with the methods feel that they are too expensive to be used when there is no regulation requiring them to use them. However, the shift from shifting cultivation to intensive farming has increased sustainable farming: forest depletion levels are lower. The method of land acquisition by the clearance of land however is seen by some traditional authorities as detrimental to the environment, leading them to move to reduce such actions. 
In summary, it is seen that land consolidation strategies that are governmentled and financed take environmental considerations very seriously from the outset, whereas the Dutch land consolidation by agreement and voluntary land exchange have more gradually incorporated environmental considerations (although, that the environmental movement's influence has grown significantly since the 1960s, in parallel or subsequent Dutch land consolidation initiatives, also explains this more gradual uptake) - provided in the legislative framework within which land consolidation is possible (Table 1 ).

\subsection{Discussion}

Several studies have attempted to generalize the development of land consolidation strategy by following the western European land consolidation development (Van der Molen, Lemmen, Van Dijk, \& Uimonen, 2004; Van Dijk, 2003a). These studies view the European land consolidation instruments as a continuum from simple and voluntary approaches to comprehensive and compulsory approaches. They therefore recommend the development of land consolidation in other areas to take the same trajectory, promoting the view that land consolidation strategies at the left-hand side of the continuum are rather rudimentary (Figure 8). This view works for the Western European with long traditions in land consolidation such as the Netherlands, as their developments followed this trajectory. However, the comparison of the existing land consolidation strategies show that the choices are borne out of necessity of the local conditions. Furthermore, land consolidation instruments that were previously not considered, such as Land Use Consolidation, are identified and can now incorporated into the continuum. The new structure looks at the land consolidation instruments as the necessary approaches to fulfil the objectives within an area, given the local conditions. It shows the land consolidation instruments, objectives, and the characteristics that make up the land consolidation strategy. The objectives compound from the left to the righthand side of the continuum.

The results show that since the nature of the factors on customary lands do not match with those countries with existing land consolidation strategies, their land consolidation strategies cannot be directly adopted on customary lands. However, a few lessons can be learnt on how the factors can be adapted onto customary lands. 


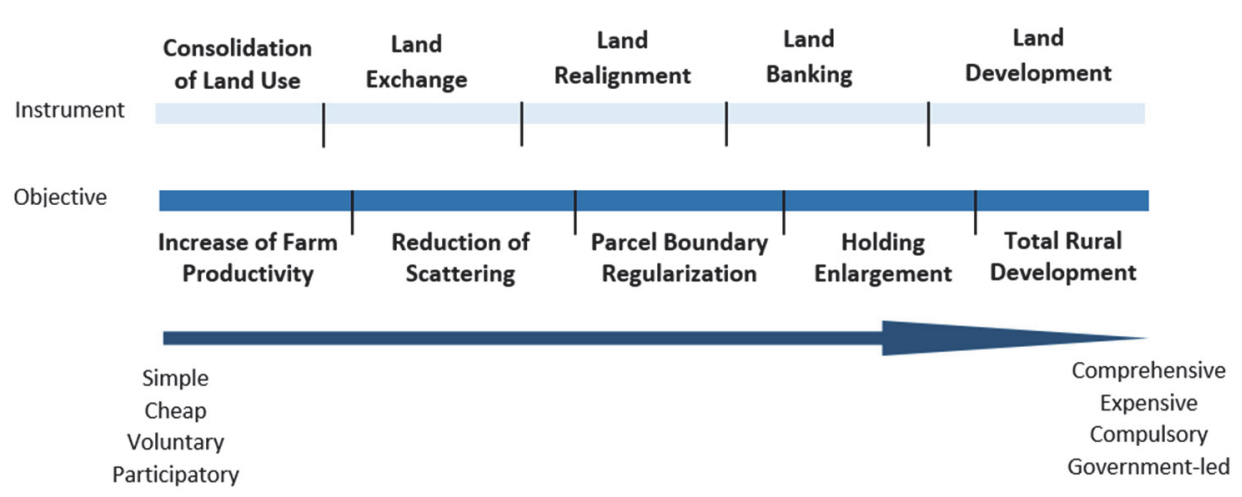

Figure 8: Continuum of Land Consolidation Strategies

(adapted from van der Molen et al. (2004))

\subsubsection{Customary Authorities as the Land Consolidation Authority}

The first point is that the level of trust in the government and the level of government support on customary lands aligns with the level of participation and compulsion. Although funding for land consolidation projects would likely result in some government influence, the planning and implementation would need a participatory approach. The existence of the chiefs, Tendanma, and the family heads creates a pseudo government authority that is found to be more influential than the government (Ubink \& Quan, 2008). These authorities can therefore aid in, or play the role, of leading and regulating the process in lieu of the government.

\subsubsection{Limitations of the Land Market}

The second point relates to the nature of the land market, land mobility, and the state of the economy. The results find that land mobility limits the operation of land markets because of the emotional attachment to the land. Furthermore, the customary land system is also seen to limit the operation of free land markets, as lands are hardly traded due to social/spiritual reasons. Despite the limitations, save for the transfers of the freehold interest in stool/skin lands, the land policy of Ghana allows for the transfers of other interests in land. This makes the operation of a conventional land market system look impossible. This does not mean that a land market does not exist in customary lands. The results show that transactions in land are possible. This is sometimes viewed as an under-developed market, as it does not follow the formal rules of the land market that is the trading of parcels for economic reasons. The possibility of the transactions in land in customary lands and the farmers' knowledge of the detrimental effects of land fragmentation means that at least, the exchange of land parcels should have taken place. However, 
the results show that the inability to undertake land exchange can be attributed to the land tenure system.

\subsubsection{Low Farming Technology, and High Physical and Land Tenure Land Fragmentation}

The legal and technological influences of land consolidation cover the farming technology, land fragmentation, the land tenure system, and the coverage of a functioning Land Information System (LIS). Land fragmentation is seen to exist in all four countries, albeit with differing causes and nature. Inheritance is seemingly the current most common cause of land fragmentation. However, with primogeniture inheritance being practiced in the customary lands under study, the farming system in combination with the land tenure system were rather the causes of land fragmentation. The forms of land fragmentation were physical and tenure fragmentation. These two types of fragmentation have two different methods of dealing with them. Although Van Dijk (2003) suggests land banking as the appropriate method for dealing with land tenure fragmentation, Lithuania rather adopts the land banks in a limited fashion in its land consolidation strategy. The existence of concentrated land banks in customary lands, albeit not a conventional form, has been confirmed by Abubakari et al. (2016). Due to the nature of land fragmentation in customary lands which is both physical and tenure, the use of land banks must be considered. The farming technology as a major driver of whether to consolidate is seen to be high in all the existing strategies, except for the Dutch Voluntary Land Exchange. A cursory look at

Table 1 suggests that areas that went through land realignment made more use of the farm machinery, since the regular parcel boundaries support the farm machinery better. The land tenure system of the existing strategies is individual tenure system. This is seen to be an advantage for land consolidation, and indeed for most land management activities as there is usually one decision-maker, the land owner. Customary lands present a different dynamic with the group ownership of land. It is already seen that the customary system allows for the transfer of land to other members of the group, since the distribution of land is according to families, the land exchange within the family can be decided by the individual members. However, outside the family, or the clan, or village, the consent of the other members has to be sought resulting in several levels of authority to be dealt with. The effect of the limited LIS is not evident in all the existing land consolidation strategies, despite the availability of a functioning LIS in these countries. Rwanda presented a different perspective as unlike the others, it did not have an LIS prior to the start of its land consolidation programme, despite its ability to increase food productivity. 


\subsubsection{Costs of Environmental Considerations}

The maintenance of the ecological diversity is seen to be low on the priorities of the voluntary and participatory land consolidation strategies but held in high regard as the government influence increases. The reason for this is argued to be that farmers view farming methods that take environmental conservation into consideration as more expensive. Secondly, the voluntary and participatory approaches are usually small projects (involving at most 20 farmers) and their effects on the environment are minimal compared to the comprehensive and compulsory large-scale land consolidation strategies. However, Lithuania shows an exception as the environmental protection reasons for the limited use of land banking is not due to the scale of the consolidation, but the regional policies concerning the environment. With regards to customary lands, scale of the land consolidation strategy will need to inform the consideration of the environmental policies.

\subsection{Conclusion}

This study started with the aim of identifying the factors that need to be understood and addressed to develop a land consolidation approach for Ghana's rural customary lands by examining the land consolidation strategies of the Netherlands, Lithuania, and Rwanda. The study finds that to develop a land consolidation approach for customary lands in the Ghanaian context, the low influence of government on land management activities, the absence of a land market, the low coverage of a functional land information system, and the customary land tenure must be addressed.

It was first found that the different existing land consolidation strategies examined were influenced by different land fragmentation situations, as well as social, political, economic and environmental issues. It was also found that certain factors in Ghana such as the state of the economy and the level of farming technology, matched with all the countries with existing land consolidation strategies. The nature of the other factors that differed from those of the existing procedures require substantial change to the culture, social, and economic structure of the area to implement. These dimensions and their status in Ghana require innovative approaches so they respond appropriately in any land consolidation strategy. These include the low influence of the government, the seeming absence of a conventional land market, the coverage of a functional land information system, and the customary land tenure system that militates against the existing land consolidation strategies - as they seem to favour individual titles. This paper found that land consolidation is possible in areas with use rights, such as the Netherlands and Lithuania. Therefore, the use rights within customary land tenure does not necessarily limit land consolidation and can be adapted when these factors that do not match are addressed. Furthermore, the benefits the 
local farmers had from land consolidation shown in Section 2.4.3 are currently not available, leading them to look for alternative ways to increase farm productivity. The paper therefore concludes that responding to the factors that do not match the existing land consolidation strategies will enable the adaption or development of a land consolidation strategy fit for customary lands.

To address these factors, the traditional authorities which are held in high regard, may aid the government to increase the latter's influence. This can be done through incentives from the government to convince the customary authorities to look at the land use systems and encourage a change in the land use pattern that fit the local livelihood system. The land market in the area can also be simulated for the purposes of land consolidation: the interviews and focus group discussions with the farmers and chiefs illustrated that the local farmers recognize the pitfalls relating to land fragmentation. With the rules of trading land parcels present in the customary system, farmers need to be able to exchange parcels in a system that will ensure that areas of similar quality will be exchanged so the future generation does not lose out. Further research is therefore needed on first how to value the rural agricultural lands in the absence of a land market for an equitable reallocation. Secondly, a fast and cheap approach to collecting land information to support land consolidation needs research, and thirdly, how to adapt land consolidation to the land tenure system of customary lands, especially with the decision-making, and land reallocation systems.

In the next chapter, an approach for collecting land information is experimented upon. 


\section{Chapter 3 Participatory Land Administration for Responsible Land Consolidation*}

* This chapter is an extended version of an ISI journal paper published as Asiama, K. O., Bennett, R. M., \& Zevenbergen, J. A. (2017c). Participatory Land Administration on Customary Lands: A Practical VGI Experiment in Nanton, Ghana. ISPRS International Journal of Geo-Information, 6(7), 186. https://doi.org/10.3390/ijgi6070186 


\subsection{Introduction}

Land consolidation is described as a land management activity that involves all the procedures for exchanging, rearranging, realigning, and expanding farm parcels in rural areas with the goal of increasing food productivity. Responsible land consolidation uses approaches that continuously align the technical and administrative requirements, and the internal processes of land consolidation to the dynamic local societal demands, economic conditions, cultural and legal requirements (K. O. Asiama et al., 2017a) (Chapter One). Although the success of land consolidation is dependent, among other things, on the economic and ecological improvements for the land and the people, one of the basic requirements of land consolidation is information related to the ownership, use, and value of the land (Bennett et al., 2015; Lemmen et al., 2012). The collection, maintenance, and dissemination of land information is described here as land administration (UNECE, 2005). This paper focuses on the collection of land information to support land consolidation. The dearth of land information on Sub-Saharan Africa's rural customary lands has been shown to be one of the militating factors to undertaking land consolidation in the area (K. O. Asiama et al., 2017b) (Chapter Two). This paper presents an experiment into a proposed approach to land administration on customary lands to support responsible land consolidation.

Over the past two decades, observations and experiences in land administration have shown that less than $30 \%$ of the world's countries have a complete land administration system capable of supporting the design and implementation of land management activities such as land consolidation (UNHabitat, 2012; Zevenbergen et al., 2013). Numerous thrusts into so called conventional western-style titling programmes have not met expectations. This is mostly because first, their pace is very slow in relation to the urgency of the results. Secondly, they have been too expensive, leaving them out of the reach of most citizens. Thirdly, these approaches have largely failed to integrate all forms of land tenure arrangements, especially secondary and customary land rights. The outcome is that parts of the community are left vulnerable to land grabs, contentious land disputes, limited investment in land, and increase in food insecurity. In response, calls for pro-poor and fit-for-purpose approaches to land administration have emerged (Enemark et al., 2014; Zevenbergen et al., 2013). These approaches, that seek to adapt local needs and circumstances in tandem with legitimate and acceptable social, cultural, and institutional practices, are described by de Vries et al. (2015b) as responsible approaches.

Advances in responsible approaches usually consider new ways through which different forms of legitimate land rights can be recorded and documented on one hand; and on the other hand, explore how emerging and cutting-edge technologies in geospatial sciences offer faster and cheaper options for spatial 
data collection. New insights into documenting all forms of land rights have been made by the continuum of land rights by the GLTN (Barry \& Augustinus, 2015), and several studies in customary and informal land rights (Lemmen, 2010; UN-Habitat, 2012; Zevenbergen \& Augustinus, 2011). On the part of spatial data collection, emerging and cutting-edge technologies have advanced new approaches to land administration in the form of crowdsourcing, voluntary geographic information (VGI), and neo-cadastres. These technologies include the use of old map documents, high resolution satellite images (HRSI), tools based on Global Navigation Satellite System (GNSS), Unmanned Aerial Vehicles (UAVs) as well as smart technologies such as Automatic Feature Extraction (AFE) of cadastral boundaries (Basiouka \& Potsiou, 2012; Crommelinck et al., 2016; de Vries et al., 2015a; Mumbone et al., 2015). These approaches that seek to involve the grassroots in land administration processes further seek to incorporate the societal goals of land administration, the structure of the society, and bring down costs. However these have still not been placed in the societal context, but rather look, among others, at aspects of VGI in applying it to land administration (Rahmatizadeh et al., 2016), the motivations of contributors (Basiouka \& Potsiou, 2012, 2014), the ability of the local people to use the technologies (Molendijk et al., 2015). The fundamental reason for these land recordation processes has been land tenure security (Zevenbergen \& Augustinus, 2011; Zevenbergen et al., 2013). These responsible approaches do not work in isolation, but thrive within a societal context driven by needs other than tenure security such as food security, supporting a land market, levying of taxes, and nature conservation (Williamson et al., 2010). These, though linked, present different purposes for undertaking land administration. There is therefore a gap in knowledge on how to shape the emerging approaches to land administration to fit into each peculiar societal context and goal, in this case to support land consolidation for food security. This requires the active involvement of the local community in land administration. This is what is termed here as Participatory Land Administration (K. O. Asiama et al., 2015). As previous innovative approaches to land administration focus mainly on securing land tenure, this paper aims at testing an approach to land administration that is capable of supporting food security-stemming from land tenure security-as a societal goal. As such, the paper presents an experiment undertaken in Northern Ghana to test how an approach to participatory land administration fits into customary lands to support responsible land consolidation.

\subsection{Participatory Land Administration: $A$ Theoretical Background}

Participatory land administration is a construct that seeks to contribute to responsible, fit for purpose, and pro-poor approaches to land administration (K. O. Asiama et al., 2015; Bennett \& Alemie, 2016; de Vries et al., 2015b; 
Enemark et al., 2014). Traditional land administration approaches have been deeply rooted in western approaches and views on land management based on the state's responsibility to collect and manage land information. These have however ended up failing most of the population, especially in developing countries, as societal and cultural considerations are ignored in favour of complex legal and professional standards.

\subsubsection{From Voluntary Geographic Information to Participatory Land Administration}

The participatory element adds to emerging approaches that challenge traditional land administration approaches. Participation in some circles is considered as a source of power (Arnstein, 1969), for others it is simply the ability to contribute (Smith, 2003), or a multi-way set of interactions among citizens and other players to produce an outcome (K. O. Asiama et al., 2015; Innes \& Booher, 2004). Smith (2003) considers participation as a stepping stone to enhance effectiveness of outcomes, resolve conflicts, enhance public knowledge and understanding, and establish legitimacy and trust. Participation in geo-spatial science stems from the increasing need for local knowledge in a field that has for many years been dominated by professionals, who carried out their tasks per strict standards and quality assurance specifications. This brought about a new approach to mapping-Participatory Geographic Information Science (PGIS) or P-Mapping, involving citizens depicting the features of their environment on the ground, on paper or on satellite imagery with the help of professionals who guide the standards of the entries. The technological innovations in the 21st century expanded the direct involvement of local people to include several other location-based services mostly due to Geo-Spatial Web 2.0-a collection of online location-enabled services and infrastructure (Goodchild, 2007; Hudson-Smith et al., 2009). This brought about a new vista for PGIS known as Voluntary Geographic Information (VGI)the collecting and editing of digital spatial data by people responding to an open call, with little or no formal qualifications, willing to share their spatial knowledge and information (Goodchild, 2007; See et al., 2016; Sui, 2008). Although VGI and PGIS share the common aim of involving local people, Fast \& Rinner (2014) and Song \& Sun (2010) differentiate between the two, with PGIS being traditionally established and controlled by someone with the skills and knowledge in organizing and presenting spatial information with imposed constraints. The basis of VGI is rooted in neogeography and crowdsourcing. Neogeography, on one hand, is the way people represent portions of the earth surface in their own way, alongside or in the manner of professional geography, making it personal, expressive, and although not reaching professional standards, does not render it of no use to geo-sciences (Gómez-Barrón et al., 2016; Turner, 2006). Crowdsourcing, on the other hand, is seen as the process of harnessing the diverse potential of large groups of ordinary people in the 
collection and aggregation of data (Geiger \& Schader, 2014). The basis of crowdsourcing is a grassroots-based approach that is often initiated to challenge formal approaches and offset its constraints and inadequacies. Many therefore view VGI as having a higher participation than PGIS, as the public has a greater control over the process. However, VGI for land administration is still a debated issue.

The success of crowdsourcing geo-spatial information in disaster management (Poorazizi et al., 2015), identifying land use patterns (Arsanjani \& Vaz, 2015), road map production (De Leeuw et al., 2011; Mahabir et al., 2017), among others, has led to exploration on how crowdsourcing can be applied to land administration. In an attempt to improve upon traditional land administration processes, initial studies into crowdsourced land administration looked at an approach of citizens directly capturing, maintaining, and disseminating information on land rights (Keenja et al., 2012; McLaren, 2011). However later studies stressed on the importance of reliability and accuracy of land information as an aspect of public administration, as opposed to the initiatives into crowdsourcing such as openstreetmaps and wikimapia (Navratil \& Frank, 2013). To maintain the reliability of the information, some suggest the use of local Trusted Intermediaries (TI) (Bishr \& Kuhn, 2007; McLaren, 2013). Furthermore, a pure crowdsourced approach to land administration which will rely on the strong relationships within local communities, is likely to produce a record of land rights that are outside the existing formal systems, limiting the ability of the people it serves to take advantage of some of its benefits (Siriba \& Dalyot, 2017).

Later contributions to the subject take a hindsight cue from Turner (2006) to look theoretically at how communities outside the state based land administration system record and maintain their land rights. De Vries et al. (2015a) characterizes this as the "Neo-cadastre"-the manner through which land holders and users indicate their land tenure rights and boundaries based on their personal views outside of state-based institutions. The impact of the Neo-cadastre has been largely speculative. Whilst De Vries et al. (2015a) contend that it will not challenge the traditional land administration systems within the foreseeable future due to its lack of standards, Schaefer \& Schaefer (2014) rather indicate the eventual need for the government to accept it when it reaches a critical stage. Neo-cadastre therefore shows the ability of local and indigenous people to devise their own ways of recognizing their land rights, and a new approach of land registration should also take that into consideration. The nature of land administration as a public administration activity, dealing with the management of sensitive information, citizen contribution requires some form of regulation and guidance at varying levels as found in PGIS, but not to the standard of traditional land administration. This is what this paper describes as Participatory Land Administration (PLA). 


\subsubsection{Aspects of Participatory Land Administration}

Participatory land administration encompasses four aspects drawn from conventional, responsible, fit for purpose and pro-poor land administration, seeking to create a meeting point for the top-down traditional and bottom-up crowdsourced land administration. These four aspects are the top-down institutional (government and professional) influence, the bottom-up citizen contributions, the push of technological innovation, and the pull of societal needs (Figure 9). Traditional land administration focuses on a top-down approach, with the government authorities and the professionals as the main contributors to land administration using strict standards with high accuracy and high-end equipment regardless of the societal needs and make up. Participatory land administration sits at the nexus of the drivers of technological innovation and approaches to development studies. The drivers of technological innovation in the last few decades have strived to strike a balance between the role of innovations in science and technology on the one hand, and an acknowledgement of a broader set of market features on the other hand (Peters et al., 2012; Stefano et al., 2012). The former, known as technological-push, advocates that innovation should be dictated by the technologies available, with little consultation with the end beneficiaries. The later acknowledges a broader set of market features including the needs and characteristics of the end beneficiaries that affect the performance of the technology known as the demand or societal-pull. This combination of the technological-push and societal-pull is deemed necessary as the two interact. It is seen that the societal-pull policies also aid in inducing and directing innovation to be closely aligned with the societal needs. However, studies into this area have mostly focused on leveraging this relationship to commercialize successful innovations, rather than the harnessing of emerging technologies to ease the approaches to services, such as land administration, in the direction of the clients it serves (Ghawana et al., 2016). The new approaches to development studies, also a construct of the last few decades, is in response to local and regional development policies responses to peculiar territorial challenges (Crescenzi \& Rodríguez-Pose, 2011). These approaches have questioned the sustained ability of the conventional top-down approaches to policy development. These new approaches therefore merge the macro and micro economic theories behind top-down approaches led by the government and professionals with meso-local concepts that inform bottom-up development strategies from the local people. Ghawana et al. (2016) describe how the harnessing of technology-push and demand-pull approaches can support research and development in land administration, making it more visible to key stakeholders and enhancing its applicability by making it more innovation oriented. However, they fall short of incorporating the stakeholders in their model. Rahmatizadeh et al. (2016) also conceptualizes the use of VGI 
in land administration, focusing on the top-down and bottom-up interaction of the actors and legal restrictions.

Participatory land administration encompasses the above approaches to innovative land administration and relies on the consideration of both the interaction of the key actors in the top-down-bottom-up approach for social inclusion (Figure 9-vertical aspect), as well as the technological-push and societal-pull drivers to innovation (Figure 9-horizontal aspect). In this regard, participatory land administration's aspects are the institutional influence (comprising the top-down influence of government and professionals and the bottom-up contribution of the citizens), the push of technological innovations, and the pull of the society's needs that form the basis for undertaking land administration.

- Institutional Influence of Professional Standards and Legal Requirements:

Conventional land administration is dominated by high professional standards and strict legal requirements that have long been established, the key actors being the professionals and government actors. The acceptance of this approach has been rooted in the trust lent to it by its proprietors as well as its sustainability. Although, as this strict approach has largely failed in $70 \%$ of the world (Enemark et al., 2016), and a citizen-led approach has been advocated by innovative approaches, PLA acknowledges the need for significant level of standards and regulations needed in the land administration process for the land rights captured to be seamlessly integrated in the formal system.

\section{- Citizen Contribution:}

This acknowledges the potential for the involvement of the local people and other relevant stakeholders in land administration activities, through carefully negotiated arrangements that ensures clear roles, rights, and responsibilities of the involved parties, and not just by way of consultation in the actual implementation. It allows process to take the local people's complete land tenure arrangements, social cultural relations, and peculiar societal needs into account. This also allows for the local people to feel a sense of ownership to the land information to enable them to build trust in it. By allowing for some oversight by local Trusted Intermediaries, information that are contributed are verified and substantiated. Trusted Intermediaries are key members of the communities who are deemed knowledgeable by the community members of the local traditions and land ownership and can aid in substantiating land rights claims in the area. 
A partnership is therefore created to balance the institutional influence of the government and professional's top-down approach, as well as the emerging bottom-up approaches that is empowering citizens.

- Societal Needs and Considerations:

The pull of societal needs is can be derived from the partnership relationship to determine the land administration goals. There is a need to identify the societal needs of the communities that the land administration seeks to serve, which will then judge the amount and depth of land information needed. These societal needs include, among others, land tenure security, taxation, support to a land market, food security, and climate change adaptation (Williamson et al., 2010). These will judge the amount of the information needed.

- Technological Innovations:

The push of technological innovations to aid land administration activities stemming from the societal needs and the balance that is achieved between the government and the other stakeholders, needs to be pro-poor (Zevenbergen et al., 2013). That is, it must be accessible and affordable to the local people, it should can support the local land tenure system, transparent and inclusive of all the people involved.

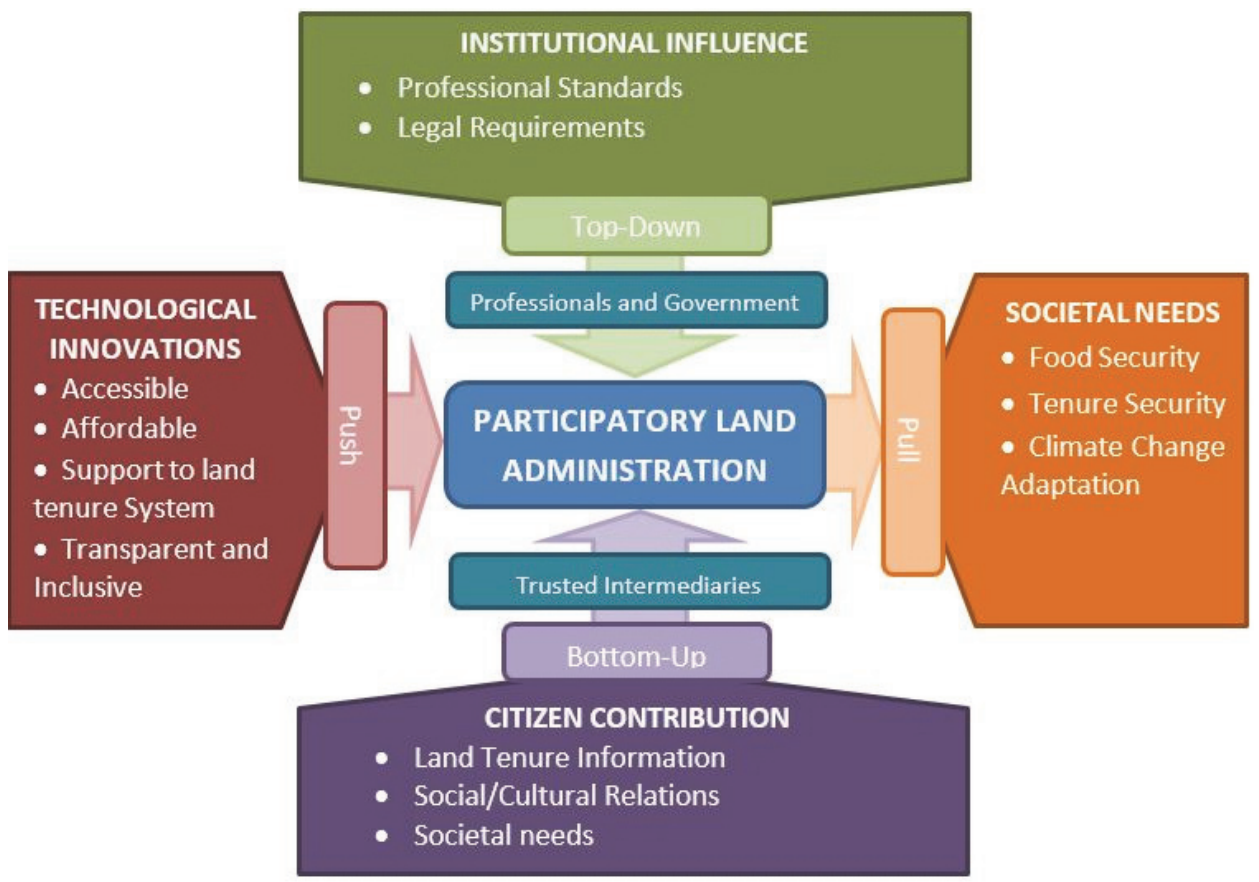

Figure 9. Structure of Participatory Land Administration

(The Societal Need considered in this thesis is Food Security) 


\subsection{The Experiment}

The experiment seeks to test the suitability of Participatory Land Administration on Ghana's rural customary lands as described in the previous sections. Current innovative approaches to customary land administration in Ghana are first explored. This is followed by an overview and justification of the selected area of interest for the experiment. The practical process of the experiment is then described.

\subsubsection{Innovative Approaches to Customary Land Administration in Ghana}

Ghana has a dual system of land registration, the deed and the title registration. However, there are attempts to phase out the former in favour of the later. Land title registration (LTR) in Ghana started with the aim of a systematic registration of common law and customary interests, namely the allodial interest, the common law freehold, the customary freehold, leasehold interests, and customary tenancy (Land Title Registration Law, 1986). However, the formulated procedures solely provide procedures for leasehold interests. This is because the roll out of the law focused on the urban areas, where land registration was deemed to be an urgent need. Leasehold interest dominates the land tenure system of the urban areas. Since the inception of the LTR, 30,000 parcels in Ghana have been registered (S. O. Asiama, 2002; Ehwi \& Asante, 2016; MASDAR, 2011). This has led to several attempts at innovative initiatives to aid the land registration process. Notable and most recent among these are the Millennium Development Authority's Systematic Titling, the Paralegal Titling Project by Corporate Initiative Development Group (CIDG), Medeem Proprietary ParcelCert, LandMapp Initiative, and the Community-based Land Survey Tool by Land Resource Management Centre (LMRC). The following is a brief overview of these initiatives in Ghana.

The Millennium Development Authority's Systematic titling was started with the aim of improving tenure security and facilitating access to land for commercial crops. In a comprehensive roll out of the process using modern high accuracy GNSS and database systems, the project was able to register 270 parcels at costs ranging from EUR200 to EUR270 per parcel (Jones-Casey \& Knox, 2011). The Paralegal Titling project was undertaken from 2007 to 2009 by a group of companies led by the Corporate Initiatives group to issue paralegal titles, that are capable of being easily converted into formal titles. This initiative, built on the open title concept, also required the use of large field teams and high accuracy GNSS equipment in order to meet the Lands Commission's requirements (Edmead, 2010). This initiative also focused on urban lands and attempted to only register leaseholds. LandMapp initiative has also made in roads with large-scale commercial cash crop farmers, providing 
land documents that are meant to ensure tenure security. This is however only available for ownership of leasehold and not customary interests (Landmapp, 2016; Pickett, 2015). The Community-based Land Survey Tool, was developed by LMRC, an indigenous Ghanaian research and development institute, as an innovative tool to support tenure security in cocoa growing areas of the country (Kakraba-Ampeh \& Yeboah, 2016).

It is shown firstly, all five recent innovative approaches in Ghana were largely led by the developing agency, with little input by the local structures and farmers involved. Secondly, these initiatives focused largely on fitting in the land title registration. Therefore, they result in either a focus on leasehold interest, or an attempt to convert customary interests into common law interests. This will allow the land information collect to be easily integrated into the land title register which has no provision for customary interests. Thirdly, the current innovative approaches rather place more emphasis on land tenure security without making allowances for other land management activities such as land consolidation. To develop an appropriate land administration system for customary lands, the principles of pro-poor and fit-for-purpose land administration must be followed. These are identified by Enemark et al. (2014) and Zevenbergen et al. (2013) as flexibility, participatory, affordability, support to land tenure system, and transparent among others. Furthermore, for the land administration system to be appropriate for land consolidation, information pertaining to topography, soil types, water distribution and the types of crops grown which are relevant to land consolidation should be included. Following the shortfalls of the current innovative approaches identified in Ghana to support land consolidation, there is the need for new approaches that place more focus on the target community, allowing them to undertake the process on their own, as well as incorporating the necessary information. This will allow for a better assessment of how the local community can sustain the system on their own.

\subsubsection{The Area of Interest}

Though the study started with three study areas, the findings in Chapter One showed the ability to generalise these study areas based on the land tenure arrangements. The area of interest chosen for this experiment is therefore Nanton, because is the most centralised in terms of customary land tenure. The area of interest is located within the Nanton Traditional Area of the traditional Kingdom of Dagbon in the Northern Region of Ghana. All lands in the kingdom are held under customary land tenure system, with the Ya-Na (the King) managing the lands at the top of the land holding hierarchy. The lands then devolve to the traditional areas, one of which is Nanton (with the Nanton-Na as the Chief), then down to the village skins. Nanton also falls under the Savelugu-Nanton local government district. The vegetation in the area is 
largely guinea savannah with tall grasses and few trees (mainly shea, acacia, baobab and mango), dotting the entire landscape. The area experiences a single rainfall season (April-October) accompanied by a long dry season (November-March) that brings in the harmattan winds. The inhabitants are mainly agro-pastoralists engaged in food crops and livestock production.

Land registration in the area takes the form of deed registration as the area has not yet been declared a Land Title Registration (LTR) area. This means little is done by way of the survey and mapping of parcel boundaries when registering land. This notwithstanding, the Nanton-Na (Chief of Nanton) has set up a Customary Land Secretariat (CLS) to assist with the management of the lands. However, since the LTR has no procedures for registering the customary interests, the CLS only focuses on the leasehold which are mostly held in residential properties, leaving out farm parcels which are mostly held in customary interests (K. O. Asiama et al., 2017b).

The farms on the Eastern part of the Nanton Village were mapped by the farmers, and family heads, with the assistance of the Trusted Intermediaries (TI) (Figure 10). Over a period of ten days, 230 farms covering an area of 3 square kilometres were mapped, with their accompanying interests recorded. This was done in a Living Lab-styled arrangement by the 85 farmers from 18 families who hold those farms, two Trusted Intermediaries and the Traditional Authorities.

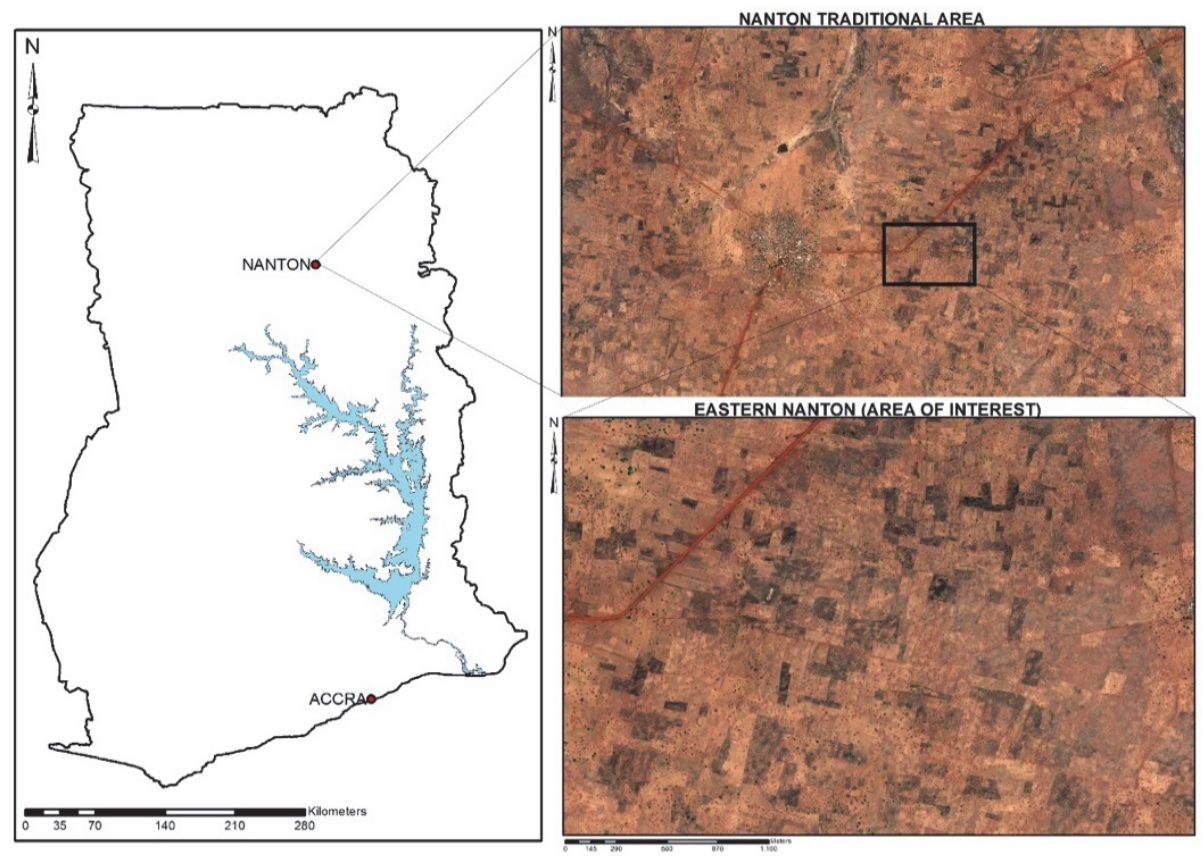

Figure 10. Map showing the area of interest in the Nanton Traditional Area and Ghana (Satellite image courtesy of DigitalGlobe Foundation) 


\subsubsection{Land Consolidation's Information Needs on Customary Lands}

This experiment seeks to collect land information to support land consolidation. The land information collected should therefore consider the local community's characteristics as well as the general land consolidation information needs. Land information in land consolidation should be geared towards mirroring the actual ground situation, to prevent losses in the intended land use plan (Lemmen et al., 2012). There are three key land information needs for land administration - the spatial information, the land rights information and the land value information (Sonnenberg, 2002). However, this experiment will only concern itself with the spatial and land rights information. Land value information is dealt with in Chapter Four. Past studies that have looked into the land information needs for land consolidation, focused on the western European goal of land consolidation, mostly being total rural development. The land information needs here include the property rights, including real and personal rights, the spatial distribution of these rights, the spatial extent of the farmland parcels, the land use information, the quality of the farmland parcel, and the soil type (Louwsma \& Lemmen, 2015; Sonnenberg, 2002; Thomas, 2006). Furthermore, social relations are an important part of land consolidation, especially in a close-knit community (Coelho et al., 1996). This means that the social relations should be recorded, in this case in the form of the landholders and the farmers' wishes.

In summary, the land information collected in this experiment to support land

Box 12: Farmland Parcel Types PP - Priority Parcel - The Parcel selected by the farmer, around which the re-allocation will be done; UP Unavailable Parcel - Parcels that cannot be reallocated. consolidation will include the name of the farmer using the parcel, the name of the farmer's family, and the rights the farmer holds to the farmland parcel. Where the farmer is a tenant (Figure 6), the usufruct (and the family) off whom the farmland

parcel is held is also recorded. For all situations, the name of the stool holding the allodial interest is added. In terms of the social situation relating to the land reallocation, the farmer has the opportunity to indicate a priority parcel and unavailable parcels. In terms of the agricultural aspect, the information relating to the use of the land, the crops grown on the land, and the farming technology used is also collected.

\subsubsection{The Practical Process}

A living lab approach is adopted for the experiment. A Living Lab is a combined lab/household system, analysing existing product service systems as well as technical and socioeconomic influences focused on the social needs of people, 
aimed at the development of integrated technical and social innovations and simultaneously promoting the conditions of sustainable development (highest resource efficiency, highest user orientation, etc.) (Almirall \& Wareham, 2011; Liedtke et al., 2012; Pallot et al., 2011). It is based on two main conceptsfirst is the involvement of users early in the innovative process, and the second is experimentation in real-world settings, aimed at integrating the social structure and governance, as well as user participation in the innovative process. The living lab approach encourages trust, allows access to adequate knowledge regarding the problem environment, and gives the users a sense of ownership of the product. The subjects of the experiment were identified first with the assistance of the Traditional Authority (the Nanton-Na and the family heads in the area) and the leaders of the Farmers' Association of the area. An interview was first conducted with land registration officers and land surveyors of the Lands Commission of Ghana to ascertain the ascertain statutory land registration and survey process. The researcher together with the two groups, identified the land tenure arrangement in the form found by $\mathrm{K}$. O. Asiama et al. (2017b) (Chapter Two). The Traditional Authority, the Farmers' Association and the researcher then used to develop the process of the mapping and recording of the land rights, with the researcher applying the inputs from the interview with the Lands Commission to align the developed process to the statutory process, and the former groups providing inputs on the local land administration.

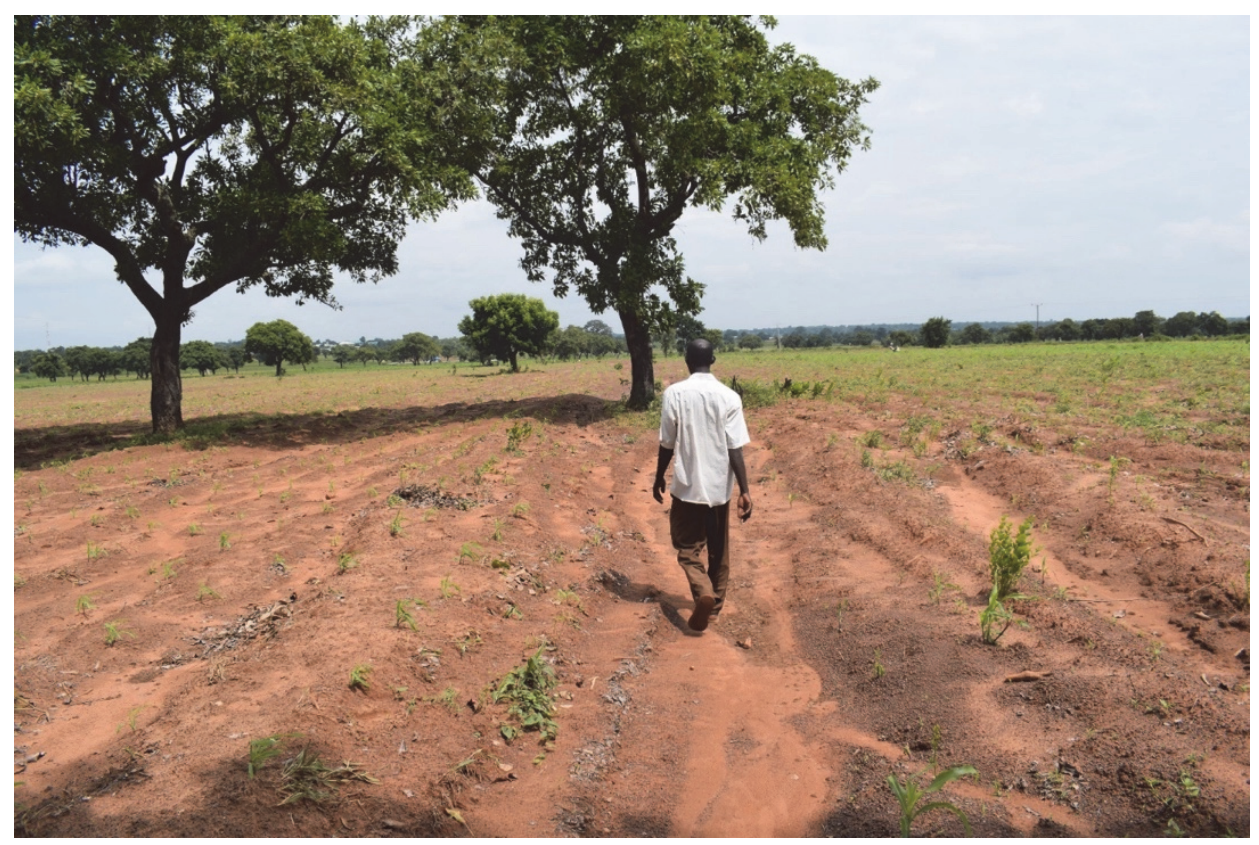

Figure 11: A Farmer walking the boundary of his farm 
Two technologies were adopted for the experiment-a smartphone app and satellite imagery. These technologies were first tested in a pilot undertaken in January 2016 to ascertain their ability. The smartphone app used was Esri's Collector for ArcGIS, which allows for a very effective and efficient collection of spatial data. The data collection method was based on polygons rather than boundaries. The polygons are associated with information relation to the farm parcel relevant to land consolidation and land tenure such as the names of the land right holders, from the allodial title (the skin involved), through the suballodial (the family holder), the customary freeholder or the tenant (the individual) if any; the crops grown on the farm, the seasons the farm is used, and the nature of the soil. This information is provided by the farmers, affirmed by the TIs, added as attributes, and regarded as the ground truth. The data collected can be viewed and processed in a cloud-based geographic information system, or alternatively downloaded for areas with limited internet connectivity. The app can also be used in combination with a GNSS receiver such as the Trimble R1 to achieve a sub-metre accuracy through Bluetooth connection.

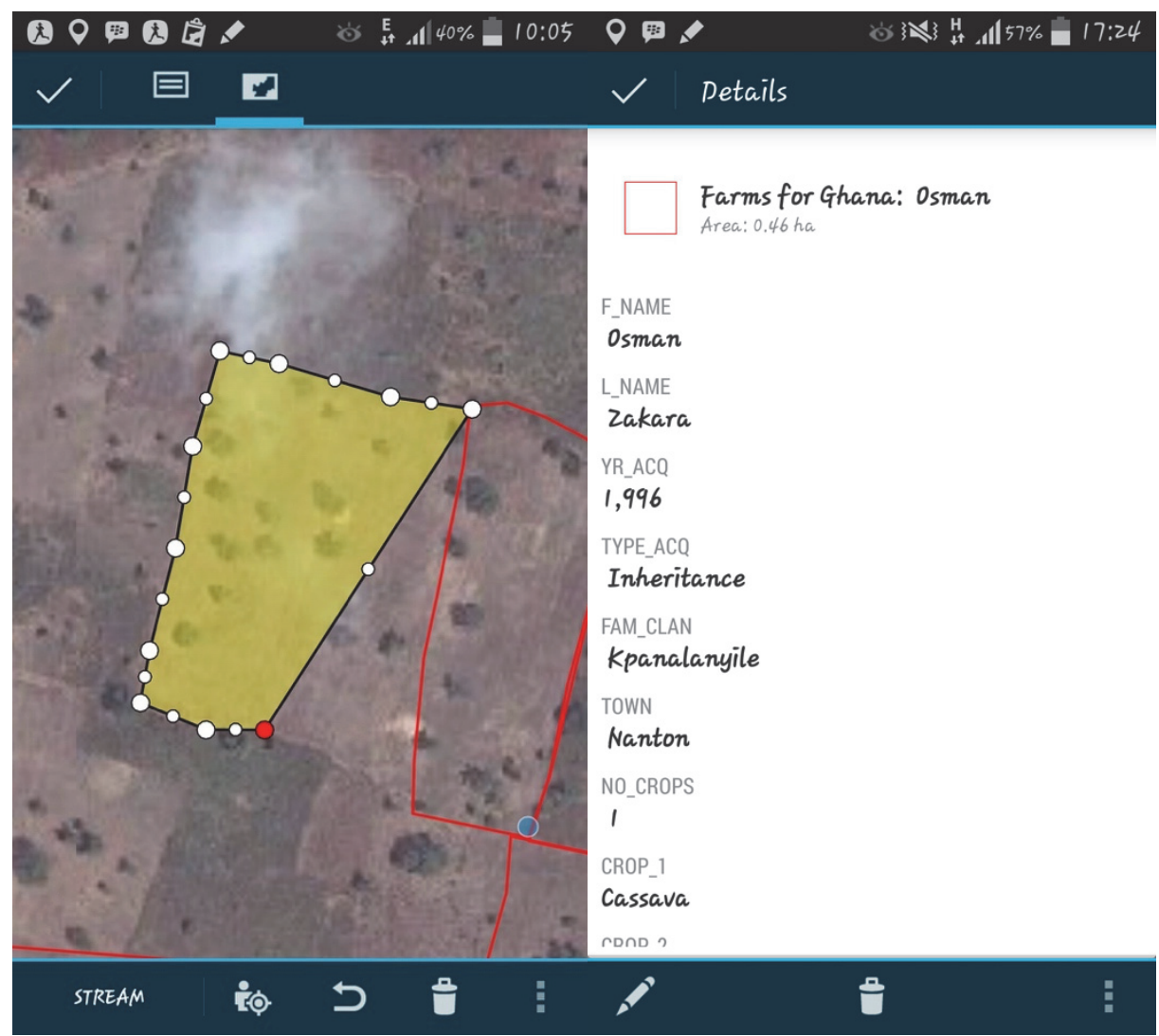

Figure 12: Interface of the Mobile App, Collector for ArcGIS 
However, since this experiment aimed at using materials and equipment within the means of the subjects, a low-priced 3G smartphone commonly found on the Ghanaian market was used. The mobile app has the ability to estimate the accuracy of the data collected. The second technology was satellite images. Here a February 2016 GeoEye-1 satellite image of the area of interest was freely acquired from DigitalGlobe Foundation, and printed at a scale of 1:4000, which is within the range of scales recommended by Byamugisha et al., (2012) for mapping rural agricultural land parcels with medium density. A February 2016 GeoEye-1 satellite image at the scale of 1:2000 (a scale at which rural houses are distinguishable (Byamugisha, 2013)) of the Nanton village was first presented to the farmers and the trusted intermediaries to train them by identifying the key features in the village such as the chief's palace, the school, the village square and their own houses. The farmers and the trusted intermediaries then gathered around the satellite image of the farms and the farmers identified their farms with red pens. When there was concurrence by the neighbours and the trusted intermediaries, the TI's marked the boundaries in black, signifying a final boundary (Figure 15). Two methods are adopted in order to be able to compare the effectiveness of the two. Other innovative approaches have taken place in areas with existing cadastral data, giving an opportunity to assess the approach against existing information. With no existing information in this area of interest, having a second approach aids with the assessment of the both innovative approaches. The satellite imagery, on the one hand, is a relatively accepted approach having been successfully used in Rwanda, Ethiopia, and Kenya, and is recommended as a fit for purpose approach for land administration (Bennett et al., 2015; Enemark et al., 2014; Lemmen \& Zevenbergen, 2010). On the other hand, the mobile app is a relatively new approach, having been tested in other parts of the world but not on customary lands (Basiouka \& Potsiou, 2012; Dyli et al., 2016; Molendijk et al., 2015).

After the mapping and the recording of the land rights, a focus group discussion was conducted with eight farmers selected from among the farmers who were part of the mapping process and trusted intermediaries at the village centre. The focus group discussion sought to ascertain their views about the process, the technology, as well as whether they will be able to replicate the process on their own. 


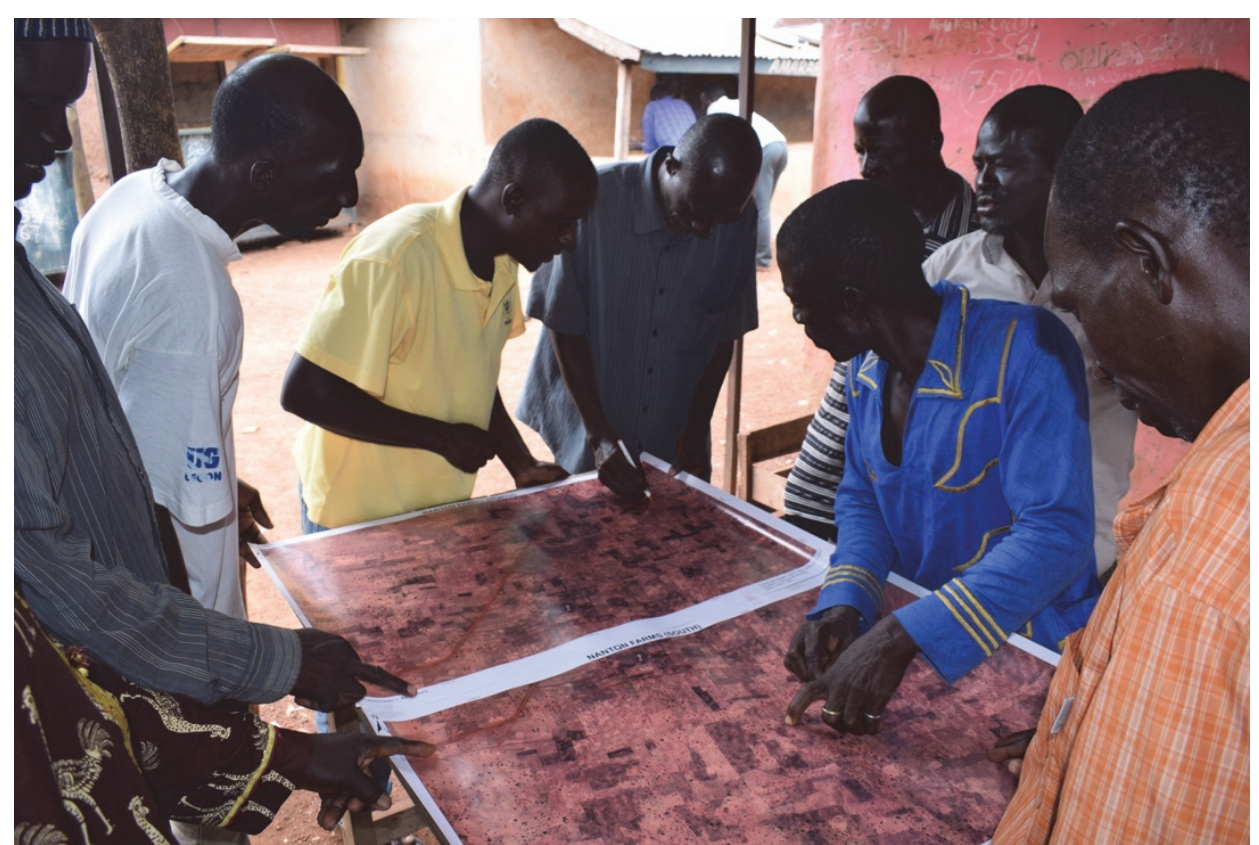

Figure 13: Farmers and Trusted Intermediaries (TIs) identifying their farmland parcels on a satellite image

(Photo by the Author)

The experiment was then assessed using the elements of fit for purpose land administration (Table 2) (Enemark et al., 2014). The fit for purpose land administration elements were selected from among a pool of other assessment frameworks such as the ISO 19157 Geographic Information-Data Quality standards and the aspects of responsible land administration (De Vries et al., 2015b). The ISO 19157 is limited to an assessment of the quality of spatial data without the accompanying land information. Responsible land administration also concerns itself with the macro level assessment of land administration. Both frameworks are therefore unsuitable for assessing this experiment. Four elements of fit for purpose land administration were selected to assess the approach as these were considered relevant to the initial experiment. The other three elements were found to be outside the scope of this work. 


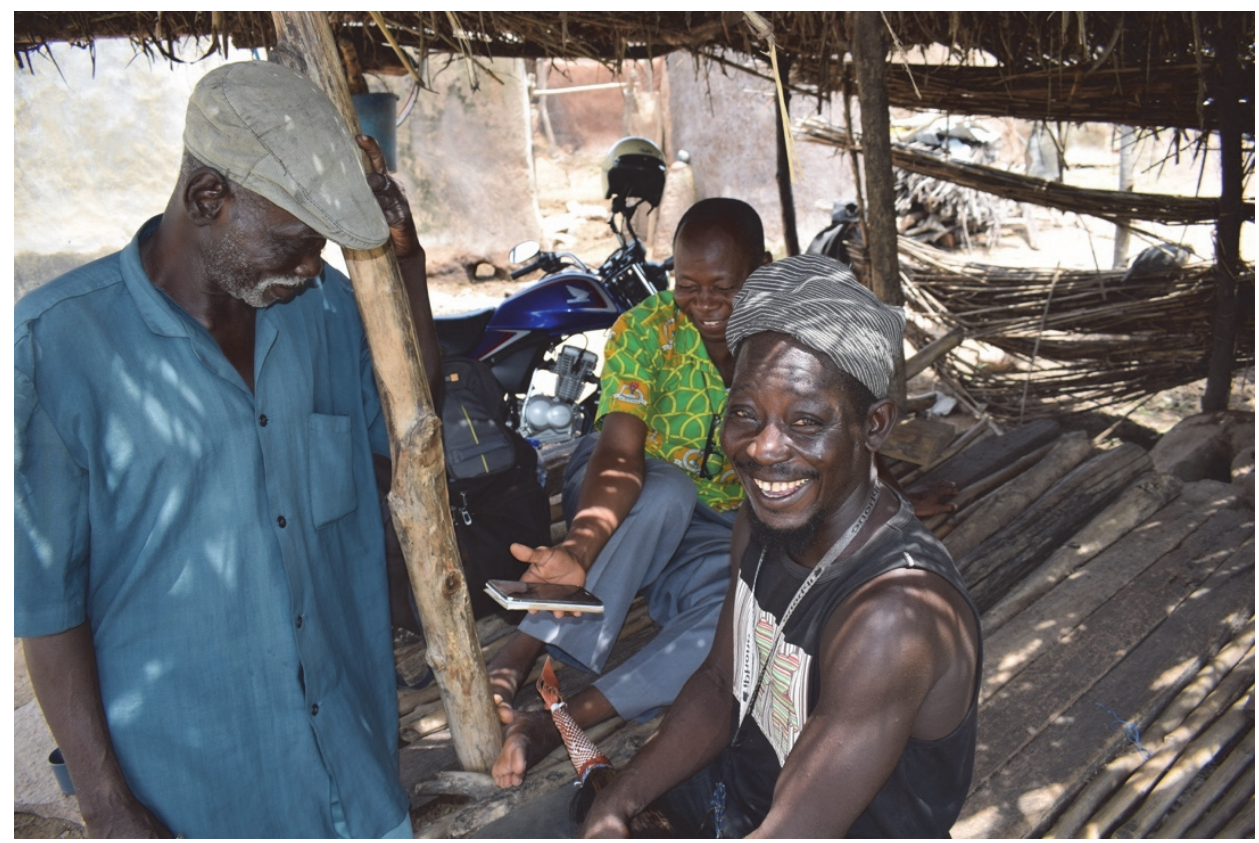

Figure 14: A Farmer and Trusted Intermediaries happy with their results (Photo by the Author)

These elements, adapted from FIG's Fit for Purpose land administration, are participation, affordability, reliability, and attainability. Participation is measured by the percentage of the procedure that involves the direct input and involvement of the local actors, and the ease with which the local actors can adapt to the technology used. The percentage of the procedure is ascertained by outlining the steps in the procedure according to the actors, and determining the number of steps each actor is involved in. Affordability involves the costs involved in the setting up and undertaking of the process vis-à-vis the current conventional and innovative approaches available, as well as the income of the users. This is determined by ascertaining the cost of the materials, equipment, and wages involved in each step. The cost of the process obtained here is then compared to the cost of the traditional process and the existing innovative approaches.

Reliability of the approach relates to the ability of the approach to accurately represent the ground truth. It is measured by the spatial accuracy of the data, the ability to achieve coverage of the area of interest, the coverage of all land tenure types. The spatial accuracy of the mobile app is obtained from the app itself. With respect to the coverage of all the land tenure types, this is determined by cross-checking from the CLS the rights inherent in the farm parcels to determine whether all the rights have been mapped and recorded. Attainability of the approach refers to the capacity to successfully establish the 
system without external support within an appropriate timeframe. Attainability is measured by the ability of the people to replicate the process and the duration of the process.

This is done by using only materials and equipment found in the area of interest, and the ability of the local people to use this equipment. The duration is measured by the average amount of time it takes a farmer and a TI to adjudicate and map the boundaries of a parcel, as well as the number of days (based on 8-hour work day) used to complete the mapping of the area of interest. Table 2 summarises the elements and their indicators.

Table 2. Summary of Assessment Elements and Indicators.

\begin{tabular}{|c|c|}
\hline RELIABILITY & $\begin{array}{l}\text { - The spatial accuracy of the approach. } \\
\text { - The ability to collect all land parcels in the } \\
\text { area. } \\
\text { - The coverage of all land tenure types. }\end{array}$ \\
\hline AFFORDABILITY & $\begin{array}{l}\text { - The cost of the Process vs the current } \\
\text { processes. }\end{array}$ \\
\hline PARTICIPATION & $\begin{array}{l}\text { - Percentage of procedure undertaken by each } \\
\text { actor. } \\
\text { - The ease of use of the technology. } \\
\text { The amount of input of the actors in the } \\
\text { process. }\end{array}$ \\
\hline ATTAINABILITY & $\begin{array}{l}\text { - The duration for data collection. } \\
\text { - The ability of the people to replicate the } \\
\text { process. }\end{array}$ \\
\hline
\end{tabular}

\subsection{The Outcome}

This section outlines the results of the experiment in terms of the assessment criteria set out in the previous section in terms of reliability, affordability, participation, and attainability.

\subsubsection{Reliability}

In the experiment, it was found that both technologies adopted were easy for the farmers to use. The use of the smartphone app enabled the farmers to walk the boundaries of their farms as the boundary was recorded by the app and automatically uploaded to a cloud-based GIS. 


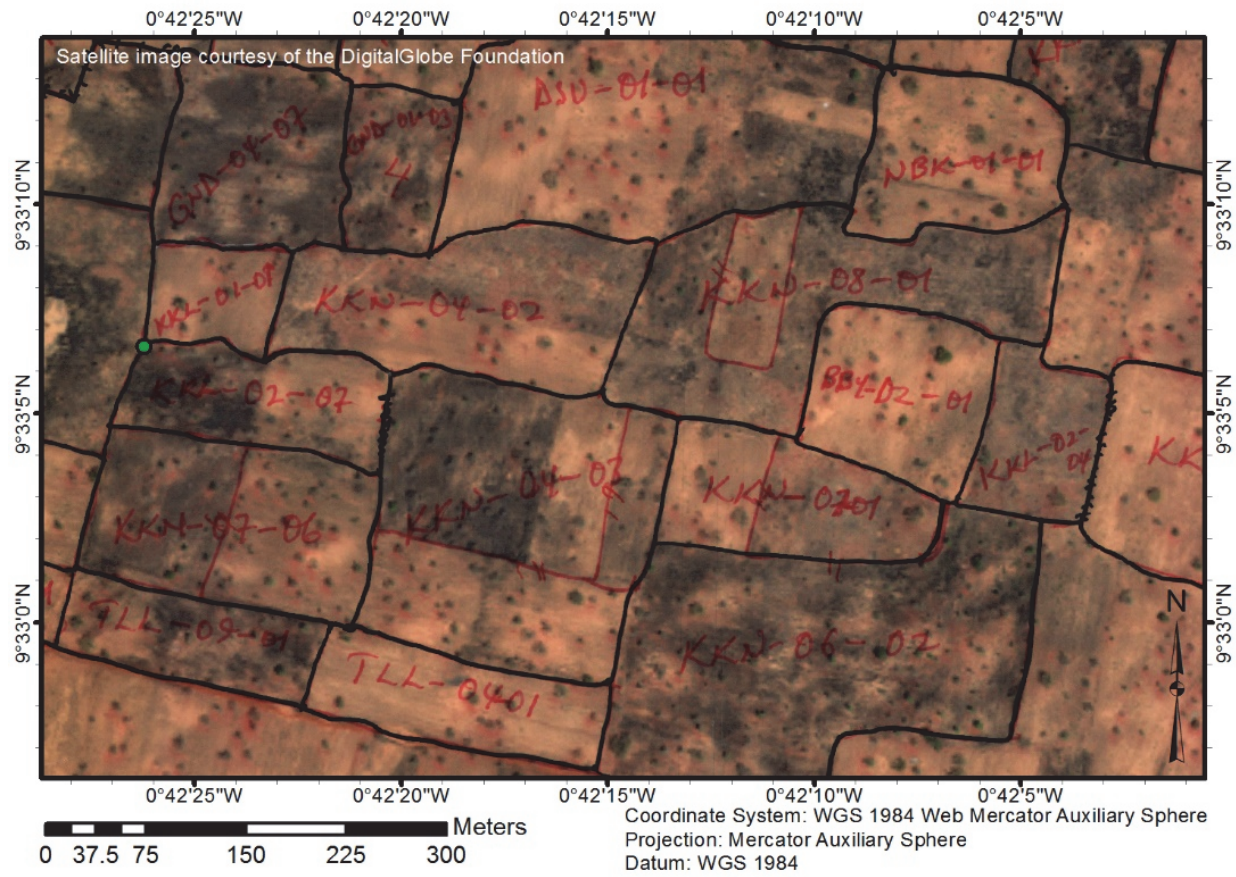

Figure 15. Part of the satellite image from the farm parcel identification showing Red Lines that are parcels identified by farmers and Black lines being parcels verified by the Trusted Intermediaries.

The main advantage of this is the reduced possibility of gross errors related to wrongly collected boundary data as the farmers know their farms best. Most of the farmers and the Trusted Intermediaries (TI) were already familiar with the use of smartphones, with most of them owning one themselves. However, the GNSS signal on the smartphones created a disadvantage with respect to the accuracy. The accuracy of the GNSS relies on the strength of the signal which is be influenced by several factors including the vegetation and the buildings in the area, as well as the terrain and atmospheric conditions. The accuracy of the mapping in the experiment ranged from one to five metres, mostly because of the cloud cover. The experiment was undertaken during the rainy season, therefore there was more cloud cover as compared to the dry season when the pilot was undertaken where an accuracy of one to three meters was observed. However, the area of interest being located in a guinea savannah grassland vegetation zone with trees several meters apart meant that vegetation had little effect on the accuracy, in comparison to an attempt by Osei-Tutu et al., (2016) to using a mobile app in the rain forest area. With respect to the satellite image, the images were not related to ground control points. Therefore, the absolute accuracy is up to $10 \mathrm{~m}$ after ortho-rectification. However, ground control points will be needed for the absolute pixel accuracy. 


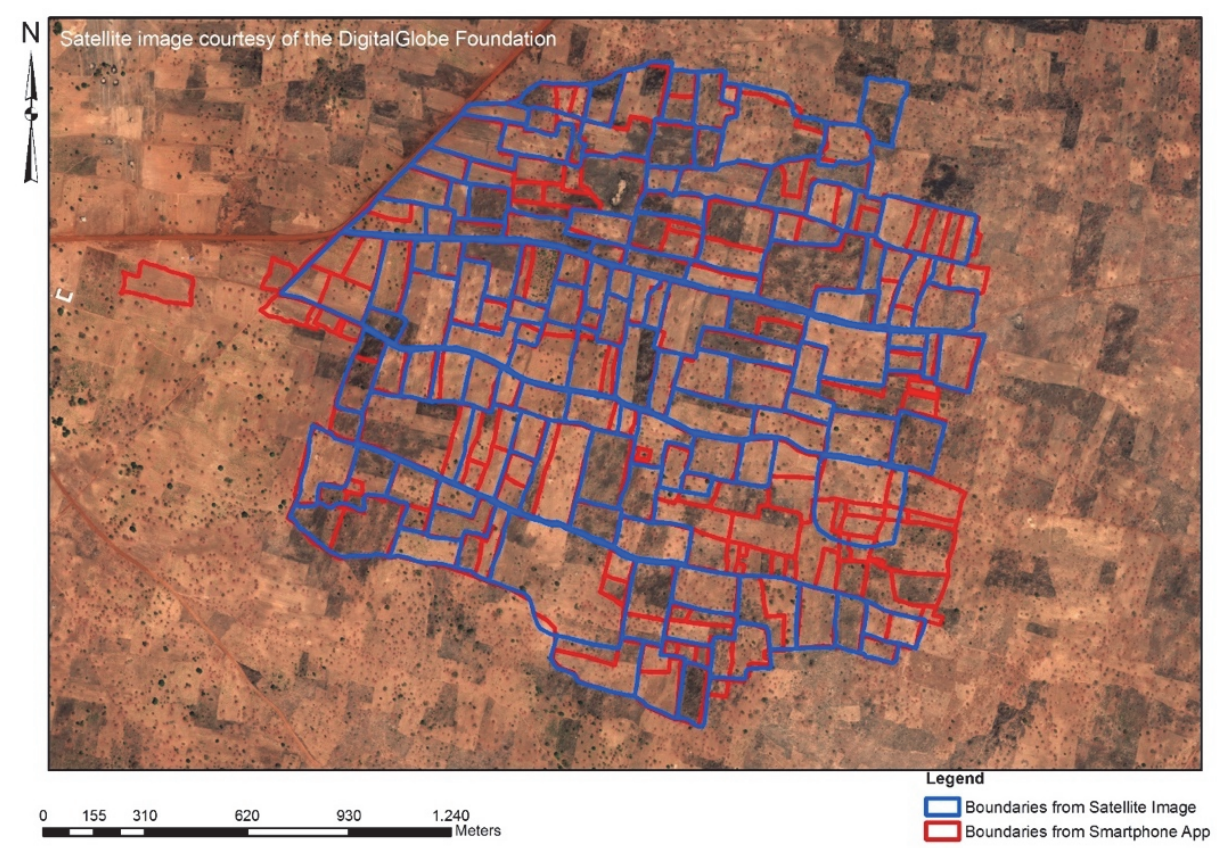

Figure 16. Parcels boundaries collected by Satellite Image (Blue) and Mobile App (Red).

No boundary disputes were witnessed during the experiment with the mobile app. The farmers during the focus group discussion attributed this to the planting of certain deep-rooted plants and footpaths that service as boundaries. Not all the farmers were present during the experiment, in which case the Traditional Authority, together with the TI's and the leaders of the Farmers' Union saw it fit that at least two farmers on neighbouring farms were enough to show the boundaries, followed by a verification by the TI (Figure 15). In such situations, all four parties were always in agreement with the identified boundaries. This was however not the case for the mapping on the satellite imagery, where at least $25 \%$ of the parcels identified by the farmers were either not confirmed or altered by the TI's.

Figure 16 shows a comparison between the farm boundary parcel data collected using the mobile app, and those collected using satellite imagery. It was found that out of the 230 Parcels collected using the mobile app, 62\% were identified on the satellite imagery (Table 3 ). Though the satellite image has been touted as an effective fit for purpose approach (Enemark et al., 2016; Lemmen \& Zevenbergen, 2010), but in this case, it does not fulfil the task.

This mostly occurred on farms which cultivated the same crop, therefore the similar vegetation cover made it difficult to distinguish the farms. The use of the satellite imagery took some training before the farmers could identify their parcels. When asked how they could identify their parcels, the farmers 
indicated that once a neighbouring farm was identified, they used the number of trees, changes in vegetation cover, and visible footpaths to define their boundaries. That notwithstanding, all the parcel boundaries that were identified from the satellite image largely corresponded with those collected through the mobile app. The use of the mobile app by walking the boundaries and satellite image had an advantage over the conventional methods used by the licensed and official surveyors as the two methods in the experiment were better suited to capture the irregularly shaped farm parcels because the conventional methods take points only at the corner of the parcel. Therefore, although the two methods tested are able to maintain the shape and area of the farm parcels collected, the mobile app is better suited for the area as it was able to collect all the farm parcels in the area of interest.

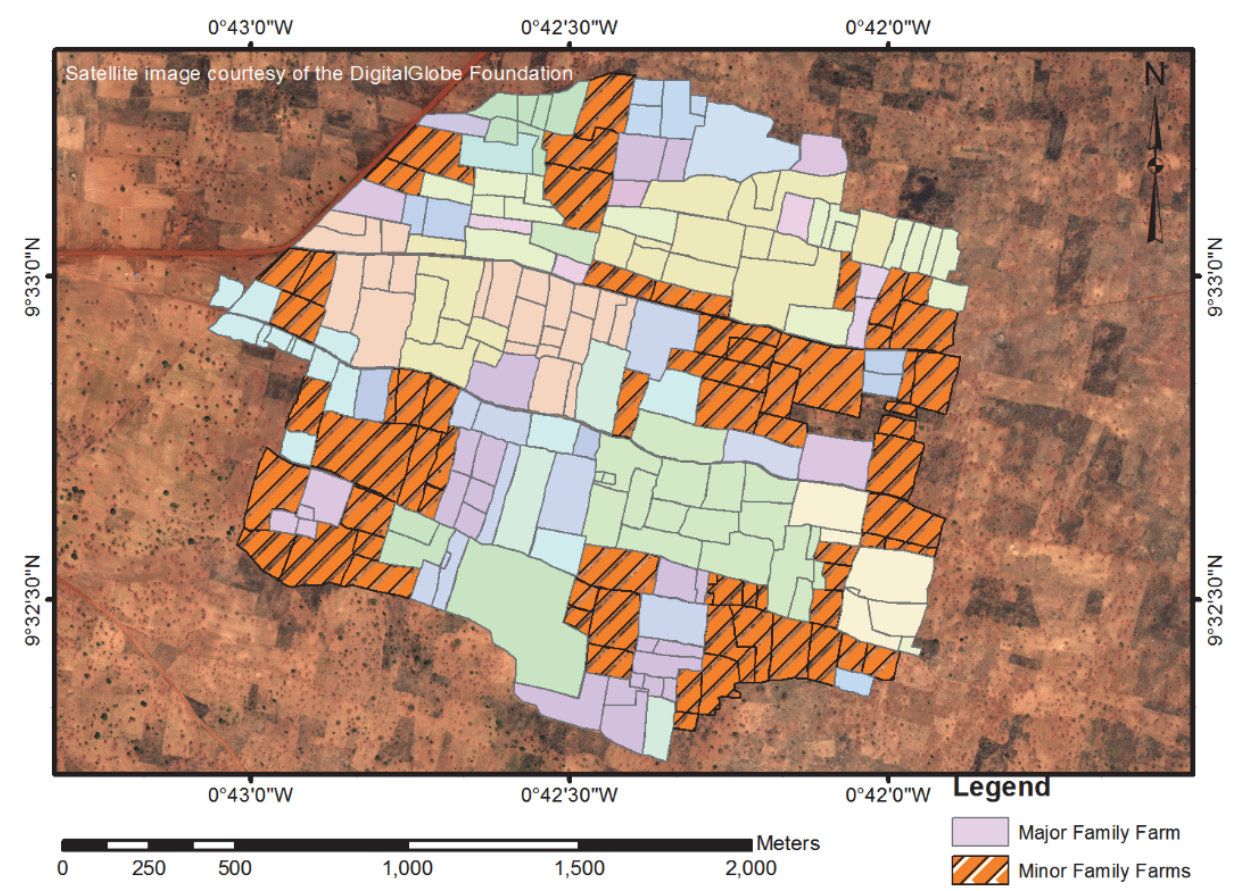

Figure 17. Family Lands in the Area of Interest

(Sub-Allodial Interest as family farms and divisions into Customary Freehold as Individual Farms. Each family land is a different colour).

In terms of the ability to capture all the farm land tenure types, the three key land tenure types ascertained in the area, from the interview with the traditional authorities, were the allodial (and sub-allodial) interest, the customary freehold/Usufructuary interest, and the customary tenancy, in order of priority. The approach adequately mapped out and recorded three interests adequately. 
Table 3. Summary of Data Collected

\begin{tabular}{|l|c|}
\hline \multicolumn{1}{|c|}{ Category } & Amount \\
\hline Size of the total area of interest & 300 hectares \\
\hline Number of individual farm parcels in area of interest & 230 Parcels \\
\hline $\begin{array}{l}\text { Number of individual farm parcels collected by mobile app } \\
\text { by participants }\end{array}$ & 230 Parcels \\
\hline $\begin{array}{l}\text { Number of individual farm parcels identifiable on satellite } \\
\text { image by participants }\end{array}$ & 144 Parcels \\
\hline $\begin{array}{l}\text { Number of Family Lands (i.e., aggregated collections of } \\
\text { parcels) }\end{array}$ & $\begin{array}{c}29 \text { Farm } \\
\text { holdings }\end{array}$ \\
\hline Area of largest farm parcel & $\begin{array}{c}11.14 \\
\text { hectares }\end{array}$ \\
\hline Area of smallest farm parcel & 0.07 hectares \\
\hline Average area of farm parcels & 1.29 hectares \\
\hline Standard deviation of farm parcel areas & 1.11 \\
\hline Number of farm parcels held in customary freehold & 220 Parcels \\
\hline Number of farm parcels held in customary tenancy & 12 Parcels \\
\hline
\end{tabular}

The land tenure types are summarized in Table 3 and shown in Figure 17, with the entire area being held in allodial interest under the Nanton skin, the family lands being held in sub-allodial interest, and the individual parcels (divisions in the family lands) being held in customary interest.

\subsubsection{Affordability}

The mobile app and the satellite imagery were found to be cheaper, more accessible, and easier to use than the current approaches on customary lands. The cost of the mobile app was found to be cheap compared to the cost of surveys by licensed and official surveyors, and the other attempts at pro-poor land administration in Ghana such as Paralegal Titling Project, at least GH $\$ 500$ $(€ 115.74)$ and $\mathrm{GH} \phi 200$ (€46.29) respectively per an acre parcel. Per the farmers and the Customary Land Secretariat (CLS), the cost is one of the main reasons why no land survey has taken place in the area. The costing of the approach took into consideration all the costs incurred from the start of the process till the end. However, later costing for the scaling up of the approach will be served better by other standard methods like the GLTN's Costing of Land Administration Services (COFLAS) (Burns \& Haile, 2015). The cost components of the mobile app and the satellite imagery added up to an estimated cost of GHф 38 (EUR 8.80) per parcel (Table 4). The cost differences mostly stem from the limited use of professionals and the reliance on the local people and technologies readily available locally. The CLS also had an official smartphone, a Samsung Galaxy Note 3, which was used for the experiment. The mobile app however requires a license costing an annual subscription of at least GHф 5600 ( $€ 1296)$. 
Table 4. Breakdown of the Cost of the Mapping Process

(Conversion rate GH $\$ 1=$ EUR 0.23 as at the $22^{\text {nd }}$ of July 2016)

\begin{tabular}{|c|c|c|c|}
\hline Activity & Cost/Wage & Quantity & Cost/Parcel \\
\hline Mapping (Workmanship) & $\begin{array}{l}\text { GH\$ } 40 \text { (EUR } \\
9.26) / \text { Day }\end{array}$ & $\begin{array}{l}20 \\
\text { parcels/day }\end{array}$ & $\begin{array}{l}\text { GH\$ } 2 \text { (EUR } \\
0.46)\end{array}$ \\
\hline Post-Processing & $\begin{array}{l}\text { GH } \$ 80 \text { (EUR } \\
18.51) / \text { Day }\end{array}$ & $\begin{array}{l}20 \\
\text { parcels/day }\end{array}$ & $\begin{array}{l}\text { GHф } 4 \text { (EUR } \\
0.93)\end{array}$ \\
\hline $\begin{array}{l}\text { Printing of Satellite } \\
\text { Image (A1) }\end{array}$ & $\begin{array}{l}\text { GH } \phi 40(E U R \\
9.26) / \mathrm{Map}\end{array}$ & 2 Images & $\begin{array}{l}\text { GHф } 0.17 \\
(\text { EUR } 0.04)\end{array}$ \\
\hline $\begin{array}{l}\text { Allocation Notes for each } \\
\text { parcel }\end{array}$ & GHф 4 (EUR 0.93) & $\begin{array}{l}1 \text { Allocation } \\
\text { Note }\end{array}$ & $\begin{array}{l}\text { GHф } 4 \text { (EUR } \\
0.93)\end{array}$ \\
\hline \multicolumn{4}{|l|}{ Equipment } \\
\hline License for Mobile App & $\begin{array}{l}\text { GH\$ 5,600 (EUR } \\
1,296) \text { for } 230 \text { parcels }\end{array}$ & 1 User & $\begin{array}{l}\text { GH } \$ 24.35 \\
(E U R 5.64)\end{array}$ \\
\hline Satellite Image & Free & 1 Strip & Free \\
\hline Smartphone & GH\$ 200 (EUR 46.30) & $\begin{array}{l}1 \\
\text { Smartphone }\end{array}$ & $\begin{array}{l}\text { GHф } 3.48 \\
(\text { EUR 0.81) }\end{array}$ \\
\hline \multicolumn{3}{|l|}{ Total } & $\begin{array}{l}\text { GH\$ } 38 \\
\text { (EUR 8.80) }\end{array}$ \\
\hline
\end{tabular}

\subsubsection{Participation}

The active participation of the local people was paramount in this experiment. Table 5 shows the process the experiment took as well as the role of the actors. The table shows the involvement of the researcher in five of the eleven steps of the experiment. All together the local people comprising the Traditional Authorities, the Customary Land Secretariat, the Farmers' Association, the Trusted Intermediaries and the local farmers undertook were involved in 10 out of the 11 steps (91\%), and undertook 6 out of the 11 steps (54\%) on their own (Table 5). With respect to the accessibility and ease of use, 49 out of the 85 farmers had low-end smartphones and were familiar with the smart phone environment. Hence the process was mostly led by the local people. Furthermore, the involvement of the trusted intermediaries and the presence of neighbouring farmers created a layer of check for the boundary information collection. This showed the ability of the local people to replicate the process on their own since all the materials and equipment used were obtained from the local market.

\subsubsection{Attainability}

The approach took ten working days (based on an 8-hour working day) to develop the process, execute it, process, and verify the information collected. This roughly translated to an average 20 min per parcel at the scale at which the experiment was executed, with the collection of the boundaries taking an average of 10 min per parcel. This may vary slightly depending on the scale of the experiment. However, the traditional approach in Ghana takes at least an hour for the boundaries of one parcel to collected. This experiment therefore proved faster than the traditional approach in Ghana. 
In terms of the ability of the local people to replicate the process, this depended on the equipment used, and knowledge of the people. As already demonstrated under participation, the local people showed their initiative by being able to lead the process with influence from the researcher. Furthermore, equipment used were all locally available with the CLS. With their local knowledge of their surroundings, the use of their familiarity of smartphones, and the ease of accessing the equipment used, this approach is easily replicable in the area. In summary, the results from the experiment showed that the approach is participatory, fast, incurs lower costs than the current approaches, and has the potential of being replicated by the local people. It is also capable of supporting the local land tenure system, though its accuracy is lower than the current approaches used.

Table 5. The Experiment Process and the Role of the Actors

Actors-Traditional Authorities (TC), Customary Land Secretariat (CLS), Farmers' Association (FA), Researcher (Rs.), Trusted Intermediaries (TI), Farmers (Fm.)

\begin{tabular}{|c|c|c|c|c|c|c|}
\hline Process of Experiment & \multicolumn{6}{|c|}{ Actors } \\
\hline Step & TA & CLS & FA & Rs. & TI & Fm. \\
\hline $\begin{array}{l}\text { Identify the land tenure } \\
\text { arrangement in the area. }\end{array}$ & $\mathrm{x}$ & $x$ & $x$ & $x$ & & \\
\hline $\begin{array}{l}\text { Determine the farming } \\
\text { arrangements in the area. }\end{array}$ & & $x$ & $x$ & $x$ & & \\
\hline Select Trusted Intermediaries. & $\mathrm{x}$ & $\mathrm{x}$ & $\mathrm{x}$ & & & \\
\hline $\begin{array}{l}\text { Develop the process of mapping } \\
\text { and recording of land rights }\end{array}$ & & $x$ & $\mathrm{x}$ & & $\mathrm{x}$ & \\
\hline Train the Trusted Intermediaries. & & & & $\mathrm{x}$ & & \\
\hline Map and record land rights. & & & & & $\mathrm{x}$ & $x$ \\
\hline Display mapped parcels. & & & & $\mathrm{x}$ & $\mathrm{x}$ & \\
\hline $\begin{array}{l}\text { Authenticate the information } \\
\text { collected. }\end{array}$ & & $x$ & $x$ & & $x$ & $x$ \\
\hline $\begin{array}{l}\text { Train farmers and TI's in the use of } \\
\text { satellite images. }\end{array}$ & & & & $x$ & & \\
\hline $\begin{array}{l}\text { Identify farm parcels on satellite } \\
\text { imagery. }\end{array}$ & & & $\mathrm{x}$ & & $\mathrm{x}$ & $\mathrm{x}$ \\
\hline $\begin{array}{l}\text { Transfer information for allocation } \\
\text { notes. }\end{array}$ & & $\mathrm{x}$ & & & & \\
\hline Percentage of Process & $18^{\circ}$ & $54 \%$ & $54 \%$ & $45 \%$ & $45 \%$ & $27 \%$ \\
\hline
\end{tabular}

\subsection{Discussion}

This section provides a discussion of the outcome of the experiment, placing it in wider theoretical context of the aspects of participatory land administration identified in Section 3.2. Discussion is couched in terms of the key aspects of participatory land administration (c.f. Figure 9), that is, the technological innovation, local participation through citizen contribution, the local need for land consolidation in support of food security, and the institutional influence of professional standards and legal requirements (Government and Professionals). 


\subsubsection{Technological Innovation Push: Mobile App vs. Satellite Images}

The experiment tested two technologies for collecting land information, satellite imagery and a mobile app, that are generally considered fast, cheap, and pro-poor by several studies (Basiouka \& Potsiou, 2012; Enemark et al., 2014; Kapitango \& Meijs, 2010; Lemmen \& Zevenbergen, 2010; Zevenbergen et al., 2013). However, whether these technologies are fit-for-purpose, is expected to depend on the context within which it is used (Enemark et al., 2014). The context in this experiment was food security in the Northern Ecological Zone of Ghana's customary lands. Most lands in this area are under the customary land tenure system, and fall within the customary land tenure system, together with a Sudan-savannah vegetation zone. The difference between this study and others that tested these technologies is that despite the lack of land tenure information in the areas within which they were tested, the approach was not compared to a pre-existing dataset to determine the validity and accuracy of the information collected. Though the use of satellite imagery is advocated for by Enemark et al. (2014) and Lemmen \& Zevenbergen (2010) as an appropriate for pro-poor land administration, this experiment found that the mobile app provided a better approach. The use of the satellite imagery was limited in its ability to identify all the farm parcels in the area of interest: only $62 \%$ of the farm parcels in the area were identified on the satellite image. This is similar to the findings by Osei-Tutu et al. (2016) on the use of satellite imagery in the rainforest areas of Ghana. Previous studies in Kenya and Ethiopia that have used satellite imagery successfully were undertaken in mostly steppe and desert scrub vegetation zones allowing for more visibility of features to aid with the identification of the parcels with farmers walking their land parcels (Bennett et al., 2015; Lemmen \& Zevenbergen, 2010; Yimer, 2014). Aside from the inability of some farmers to identify their parcels, some of the parcels were also misplaced and the Trusted Intermediaries (TI) were unable to confirm these. This affects the support to the tenure security of the farmers as the unidentified farms may not end up in the land administration system. It also limits the ability to undertake land consolidation: some of the farms will be left out of the process. Furthermore, differences in the parcel shapes were found between the two methods. This would have a direct impact on the success of land consolidation as some land consolidation approaches rely on the shape of the parcels to determine the existence of land fragmentation and to regularize the parcel shape. Therefore, in terms of a fit-for-land consolidation and support to the tenure security, this study finds that the mobile app provides a result for the case location at hand.

In terms of the affordability and accessibility, there was a trade-off with accuracy. A core aim of this experiment was the ability of the local people to be able to replicate the process without external support. This led to the use 
of locally accessible tools as these lowered the costs incurred (Zevenbergen et al., 2013). However, other studies such as Dyli et al., (2016) and Molendijk et al. (2015) who used a similar approach in their experiment, but added the Trimble R1 into the process, had a higher accuracy in their results, however at a significantly higher cost that would be unaffordable in the area of interest of this experiment. This notwithstanding, the costs of the experiment were also affected by the scale of the project at 230 parcels, which influenced significant cost components such as the licence for the mobile app, and the cost of the smartphone. Though the current cost of the experiment is closer to AfDB (AfDB, 2016) estimate for the cost per parcel in Rwanda at $\$ 8$ (Table 4), the scaling up of the experiment (for example, tens of thousands of parcels rather than hundreds) is expected reduce these costs and put it far closer to Deininger et al., (2008) \$1 per parcel recommendation for pro-poor land administration.

\subsubsection{Bottom-Up Citizen Contribution: CLS, TIs and Quality Control}

The customary land administration set up in Ghana puts the allocation of customary lands in the hands of the local traditional authority, with the consequent land rights recordation and documentation in the hands of the governmental bodies (Biitir \& Nara, 2016). However, advances by some customary land secretariats in the maintenance of update land rights registries show the potential of Customary Land Secretariats (CLS) as an alternative/informal land registry. These CLSs which are run by the local people, albeit mostly without formal training, are based on the local social and cultural customary practices. Mireku et al. (2016) further demonstrates this with how some CLSs can regulate land registration in their area of jurisdiction with the use of allocation papers. However, these allocation papers lack supporting spatial information. The support of Participatory Land Administration (PLA) was found in the experiment as an effective approach to adding spatial information to the land records of the CLSs, as well as aiding in the effective allocation of lands.

Much like other studies conducted in crowdsourcing land information such as Basiouka \& Potsiou (2012), it was found that the limited motivation of the local farmers to take part in the registration is linked to the cost of survey, and the long process of land registration. Furthermore, the farmers also saw the experiment as an opportunity to better ascertain the area of their farm parcels. On the part of the CLSs, this was an opportunity for them to be able to take an inventory of their lands based on their customary arrangements, taking the local needs into consideration. Though they lacked professional expertise, the CLS staff as TI's proved to be effective in the process as observed in Rwanda (Enemark et al., 2014; McLaren, 2013). They were also highly respected by the community, being able to manage the process together with the local 
people and ensuring that any dispute that arose during the use of the satellite images was quickly resolved without the involvement of the researcher. This is unlike other pilots where the researcher was a party in the process in order to regulate it, and pure crowdsourcing approaches where information is deemed correct where a lot of people agree with it (Navratil \& Frank, 2013; Osei-Tutu et al., 2016).

In summary, the local participation through TI's ensured a revered quality check on the citizens' contributions, with the CLS serving as a local land administration body to collect, manage, and disseminate land information.

\subsubsection{Societal Needs and Pull: Land Consolidation in Support of Food Security}

The main local needs in the area of interest are tenure security and food security. In the land administration domain, many existing innovative approaches support tenure security. A detailed record on land ownership, use rights, as well as the spatial extent of those rights is a condition sine qua non for land consolidation processes, but the success of land consolidation is dependent on the economic and ecological improvements for land and people (Abubakari et al., 2016). PLA also allows for the inclusion and collection of other information relevant for land consolidation such as the types of crops that are grown on the farm parcels, as well as the crops that can potentially be grown, the topography of the area, the soil types, as well as the land values of the farm parcels (Lemmen et al., 2012; Sonnenberg, 2002). However, information such as the topography, and soil types cannot be crowdsourced but need professional help in their identification and recording. This establishes the need for a partnership between the local people on one hand, and the government and professionals on the other hand to aid in the integration of the relevant information for land consolidation.

Recent approaches to land consolidation also largely favour a participatory approach to the planning and implementation (Hartvigsen, 2015b; Louwsma et al., 2014). This is to ensure that land consolidation is first demand driven, and secondly undertaken in a manner that fits the local conditions. PLA fits within these objectives as the active participation of the local people in the collection of land information builds their trust in the system and gives them confidence in the land management activities that will arise from it.

In summary, though a full land consolidation experiment was not undertaken, this first test of the PLA showed that it can incorporate land information relevant for land consolidation by involving the local people in the collection of land information. This experiment also showed how PLA is likely to make the 
local people feel a sense of ownership of the system that results and builds their trust in the land management activities for which it will be used.

\subsubsection{Top-Down Institutional Influence: Professional Standards and Legal Requirements}

In order for the innovative approach to fit into the formal system at a later time, it is necessary for it to fit into the current legal framework (McLaren, 2013). The legal framework provides the laws and regulations upon which authorities rely upon to determine land administration processes. In Ghana, the laws that cover the land administration processes include the Land Title Registration Laws of 1986 (PNDCL 152), the Land Registry Act of 1962 (Act 122 ), which deal with title and deed registration respectively, as well as the nature of registrable rights; the Survey Act of 1962 (Act 172) governs the land survey practice in the country. The Survey (Supervision and Approval of Plans) Regulations of 1989 (LI 1444) and the Technical Guidelines for Spatial Data Capture and Presentation in Ghana of 2008 set the standards for land surveying, for the purposes of conveyances, leases, assignment, charge, or transfer. However, these standards fall short of specifying the regulations for mapping customary rights and interests and the administration of customary lands outside the land registries. The customary lands are governed by the customs and traditions of the area by the Traditional authorities, usually through their CLSs (Biitir \& Nara, 2016; Mireku et al., 2016). The Land Title Registration law allows for the use of general boundaries in the first survey. This provides an opportunity to use innovative approaches in rural areas where a high accuracy is not a necessity. The authority of the CLSs drawn from the traditional authorities is empowered by the constitution. The CLSs can therefore legally keep a registry of lands outside the formal registry, although these have very little legal implications outside that particular traditional area (Mireku et al., 2016).

In summary, it is seen that PLA is supported by the legal framework of Ghana because first, the general boundary concept used in supported by the land title registration law; secondly, the customary rights that will be recorded are supported by the laws, and thirdly, the process and the system will be managed by the Traditional Authority, through its CLS, which is mandated to manage customary lands.

\subsection{Conclusions}

This paper examined how participatory land administration fits into customary land administration to support responsible land consolidation. This was done by undertaking an experiment using two technologies, a smartphone app and a satellite image. The experiment was then evaluated in terms of reliability, 
affordability, participation and attainability. Though this experiment does not test the results on a land consolidation project, it evaluates the potential of its use on land consolidation projects. This first approach to use participatory land administration on customary lands shows that, theoretically, it can support the land tenure system, it is cheaper, and faster than the traditional approaches, and the technologies tested are easy to use by the community and supported by the local land administration structures. It is found to have the potential to support land consolidation, as it is able to collect the needed land information. However, this experiment did not undertake land consolidation to test this. Further studies are needed to understand how it can hold up when it is scaled up and applied in a land consolidation project.

The two technologies used, the mobile app and satellite image, have been recommended as fit for purpose approaches. However, in terms of reliability and attainability, the mobile app was found to be a more appropriate technology for capturing the farm boundaries in the area. This is because the smartphone app was found to be easy to use after the farmers received little training and all the farm parcels were captured using it. The use of the mobile app however needs more investigation in the context of customary lands. The satellite image was found to be more difficult and the identification of the farms was confusing for the farmers. Both were however affordable and faster than the traditional approaches. No major disputes were encountered that required the intervention of the traditional authorities, however, some confusion arose in the identification of the parcels on the satellite image. These disputes were settled by the farmers themselves.

In terms of the participation, there was a general willingness to participate. The famers' involvement and contribution built up their trust in the system as they were involved in the building of the approach, and they collected the information themselves. The local land administration structure which had also started to build its local registry provided an adequate support for the for the approach as Participatory Land Administration (PLA) is capable of spatially supporting the allocation process of the Customary Land Secretariat (CLS), in anticipation of the land title registration of the area. In relation to the statutory requirements, although the PLA approaches meet the legal requirements of the set by the laws governing the registration of land, the professional regulations are not adequately met. However, the progress towards the registration of all customary interests eventually enable the integration of the data collection using this approach to the land title registry. It is therefore recommended that further investigation be conducted into how the various customary land rights can be integrated into the land title registry. Further research needs to be done in terms of how to scale up the approach to involve more than one customary land secretariat to further reduce the costs and provide a level of standardization. 
With respect to the support for land consolidation, though this experiment did not undertake a full land consolidation, it was found to enable the capture of all customary land rights as well as other information relevant to land consolidation. Furthermore, the participatory nature of the process provides a stepping stone to the community's participation in land consolidation, further enabling a participatory approach to land consolidation. In developing a responsible land consolidation on customary lands, further research will be done on using the land information collected through PLA to aid with valuation of customary rural farm parcels as well as a land reallocation process. 


\section{Chapter 4 Land Valuation on Rural Customary Farmlands*}

* This chapter has been published as an ISI journal paper;

Asiama, K. O., Bennett, R. M., Zevenbergen, J. A., \& Asiama, S. O. (2018). Land valuation in support of responsible land consolidation on Ghana's rural customary lands. Survey Review, 50(361), 288-300.

https://doi.org/10.1080/00396265.2018.1467672 


\subsection{Introduction}

Land consolidation, in various forms, has been successful in curbing land fragmentation and increasing agricultural productivity in much of the European Union and various Asian countries including China and Nepal. Land consolidation is a land management activity that involves all the procedures for exchanging, rearranging, and expanding farmland parcels with the goal of increasing farm productivity (K. O. Asiama et al., 2017) (Chapter One). However, despite successful implementation in Europe and Asia, its implementation in Sub-Saharan African customary lands, for example in Malawi (1950) and in Kenya (1954), has been largely unsuccessful (Nothale, 1986; Thurston, 1987). The failure of land consolidation in these areas has been attributed to the direct transfer of land consolidation practices from Europe to Sub-Saharan Africa without due regard to the latter's social, economic, cultural, and political situation (K. O. Asiama et al., 2017a; Van Dijk, 2003). To resolve this, K. O. Asiama et al. (2017b) suggests the development of responsible approaches to land consolidation in Sub-Saharan Africa. Responsible land consolidation uses practices that continuously align the technical and administrative requirements, and the internal processes of land consolidation to the dynamic local societal demands, economic conditions, and cultural and legal requirements (K. O. Asiama et al., 2017b).

One of the key stages of land consolidation is the inventory and planning stage where a list of land parcels, the based on an inventory of the land parcels, their characteristics, and the rights inherent, is created or updated to assist in the comparison of the land parcels (Van Dijk, 2003a). Though the use of the market value is recommended by several studies, customary land holders, having a strong cultural and spiritual bond with their lands, are unlikely to trade in their lands. This limits the operation of a land market on customary lands. There is therefore the need to develop an approach to assigning values to the customary rural farm land parcels that is reflective of the local people's view of the land value.

Land reallocation in land consolidation relies on land valuation to describe and assign a value to the farmlands that will be reflective of the local farmers' perception of their farmland values. This will increase their trust in the land consolidation project. Experiences in land consolidation in other parts of the world demonstrate that farmers and land owners usually compare the land value assigned to their farmland parcels to those of similar and neighbouring parcels, and raise objections to the inconsistencies they feel arise (Demetriou, 2016b). This slows down the land consolidation process. Customary lands present a peculiar case as the social, spiritual, and cultural bonds with the land also influence the factors which affect the land value, making it different from lands held in individual ownership. In response, this paper seeks to contribute 
to the approaches for valuing land in areas without a land market - in order to support land consolidation - by proposing a new framework for valuing customary lands. To this end, this paper will seek to ascertain the current approaches to valuing lands in Ghana, and for land consolidation; identify the factors considered when valuing farmland land for land consolidation; determine the relevance of these factors in the customary rural setting; determine the requirements for a land valuation approach to support land consolidation for rural customary lands; and identify the strengths and weaknesses of this approach.

In the next section, the paper links land valuation to land consolidation, underscoring the importance of land valuation in the land consolidation process. Section 4.3 places land valuation within the context of customary lands, with a focus on Ghana. Section 4.4 follows and delivers the outline of the valuation approach covered in the paper. Section 4.5 presents the land consolidation case study in which the valuation approach is applied. An overview of the case study area is provided with the valuation factors and available data presented. The results of the case study are also presented and discussed in terms of the strengths and weaknesses of the approach. Section 4.6 concludes the paper and suggests areas for further research.

\subsection{Background on Land Valuation for Land Consolidation}

Land valuation is the process of estimating the amount at which a parcel of land will be exchanged on a stated basis, having regard to the nature of the asset and the purpose of valuation (RICS, 2017). Land valuation looks at three aspects to determine the process - the nature of the asset, the basis of the valuation, and the purpose of the valuation. The purpose of valuation informs the basis upon which the valuation will be undertaken (Awuah et al., 2016). Land valuation draws on the theory of demand and supply, explaining the competitive behaviour of the players of a market to meet their unlimited wants within their limited means and in the context of the limitations of the supplyside. Valuation is therefore an attempt to predict the result of meeting demand with supply under specified conditions and factors. These conditions may be objective or subjective, depending on the context within which the valuation is being undertaken. The basis upon which the value is assessed includes the market value, the market rent, worth and fair value. The purposes of valuation among others include sale and purchase, rental, insurance, mortgage, and, in this study, land consolidation.

Land consolidation as a land management activity comprises three main stages - the data preparation stage, the inventory and planning stage, and the implementation stage. The inventory stage involves the collecting and/or 
updating of cadastral and land information records within the land consolidation area and the valuation of the land parcels in the area, to lay the grounds for the planning of the land consolidation works. This includes the identification and adjudication of land parcel boundaries, the determination of the legal status of the parcels, delimitation of the environmental areas, and handling of objections. With the underlying principle of land consolidation being that the land holder/farmer should not be worse off after the project, there is the need to ensure that the value of the land received after the project would be equal or higher than the value of the lands held before the project (Demetriou, 2014; Haldrup, 2015). The rule of thumb has been that where the value of a land holder's farm parcel is smaller than it was prior to the land consolidation project, he may receive monetary compensation, or he may be allocated a larger amount of land to ensure equivalency. On customary lands, where land is a social, cultural, and spiritual symbol, the most commonly accepted form of compensation is replacement instead of financial compensation (Asiama, 2015; Asiama, 1981).

Land valuation in support of land consolidation is the process of assigning land values, in monetary terms or in the form of relative scores, to all the land parcels in a land consolidation project area, as well as all the fixtures to those lands including the structures, the trees, etc. (Branković et al., 2015; Bullard, 2007; Demetriou, 2014). However, a critical ongoing debate is the basis upon which land valuation for land consolidation should be undertaken. There are currently two bases of value in use for land consolidation; open market value and the agronomic value. The open market value is the land value, expressed in monetary terms, in an arm's length transaction between a willing buyer and willing seller, after suitable marketing and where the parties acted knowledgeably, prudently, and without compulsion (RICS, 2017). The agronomic value is the land value solely based on the agricultural productivity and the soil quality and expressed on a predetermined scale. The basis of value used by various countries depends on the permitted land use and the land market proliferation in the area, with Van Dijk (2003) suggesting the use of soil productivity and agricultural productivity, which he views as the two factors most closely associated with farm land value. Demetriou (2014) however suggests that the use of the agronomic and soil productivity values is appropriate for areas where housing and other land uses are not possible on agricultural lands, with agriculture being the only possible land use in the area. The approach and the bases for valuing farm lands for land consolidation therefore differ among countries. For some, it is based solely on agronomic value and soil quality, with the valuation process being undertaken by a committee of agricultural experts with inputs from the local farmers (e.g. Germany), or a valuation committee of local farmers (e.g. The Netherlands), using a relative scale with a unique set of categories for each project area (Van Dijk, 2003a). In this first group of countries, the productivity of the soil is seen 
to be more important than all other factors. Where the areas have the same soil quality, then the basis of the comparison will be only the size of the farmland parcel. In Germany, where there is microclimate in hilly areas, these are also taken into consideration. Therefore, for the agronomic value here, the production potential of the farmland parcel is used as a basis of production, with little regard for the contextual factors. The second group bases the land value on the open market value with a local community of experts that determines open market land values (e.g. Moldova and Cyprus) or categorises them into an interval scale with the highest land being 100 (e.g. Denmark) (Demetriou, 2014; Hartvigsen, 2015c).

\subsection{Valuation of Customary Lands in Ghana}

Customary lands is a multi-dimensional term used by different authors to variously describe other terms including commons, communal lands, traditional lands, and indigenous lands (Abubakari et al., 2016; Arko-Adjei, 2011; Asiama, 2004; Hardin, 1968; van Gils et al., 2014). In an attempt at a universal definition, several studies have tried to streamline the various definitions from different contexts and regions. In this study, customary lands is defined with three elements; first land that is held on the basis of indigenous tenure rules that have evolved locally; secondly, the land holding is based on a combination group individual rights; and thirdly, the rights, responsibilities and restrictions over these lands have arisen as a result of accepted practices based on the customs and traditions of the group (Arko-Adjei, 2011; van Gils et al., 2014b). Customary lands make up about $80 \%$ of the lands in Ghana, with the $20 \%$ being public lands held by the President in trust for and behalf the people of Ghana (Kasanga \& Kotey, 2001). The key interests in customary lands are allodial, customary freehold (Usufructuary) interests and customary tenancy. The allodial interest is held by the group (tribe or family/clan) and managed by the leaders, free from any encumbrances or restrictions, except those emanating from the laws of Ghana. The second, the customary freehold interest, exercised by members of a community, is borne from their inherent rights to use and enjoy the community's lands subject to certain restrictions and responsibilities imposed by the community and the laws of Ghana. The third is the customary tenancy, the land rights obtainable by all persons, indigenes or non-indigenes, based on prior agreed terms upon the passing of some consideration. Furthermore, the land title registration allows granting of statutory leaseholds on customary lands.

Land valuation methods include the investment method, the sales comparison, the cost method, the residual method and the profits approach, with the first three being the most commonly used in Ghana. These are often used for urban lands and rural residential land parcels as these are mostly held in leaseholds which are traded on the land market (Awuah et al., 2016). However, the 
licences and customary freeholds are not valued much since they are hardly traded, except for cases of compulsory land acquisition (K. O. Asiama et al., 2017a; Kidido et al., 2015). Valuation of customary lands further presents a challenge in the process of land valuation, as customary lands are unlikely to be registered due to the layered land tenure, and the low land mobility by which it is characterised. However, this does not mean land mobility is banned on customary lands, as found by K. O. Asiama et al. (2017), where it was found that in one community, lands were rented out on tenancy for a flat rent irrespective of the characteristics of the land. This therefore does not correspond with the conventional neo-classical approach to the value theory, based on the concept of demand and supply and the role of prices in resource allocation (Mooya, 2009; North, 1990). Customary land holders in Ghana view themselves as mere custodians of the land, holding it in trust for future generations. This is characterised by Elias (1956), who describes customary lands as belonging to many who are dead, a few who are living and a countless host yet unborn. However, despite this characterization, where land is acquired by the government for public purposes or by private companies for large scale investments, these bodies strive to pay fair and adequate compensation (AnimOdame, 2011; K. O. Asiama et al., 2015; Kidido et al., 2015). This is done in a manner to ensure that all stakeholders in the land are considered and catered for, as Boydell (2015) demonstrates through use of stakeholder analysis. The approach shows that customary land valuation needs an approach that considers solely the parties involved. Valuation that estimates the consideration for the transfer of land between two identified, knowledgeable, and willing parties is based on fair value (GLTN, 2017). In land consolidation on customary lands, the parties involved are the farmers, the families (represented by the family heads), and in some cases, the chiefs. This means that to undertake valuation for the exchange of farm parcels, the local people's perception and understanding of land value will form a major aspect of the process.

\subsection{The Framework for a Valuation Approach for Customary Lands}

This section outlines the framework for a valuation approach for customary lands. In determining the land value index of the farmland parcels, the new approach seeks to provide a basis for comparison among the farmland parcels (Figure 18). Land Value Indices are used here instead of scores as used by Branković et al. (2015) and Demir et al. (2002), to allow for continuous values in comparison instead of discrete values. The approach is flexible and contextspecific, as it can be adapted in any geographic area to support land consolidation because it is possible to tailor the factors and the weights to fit into specific contexts. The approach is knowledge-based, using local and expert judgement through value functions. 
The development of the Land Value Index (LVI) is based on the general land valuation approach using the Multiple Attribute Decision-Making (MADM) method. MADM methods are flexible and can be adapted with ease to the development of indices being represented by a set of parameters, where the aim is to evaluate an object compared to a standard for which the application is concerned (Rao, 2007). The MADM is valid if the decision attributes are expressed in identical units of measure. Hence decision attributes that are not uniform have to be standardised before being adapted into the decisionmaking. The table of MADM methods comprise four aspects as shown in Table 6. This shows Alternatives, which are the farmland parcels $(p)$ in this case; Attributes, which are the Land Value Factors $(F)$ in this case; the weights $(w)$ of the attributes; and the measures of the alternatives, which are the Land Value Scores $(S)$ in this case. Figure 18 shows the process through which the land value factors are selected and incorporated into the model.

Value functions are used to standardise the values of the Land Value Factors. Value functions are mathematical equations reflecting the factors in terms of their desired values, ranging from the best to the worst conditions (Beinat, 1997). The approach measures how far the Land Value Factors (LVFs) deviate from the most suitable condition. LVFs are the individual factors that influence the value of land. Where the parcel will achieve the maximal agricultural outputs, and profits the LVF is denoted by the Score 1 . The most unsuitable conditions for the LVFs are denoted by the Score 0. The assignment of the scores is done in two ways; 1 ) through a quantitative method for the continuous variables, and 2) a categorical rating method for discrete variables using the appropriate ordinal scale both through expert and local judgement. Both methods will result in a numerical scale from 0 to 1 . To identify and understand the factors that affect farm land value on rural customary lands, the factors found in previous studies relating to the valuation of other types of land were identified.

A structured interview was conducted with all 72 farmers who farmed in the study area: perceptions of the land value factors were identified, including factors that were not identified, and factors were weighted according to their importance. The weights assigned, ranging between 0 and 10, were then standardised. Further semi-structured interviews were conducted with 15 individual farmers, two staff of the customary land secretariat, two elders of the community, and an agricultural officer, as well as a Focus Group Discussion (FGD) with the leaders of the Farmers' Union of the village.

This was done to understand the rankings and the weights assigned to the land value factors assigned by the local farmers. The scores of the factors were standardized using the direct value rating to allow for comparison on the scale. The direct value rating is described in five steps by Beinat (1997). The 
attributes are first described and then the value range is selected; in this case corresponding to $\mathrm{O}$ (worst) and 1 (best) respectively. The qualitative characteristics of the value function were then defined (monotonicity, concavity/convexity, etc.). The third step was to specify the values for the selected attribute scores. In this approach, this is done via the bisection technique i.e. assigning values to selected scores at equal intervals between the maximum and minimum scores. The fourth step was to fit a mathematical equation and/or a curve through the identified points. In the last step, the function was checked for consistency. The standardised scores $(S)$ were then input into the Land Value Indices Table (Table 6), where each row represented a land parcel $(p)$, and each column represented an LVF (F).

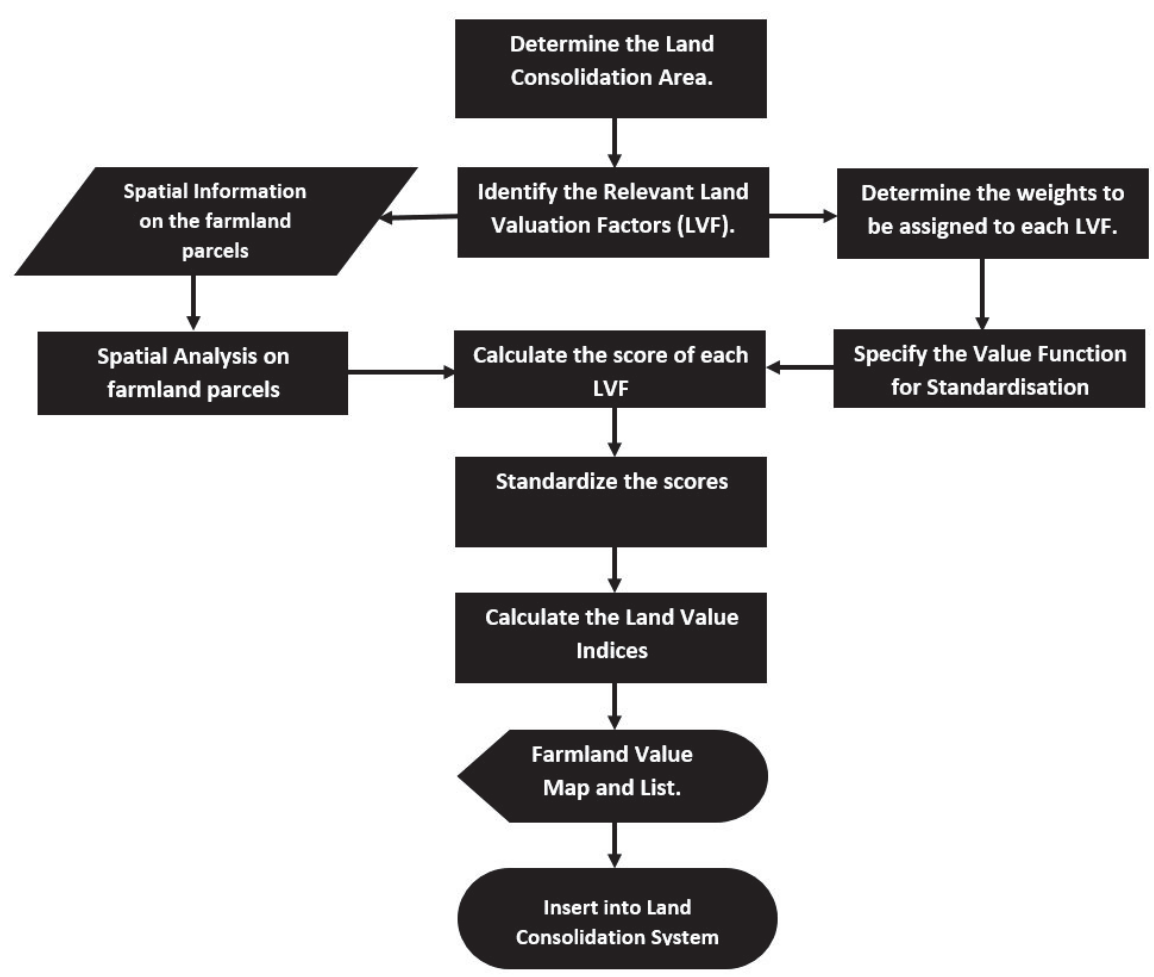

Figure 18: Flowchart of the Farmland Parcel Valuation Process

The elements of the Table represent the Land Value Score $(S)$ of a farmland parcel $(p)$ and the factor $(f)$. 
Table 6: Land Value Indices Table for Farmland Parcels

\begin{tabular}{|c|c|c|c|c|c|c|c|}
\hline & \multicolumn{6}{|c|}{ Land Valuation Factors (Weight) } & \multirow{2}{*}{$\begin{array}{l}\text { Land } \\
\text { Value } \\
\text { Index }\end{array}$} \\
\hline $\begin{array}{l}\text { Farmland } \\
\text { Parcel }\end{array}$ & $F_{1}\left(w_{1}\right)$ & $F_{2}\left(w_{2}\right)$ & $F_{3}\left(w_{3}\right)$ & $F_{f}\left(W_{f}\right)$ & $\ldots$ & $\begin{array}{l}F_{m} \\
\left(W_{m}\right)\end{array}$ & \\
\hline 1 & $S_{11}$ & $S_{12}$ & $S_{13}$ & $S_{1 f}$ & $\ldots$ & $S_{1 m}$ & $L V I_{1}$ \\
\hline 2 & $S_{21}$ & $S_{22}$ & $S_{23}$ & $S_{2 f}$ & $\ldots$ & $S_{2 m}$ & $L V I_{2}$ \\
\hline 3 & $S_{31}$ & $S_{32}$ & $S_{33}$ & $S_{3 f}$ & $\ldots$ & $S_{3 m}$ & $L V I_{3}$ \\
\hline$p$ & $S_{p 1}$ & $S_{p 2}$ & $S_{p 3}$ & $S_{p f}$ & $\ldots$ & $S_{p m}$ & $L V I_{p}$ \\
\hline$\ldots$ & $\ldots$ & $\ldots$ & $\ldots$ & $\ldots$ & $\ldots$ & $\ldots$ & $\ldots$ \\
\hline $\mathrm{n}$ & $S_{n 1}$ & $S_{n 2}$ & $S_{n 3}$ & $S_{n f}$ & $\ldots$ & $S_{n m}$ & $L V I_{n}$ \\
\hline
\end{tabular}

The Land Value Index (LVI) for each parcel is calculated by multiplying the score of each factor $\left(S_{p f}\right)$ by the corresponding weight of the factor $\left(w_{f}\right)$, and summing for each farmland parcel (each row on the table), as depicted in the equation function below;

$$
L V I_{p}=\sum_{p=1}^{n} s_{f p} W_{f}
$$

\subsection{The Case Study}

This section presents a case study in which the framework developed in the previous section is applied and discussed. The section starts with an overview of the case study area and gives details of the area relevant to the study. 


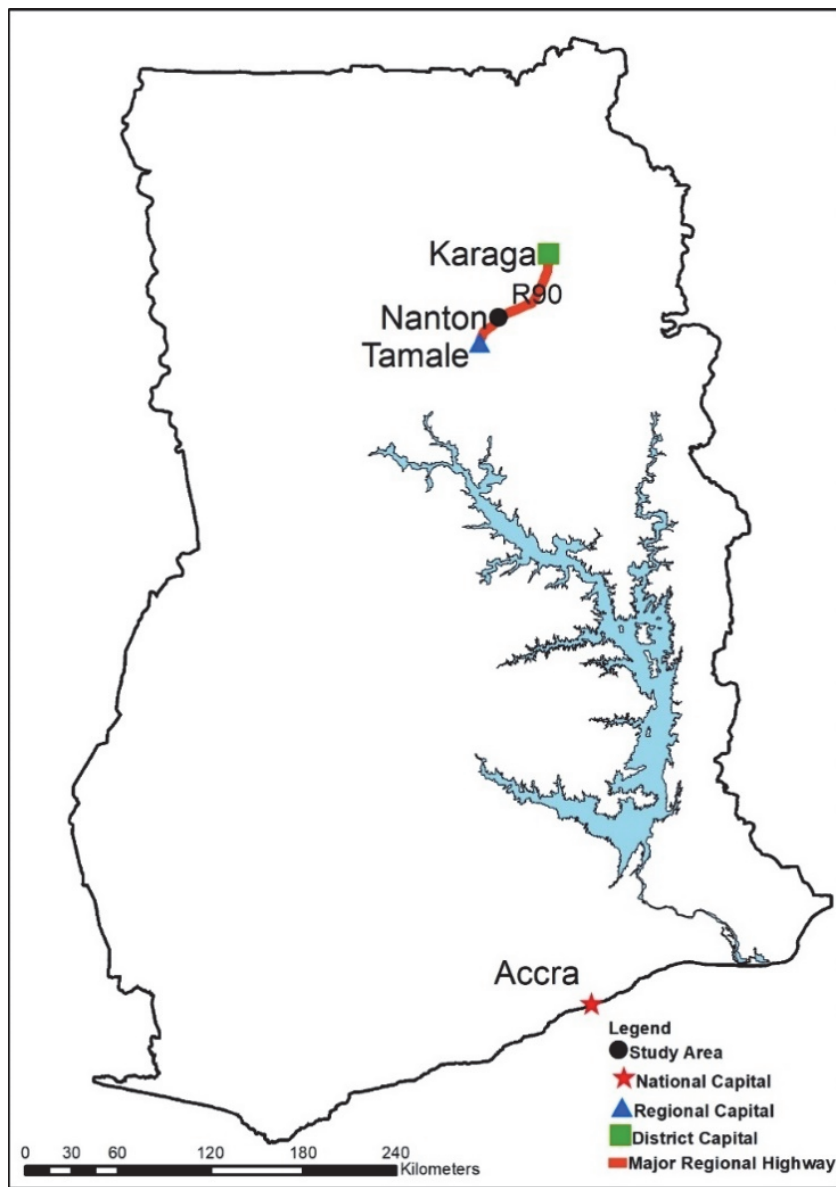

Figure 19: Map of Ghana showing the Study Area and other areas relevant to the study

The development of the land valuation factors follows, and the framework is applied to ascertain the land value factors relevant to the area under study. The Land Value Indices of the land parcels under study are also derived here. Three analyses are conducted and discussed. The first is a scenario analysis, the second is a sensitivity analysis, and the third focuses on the influence of Automatic Valuation Models (AVMS). Sensitivity analysis is used to understand the impact of a range of variables on the outcome by isolating the variables and recording the range of outcomes (Rajaonson \& Tanguay, 2017; ZahediSeresht et al., 2017). With scenario analysis, a situation is determined, and all the variables are altered to align with that situation.

\subsubsection{The Area of Interest}

The study takes place in a farming village called Nanton in northern Ghana where there is a need for land consolidation (K. O. Asiama et al., 2017). Nanton 
is located 18 kilometres from Tamale, the regional capital, and $646 \mathrm{~km}$ from Accra, the national capital (Figure 19).

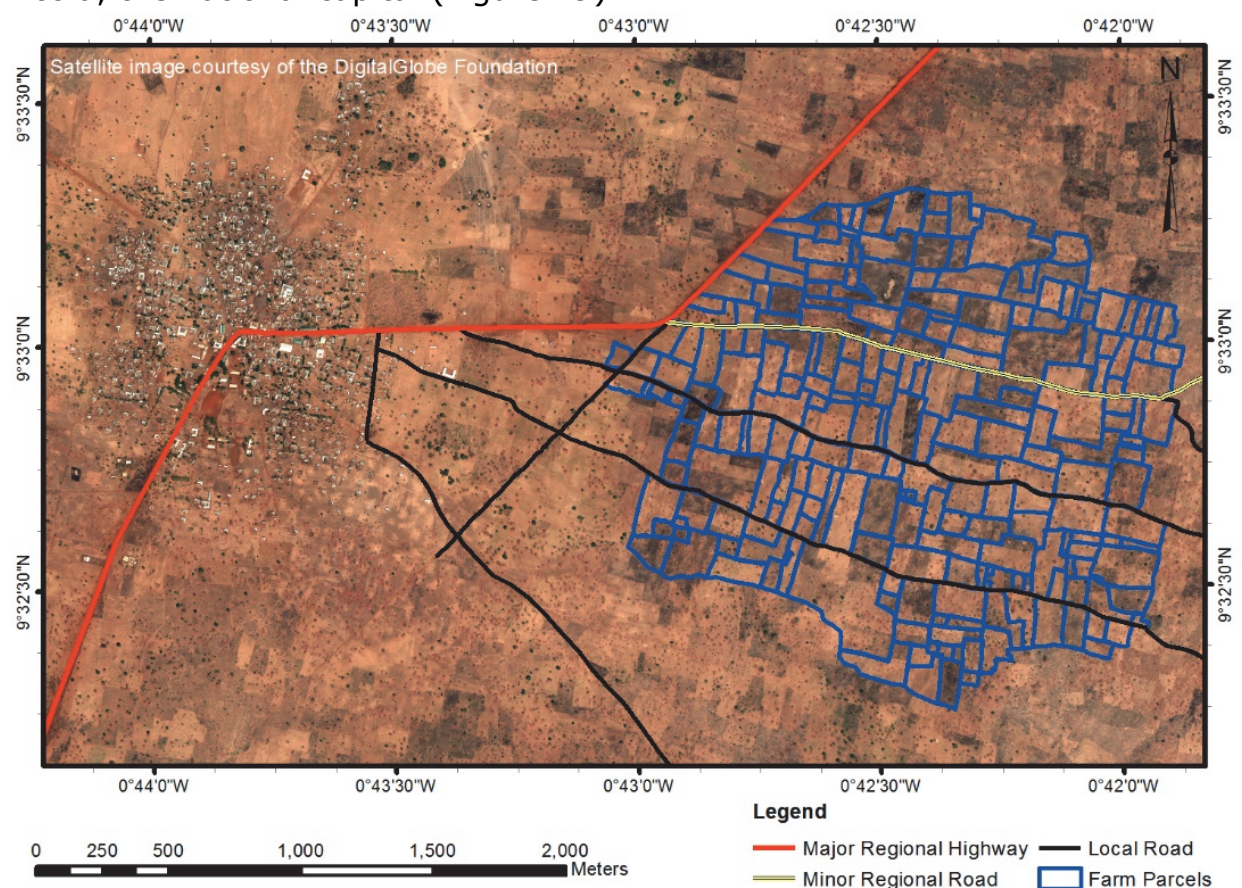

Figure 20: The Area of Interest (with farm boundaries denoted by blue lines) and the Nanton Village

The village lies in the Guinea Savannah grassland vegetation zone, characterised by vast grassland, dotted with shrubs (Figure 20). The area of interest for this study lies on the east of Nanton village. It has an average height of about $170 \mathrm{~m}$ above sea level and falls along the Regional Highway 90, which connects Tamale and Karaga, a district capital. It is about 300 hectares in size and the main land use is crop farming, with a few farmers undertaking cattle rearing. For the purposes of this case study, the area of interest is the land consolidation area.

The area of interest comprises 230 farmland parcels, with an average size of 1.29 hectares (Figure 20). The base map used is a land rights map collected using the Participatory Land Administration approach developed in $\mathrm{K}$. O. Asiama et al. (2017), which seeks to harness the push of emerging technologies to meet the current societal needs, balancing the traditional government-led top-down land administration with the emerging crowdsourced bottom-up land administration. Other information was collected from the Survey Division of the Lands Commission and the Savannah Agricultural Research Institute in Tamale. 


\subsubsection{The Land Valuation Factors}

To derive the factors that influence rural customary land values, the land value factors used in previous studies such as Branković et al (2015), Clark (1973), Demetriou (2016), and Wyatt (1996), are examined. In all, 13 factors are found to be relevant to the valuation of rural customary lands for land consolidation from the existing literature and the interviews (Figure 21). The land value factors have been generally classified by Wyatt (1996) into two groups - the internal and the external group of factors. The internal group of factors are those integral to the land parcels such as the physical characteristics of the property, the legal conditions, and the farm productivity. The second group relates to factors that are external to the property such as the locational attributes, planning scheme, and provision of services. These factors are assessed using specific factors (under them) to measure their impacts. The physical characteristics include the size, shape, elevation, slope, and the soil type of the farm parcels. The legal conditions deal with the land tenure arrangements, whilst the agricultural productivity is determined by the soil quality and the soil type. Under the external group of factors, locational attributes are determined by the access to roads, proximity to perennial water sources, and proximity to the town square.

The internal factors are viewed as the more important factors as they directly affect the outputs from the farms (Awuah et al., 2016; Branković et al., 2015; Nzioki et al., 2013). The size of the farm parcel determines how much can be grown on it. As a result, all other things being equal, the larger the farm parcel, the higher the output and the value. The shape of the farm parcel is also relevant, especially in terms of scaling up the farm operations through mechanisation of cultivation and harvesting activities to make optimal use of the farm parcel (Bullard, 2007; Migot-Adholla et al., 1991; Van Dijk, 2003). This is especially relevant for areas like Nanton where the mechanised farming equipment are hired, and the owners give them out to farmers who own larger and more regularly shaped farms first (Focus Group Discussion with local Farmers' Union). 


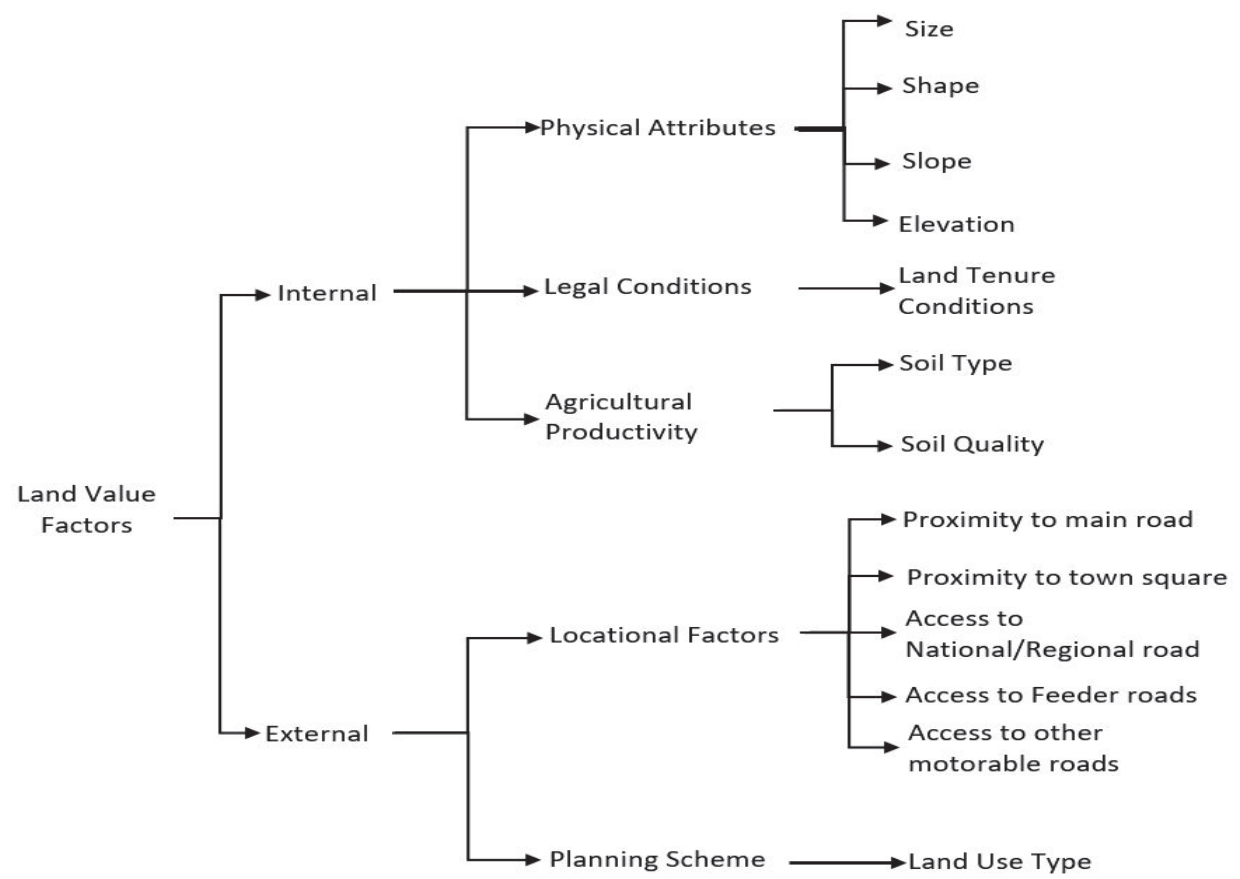

Figure 21: Summary of Land Value Factors (Adapted from (Wyatt, 1996)

In the assessment of the optimum parcel shapes for agricultural production, several indices exist, such as the Shape Index and the Fractal Dimension used by Aslan et al (2007) and Gonzalez et al. (2004). These indices are however not sensitive to their regularity, resulting in regular and irregular parcels having similar indices, since the area and perimeter are the factors considered. This paper therefore uses the Parcel Shape Index (PSI) developed by Demetriou et al. (2013), which integrates the perimeter, the acute angles, the reflex angles, boundary points, compactness, and regularity as the geometric parameters and is independent of the size of the farmland parcel. The result of this index is a value between 0 and 1 for each parcel, with 0 representing the worst shaped parcels, and 1 representing the best shaped parcels; in this case a rectangular shaped parcel with the ratio of the sides being $2: 1$. The slope of the farm parcels also affect the mechanisation costs in terms of the machine power and fuel needed for the farm operations (FAO, 2008). Furthermore, being a guinea savannah grassland, with a risk of erosion, the slope also determines how much will be spent on erosion control. The elevation of the farm parcels in general affects the types of crops grown, as well as the time of planting and harvesting (Netting, 1972).

The local farmers expressed an indifference over the effect of the elevation on their farming activities (Interview with local farmers). The type of soil also influences the farmland value as it also determines the type of crops that can 
be grown, as well as how much money will be spent on growing the crops. The soil in the study area is classified as Ferric Luvisols by Savannah Agricultural Research Institute of Ghana.

The land tenure arrangements in the study area comprise the allodial title, which is considered to be the most secure interest by the local people, the customary law freehold (or usufructuary interest), the tenancy, and the farming license, considered the least secure (Interview with local farmers and local elders). The customary law freehold is however the highest interest and most secure interest an individual may hold, which burdens but does not extinguish the allodial title held by the larger community. The holder has the right to the use and enjoyment of the land during his lifetime and may pass it to his heirs through the normal rules of succession. The tenancy is held off the customary law freeholder and is irrevocable and inheritable, unless terms stating otherwise have been expressly agreed upon (Arko-Adjei, 2011). There are also farming licenses given by the customary freeholder to another farmer to farm on his land for a farming season for a fee. The licenced farmland was deemed to be the least desirable interest in land in the area by the local farmers (Focus Group Discussion with local farmers' union).

The scores for the land tenure are calculated as the customary freehold being 1 , the tenancy as 0.5 and the farming licence being 0 as the least desired. With respect to the soil quality and productivity, the local farmers keep very little information on their outputs. However, they determine the productivity of a farm by the crops being sown (FGD with local farmers' union). Where the productivity is low, farmers try to improve the fertility by planting leguminous crops such as groundnuts and beans. The farmers with inadequate resources leave their least productive or desirable farm parcels bare and cultivate their other farm parcels (Interview and FGD with the farmers). The scores for the farm productivity are therefore assigned according to the crops grown on the farms as this is how the farmers themselves determined the productivity. Farms with non-leguminous crops were assigned 1 as they were seen to be the most fertile. Farms with leguminous crops were assigned 0.5 , and bare farmlands were assigned 0 . Though the weights attached to the individual land value factors were determined by the local people's, the scores for five of the LVFs, shape, slope, elevation, soil type, and soil quality were determined through technical processes and expert judgement, not by the local farmers. The factors external to the land parcels are essential to determine how they interact with other parcels as well as the availability of services in their locality. 


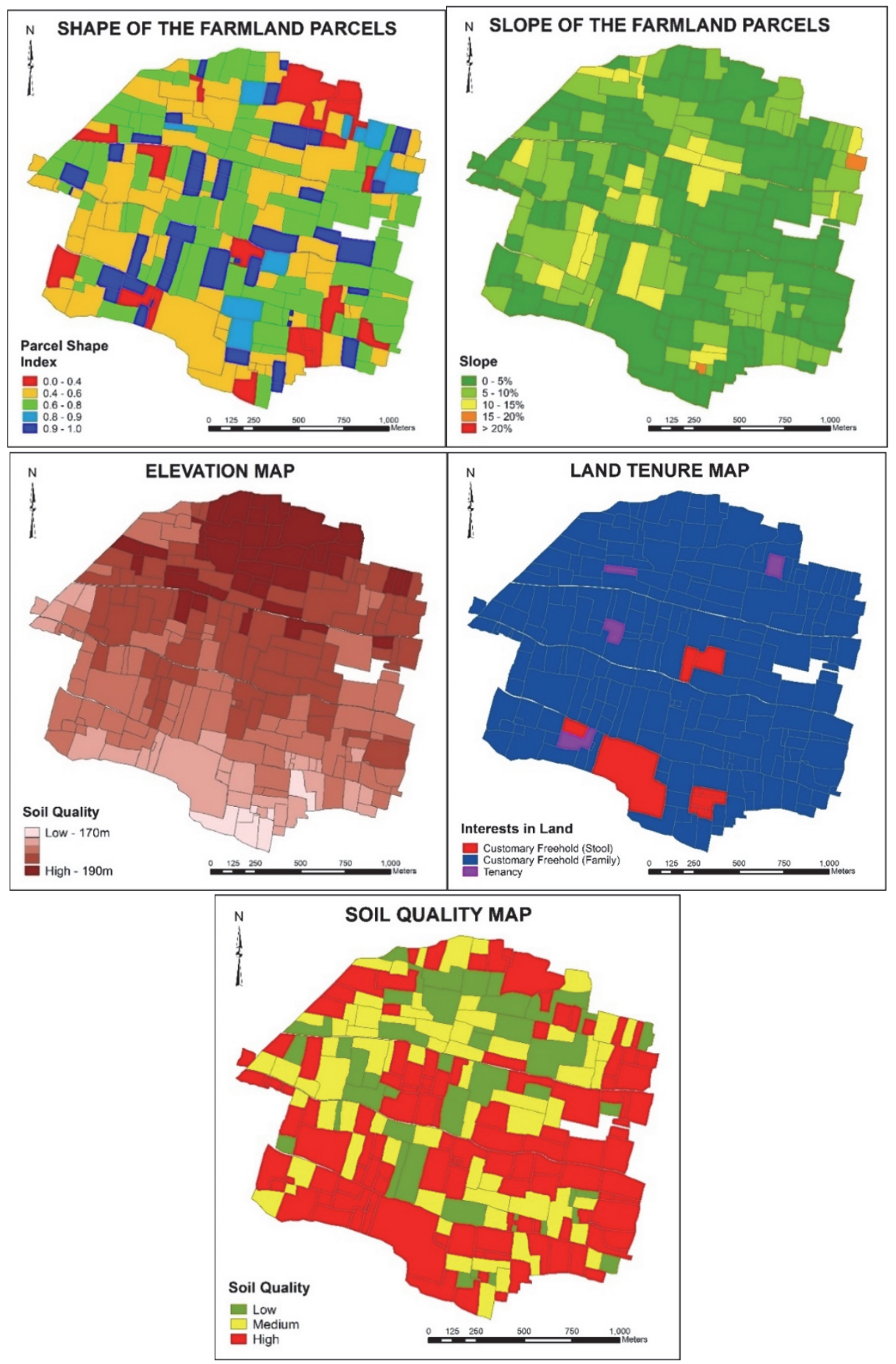

Figure 22: The Physical Attributes and Legal Conditions in the Area of Interest 
The locational characteristics of the property are considered to be the most important group of factors here, however, other factors such as the land use planning scheme in the area also influence the land value. With respect to locational attributes, access to roads was identified as the most crucial factor influencing land value because the transportation of the harvested crops is a general problem in the area. The closer a farmer is to the road, the easier it is for his food crops to be transported to the market square using a vehicle.
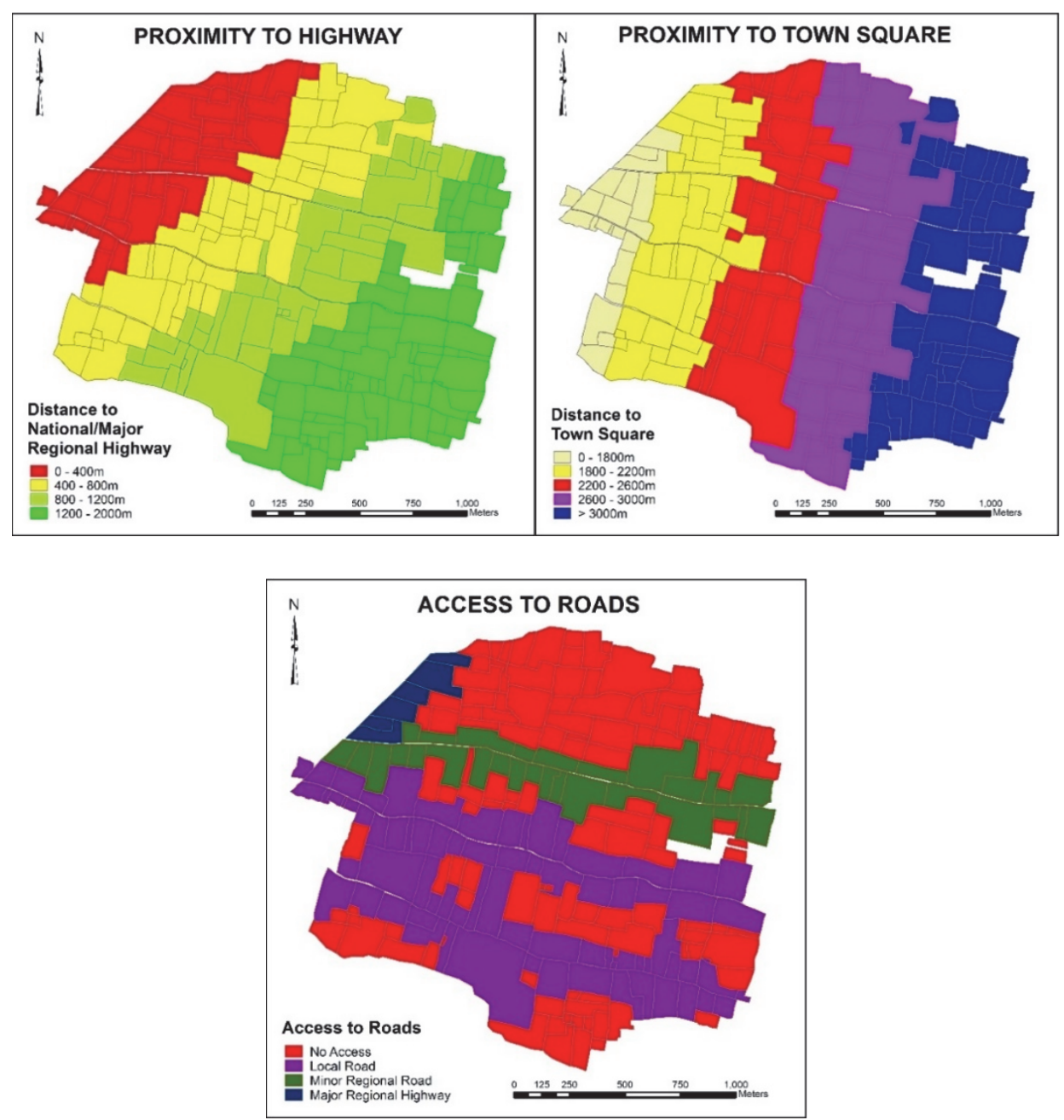

Figure 23: Locational Factors in the Area of Interest

Short of this, food crops must be carried on a head pan to the road, or even to the market square. Three types of roads are found in the study area. The first is a major regional highway, the R90, which connects district capitals to regional capitals and the national highway. The R90 which borders the study area, connects Tamale, the regional capital to Karaga, a district capital. The 
second type of road is the minor regional highways that serve as feeder roads, connecting small towns and villages to the national and major regional highway system. The third type of roads are the locally developed roads that ease the transportation problems in the locality. These roads are not usually tarred.

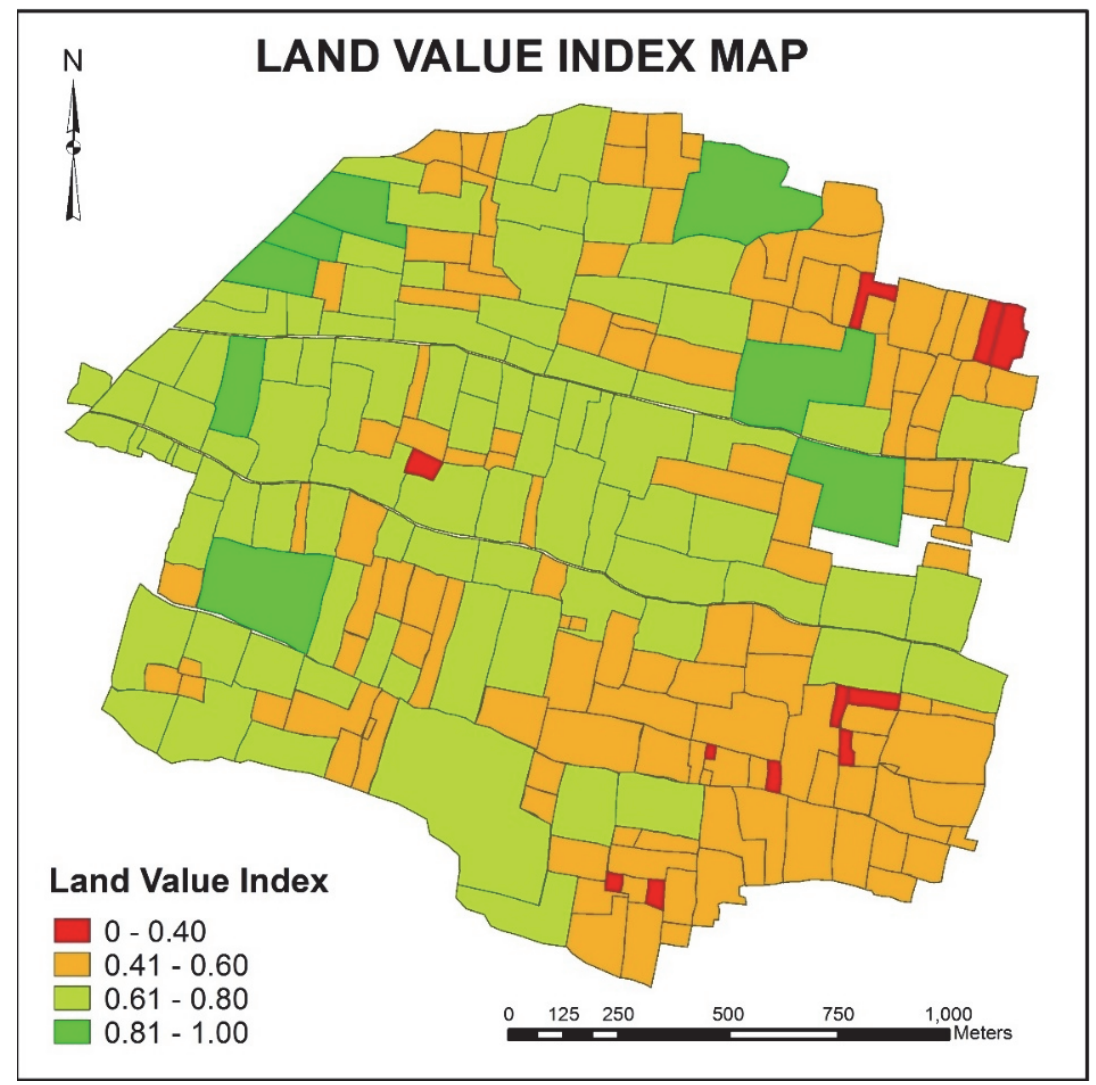

Figure 24: Land Value Indices of the Farmland Parcels

Aside from the three types of roads, there are also footpaths that allow for access to the farms by foot, bicycle, or motorcycle. However, these footpaths, according to the local farmers, bare little relevance to their view of the farmland values, so they are not used in the analysis for value. The proximity of the farmland to the national and major regional highway is a factor suggested by the local farmers as important and independent to road access. The proximity to the highway was deemed important because it provided a market for the farmers who could stand along these roads and sell their produce to passers-by, without having to transport them to the market. The proximity of the farmland parcel to the town centre is also important as this is where the market square is located, therefore the farms located closer to it are considered to have a higher value. With respect to the planning scheme of the area, this determines the likelihood of the farm remaining in the current land 
use in the future, and thus affecting the value of the land parcel as a farm. However, the whole area is designated to be a farming area, and therefore the land use of the area is the same. The weights attached to these land value factors are displayed in Table 7. The Land Value Indices of the area of interest according to the LVFs are displayed in Figure 24.

\subsubsection{Scenario Analysis: The Impact of the Weights on the Land Value Index}

The strength of the new approach is considered to be the direct involvement of the local people, in not just the selection of the land value factors, but also the weighting of the factors. This approach is needed because the area of interest is without a land market to provide for a basis of comparison to reach a market value. Therefore, the perception of the local farmers and other relevant stakeholders is mostly embodied in the weights attached to the land valuation scores. Therefore, to ascertain how significant the weights are in determining the LVI, three scenarios are simulated with respect to the weights, and are compared to scenario 0 , the LVIs determined by the weights assigned by the local community and experts. In the first scenario, all the LVIs are assigned equal weights. In the second scenario, the weights are assigned in line with the Dutch and German Agronomic approach, which gives priority to the internal land value factors which are assigned higher weights and prioritizes the internal factors. In the third scenario, the weights are assigned in an inverse order to those assigned by the local community, with respect to the LVFs.

Table 7: Weights assigned to the LVFs according to the scenarios

\begin{tabular}{|l|r|r|r|r|}
\hline Land Value Factor & $\begin{array}{c}\text { Scenario } \\
0\end{array}$ & \multicolumn{1}{|c|}{$\begin{array}{c}\text { Scenario } \\
2\end{array}$} & 10 & Scenario 3 \\
\hline Shape & 6 & 10 & 10 & 5 \\
\hline Slope & 3 & 10 & 10 & 7 \\
\hline Elevation & 2 & 10 & 10 & 2 \\
\hline Land Tenure & 10 & 10 & 10 & 3 \\
\hline Soil Quality & 7 & 10 & 10 & 8 \\
\hline Soil Type & 2 & 10 & 1 & 6 \\
\hline Proximity to Main Road & 5 & 10 & 1 & 2 \\
\hline Proximity to Town Square & 8 & 10 & 1 & 2 \\
\hline Road Access & 8 & 10 & 1 & 8 \\
\hline Land Use & 2 & 10 & 10 & 10 \\
\hline
\end{tabular}

(Scenario 0 - Weights determined by local community; Scenario 1 - Equal weights; Scenario 2 - Internal factors weighed higher than external factors; Scenario 3 - Weights assigned in an inverse order to those assigned by the local community.

The resulting average LVIs for the four scenarios are $0.68,0.70,0.74$, and 0.75 respectively. Though these results show that the different combinations 
of the weight do not yield any significant difference in the average LVIs, however, a closer look at the individual LVIs (Figure 25) show otherwise. With an difference between the LVIs of scenario 0 and scenarios 1,2 , and 3 respectively being $0.02,0.06$, and 0.07 . at least an LVI of 0.05 is needed for the parcel to be classified at a higher land value grade with different comparable parcels. Therefore, the differences realized from scenarios 2 and 3 are enough for a change in the land value grade. Furthermore, the individual LVIs show that at least 160 LVIs of scenarios 2 and 3 have a difference of more than 0.05 from scenario 0 . Therefore, the weights have a significant effect on the LVIs in the area of interest.

A further strength of the approach stemming from the assignment of weight in the process is the transparency and participation it affords the local people. Other approaches that use AVMs as suggested by Branković et al., (2015) and Demetriou (2016) that rather use multiple regression and geographically weighted regression, present approaches that do not involve the local people. They also present cases that cannot be analytically explained to local farmers. However, this approach has been developed based on the local farmers' understanding of their land value, and hence their involvement from the first to the last step. The success of land consolidation relies on the trust the local farmers and people have in the process. Therefore, first if their understanding about the process is low, it is likely that they will not be satisfied with the end result and will object or reject the project. Secondly, the involvement of the farmers will produce a result that aligns best with the views of the local farmers on the value of their farmlands.

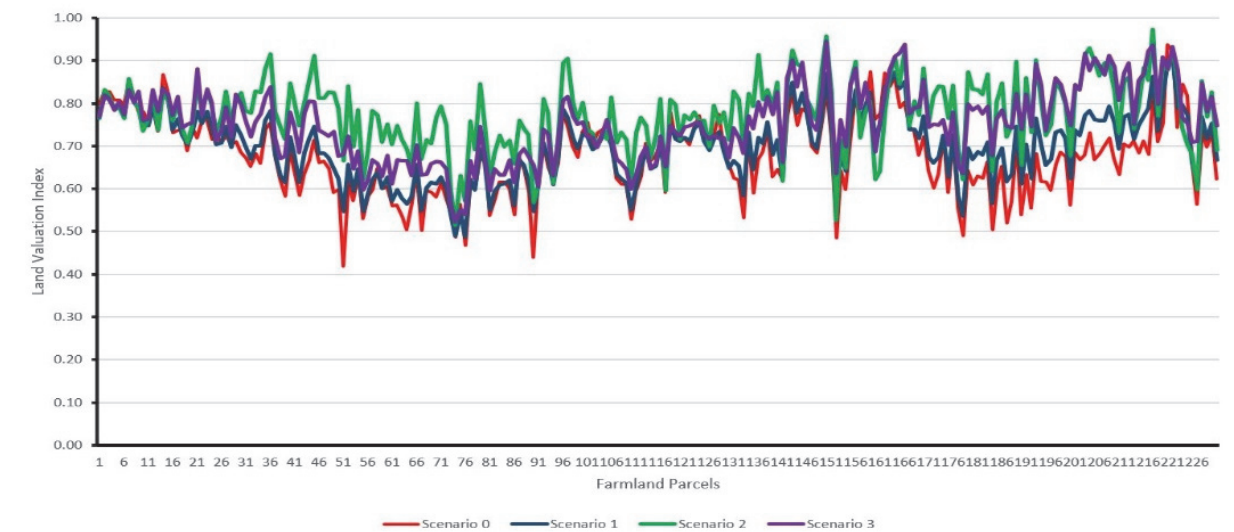

Figure 25: The comparison of the four scenarios 


\subsubsection{Sensitivity Analysis: The Effect of Individual Weight Changes in the Land Value Indices}

The sensitivity of the LVI shows that in general the LVI is not significantly sensitive to changes in the weight of the individual factors. This is shown in Figure 26 , where a $100 \%$ increase or decrease in the weight of land tenure resulted in an average of $8.82 \%$ change in the LVIs. The sensitivity of the LVI is the maximum percentage difference in the absolute values of the overall LVI for the minimum to maximum change $(0-100 \%)$ for either an increase or a decrease in the weight of the factor. The result indicates a stability in the indices, and reliable decisions can therefore be taken based on them. Figure 26 shows land tenure and road access as the two most sensitive factors to the decrease and increase in weights respectively, with soil quality being only sensitive to the decrease in weight. Elevation is neither sensitive to increases nor decreases.

The shape, slope, soil type, proximity to main road and town square, and the land use are all slightly sensitive. Therefore, land tenure and road access are the most critical LVFs, with both having positive and negative impacts on the LVI. This means that the more important these factors are, the higher the LVI, and vice versa. The LVI is not sensitive to a change in the weight of the elevation. This shows the elevation's independence of the weights. This finding shows that some factors such as the shape, slope, and soil type of the parcels have a high influence on the LVIs (though they may have low sensitivity), whereas land tenure, road access, soil quality, and elevation have less impact.

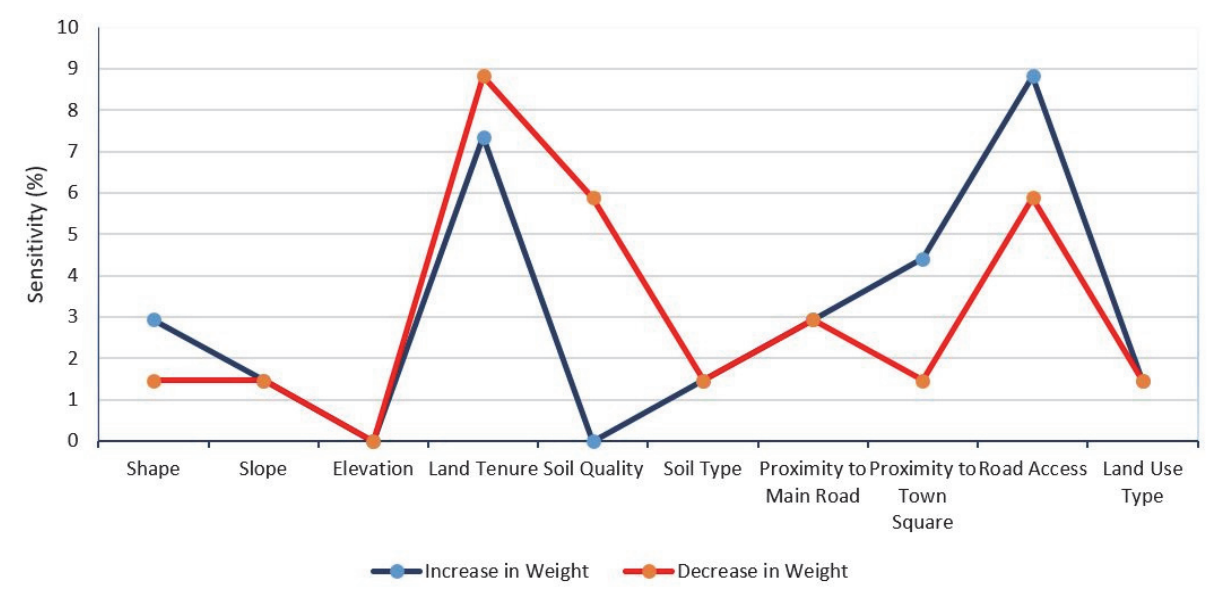

Figure 26: The sensitivity of the overall LVI for either an increase or decrease in the weight of each LVF 


\subsubsection{The influence of Automatic Valuation Models (AVMs)}

The main weakness of the framework in this paper is the drive towards AVMs, especially with regards to land consolidation (Demetriou, 2016b). These approaches harness multiple regression analysis and geographically weighted regression in a GIS environment. AVMs represent a wider trend in decisionmaking platforms especially with GIS to support faster and more cost-effective decision-making processes. AVMs can estimate the market value of a parcel based on an analysis of the market and the characteristics of the particular group of properties at a specified point in time. Comparing AVMs to the approach suggested in this paper shows that AVMs are more objective, as they predict the land value from the available data of sales, without a direct interaction with the people it seeks to serve, as demonstrated by Branković et al. (2015) and Demetriou (2016). The AVM is cheaper than the approach suggested in this paper which points to the use of empirical data for each land parcel to determine the value. The suggested approach took five working days in an area with a size of 300 hectares, containing 230 farmland parcels. This is opposed to Branković et al. (2015) and Demetriou (2016a) who used less than a day for areas of size 6,065 and 266 hectares respectively. However, the use of the suggested approach will enable data to be created to form a basis for future modelling of the land values on customary lands in the area.

\subsection{Conclusion}

This paper set out with the aim to contribute to the approaches for valuing rural customary farmlands without a land market to support land consolidation by developing a framework for a new approach. The five research questions laid out in the introduction were each tackled in the preceding sections. This section provides a summary of the findings and concludes the paper with recommendations.

It was first found that the current methods for valuing customary lands in Ghana only cover urban lands and rural residential lands which are held in leasehold and are registered. Although land mobility is low in rural customary lands, the customs do not necessarily ban the sale and exchange of lands but rather restrict the operation of a land market. It discourages market transactions as lands are held in trust for the next generation, thus reinforcing the need for a valuation approach that will provide a sound basis for comparing the farmlands for exchange. Furthermore, there exists the arrangement where farmers rent out their lands for a nominal flat rate, lending credence to the non-economic view of land in these areas. The standard approaches to valuing land for land consolidation in general were found to be either the market value approach, or the agronomic approach. Thirteen valuation factors were found to be relevant to the valuation of rural customary lands for land consolidation. 
These factors generally fell under two groups, the internal factors that were integral to the farmland parcel and the factors that relate to the outside - the external factors. Under the internal factors, there were the factors related to the physical attributes of the property, the legal conditions inherent, and the agricultural productivity. The external group of factors included the locational factors, and the planning scheme in the area. Among the identified factors, the local farmers assigned weights according to their importance. The most important factor in the area was found to be the land tenure arrangement. This was followed by the proximity to the town square and the road access. The relevance of the weights assigned to the land value factors were tested with three scenarios where the results of the three different weights were compared to the weights assigned by the local farmers. Here, it was found that the different sets of weights resulted in significant differences in the resulting LVIs which could affect the comparative basis for the farmland parcels. The strength of this approach was found in the transparent and participatory nature, which has been found to give local people a sense of confidence in projects and increases their trust (K. O. Asiama et al., 2017c). Furthermore, the local people's view on land value that is incorporated reinforces the ability of the approach to determine the land value the people will agree with. This is needed especially in the land reallocation stage of land consolidation. However, this strength also contributes to its weakness, the direct interaction with the local farmers which is more expensive and time-consuming compared to other studies that advocate the use of automatic valuation models. As the local farmers have little economic regard for the land, it is very important that their perception be ascertained. This notwithstanding, once the suggested approach is used over time, the data can be standardized for comparable areas to enable the modelling of the land values.

Based on the above findings, it is found that there is the need for a further verification for the land value indices that resulted from the case study framework with the local farmers to confirm the LVIs with respect to the farmers' perception of their land values in relation to neighbouring and similar farmland parcels. Further research also needs to be conducted on how this process can fit into land consolidation projects' land reallocation phase, and into the land valuation practices on customary lands in general. 


\section{Chapter 5 Customary Land Reallocation*}

* This chapter is based on a paper published with an ISI Journal;

Asiama, K. O., Bennett, R. M., Zevenbergen, J. A., \& Da Silva Mano, A. (2019). Responsible consolidation of customary lands: A framework for land reallocation. Land Use Policy, 83, 412-423. https://doi.org/10.1016/j.landusepol.2019.02.006 


\subsection{Introduction}

Ghana's rural customary land are characterised by population growth and changing agricultural systems. The nature of the customary land tenure system has resulted in agricultural lands being transformed into small and irregularly shaped farmland parcels that are not optimum for agricultural productivity, and arguably sustainable livelihoods (Diao et al., 2014; Houssou \& Chapoto, 2014; Pingali et al., 1987). Though Ghana's agricultural sector remains one of the fundamental drivers of the Ghanaian economy, studies agree that land fragmentation on Ghana's rural customary lands undermine food productivity: $90 \%$ of the farmland parcels are held by smallholder farmers with less that $2 \mathrm{ha}$ of land (K. O. Asiama et al., 2017c; Blarel et al., 1992; Migot-Adholla et al., 1994; MoFA-SRID, 2016). The small separate and irregularly shaped farmland parcels, especially in the rural areas, result in the inability of rural farmers to harness mechanized farming procedures and take advantage of economies of scale, to increase farm productivity. Land fragmentation is the dispersion of a single farmland holding into several farmland parcels as well as a discrepancy between land use and ownership (Binns, 1950; King \& Burton, 1982; Van Dijk, 2003a). Land fragmentation causes serious damage to land and is a global problem with far-reaching economic and environmental impacts as it is difficult to implement new production approaches, utilize the appropriate machinery and equipment, and protect the environment (Baudron et al., 2015; Diao et al., 2014; Sims \& Kienzle, 2016). This paper presents an approach to undertaking land reallocation that is more readily able to support responsible land consolidation, fit for Ghana's rural customary lands.

The primary interventions to increase food productivity in Ghana have been largely focused on intensive cropping of farms, use of fertilizers, and mechanized farming (K. O. Asiama et al., 2017; Houmy et al., 2013; NDPC, 2014). However, the small and separated farmland parcels that resulted from the shifting cultivation farming system, practiced in the past, militated against these approaches, creating an inverse relationship between the farm size and productivity (Abunyewa et al., 2007; Ansoms et al., 2008; Diao et al., 2014; Holden \& Otsuka, 2014; Pingali, 2007; Sims \& Kienzle, 2016). An approach used in many Western European countries for at least a century and more recently in many Central and Eastern European and South East Asian countries, to counter land fragmentation has been land consolidation (K. O. Asiama et al.., 2017a; Bullard, 2007; Demetriou et al., 2012; Grossman \& Brussard, 1988; Hartvigsen, 2013). Land consolidation in this paper is defined as a land management activity that involves all the procedures for exchanging, rearranging, and expanding farmland parcels, with the goal of increasing farm productivity (K. O. Asiama et al., 2017a). 
Land reallocation is seen as the most important stage of land consolidation where property rights are exchanged, and farmland parcels are redistributed and reorganized. Land reallocation is therefore a potential source of dissatisfaction among farmers and land owners. Several attempts have hence been made to make land reallocation processes more objective. The multidisciplinary approaches to land reallocation, in the past decade, have been mostly geared towards improving the technical aspect, at the expense of the socio-cultural aspects (Akkaya Aslan et al., 2018; Demetriou, 2014; Haklı et al., 2016; Zhang et al., 2018). Cay and Uyan (2013) use the Analytic Hierarchy Process (A.H.P.) to determine the preferences of the landowners in the land consolidation process. This approach requires farmers to define their preference and criteria through which the land reallocation will be developed. The preferences are indicated first through the following criteria - the largest parcel, fixed installations, parcel density, and high degree. These criteria are then scored as equally important (1), moderately important (3), important (5), and very important (7). The main drawback in this approach is its complexity which requires the rapt attentiveness needed for the farmers to score their parcels in four criteria, with seven categories. Akkaya Aslan et al. (2018) tries to improve and simplify this approach also based on land owners' preferences, spatial spread of the farms, blocks, and priority parcels. The model is divided into two parts - the request entry and the re-allocation modules. The former deals with taking requests from the land owners about their preferences and priorities, and the latter is where the re-allocation is operationalized. The land owner or farmer here only indicates the block within which they want their parcels. Uyan et al. (2013) also compare a Spatial Decision Support System (SDSS) and Genetic Algorithm (GA) with the Turkish cadastral land reallocation approach and find the GA to be more successful in terms of average parcel size, number of parcels, and number of parcels per land holding. Further studies along this line have seen Ertunç et al., (2018) using a hybrid approach with the GA and fuzzy logic techniques to form a crossover and process of the former with the later in a self-adaptive manner. Like the other approaches, this approach also seeks to improve the physical structure of the farms.

Previous studies that focused on the technical aspect have also attempted to involve variables that consider the social, cultural, and governance aspects of the project's local community through interviews with the farmers and land owners (Cay \& Uyan, 2013). Haldrup (2015) also focuses on Central and Eastern European countries, examining the socio-governance make-up, especially relating to weak governance capacities, in state and civil society, as well as lack of trust among stakeholders using the Danish Agreement based land consolidation approach. On the purely governance side, Zhang et al. (2018) examines the incentives of farmers to participate in land consolidation, and the interaction between them in land reallocation from a collective action perspective in China. Comprehensive and integrated decision support systems 
that guide the planning of land consolidation in all technical steps whilst considering the legal economic, social, and environmental factors has also been developed such as the Dutch TRANSFER and LACONISS (LAnd CONsolidation Integrated Support System) (Demetriou, 2014; Lemmen et al., 2012). However, with regards to Sub-Saharan Africa's (SSA) customary lands, little has been explored with land reallocation. Previous attempts at land consolidation on SSA's customary lands resulted in the breakdown of the customary land tenure system, as happened in Kenya, or a later breakdown of the new parcel arrangement with farmers returning to their old farms, as happened in Malawi (Coldham, 1978; Nothale, 1986). The main reason attributed to the inability of land consolidation projects to thrive in SSA is the inadequate consideration for the local customary land management system ( $\mathrm{K}$. O. Asiama et al., 2017a). This is a result of transferring western European approaches to land consolidation directly to SSA without acknowledging the differences between the two regions (Van Dijk, 2002; Zhang et al., 2018). To solve this problem, K. O. Asiama et al. (2017c) recommends the development of responsible approaches to land consolidation for sub-Saharan Africa. Responsible land consolidation uses practices that continuously align the technical and administrative requirements, and the internal processes of land consolidation to the dynamic local societal demands, economic conditions, political forces, and cultural and legal requirements (K. O. Asiama et al., 2017c). K. O. Asiama et al. (2017a), in a comparative study between three countries with a functioning land consolidation approach (the Netherlands, Lithuania, and Rwanda) on one hand; and a country predominantly with customary lands but without a land consolidation approach (Ghana) on the other hand, finds three factors that militate against the success of land consolidation on customary lands - the coverage of a supportive land administration system, the absence of a conventional land market, and the customary land tenure system. To fill the gap of a supportive land administration system, K. O. Asiama et al. (2017a, 2018) develop the customary cadastre based on the participatory land administration approach to collect land information relating to customary lands to support land consolidation as well as other land management activities. K. O. Asiama et al. (2018) further develops a land valuation approach to place quid pro quo land value indices on rural customary farmlands to facilitate the exchange of farmland parcels. Building upon these previous studies, this paper develops the framework for a land reallocation approach to support responsible land consolidation on customary lands. To achieve this goal, the research approach and methodology is first described. Subsequently, section 5.3 presents the model design and development, where the general requirements for land reallocation are identified together with the general characteristics of customary lands, to develop a framework for land reallocation model on customary lands. In section 5.4, the model is applied to a case in northern Ghana, with the findings presented and discussed in terms of land 
fragmentation and the farming system, mediating authority and the land tenure system, local customs, and land mobility.

\subsection{Research Approach and Methodology}

The framework for the customary land reallocation approach is developed using a process model that details the steps of the approach taking into consideration the social, economic, cultural, technical, and political considerations on customary lands. The development of a process model is organized into two dimensions - the model scope, and the model type dimensions (Wynn \& Clarkson, 2018). The model scope includes micro, meso, and macro levels, and the model types are the procedural, analytical, abstract, and management science/operations research (MS/OR) models. These dimensions, though different, are not mutually exclusive. The process model developed in this paper is a meso-micro-level procedural model. The meso-micro-level procedural model conveys best practices intended to guide real-world situations by providing prescriptive guidelines for a design and/or problemsolving activity with a focus on individual steps as well as end to end flows of the activity, where each step establishes objectives, and constraints for the next, with feedback loops between the steps for the possibility to re-work undesirable outcomes. The development of the procedural model comprises three steps;

- Analysis - Focuses on the problem and structuring it into a set of objectives.

- Synthesis - Involves solution generation for the problem.

- Evaluation - Critical appraisal of these solutions against the objectives to drive iterative improvements or to select the best solution.

The analysis of the problem has been given in the introduction section, resulting in a set of objectives. In the synthesis stage, the general requirements of land reallocation are identified based on current models for land reallocation in other regions. These are categorised under the key areas of consideration - political considerations, economic and social issues, and technical and legal aspects. The basic principles of customary land management practices are also identified through literature. Based on the identified requirements and principles, a generic framework for the customary land reallocation model is developed. This framework is then tested and assessed to identify ways to develop a definitive local land reallocation model, tailored more to the area of interest and how it can be improved. 


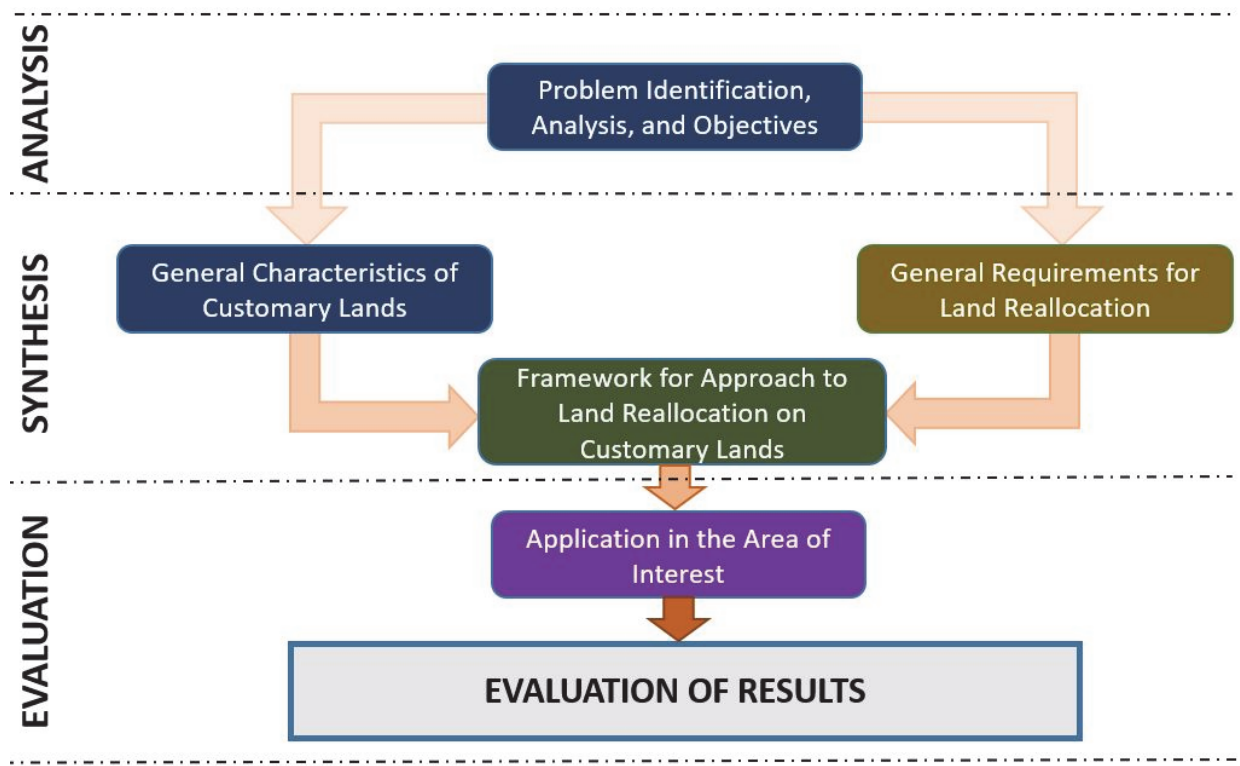

Figure 27: Overview of Research Approach

\subsection{Model Design and Development}

In this section, the model for customary land reallocation is developed. The framework for the customary land reallocation model has similar constructs to previous land reallocation models developed for other regions in the world. However, these were developed under different circumstances and conditions. Therefore, to understand the general requirements under which a land reallocation approach is developed, the current models are studied under the three key criteria for responsible approaches - political considerations, economic and social issues, and technical and legal aspects (K. O. Asiama et al., 2017; de Vries et al., 2015; Masser \& Williams, 1986; Van Dijk, 2002). The nature of customary lands and the land fragmentation on customary lands are then explored and identified to provide a background for the development of the approach. The process of the land reallocation is then developed in line with the general requirements and principles identified.

\subsubsection{General Requirements for Land Reallocation}

This section provides details of the general requirements that a responsible approach to land reallocation should meet. The requirements for land reallocation within these criteria are explored in the general context from literature on current land reallocation models and summarised at the end of the section in Figure 28. 
The political considerations for land reallocation centres around the ability of a mediating authority to act as an arbitrating force during the planning and implementation (Tang et al., 2015; Zhang et al., 2018). This is because land reallocation may provoke disputes and dissatisfactions due to the resulting rearrangements of property rights (Cay et al., 2010). The ability of the mediating authority to broker agreements and intervene in disputes without force rests on the trust and respect the parties have for the authority and each other (Rothstein, 2005). The central government and its agencies have been natural mediating forces in the past land reallocations, however, recent approaches to land consolidation, being more participatory and locally managed, have seen local leaders as the mediating authorities (Liu et al., 2016; Louwsma et al., 2014; Zhang et al., 2018). These local leaders have been found to drive up local participation and agreements more than the government is able to, as existing trust relationships can be leveraged (Haldrup, 2015; Liu et al., 2016). The existence of a trusted and respected mediating authority to oversee the land reallocation is therefore a basic requirement for land reallocation.

The economic and social issues in land reallocation revolve around land mobility, via land markets and the social/cultural views of land. Land mobility is described as the extent to which land rights can be exchanged, sold, or leased as it proves possible for land reallocation within a particular system of land holding (K. O. Asiama et al., 2018; Hartvigsen, 2014). Soerensen (1987) in developing the theory of land mobility in the Danish context, identifies three key factors that determine land mobility as the local agricultural structure, the available land pool, and the availability of knowledge and capacity (Hartvigsen, 2014). This form of land mobility focuses on rational economic decisions which are characteristic of areas with already existing land markets. However later studies find that land mobility goes beyond rational economic decisions, but border on the nature of social structure and relations in the locality as well as the emotional and psychic ties to the land (Akudugu et al., 2012; Van Dijk, 2007; Van Dijk \& Kopeva, 2006). This results in a social land mobility - the ease with which land can pass hands in the context of social and cultural norms and rules existing in the local community. Therefore, land reallocation requires not just economic views about land, but also a social ease for the re-allocation.

The technical and legal aspects of land reallocation cover the land tenure system, the land fragmentation situation and the land reallocation process. The land tenure arrangements in an area informs the extent to which land can be reallocated, especially in areas with several land tenure types and layers existing. This follows the legal principle of nemo dat quod non habet (one cannot give what one does not have). This was an often-overlooked aspect of land consolidation as most land fragmentation situations tended to be a physical problem, not a legal one, as the farmers holding ownership rights to 
their farmlands. This further explains the failure of land consolidation in countries like Malawi where even though land fragmentation was considered a physical problem, the legal aspect was not given much consideration. This resulted in the re-allocation of farmland parcels that mixed up the land tenure arrangements (Nothale, 1986; Takane, 2008). The farmers ended up returning to their old parcels after the first farming season as the new parcel arrangements were not in line with their land tenure system. Furthermore, in areas where there are secondary, flexible, and spatio-temporal rights, such as gathering rights, and pastoralists' access rights, which conventional land administration system mostly neglect, this lack of consideration could lead to conflicts in the area (Lengoiboni et al., 2010; Mwangi, 2007). These rights are often seen as subordinate to private ownership rights in conventional land administration systems but are still relevant in reality.

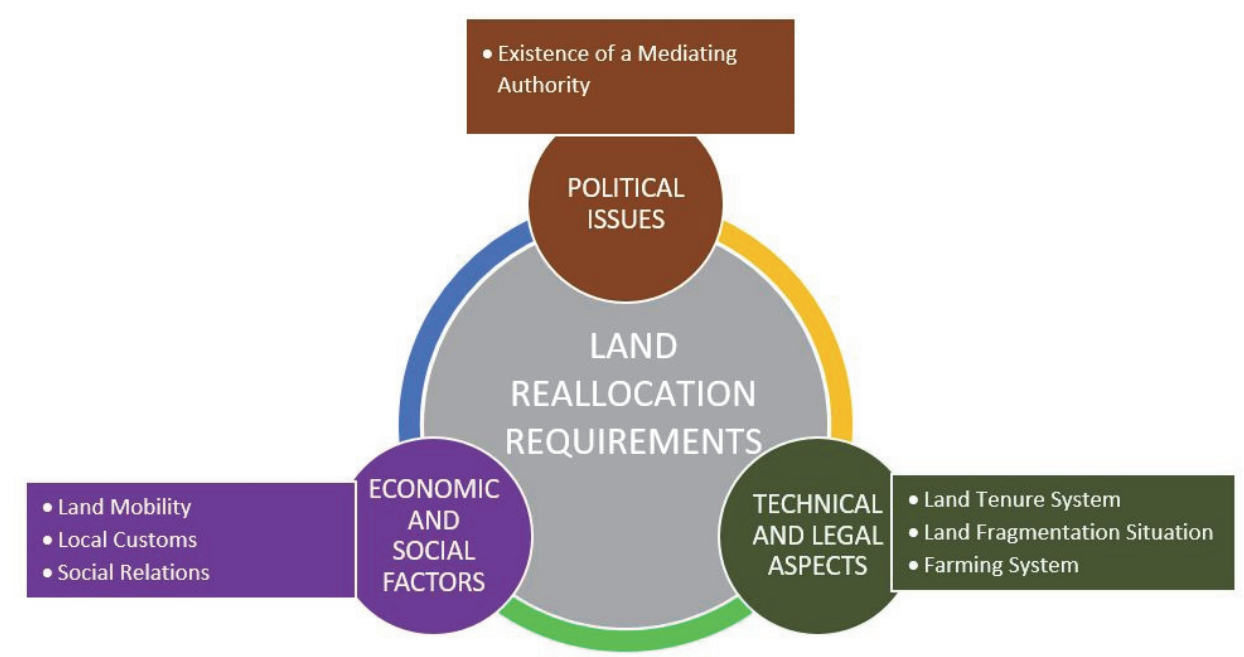

Figure 28: Summary of the General Requirements for Land reallocation

Land fragmentation takes two forms - physical and tenure (legal) land fragmentation. Physical land fragmentation refers to the spatial dispersion of farmlands over a large area of land, known as scattering, and the division of farmland parcels into small near-unproductive parcels, known as sub-division (Bullard, 2007; King \& Burton, 1982; McPherson, 1982; Van Dijk, 2003b). Physical land fragmentation has been the Western European view of land fragmentation, as the key causes of fragmentation in that region are inheritance and population growth, hence the solution to land fragmentation had been geared towards dealing with the physical aspect. Several studies limit the indicators for physical land fragmentation to the number of farmland parcels owned by a farmer, and the sizes of the farmland parcels (Akkaya Aslan et al., 2018; Cay \& Uyan, 2013; Ertunç et al., 2018; Uyan et al., 2013). Though the shape of the parcels, and the accessibility to the parcels also play a role in 
the effects of fragmentation (Demetriou et al, 2013). Van Dijk (2003b) in examining land fragmentation in Central and Eastern European (CEE) postsocialist countries, further finds that the four indicators identified do not provide a complete picture of land fragmentation, observing land tenure fragmentation as another form of land fragmentation. Land tenure fragmentation is described as a discrepancy between land use and land ownership. The indicators for land tenure fragmentation are therefore the ownership distribution, the land use structure, and the overlap between the land ownership and land use. The overlap is a representation of the owners that are at the same time users - the ideal situation. A small overlap means that leases and tenancy play a very important role in the agriculture. Land reallocation should therefore consider the form of land fragmentation and understand the aspect to deal with.

\subsubsection{Customary Lands: A Background and General Characteristics}

This section explores the nature of customary lands, customary land tenure, and land fragmentation on customary lands to contribute to the development of the framework for customary land reallocation model.

Customary land is defined in several ways depending on the origins. However, there are three fundamental elements. The first is that land is held on the basis of locally evolved native land tenure; secondly, the basis of the land holding is both group and individual rights, with the former superseding the later; and thirdly, the mechanisms for obtaining, using, distributing and disseminating these rights arise from accepted practices based on the group's customs and traditions (Arko-Adjei, 2011; Kalabamu, 2014; van Gils et al., 2014). Customary lands may also be referred to as community lands, communal land, indigenous lands, traditional lands, among others (Asiama, 2004; MigotAdholla et al., 1991; Quiggin, 1995; van Gils et al., 2014). Customary land tenure reflects the socio-cultural and spiritual bonds among generations - the many who have passed on, the living few, and the countless generation yet unborn. The basic tenet of customary land administration is that the current generation is a mere caretaker of the land meant to protect it as the legacy of their ancestors and safeguard it for the future generation. In Ghana, customary lands cover $80 \%$ of the lands in the country, with the remaining $20 \%$ being held as public lands (K. O. Asiama et al., 2017; Biitir \& Nara, 2016; Kuusaana \& Eledi, 2015). Four main customary interests in land are relevant to farming and hence land consolidation - the allodial title, the Usufructuary (customary law freehold) interest, the tenancy and licenses (Figure 6). The allodial title, the highest interest, is vested in the stool/skin, the clan, or the Tindana. The allodial title is acquired through conquest, settlement, or a gift. The allodial title is managed by the community leaders for and on behalf of the community 
members. It is free from all restrictions, obligations, and encumbrances, save for those imposed by the laws of Ghana. The sub-allodial title is held by the sub-stools, families or clans under the stool/skin, clan, or Tindana respectively. The acquisition of the sub-allodial is synonymous to the allodial interest as they are both acquired at the same time, but at different levels of importance (Ollennu, 1962, p.15). The 1992 Constitution of Ghana restricts the transfer of the allodial interest in stool/skin lands in order to save these lands for the future generation. The Usufructuary interest is the highest interest that an individual may hold on customary lands. It is held by members of the allodial title holding group subject to certain restrictions and obligations, upon the

\section{Box 13: Customary Share Cropping}

Abunu and Abusa is a system of share cropping where the landowner of a cultivated or an uncultivated land grants it to another person (usually a stranger) to maintain or cultivate and share the produce with the land owner equally for abunu or in a ratio of $2: 1$ in abusa respectively (Ollennu, 1962). Abunu literally means to share into two, and abusa is to share into three. payment of a nominal amount of money. The Usufructuary interest is transferable within the land holding group upon the agreement of the members of the group. The holder of the Usufructuary

interest may pass his interest to his successor upon his demise. Exercise of this interest is through active occupation, and in a situation of abandonment, or want of successor, the land reverts to the allodial title holder for reassignment. Tenancies can be acquired by any person, indigene or stranger, and is held off the usufruct based on standard terms for the landholding group, including payment of rent, provision of services, with the more common sharecropping arrangements being abunu and abusa. The tenant may not alienate the land to another because this interest is personal to the tenant. However, since customary law looks at an individual as an integral part of the family - the individual himself being a property of the family, the family may step in the place of the individual upon his demise on condition that they honour his part of the tenancy agreement (Kludze, 1973). A tenancy may be determined in cases where the tenant refuses to perform his obligations to the landlord, the ruin of the farm through an act of God or the tenant's negligence, abandonment, or where the tenant denies the title of his landlord and asserts his own title or that of another. A customary license is the right to occupy and enjoy land for a specific period of time or indefinitely, based on agreed terms. Woodman (1996) draws a strict distinction between a tenancy and a licence as the former is held on terms set predominantly and strictly by standard categories of the land holding group, while the latter is held on the basis of expressly negotiated terms. 


\subsubsection{Framework for General Land reallocation Process on Customary Lands}

The conditions and constraints in the framework for the model of land reallocation on customary lands is developed by drawing from the general requirements of land reallocation (Section 5.3.1) and the principles of customary land tenure (Section 5.3.2). The process centres around the technical and legal aspects of land reallocation.

In terms of the nature of the land rights that can be exchanged, it is seen that customary lands have several layers of interest in land, depending on the area being dealt with. However, the minimum ownership right is at the family level, from where the individuals receive their Usufructuary interests. Furthermore, since the goal is to keep lands within the family as much as possible in favour of the future generation, land exchanges should be done within the families first before it is done between families. The Usufructuary interest is also exclusive to the members of the family, and the tenancy is also derived from this interest. The tenancy can however be held by a person who is not a member of the family, therefore in order to keep the land within the family in accordance with the customary laws, tenancy will be excluded from the initial land reallocation. To facilitate the preservation of the lands as much as possible, the parcel shapes will not be altered.

On the level of the family, since customary land tenure allows for the alienation of land outside the family, with the consent and concurrence of the family members and elders. Therefore, any land exchanges that are done outside the family should be done with the consent and concurrence of both families. The same applies to the exchanges of land between two villages. Therefore, the undertaking of these re-allocations will require the presence of the two families.

In terms of the farms to be included in the land exchanges, in order to allow farmers to have their parcels where they most need them, they may pick one parcel (the priority parcel) around which their new parcels will be re-allocated. In the absence of a choice of the priority parcel, the largest parcel will be used. The farmers can also indicate the parcels they do not want included in the land reallocation as the unavailable parcels.

Finally, to facilitate the exchanges at the family level, only families with more than two farmland parcels in the area of interest, with at least one family member holding 2 farmland parcels in the area will be included in the first round of re-allocation. The re-allocation framework will therefore cover exchanges within the families, and the farmland parcels that may potentially 
be re-allocated outside the family lands will be placed in the village reallocation pool.

Based on the above conditions and constraints, in the land reallocation process, only family lands with more than two farms, with at least two farmers are selected. These are grouped into blocks as the Eligible Blocks (EB). The farms in each block are ranked according to the Land Value Indices (LVI). A farmer is selected from the Eligible Blocks. If this farmer has designated a priority parcel (PP), that parcel is immediately allocated to the farmer. Where no priority parcel has been designated, the largest parcel is selected, designated as the priority parcel and allocated to the farmer and eliminated from the process. Where the farmer has designated Unavailable Parcels (UP), those parcels are selected, allocated to the farmer and then eliminated from the process.

All the farmers' remaining parcels are then added to the re-allocation pool. If the farmer has more than one parcel in the block, the priority parcel is selected and all neighbouring parcels to the priority parcel in the block (which are not other farmers' priority or unavailable parcels) are ranked by the LVI as Available Parcels (AP). 


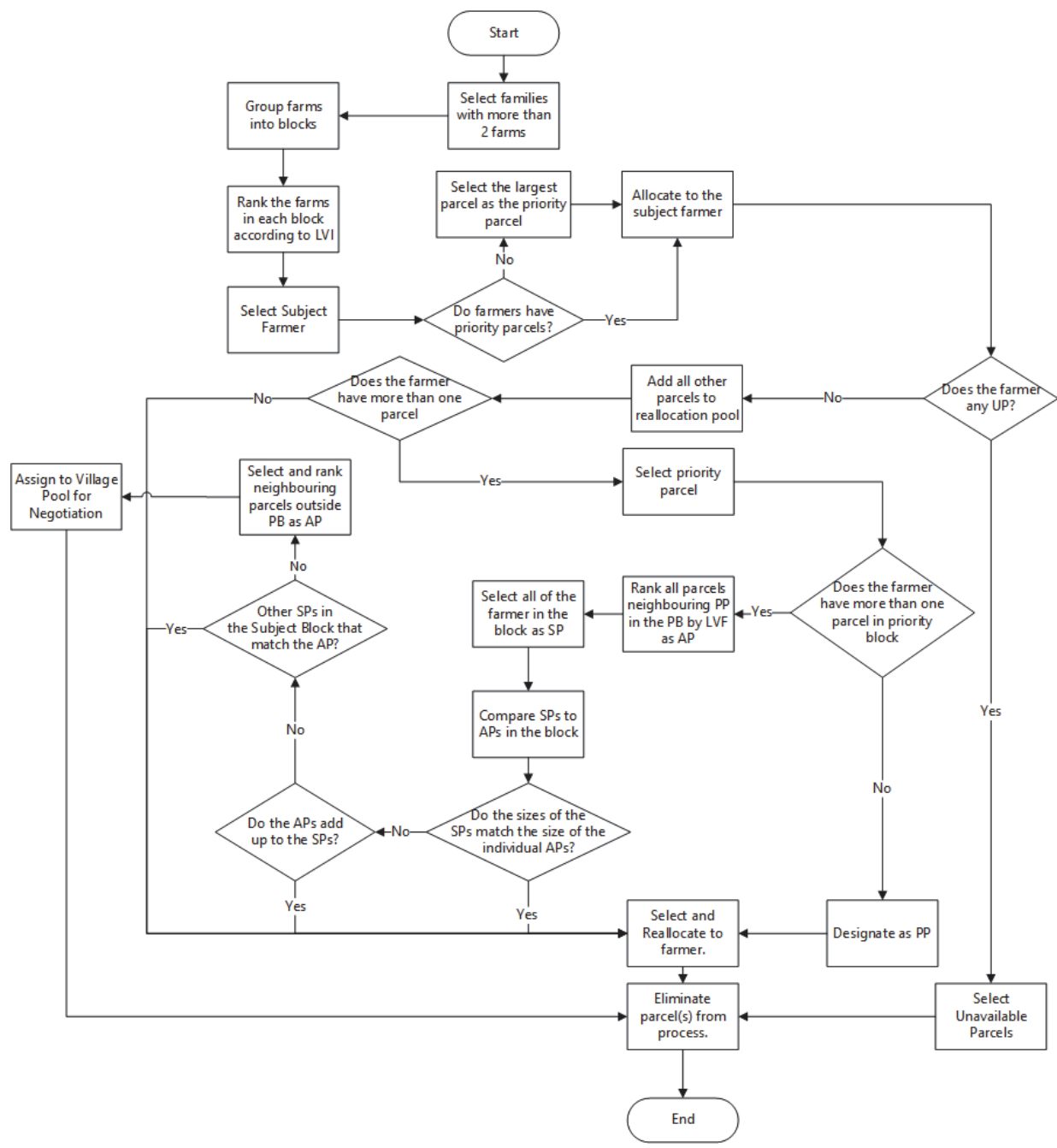

Figure 29: Flowchart of the Land reallocation Framework for Customary Lands

Block - Contiguous farmland parcels that belong to the same family; PP - Priority Parcel - The Parcel selected by the farmer, around which the re-allocation will be done; PB - Priority Block - The block in which the priority parcel lies; AP - Available Parcel - Parcels that can be re-allocated; UP - Unavailable Parcel - Parcels that cannot be reallocated; SP - Subject Parcel - Parcels held by a farmer with a block that are available for re-allocation; LVI - Land Value Indices; Farms in this diagram mean farmland parcels. 


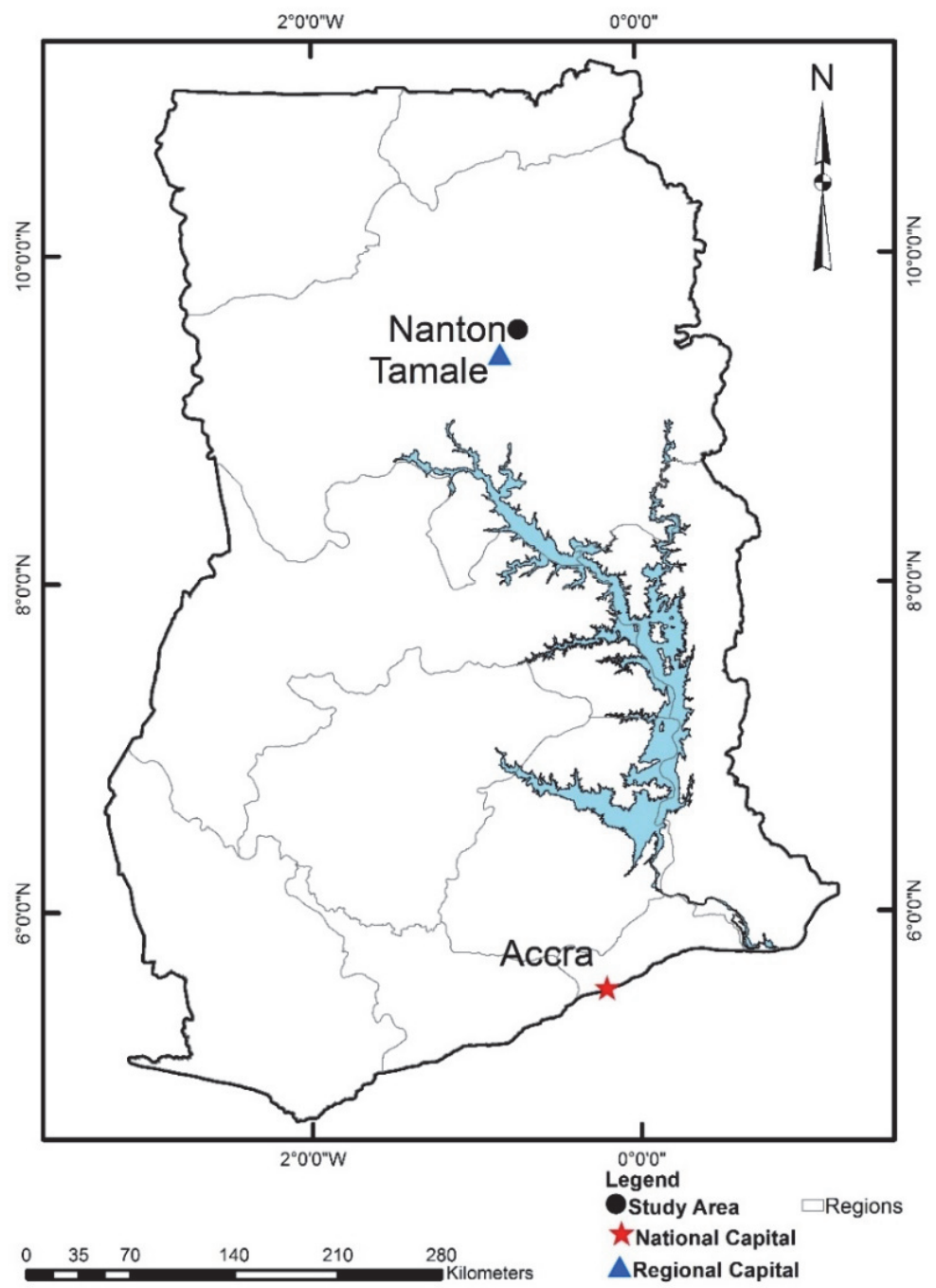

Figure 30: Map of Ghana Showing the Location of the Area of Interest

All the farmer's parcels in the block are selected as Subject Parcels (SP). The subject parcels and the available parcels in the block are compared. Where there are matches, the available parcels are selected, reallocated to the subject farmer and eliminated from the process. Where there are no matching available parcels, the subject parcels are compared to available parcels in the other blocks of the same family, for the exchange to be done. Where this is not possible, neighbouring parcels outside the priority block are selected and ranked according to the LVI. Where there are matches, those parcels are placed in the Village Re-allocation pool for re-allocation through negotiations. This process is summarised in Figure 29. This will be tested and assessed in the next section. 


\subsection{Applying the Model: Case and Findings}

This section details the testing and evaluation of the responsible approach to land reallocation on customary lands developed in the previous sections. The section begins with an overview of the area of interest as well the details of the testing procedure. The results of the framework's application is presented in the context of the land fragmentation situation and the farming system, the mediating authority, and the land tenure situation, local customs and land mobility.

\subsubsection{Overview of the Area of Interest}

The study takes place in a farming community in the Northern Region of Ghana called Nanton. Nanton village is the seat of the Nanton Traditional Area (State), within the traditional Kingdom of Dagbon. Nanton is located $18 \mathrm{~km}$ from Tamale, the regional capital and $646 \mathrm{~km}$ from Accra, the national capital. The community is within the Guinea Savannah grassland vegetation zone, characterised by tall grasses and dotted by a few big trees (mainly mango, shea, acacia, and baobab). The area experiences a single short rainfall season (April to September) accompanied by the long dry season that brings harmattan winds from the Sahara.

Table 8: Summary of the Farms in the Area of Interest

\begin{tabular}{|l|l|}
\hline Category & Amount \\
\hline Size of the total area of interest & 300 Hectares \\
\hline Number of individual farmland parcels in area of interest & 230 Parcels \\
\hline Number of Farmers in the area of interest & 95 Farmers \\
\hline $\begin{array}{l}\text { Average number of farmland parcels per Farmer } \\
\text { pumber of Family Lands (i.e. aggregated collections of }\end{array}$ & 2.4 Parcels \\
\hline Average number of farmland parcels per Family & 5.4 Parcels \\
\hline Area of largest farmland parcel & 10.79 Hectares \\
\hline Area of smallest farmland parcel & 0.07 Hectares \\
\hline Average area of farmland parcels & 1.29 Hectares \\
\hline Standard deviation of farmland parcel areas & 1.11 \\
\hline Number of farmland parcels held in customary freehold & 218 Parcels \\
\hline Number of farmland parcels held in customary tenancy & 12 Parcels \\
\hline
\end{tabular}

Data for the area of interest was collected according to the land consolidation needs. The area of interest was mapped using the participatory land administration approach developed by K. O. Asiama et al., (2017b), and adapted into the customary cadastre (K. O. Asiama et al., 2018). Here, the parcel boundaries were mapped using a smartphone app, the ESRI collector for ArcGIS, taking into careful consideration the land rights in the area, primary 
and secondary, with all being considered and mapped. This was done in order to get a snapshot view of the land rights in the area, as well as their spatial extent. Furthermore, the farmland parcel values were derived through the land value indices approach developed by K. O. Asiama et al., (2018) that provides quid pro quo values on rural agricultural farmlands that have no land markets. In the assessment of the approach, the land reallocation was done using the developed process in Section 5.3.3.

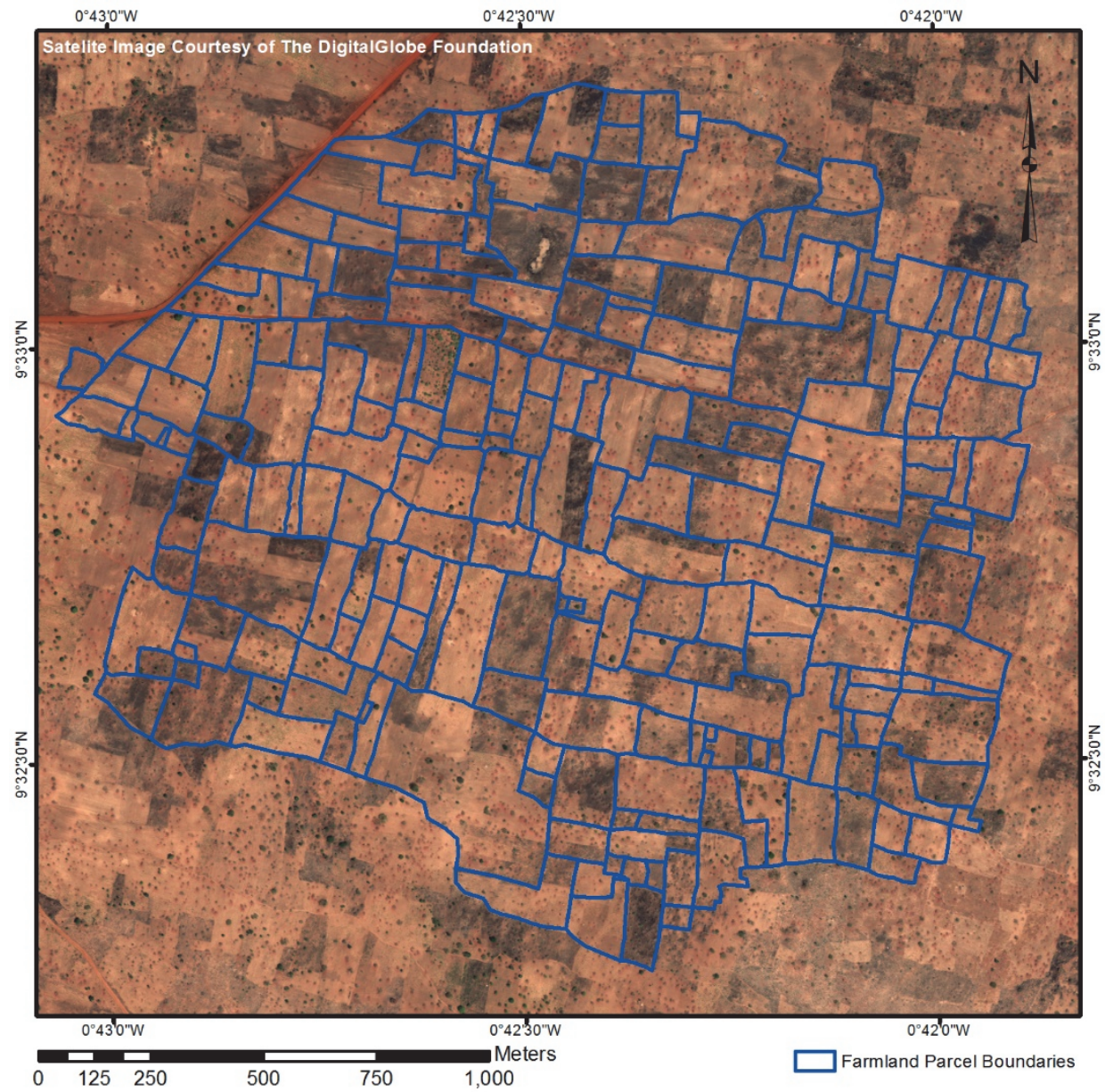

Figure 31: Map Showing the Farmland Parcels in the Area of Interest

The village re-allocation was then done in five small families with all the farmers within the family and the elders present. The results were then presented to the local community for their inputs. The inputs and views on the developed process were collected through interviews with the Nanton-Na, the head of the farmers' union in the area, the staff of the customary land secretariat, two land registration officers and a land surveyor from the Lands Commission, and an agricultural extension officer from the Savannah 
Agricultural Research Institute. Focus group discussions were also conducted with the traditional authority (excluding the Nanton-Na), the farmers in the area, and family heads.

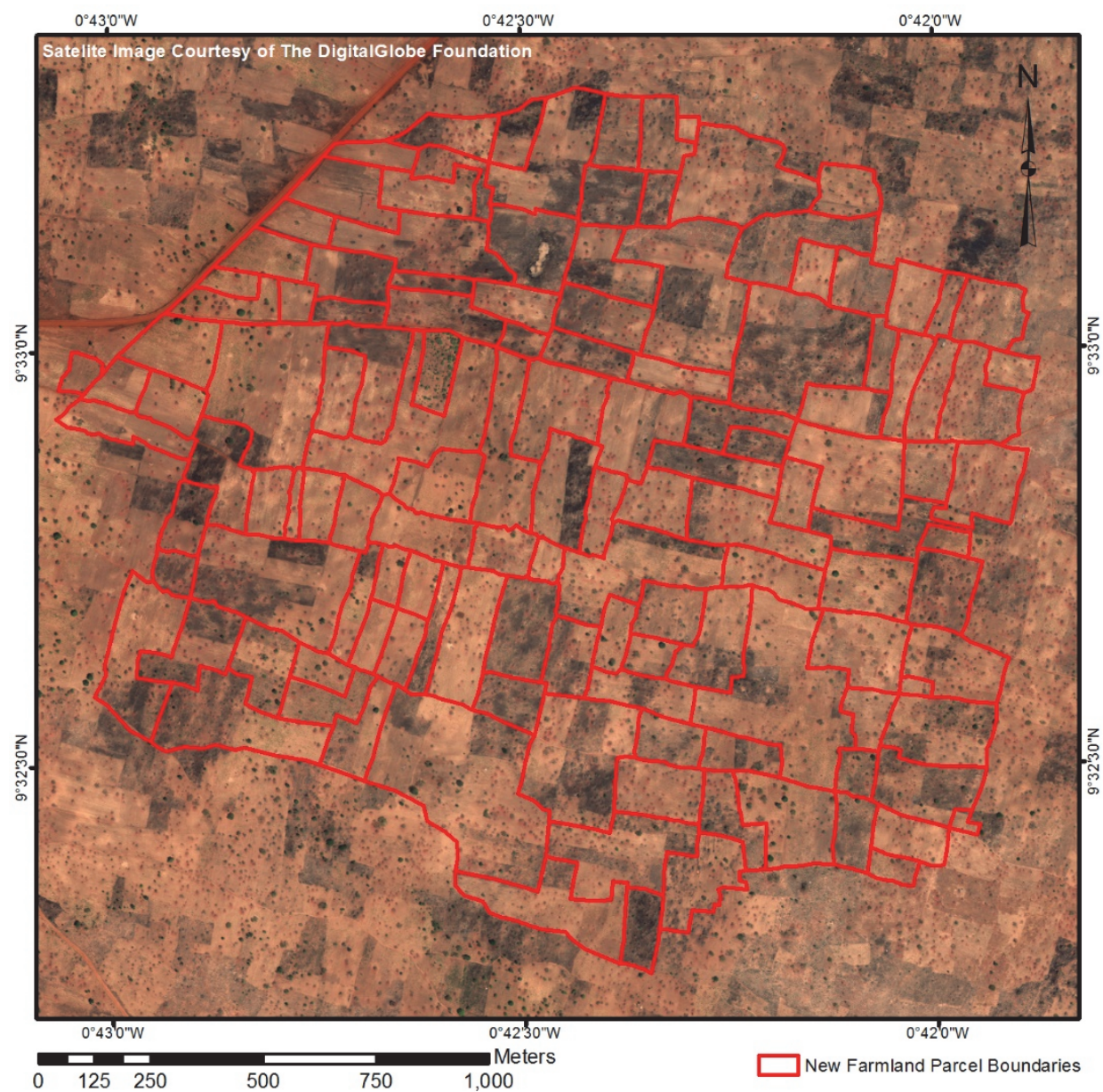

Figure 32: New Farmland Parcel Arrangements

\subsubsection{The Land Fragmentation Situation and Farming System}

The results from the application of the approach on the physical land fragmentation is presented in the following paragraphs. Physical land fragmentation was assessed based on the four factors identified in Section 5.3 - the number of farmland parcels per landholding, the size of the farmland parcels, the shape of the farmland parcels, and the accessibility to the parcels. The physical land fragmentation situation in the area of interest improved significantly with the application of the developed land reallocation approach (Figure 33). The largest farmland parcel in the area of interest remained 
10.79ha before and after the land reallocation. However, the smallest farmland parcel size increased from $0.06 \mathrm{ha}$ to $0.22 \mathrm{ha}$. The average size of the parcels increased from 1.25 to $2.20 \mathrm{ha}$, with standard deviations of 1.08 and 1.68 respectively.

In a focus group discussion, the farms identified one of the problems with the farm sizes is their inability to hire mechanised farming equipment. Since the hiring companies do not rent out to farmers with parcels less than 3ha, this is a significant figure with respect to farmland parcel sizes for mechanisation. The number of farmland parcels in the area of interest that were more than 3ha was 20 out of 230 (9\%) with this proportion increasing to 39 out of 130 parcels $(30 \%)$ after the re-allocation. The number of farmland parcels per holding also reduced after the re-allocation.

Table 9: Summary of the Effect of the Approach of the Physical Land Fragmentation

\begin{tabular}{|l|l|l|}
\hline Category & Initial & Final \\
\hline $\begin{array}{l}\text { Number of individual farmland parcels in area } \\
\text { of intert }\end{array}$ & Parcels & 130 Parcels \\
\hline $\begin{array}{l}\text { Number of Farmers in the area of interest } \\
\text { Farmer }\end{array}$ & 95 Farmers & 95 Farmers \\
\hline $\begin{array}{l}\text { Number of Family Lands } \\
\text { Average number of farmland parcels per }\end{array}$ & $\begin{array}{l}5.4 \text { Parcels } \\
\text { hamily }\end{array}$ & $\begin{array}{l}\text { holdings } \\
\text { Farmoldings }\end{array}$ \\
\hline Area of largest farmland parcel & 10.79 Hectares & 10.79 Hectares \\
\hline Area of smallest farmland parcel & 0.07 Hectares & 0.22 Hectares \\
\hline Average farmland parcel size & 1.25 Hectares & 2.20 Hectares \\
\hline Standard deviation of farmland parcel areas & 1.08 & 1.68 \\
\hline Maximum Parcel Shape Index & 1.0 & 1.0 \\
\hline Minimum Parcel Shape Index & 0.00 & 0.02 \\
\hline Average Parcel Shape Index & 0.66 & 0.76 \\
\hline
\end{tabular}




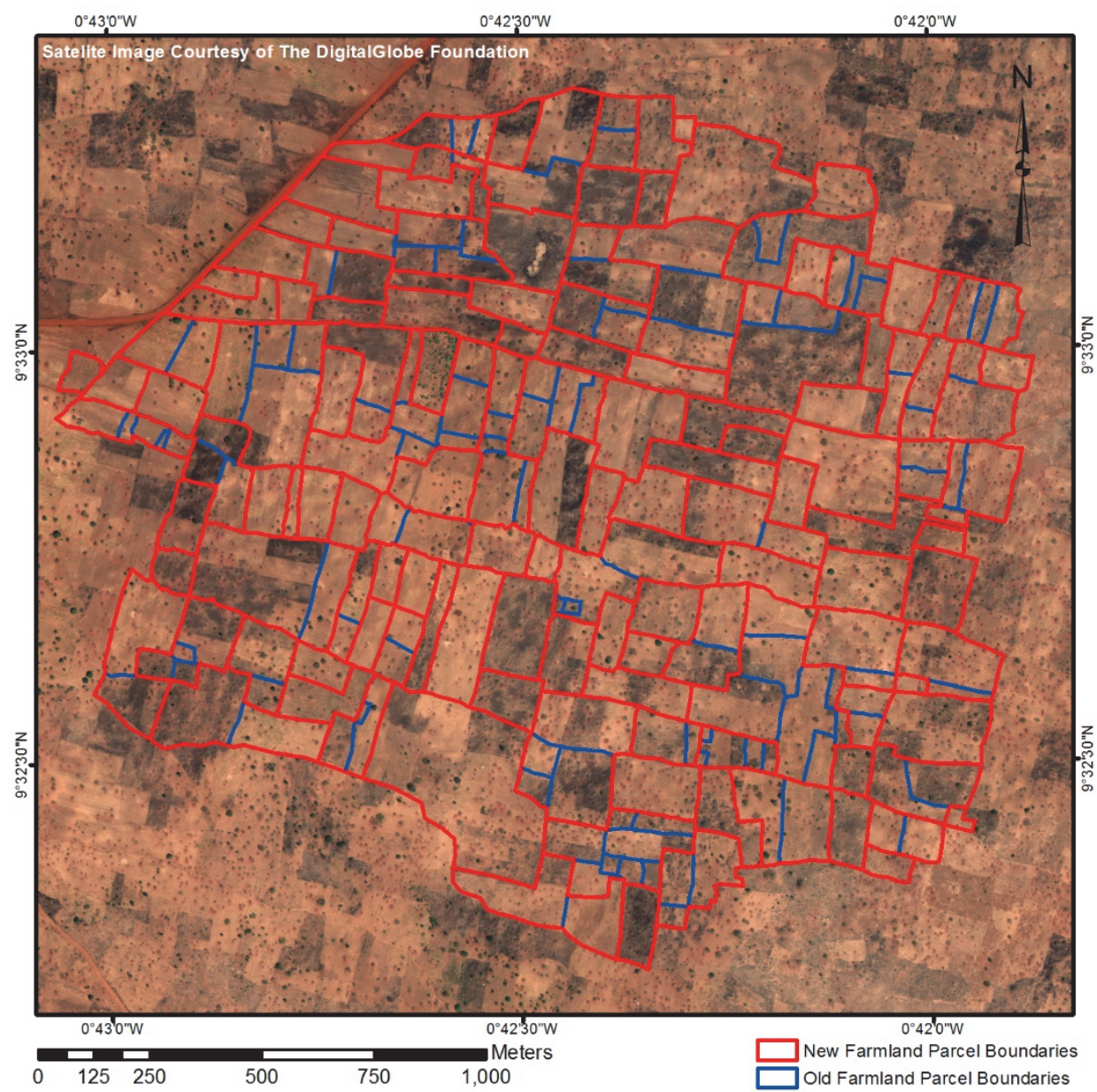

Figure 33: Change Detection Map for Original and New Farmland Parcel Arrangements

The ideal situation for the farming would be 1 parcel per land holding. However, the initial average parcels per landholding in the area of interest was 2.4, with a maximum of 9 parcels in a landholding and a minimum of 1 . This reduced to a maximum of 3 parcels per holding.

The accessibility of farmland parcels is determined by how many farmland parcels have access to the key lines of transportation. In the area of interest, the key lines of transportation - the major and minor regional highways and the local roads. However, the footpaths were not deemed important by the local people as they connected every parcel. The road access is particularly important in this area because farmers with road access are able to access mechanised equipment and transport their farm produce quicker (Focus group discussion with Farmers). It was found that before the re-allocation, 108 out of 230 farmland parcels, representing $47 \%$ were accessible. After the re- 
allocation, this proportion increased to 76 out of 130 farmland parcels representing 59\% (Figure 33).

To assess the parcel shape, the Parcel Shape Index (PSI), developed by Demetriou et al., (2013), is used to calculate scores that serve as a basis for comparison. The PSI uses six geometric parameters through a multi-attribute decision-making, combined with value functions for parameter standardisation. The average PSI for the original parcel arrangements was 0.66 , with a standard deviation of 0.21 . The average PSI after the re-allocation increased to 0.76 , though it wasn't considered (Figure 32).

\subsubsection{Mediating Authority}

The results relating to the appropriate mediating authority is presented in this section. The section starts with the local view of the appropriate mediating authority, and a description of the mediating authority and why it is viewed as such follows.

There are two key centres of authority in the area of interest - the traditional authority (the chief, elders, and the family heads), and the local government authority (the district assembly member and the unit committee members). However, the local people and the local government authority point to the traditional authority as the most appropriate mediating body to deal with matter relating to land and farming in the area. The traditional authority's role in the community is three pronged - religious, judicial, and land management. These roles are enforced through the respect that the people have for them. In its historical religious role, the traditional authority plays the role of the intermediary between the local people and the gods of the land. The traditional authority is viewed as a council of wise men and women, hence their judicial role, where minor issues in the community are arbitrated. The third role is that of land management. As custodians of the land, they are required to manage the land for and on behalf of the local people for their benefit.

The structure of the traditional authority in Nanton is in consonance with the land tenure arrangements in the area. The Ya-Na skin is at the top of the traditional authority structure. Under this skin are the divisional skins of which the Nanton skin is one. Directly under the Nanton skin are the family heads. This is in line with the customary administration structure described in Section 2.4 and shown in Figure 6. The role of the traditional authorities in the management of land is also exercised in the manner of the hierarchy. The family heads are responsible for the allocation of the family lands, especially in cases of abandonment and the passing of a land holder. The family heads were therefore pointed to as the appropriate mediating authority in the re-allocation of land within the family lands. The family head here is the most respected and usually the oldest member of the family. In terms of re-allocation between 
families, the chief and his elders are regarded as the most appropriate mediating authority.

\subsubsection{The Land Tenure Situation, Local Customs and Land Mobility}

This section presents the results on the effects of land reallocation on land tenure situation, local customs and land mobility.

The land tenure system in the area of interest that relates to farming are allodial title, the Usufructuary interest, and tenancy (Figure 6). The allodial title is held by the Dagbon (Kingdom) Skin, with the Ya-Na (the King) as the occupant of the skin, in trust for the people. The allodial title is however managed at the Traditional Area level by the divisional skin (Nanton Skin), with the Nanton- $\mathrm{Na}$ (with the traditional council) as the custodian. The families hold their sub-allodial interests off the divisional skin, from whence the individual farmers within the families derive their Usufructuary interest. There are also a few farmers in the area that hold the tenancy. The nature of the land tenure system creates a land tenure fragmentation between the usufructs as the "owners" and the tenants as the "users", thus affecting the land reallocation. Per the customs in the area, a tenant cannot transfer his tenancy, therefore the tenancy cannot be included in the land reallocation plan. The usufruct's interest may however be included, with consideration for the tenancy's encumbrance.

Due to land mobility, the initial re-allocation was therefore done only with respect to the farms with the Usufructuary interest in the same families. Tenancies were not included as the initial re-allocations were done on the basis of the usufructs' families. The re-allocation also took the ownership into higher consideration then users. The tenant in the area of study does not hold a fixed term, but rather renews his tenancy every farming season until the farmer needs his farm back. The tenant is also only allowed to plant annual crops, which he may share with the usufruct on sharecropping terms. Out of the 95 farmers in the area, there were five tenant farmers. All five tenant farmers confirmed their terms of tenancies, and the usufruct's family's sub-allodial interest. The usufructs in answering why they rented out their farms, indicated the distance between their farmland parcels as a key factor. The tenancies were therefore a result of the physical land fragmentation in the area and would likely cease when land fragmentation is reduced. Thus, tenancies can therefore only be reallocated according to the usufruct's family, reducing the land tenure fragmentation in the area.

Land reallocation outside families was also not done during the initial reallocation. The allocation outside of families means the families would have to 
give up their sub-allodial interest in exchange for another. This suggestion was however, flatly rejected by all the participants of the focus group discussions, as they described the act as an absolute affront to the ancestors who strived to hold the land for them to meet it, and their future generation. An elder remarked that the only good reason to sell one's family land is to defray debts and that reason makes parting ways with the land disgraceful. The traditional authority however suggested a solution to this as the grant of tenancies as the basis of exchange in lieu of the sub-allodial interest.

\subsection{Discussion}

The results of the application of the customary land reallocation model in the area of interest have a number of implications and sometimes at odds with the wider body of land reallocation knowledge. These are discussed in terms of land fragmentation; mediating authority; and land tenure situation, local customs, and land mobility.

In terms of the land fragmentation, the results showed that land fragmentation, physical and legal alike, was reduced in the area of interest. The approach significantly reduced the number of farmland parcels, increase the farmland parcel sizes, reduce land tenure fragmentation, increase accessibility to lines of transportation and slightly improve the parcel sizes in the area. The size of the farmland parcels and the number of parcels per holding have been used by many studies as the key indicators of land fragmentation and the success of land reallocation (Akkaya Aslan et al., 2018; Cay \& Iscan, 2011; Ertunç et al., 2018; Uyan et al., 2013). In the area of interest, the increase of the average farmland parcel size from 1.25 to 2.20ha, put it above the national average of 2 ha (MoFA-SRID, 2016). However, the measure of whether this is significant rests on whether the increased sizes reduce the effects of land fragmentation. In the area of interest, the farmers do not own mechanised farming equipment, but rather hire them. The results showed that the threshold for mechanisation in the area of interest is 3ha. With the proportion of farms that meet this threshold increasing from $9 \%$ to $30 \%$, the effects of land fragmentation have been reduced in that respect. The parcel shape has been a less considered indicator of land fragmentation and success of land reallocation in many recent studies (Akkaya Aslan et al., 2018; Cay \& Iscan, 2011; Ertunç et al., 2018; Uyan et al., 2013; Uyan et al., 2015). Parcel shape determines the ease with which linear field operations like ploughing and mechanised harvesting can be undertaken (Demetriou et al., 2013; Lee \& Sallee, 1970; Wheeler, 1973). The ideal shape for a farm in terms of mechanised farm operations is a square or a rectangle (Bullard, 2007; King \& Burton, 1982). This can be attributed to the nature of many current land consolidation approaches, which involve land re-alignment (K. O. Asiama et al., 2017b; van der Molen et al., 2004). Though due to the local customs of 
Nanton, the regularization of farmland shapes was not an objective of the developed land reallocation approach, parcel shape was still assessed to check whether there was an improvement or otherwise in the parcel shapes. It was found that the average Parcel Shape Index of the farmland parcels significantly increased. Other studies into land reallocation where the regularization of the parcel boundaries was an objective such as Demetriou (2014), had the PSI being increased to almost 1 . The parcel shape manipulation would have very much reduced the effect of land fragmentation as was shown in other studies. This means that the customs of the area were an impediment for this aspect of the land reallocation.

The most appropriate central mediating authority in the area was found to be the traditional structure in the area as against the local government authority. The three roles of the traditional authority found in the area of interest, historical religious, judicial, and land management roles are all important to the (re-)allocation of land on customary lands. These roles and the respect of the local people for the traditional authorities has caused the government to adopt a hands off approach in the management of customary lands, in favour of the traditional authorities (Ubink \& Quan, 2008). The co-existence of the traditional and local government authorities displays the strong institutional pluralism for which Ghana is known. This is a stark difference in comparison to other countries where a bottom-up or decentralised land consolidation are better by local government entities (Grossman \& Brussard, 1988; Louwsma et al., 2014; Van Dijk, 2003a). Furthermore, the role of the traditional authorities, among others, of land management made it an appropriate body to mediate the process. The traditional authorities included the various levels of chiefs and their traditional councils, as well as the family heads.

In terms of the land tenure system, local customs, and land mobility, the study found the allodial title, Usufructuary interest, and tenancy as the main interests that relate to farming in the area of study. The relationship between the tenant and the usufruct was found to be a key cause of land tenure fragmentation. The finding that land reallocation could also only be done with only the Usufructuary and allodial interests, differs from the other areas with approaches to land reallocation. As with European land consolidation approaches, such as the Dutch case where the user (if different from the owner) is usually a leaseholder with a fixed term (Grossman \& Brussard, 1988; Louwsma et al., 2014). Despite this, the results showed that land tenure fragmentation would be reduced with the application for the approach. This is because the tenancies that came up in the area are a result of the physical land fragmentation which discouraged farmers from farming all their farmland parcels, thus renting them out. With regards to the land reallocation between families, it was found that the developed approach could not handle this as the local people were vehemently against families parting with their sub-allodial 
interests in land. Hence even though it is theoretically possible for re-allocation to be done between families, it practically improbable (Akrofi \& Whittal, 2014; Arko-Adjei, 2011; Ollennu, 1962; Woodman, 1967). The only suggested solution was to rent out the family land to serve the purposes of re-allocation. This is also not an optimum solution, because even though it would reduce physical land fragmentation, land tenure fragmentation would be further increased. Therefore, as with the implication of the approach on the physical fragmentation, the local customs are also an impediment to the reduction of the land tenure fragmentation.

\subsection{Conclusion}

The main objective of this paper was to develop a land reallocation approach to support responsible land consolidation on customary lands. The study arises out of the recent trend of land reallocation studies that focus mainly on the technical processes. To achieve the objective, the general characteristics of customary lands and the general requirements for land reallocation were identified from literature and developed. Based on the relationship between these factors and the general principles of customary lands, a land reallocation approach was developed to fit the context of Ghana's rural customary lands and tested in Nanton, Ghana.

The results showed that even though the developed approach was able to significantly reduce land fragmentation, both physical and land tenure, in Nanton, the local customs were an obstruction to the technical processes to achieve the best form of the farm structures. However, this is the basic tenet of a responsible approach - to consider all aspects of a society and technology when undertaking a process (K. O. Asiama et al., 2017a). This study recommends two lines of further research. First, the local customs should be further studied to understand how the re-allocation between two families can be undertaken without compromising the land tenure system or increasing land tenure fragmentation. Secondly, the framework of the customary land reallocation should be further developed into a spatial decision support system to enable its easy application. 
Chapter 6 Towards Responsible Land Consolidation: Summary and Conclusion 


\subsection{Introduction}

Achieving food security through the increase of food productivity on SubSaharan Africa's customary lands has been one of the key goals of many international organisations. However, the land administration aspect had often been ignored: customary land tenure was seen to be an impediment to development of land management activities, given their failure. Chapter one sets the tone of this work, describing the relationship between food security and land and the problem of low food productivity in Ghana in terms of the farming and the land tenure system as well as attempts to increase food productivity. The chapter further describes the failure of land consolidation on sub-Saharan African rural customary lands as a research problem, and points to the development of responsible approaches to land consolidation as a solution to the problem. These underpin the overall research objectives and questions. Chapter Two seeks to develop the requirements for a responsible land consolidation approach on customary lands. Based on the findings of Chapter Two, Chapters Three and Four build land administration process for collecting land information and valuing customary lands to support responsible land consolidation respectively. The results feed into Chapter Five to build a land reallocation approach, the crux of customary land consolidation. This Chapter synthesises the results from Chapters Two to Five based on the research objectives formulated in the proposition;

- To explore how the factors, need to be addressed to develop a responsible land consolidation approach for customary lands

- To develop and assess an approach for collecting land information to support responsible land consolidation on customary lands.

- To develop and assess a land valuation approach to support responsible land consolidation on customary lands.

- To develop the framework for a reallocation approach to support land consolidation on customary lands.

Section 6.2 summarizes the main findings of each of the specific objectives. Section 6.3 discusses the implications of the results for knowledge, food and agriculture policy and land policy formulation, to the study areas, and to other challenges, and Section 6.4 suggests future research prospects.

\subsection{Main Findings}

This section summarises the main findings of each of the main objectives. 


\subsubsection{To explore how the factors, need to be addressed to develop a responsible land consolidation approach for customary lands}

The first objective started from the endpoint of several studies including (Abubakari et al., 2016; Blarel et al., 1992; Makana, 2009; Takane, 2008), which conclude that conventional approaches to land consolidation are not viable on customary lands. These studies however stopped short of identifying the factors needed to be considered in order to develop a land consolidation approach on customary lands. A deeper analysis of specific cases was deemed necessary. To this end, three countries with contemporary land consolidation approaches were identified - the Netherlands, Lithuania, and Rwanda. The Netherlands was found to have land consolidation approaches that have evolved over five centuries, from Voluntary Land Exchange, to Land consolidation by agreement and Land Development. Lithuania has developed the Voluntary and Simple Land Consolidation over the past fifteen years, and Rwanda developed its own form of land consolidation, the land use consolidation in 2008. A harmonisation of the land consolidation approaches in these three countries shows that generalising the development of land consolidation approaches in a continuum from simple and voluntary approaches to comprehensive and compulsory approaches (Figure 8), as is done in certain studies, based on the development level of the locality, does not result in development of a responsible land consolidation strategy, but the local needs and societal makeup is key in the selection of the land consolidation approach. The results showed five key areas around which the development of the land consolidation approaches centre - the government support and role in land management activities; the land market and land mobility; land tenure, land fragmentation and farming technology; the coverage of a land information system, as well as environmental and ecological considerations.

Comparing these influences, it was found that the state of the economy, the type of land fragmentation, ecological considerations, and the level of farming technology in Ghana was similar to at least one of the countries with an existing land consolidation approach (Table 1). The conditions that did not bear any similarities with existing land consolidation strategies were the low influence of the government in land management activities, the absence of a land market, the inadequate coverage of a supportive land information system, and the customary land tenure. However, it was found that the conditions that did not adequately match the countries with existing land consolidation approaches require a substantial change to the social, economic, and cultural structure of the communities, in order to align them with the existing approaches. These conditions therefore require innovative and responsible interventions to enable response to the requirements of land consolidation. 


\subsubsection{To develop and assess an approach for collecting land information to support responsible land consolidation}

The need for land information for land management activities has been increasingly recognised, especially in areas without a well-functioning land administration system by studies such as Arko-Adjei (2011), Bennett \& Alemie (2016), Enemark, et al. (2016), Zevenbergen, et al. (2013). However, since countries that have developed land consolidation approaches had an existing supportive land administration system, little has been investigated on the land information needs for land consolidation. The existing land administration systems on customary lands have been found to be inadequate in supporting land consolidation activities, as well as other land management activities, as is common in about $70 \%$ of the countries in the world. Land administration processes in these countries have been found to be slow and expensive in relation to the urgency of the results, and out of reach of the majority of the citizens. Furthermore, they have failed to integrate all forms of land tenure arrangements especially secondary and customary land rights. It was found that the innovative approaches to land administration on customary lands in Ghana which include the systematic titling by the Millennium Development Authority, the Paralegal Titling Project and the Community-based Land Survey Tool, all had the same problem of being slow, expensive, and concentrated in urban areas and on large-scale farms.

This chapter brought together traditional land administration approaches, deeply rooted in western views, together with bottom-up emerging approaches that challenge traditional approaches, as well as technological advances that drive these approaches together with the growing societal needs. The result was Participatory Land Administration (PLA) that sits at the nexus of the drivers of technological innovation and approaches to development studies. In this chapter, the four aspects of PLA were assessed in an experiment in Nanton, Ghana, in gathering land information for land consolidation. The study found that of the two approaches that were adopted in the collection of the land information - satellite imagery and a smartphone app, the smartphone app was found to be easier to use by the local community and more readily assessable than the satellite image that is recommended by Enemark et al. (2014) and Lemmen \& Zevenbergen (2010). It was also found that the use of the mobile app supported the societal goal, in this case by providing a onestop device to collect spatial and non-spatial land information that support land consolidation including the property rights - both real and personal rights - the spatial distribution of these rights, the spatial extent of the farmland parcels, the land use information, the quality of the farmland parcel, and the soil type. The bottom-up approach used also built up the trust of the local farmers in the 
system, giving them the confidence and trust in the system, as they collected the data with their own devices.

\subsubsection{To develop and assess a land valuation approach to support responsible land consolidation on customary lands}

Land value is not explicit on rural customary lands, mostly because the social, cultural, and spiritual bonds with land inhibit the free operation of a land market. Land valuation is the second aspect of data inventory in land consolidation where farmland parcels are appraised to form a basis for farmland parcel reallocation. Land reallocation in land consolidation relies on land valuation to describe and assign a value to the farmlands that will be reflective of the farmers' perception of their farmland values. The traditional valuation approaches, including the cost, investment, and comparative methods, are used to value customary lands. However, in rural areas, it is found that even though the sales of land is very uncommon and unlikely, where land is rented out, the money that exchanges hand is a flat rate that is charged regardless of the nature of the farmland parcel.

There are two approaches to land valuation in land consolidation - the agronomic value, with its basis being the soil productivity and quality, and the market value. The market value has been touted as the better approach with studies pointing out the deficiencies in the agronomic value approach. However, the market value approach cannot be used in Sub-Saharan Africa's customary lands due to the limited land market. Here, a framework developed for an approach for assigning values to customary rural farm land parcels that reflects the local people's view of land value. It was found in a case study of Nanton that key land value factors that determine land values relate to the physical attributes, legal conditions, agricultural productivity, locational factors, and the planning scheme of the farmland parcels. These factors were weighted by the local community according to their perception of what affected their choice of farmland parcels. The weights were integrated into the framework the produced the Land Value Index (LVI) for each land parcel in the area of study. The results showed that in a scenario analysis, a change in weights affected the land value indices at a scale that could change the comparative basis of the land parcels. The sensitivity analysis however showed that the LVIs were not significantly sensitive to the changes in the weight of the factors. However, a prime weakness of this framework is that it is more expensive to use than automatic valuation models. The results demonstrate that it is possible to place relative quid pro quo values on rural agricultural farmlands that are not part of a land market. These quid pro quo values will serve as a basis for the reallocation of the farmland parcels. 


\subsubsection{To develop the framework for a reallocation approach to support land consolidation on customary lands}

Chapter five synthesises the results of chapters three and four to develop the framework of a land reallocation model. Land reallocation is seen as the most important stage in the land consolidation process, where property rights are exchanged, and farmland parcels are redistributed and reorganised. A model of land reallocation should therefore consider all related land information (spatial, rights, and value) and the wishes of the involved land holders. The framework for the model is developed using a process model taking into consideration the social, economic, cultural, technical, and political considerations on customary lands, through the steps of analysis, synthesis, and evaluation.

The undertaking of land reallocation generally has three key requirements and considerations. Politically, land reallocation requires a mediating authority to act as an arbitrating force during the planning and implementation, because of the disputes that land reallocation may spark. Like land consolidation in general, land reallocation also requires a level of land mobility that will allow for the exchange of farmland parcels, in this case related to social land mobility, i.e. land mobility based on the social and cultural norms in the community. The development of a land reallocation model further requires a consideration for the land tenure system and the land fragmentation situation. Customary lands characteristics that are relevant to land reallocation relate to the rules that relate to the transfer of land between two parties. Here, even though it is generally accepted that customary lands cannot be transferred, it is found in Chapter Two that customary land tenure rules do indeed allow for the transfer of land, but with strict restrictions. The framework of the land reallocation model is built around the legal and technical aspects of land reallocation, taking into consideration the levels of landholding (individual, family/clan, village etc.). The framework for the land reallocation is focused on the family level as Chapter Two shows that transfer of lands within families involves only the individuals concerned. However, where land is transferred outside the family, it requires the consent of the two families.

When the model framework was applied to the area of interest, it was found that physical land fragmentation was significantly reduced, with a reduction in the number of farmland parcels, an increase in the parcel sizes, a reduction in the land tenure fragmentation, an increased accessibility to key lines of transportation, and slight improvement in the parcel shapes in the area, even though this was not a goal of the approach. The most appropriate central mediating authority in the area was found to be the traditional authority in the 
area, much different from the other areas in the world where land re-allocation has been done.

In terms of the land tenure system, local customs, and land mobility, the study found the relationship between the tenant and the usufruct to be a key cause of land tenure fragmentation. However, the study further showed that land tenure fragmentation would be reduced with the application for the approach. With regards to the land reallocation between families, it was found that the developed approach could not handle this as the local people were vehemently against families parting with their sub-allodial interests in land, even when it is swapped for a similar parcel of land. The only seeming solution was to rent out the family land to serve the purposes of re-allocation. However, although this would reduce the physical land fragmentation, the land tenure fragmentation would worsen. In conclusion, even though the developed approach was able to significantly reduce land fragmentation, both physical and land tenure, the local customs were an obstruction to the technical process to achieve the best form for the farm structure. However, this is the basic tenet of a responsible approach - to consider all aspects of a society and technology when undertaking a process.

\subsection{Implications of Results}

\subsubsection{To Knowledge and Literature}

As shown in the different chapters, land management activities are very much dependent on the local context in which they are being applied. However, there is very little literature on the considerations for the transfer of land management activities into other areas. This work, using land consolidation as a land management activity, explores the factors that must be considered and how to achieve those factors when transferring the processes to Ghana's rural customary lands. This is important because even though the problems in two areas may be similar, the response to those problems may differ, as shown in Chapter Two, and therefore need comparative analysis. The results in this work further contribute to the literature and scientific knowledge on how land management activities could be transferred from one part of the world to another, in this case from western countries to sub-Saharan Africa. Thus building upon the works of Masser \& Williams (1986) and Van Dijk (2002), where the later explored the transfer of land consolidation knowledge from Western Europe to Eastern and Central Europe.

This work further builds upon other works in land consolidation such as Hartvigsen (2015c) and Van Dijk (2003a) that looked at the land consolidation approaches and policies in Central and Eastern Europe viz-a-viz Western Europe at a macro-level, and Demetriou (2014) who looks at the development 
of systems to support the undertaking of the individual stages of land consolidation at a micro level. These three studies however dwell on areas with already existing and functioning land administration systems. Hence a lot of core and key steps of land administration functions in land consolidation are not considered. This thesis is developed three steps - a land administration process, a land valuation approach, and a land reallocation model, contributing to the scientific knowledge of land consolidation at a micro-level (Figure 4). All these three steps exist in literature, the difficulty in using them elsewhere stems from the inadequacy of a general framework for all of them that can be adapted to a local context. This is because each of these three processes are developed to fit a particular local and legal context. In this work, the general requirements and processes for each approach were explored and defined, before the case specific adjustments were developed. This means that some processes had to be deconstructed as they assume certain minimum characteristics in the conventional approaches such as land mobility and a land market which did not exist. In this regard, the processes developed in this work can be applied to any area, with consideration for the local context. This work therefore contributed the knowledge of developing general processes for land administration processes that are needed to support land consolidation.

Figure 34 summarises the findings of the thesis, connecting the concepts where the gaps were identified in the introduction.

\subsubsection{To Policy Formulation and Implementation}

Policies form one of the bases for land management (the other two being Land Information Infrastructures and country context) (Enemark, 2005). The results in Chapter 3 demonstrated the inability of the collected land information to support land management activities for sustainable development. The need for land policies to consider the gap between land information collection or the building of a cadastre on the one hand and sustainable development on the other, is shown in that chapter. The results show that merely collecting land information is not enough, but the land information should be meant for a particular purpose. Such an approach as collecting land information is not immediately obvious when looking at western countries, however, it is more obvious with SSA countries.

Therefore, this work can help with the formulation and improvement of land policies to re-orient them towards gearing land information to land management activities to support sustainable development. The formulation of food and agricultural policy can also be influenced by the results of this work. As shown in Chapter One, policies on increasing food productivity focused mostly on mechanisation and fertilisation, rather than looking at land availability, the size of farmland parcels, and the land tenure security of 
farmers. The crux of this thesis, Chapter Five, describes the framework for the land reallocation model and its application in a case area, shows how the application of the approach can be applied to increase the size of the farmland parcels and reduce the fragmentation of land tenure. This research therefore enriches the need for a stronger link between food policy and land, especially in terms of food productivity.

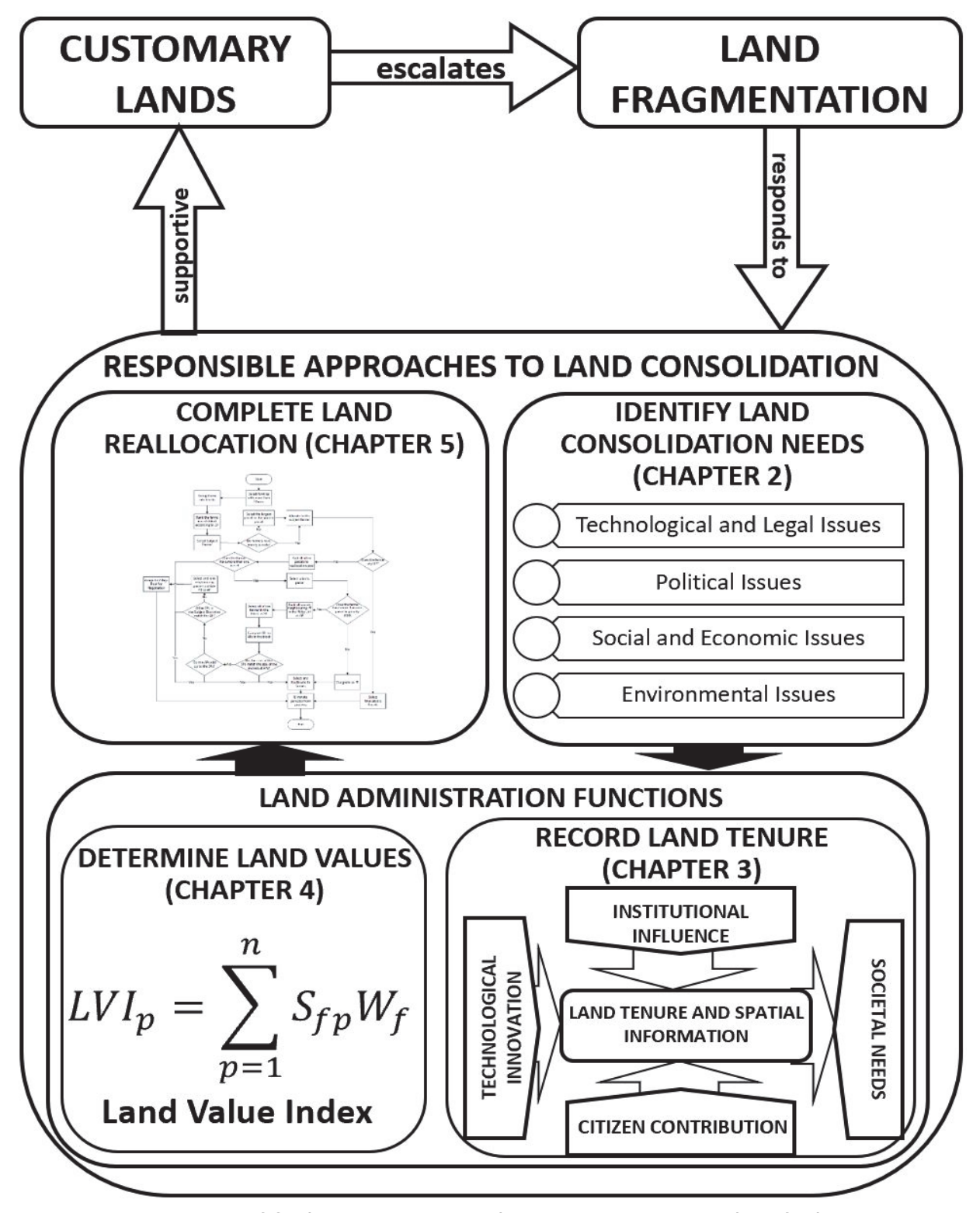

Figure 34: Summary of findings connecting the gaps in concepts identified in Figure 1 Please see Figures Figure 5,Figure 9,Figure 18, and Figure 29 for the detailed figures 


\subsubsection{To Meeting Other Societal Challenges and Needs}

Societal challenges such as climate change adaptation, poverty alleviation, food security, post conflict nation building, and tenure security all have a land footprint. Land has been viewed as the key driver for sustainable development. Therefore, its effective management will contribute to meet the aforementioned challenges and needs towards sustainable development. Though the focus of this research is on food security, and more specifically food productivity, the findings have further impacted on the other societal challenges and needs.

Chapters Three and Four develop innovative land administration processes that may assist in land management activities that are geared towards meeting the identified societal needs and challenges. In Chapter Three, the Participatory Land Administration (PLA) approach developed can be used to collect land information to support other activities, such as large-scale land acquisitions, disaster risk management, and post conflict nation building, with the goal of land tenure security. PLA may also aid with economic and infrastructure development and increasing investments in property by providing land documents to aid in the procurement of loans for property investments within the legal framework. This further contributes to food security, as farmers are more likely to invest in their farms when they are more tenure secure. With scaling up, this thesis showed that the land administration process can cost as Iow as EUR1. In Chapter Four, the land valuation approach developed does not only apply to rural customary lands and land consolidation. This land valuation approach is applicable for large-scale land acquisitions, by the government or by private entities, especially in areas without land markets. This will ensure that the values arrived at bear close resemblance to the market value. Furthermore, the land valuation approach may be used by the government for the fair assessment of taxes and the payment of fair and adequate compensation for compulsory land acquisition.

\subsubsection{To the Areas of Interest in Ghana}

This work developed a land consolidation approach for rural customary lands in Sub-Saharan Africa, using three areas in Ghana as the area of interest. Chapter Two identified the factors that need to be addressed in order to develop a land consolidation approach for customary lands. Here three areas of interest were selected in Ghana, based on the agro-ecological characteristics, the types of crops grown, and the land tenure system. The first two bases of selection were chosen because of their commonalities in the three areas of interest, however, the land tenure system was chosen because of its variety in the three areas. The findings of Chapter Two demonstrated that all three tenure types have common underlying basic principles, therefore, one area of interest was adequate for the remainder of the work. Nanton was the 
area of interest chosen for the remainder of the work, because it has the most complex land tenure structure among the three (Figure 6). This implies that the results of this work can be directly applied in Nanton. In the remaining two areas of interest the results need to be adjusted according to the complexity of the land tenure system. The results of this work can be further extrapolated to other areas of Ghana with skin, family, or Tindana lands. However, this work did not cover stool lands as they have similar land tenure characteristics as skin lands as shown in Chapter Two. Therefore, minimum adjustments would be expected to be made to apply the results on stool lands.

Furthermore, cases from the Netherlands, Lithuania, and Rwanda are useful for the areas of interest and Ghana as a whole, especially regarding the evolution of land consolidation approaches and land management activities in general.

\subsection{Limitations of the Study}

Being partly a socially oriented research, social dynamic unforeseen events in the study areas influenced this study. Throughout this study, the simmering and lingering historical tensions in some of the study areas caused a few issues. The first is the lingering tensions between the Tindana and the Tongo-raan (Paramount Chief of Talensi Traditional Area where Tongo lies), that has brewed from historical struggles over the land, which was first shown when the pilot survey began, in the decision over which traditional leader should be seen first. This was however diffused by following the longstanding traditional protocol. The second limitation has to do with the passing of traditional leaders. During the pilot and first fieldwork, the late Nanton-Na and his secretary (the Prince of Nanton, also the head of the Nanton Customary Land Secretariat) expressed a lot of interest in the mapping and consolidation of their farmlands and saw promise in the project. However, during the second fieldwork, the Nanton-Na had passed, and the skin was in the hands of the regent, the Crown Prince of Nanton (Boafo, 2017; Ghanaweb, 2016; Kombat, 2016). With the accounts of the landholdings in the traditional area still being accounted for, as well as some chieftaincy succession tensions in the area, it was not possible for the land reallocation to be attempted on the whole area of interest. Hence it was attempted for five of the forty-two families in the area of interest, with their senior members and concerned farmers present.

\subsection{Future Research Prospects}

This work described how to adapt the relevant factors that need to be addressed in order to undertake responsible land consolidation on SubSaharan Africa's customary lands, using Ghana as a study country. In terms of the work as a whole, a comparative study can be undertaken on other SSA countries' rural customary lands to further understand the differences, in terms of the requirements of land consolidation. In addition, future work should focus 
on further developing land valuation and land reallocation approaches by automating them using Computer Assisted Mass Appraisal (CAMA) systems with GIS, and Spatial Decision Support Systems (SDSS) respectively. This is because the processes developed in this thesis were generalised processes of processes that exist in other regions of the world.

The valuation approach was developed in the rural farming context, it can therefore also be developed further looking at urban land to put it in a broader context. This will further deepen and enrich the use of market information in the valuation of urban lands, especially for slum areas for non-market values. Furthermore, as shown in Chapter Two, customary lands are independently managed in each community, save for the national legal framework that tries to harmonise their management. This means that a single land consolidation approach will not fit the whole country. Further research should therefore be conducted into the legal framework of Ghana, vis a vis land consolidation in order to develop an integrated, flexible, and inclusive framework for customary lands towards land consolidation.

Further research also needs to be done in the implementation, through active research in the conduct of a pilot land consolidation process in the customary areas, to further ascertain the limitations that the approaches have in other areas. This in tandem with the scaling up the approach by further establishing workflows that will enable the testing of the approach with a wider coverage. 


\section{Bibliography}

Abubakari, Z. (2015). Investigating the Feasibility of Land Consolidation in the Customary Areas of Ghana (MSc Thesis). Enschede: University of Twente - ITC.

Abubakari, Z., Van der Molen, P., Bennett, R., \& Kuusaana, E. D. (2016). Land consolidation, customary lands, and Ghana's Northern Savannah Ecological Zone: An evaluation of the possibilities and pitfalls. Land Use Policy, 54, 386-398.

Abunyewa, A. A., Osei, C., Asiedu, E. K., \& Safo, E. Y. (2007). Integrated Manure and Fertilizer Use, Maize Production and Sustainable Soil Fertility in Sub Humid Zone of West Africa. Journal of Agronomy, 6(2), 302-309.

AfDB. (2016). Land Tenure Regularization in Rwanda: Good Practices in Land Reform - Case Study. Abijan. Retrieved from https://www.afdb.org/fileadmin/uploads/afdb/Documents/Publications/a nrc/AfDB_RwandaLandReform_FA.pdf

Akkaya Aslan, S. T., Kirmikil, M., Gündoğdu, K. S., \& Arici, I. (2018). Reallocation model for land consolidation based on landowners' requests. Land Use Policy, 70, 463-470. https://doi.org/10.1016/j.landusepol.2017.11.028

Akrofi, E. O., \& Whittal, J. (2014). A precedent-setting case of allodial ownership of customary land in Ghana. In AfricaGEO - Developing Geomatics for Africa. Cape Town: CONSAS Conference.

Akudugu, M. A., Guo, E., \& Dadzie, S. K. (2012). Adoption of Modern Agricultural Production Technologies by Farm Households in Ghana: What Factors Influence their Decisions? Journal of Biology, Agriculture and Healthcare, 2(3).

Ali, D. A., Deininger, K. W., \& Ronchi, L. (2015). Costs and benefits of land fragmentation: evidence from Rwanda (1 No. 1). Washington, DC.

Almirall, E., \& Wareham, J. (2011). Living Labs: arbiters of mid- and groundlevel innovation. Technology Analysis \& Strategic Management, 23(1), 87-102. https://doi.org/10.1080/09537325.2011.537110

Anim-Odame, W. K. (2011). Compulsory Acquisition and Compensation in Ghana: Principles and Practice. American Real Estate Society Conference. Seattle-Washington, USA: American Real Estate Society.

Anna, B., \& Adrianna, K. (2009). Influence of Soil Conditions on Landscape Shaping in Rural Areas. Natural and Cultural Transformation of Landscape, 3, 67-82.

Ansoms, A., Verdoodt, A., \& Ranst, E. Van. (2008). The Inverse Relationship between Farm Size and Productivity in Rural Rwanda (IOB Discussion papers No. 9). Antwerpen. Retrieved from https://ideas.repec.org/p/iob/dpaper/2008009.html

Arko-Adjei, A. (2011). Adapting Land Administration to the Institutional Framework of Customary Tenure (PhD Thesis). Delft: Delft University of 
Technology.

Arnstein, S. (1969). A Ladder of Citizen Participation. Journal of the American Institute of Planners, 35(4), 216-224.

Arruda Filho, N. de P. (2017). The agenda 2030 for responsible management education: An applied methodology. The International Journal of Management Education, 15(2), 183-191. https://doi.org/10.1016/j.ijme.2017.02.010

Arsanjani, J. J., \& Vaz, E. (2015). An assessment of a collaborative mapping approach for exploring land use patterns for several European metropolises. International Journal of Applied Earth Observation and Geoinformation, 35, 329-337.

Asiama, K. O. (2015). Governance in Resettlement from Compulsory Land Acquisition and Resettlement: A Case Study of the Bui Dam Project (MSc Thesis). Enschede: University of Twente.

Asiama, K. O., Bennett, R. M., \& Zevenbergen, J. A. (2015). Participatory Land Administration: A New Vista towards Responsible Land Consolidation in Customary Lands? In Joint Workshop FIG Commission 3 \& Commission 7: Crowdsourcing of Land Information. Malta: International Federation of Surveyors (FIG).

Asiama, K. O., Bennett, R. M., \& Zevenbergen, J. A. (2017a). Land consolidation on Ghana's rural customary lands: Drawing from The Dutch, Lithuanian and Rwandan experiences. Journal of Rural Studies, 56, 8799. https://doi.org/10.1016/j.jrurstud.2017.09.007

Asiama, K. O., Bennett, R. M., \& Zevenbergen, J. A. (2017b). Participatory Land Administration on Customary Lands: A Practical VGI Experiment in Nanton, Ghana. ISPRS International Journal of Geo-Information, 6(7), 186. https://doi.org/10.3390/ijgi6070186

Asiama, K. O., Bennett, R. M., \& Zevenbergen, J. A. (2018). Participation, Innovative Approaches and Customary Cadastres: A Practical VGI Experiment in Nanton, Ghana. In Annual Word Bank Conference on Land and Poverty. Washington, DC: The World Bank. Retrieved from https://www.conftool.com/landandpoverty2018/index.php/08-05-

Asiama-128_paper.pdf?page $=$ downloadPaper\&filename $=08-05-$ Asiama128_paper.pdf\&form_id=128\&form_version=final

Asiama, K. O., Bennett, R. M., Zevenbergen, J. A., \& Asiama, S. O. (2018). Land valuation in support of responsible land consolidation on Ghana's rural customary lands. Survey Review, 50(361), 288-300. https://doi.org/10.1080/00396265.2018.1467672

Asiama, K. O., Bennett, R., \& Zevenbergen, J. A. (2017c). Land Consolidation for Sub-Saharan Africa's Customary Lands - The Need for Responsible Approaches. American Journal of Rural Development, Vol. 5, 2017, Pages 39-45, 5(2), 39-45. https://doi.org/10.12691/AJRD-5-2-2

Asiama, K. O., Lengoiboni, M. N., \& Van der Molen, P. (2015). Compulsory Land Acquisition and Resettlement on Customary Lands in Ghana - A 
Governance Perspective. In LANDac International Conference on Land Governance for Equitable and Sustainable Development. Utrecht: LANDac.

Asiama, K. O., Lengoiboni, M., \& Van der Molen, P. (2017). In the Land of the Dammed: Assessing Governance in Resettlement of Ghana's Bui Dam Project. Land, 6(4), 80. https://doi.org/10.3390/land6040080

Asiama, S. O. (1981). Chieftaincy - a Transcient Institution in Urban Ghana? Sociologus, 31(3), 122-140.

Asiama, S. O. (2002). Comparative Study of Land Administration Systems. Retrieved

from http://www.ibrarian.net/navon/paper/COMPARATIVE_STUDY_OF_LAND _ADMINISTRATION_SYSTEMS.pdf?paperid $=1140240$

Asiama, S. O. (2004). Current Changes in Customary/Traditional Land Delivery Systems in Sub-Saharan African Cities - Ghana. In M. Mattingly \& A. Durand-Lasserve (Eds.), Housing the Poor through African NeoCustomary Land Delivery Systems (pp. 41-57). London: DFID.

Aslan, S. T. A., Gundogdu, K. S., \& Arici, I. (2007). Some metric indices for the assessment of land consolidation projects. Pakistan Journal of Biological Sciences: PJBS, 10(9), 1390-7. Retrieved from http://www.ncbi.nlm.nih.gov/pubmed/19069948

Awuah, K. G. B., Proverbs, D., Lamond, J., \& Gyamfi-Yeboah, F. (2016). An Evaluation of Property Valuation Practice in Sub-Saharan Africa: A Case Study of Ghana. London: Royal Institute of Chartered Surveyors (RICS). Retrieved from www.rics.org/research

Bagdonavicius, A., \& Kasperavicius, R. (2003). Development of Land Administration - Lithuanian Experience. In FIG Working Week Development of Land Administration - Lithuanian Experience. Paris: FIG. Retrieved from https://www.fig.net/resources/proceedings/fig_proceedings/fig_2003/T S_4/TS4_5_Bagdonavicius_Kasperavicius.pdf

Barry, M., \& Augustinus, C. (2015). Property Theory, Metaphors and the Continuum of Land Rights. Nairobi: UN-Habitat.

Basiouka, S., \& Potsiou, C. (2012). VGI in Cadastre: a Greek experiment to investigate the potential of crowd sourcing techniques in Cadastral Mapping. Survey Review, 44(325), 153-161.

Basiouka, S., \& Potsiou, C. (2014). The volunteered geographic information in cadastre: perspectives and citizens' motivations over potential participation in mapping. GeoJournal, 79, 343-355.

Baudron, F., Sims, B., Justice, S., \& Kahan, D. (2015). Re-examining appropriate mechanization in Eastern and Southern Africa: two-wheel tractors, conservation agriculture, and private sector involvement. Food Security. Retrieved from http://link.springer.com/article/10.1007/s12571-015-0476-3

Beinat, E. (1997). Value Functions for Environmental Management. Dordrecht: 
Springer Netherlands. https://doi.org/10.1007/978-94-015-8885-0

Bell, K. C. (2007). Good Governance in Land Administration. Responding to the Global Agenda - FIG Working Paper.

Benin, S., \& Nin-Pratt, A. (2016). Intertemporal Trends in Agricultural Productivity. In S. Benin (Ed.), Agricultural Productivity in Africa: Trends, Patterns, and Determinants. Washington, DC: International Food Policy Research Institute. Retrieved from http://ebrary.ifpri.org/utils/getfile/collection/p15738coll2/id/130468/file name/130679.pdf

Bennett, R., \& Alemie, B. K. (2016). Fit-for-purpose land administration: lessons from urban and rural Ethiopia. Survey Review, 48(346), 11-20. https://doi.org/10.1080/00396265.2015.1097584

Bennett, R., Rajabifard, A., Williamson, I., \& Wallace, J. (2012). On the need for national land administration infrastructures. Land Use Policy, 29(1), 208-219. https://doi.org/10.1016/j.landusepol.2011.06.008

Bennett, R., Rockson, G., Haile, S. A., Nasr, J., \& Groenendijk, L. (2015). Land Administration for Food Security. In J. A. Zevenbergen, W. T. De Vries, \& R. Bennett (Eds.), Advances in Responsible Land Administration (pp. 3752). Boca Raton: CRC.

Bennett, R., Yimer, F., \& Lemmen, C. (2015). Toward Fit-for-Purpose Land Consolidation. In Advances in Responsible Land Administration (pp. 163182). Boca Raton: CRC Press. https://doi.org/10.1201/b18988-14

Benthem, R. J. (1969). Changing the Countryside by Land Consolidation. Biological Conservation, 1(3), 209-212.

Bentley, J. W. (1990). Wouldn't you like to have all of your land in one place? land fragmentation in Northwest Portugal. Human Ecology, 18(1).

Biitir, S. B., \& Nara, B. B. (2016). The role of Customary Land Secretariats in promoting good local land governance in Ghana. Land Use Policy, 50, 528-536. https://doi.org/10.1016/j.landusepol.2015.10.024

Binns, B. O. (1950). The Consolidation of Fragmented Agricultural Holdings (FAO Agricultural Series No. 11). Rome: Food and Agriculture Organization.

Binns, B. O. (1953). Cadastral Surveys and Records of Rights in Land. Rome.

Binswanger, H. P., \& Pingali, P. (1989). Technological priorities for farming in Sub-Saharan Africa. Journal of International Development, 1(1), 46-65.

Bishr, M., \& Kuhn, W. (2007). Geospatial Information Bottom-Up: A Matter of Trust and Semantics. In S. I. Fabrikant \& M. Wachowicz (Eds.), The European Information Society (pp. 365-387). Berlin, Heidelberg: Springer Berlin Heidelberg. https://doi.org/10.1007/978-3-540-72385-1

Bizimana, C., Nieuwoudt, W., \& Ferrer, S. (2004). Farm size, land fragmentation and economic efficiency in southern Rwanda. Agrekon, 43(2).

Blarel, B., Hazell, P., Place, F., \& Quiggin, J. (1992). The Economics of Farm Fragmentation: Evidence from Ghana and Rwanda. World Bank Economic 
Review, 6(2).

Boafo, O. (2017). Nanton: Sub chief duped after attempts to 'buy' kingship. Ghana: Ultimate 106.9fm. Retrieved from http://ultimatefmonline.com/2017/09/09/sub-chief-duped-attemptsbuy-nanton-kingship/

Bourgon, J. (2007). Responsive, Responsible, Respected Government: Towards a New Public Administration Theory. International Review of Administration Sciences, 73(1), 7-26.

Boydell, S. (2015). Demystifying the Valuation of Customary Land. In World Bank Conference on Land and Poverty2. Washington DC: The World Bank. Retrieved from https://customarylandsolutions.files.wordpress.com/2016/05/boydell2015-demystifying-the-valuation-of-customary-land-world-bank-landpoverty-conference.pdf

Branković, S., Parezanović, L., \& Simović, D. (2015). Land consolidation appraisal of agricultural land in the GIS environment. Geodetski Vestnik, 59(02), 320-334. https://doi.org/10.15292/geodetskivestnik.2015.02.320-334

Brotherhood, R. W. (1964). The Land Consolidation Service of the Land Registry - History and Function of the Land Registry in the Netherlands. Retrieved from http://www.krcmar.ca/sites/default/files/1965_Fall_The Land Consolidation Service_0.pdf

Bullard, R. (2007). Land Consolidation and Rural Development (Papers in Land Management No. 10). Chelmsford.

Burns, T., \& Haile, S. A. (2015). Costing and Financing of Land Administration Services (CoFLAS) in Developing Countries (Draft). Nairobi. Retrieved from http://www.gltn.net/index.php/publications/publications/send/2gltn-documents/2214-costing-and-financing-of-land-administrationservices-coflas-in-developing-countries

Byamugisha, F. (2013). Securing Africa's land for shared prosperity: a program to scale Up reforms and investments. Retrieved from https://books.google.nl/books?hl=en\&lr=\&id=nVEDAAAAQBAJ\&oi=fnd\& $\mathrm{pg}=\mathrm{PP} 2 \& \mathrm{dq}=$ rwanda + land + consolidation + and + land + tenure + regularizat ion\&ots $=$ BK81zTrflJ\&sig=305WEfSW1e4IMojFhkVGK9H02h8

Byamugisha, F. F. K., Burns, T., Evtimov, V., Santana, S., \& Zulsdorf, G. (2012). Appraising Investments and Technologies for Surveying and Mapping for Land Administration in Sub-Saharan Africa (Report). Washington DC: World Bank.

Cay, T., Ayten, T., \& Iscan, F. (2010). Effects of different land reallocation models on the success of land consolidation projects: Social and economic approaches. Land Use Policy, 27(2), 262-269. https://doi.org/10.1016/j.landusepol.2009.03.001

Cay, T., \& Iscan, F. (2011). Fuzzy expert system for land reallocation in land consolidation. Expert Systems with Applications, 38(9), 11055-11071. 
Cay, T., \& Uyan, M. (2013). Evaluation of reallocation criteria in land consolidation studies using the Analytic Hierarchy Process (AHP). Land Use Policy, 30(1), 541-548. https://doi.org/10.1016/j.landusepol.2012.04.023

Chimhowu, A., \& Woodhouse, P. (2006). Customary vs Private Property Rights? Dynamics and Trajectories of Vernacular Land Markets in Sub-Saharan Africa. Journal of Agrarian Change, 6(3), 346-371. https://doi.org/10.1111/j.1471-0366.2006.00125.x

Clark, C. (1973). The Value of Agricultural Land. New York: Pergamon Press.

Coelho, J. C., Portela, J., \& Pinto, P. A. (1996). A social approach to land consolidation schemes. Land Use Policy, 13(2).

Coldham, S. (1978). The Effect of Registration of Title Upon Customary Land Rights in Kenya. Journal of African Law, 22(2).

Coldham, S. (1979). Land Tenure Reform in Kenya: The Limits of the Law. The Journal of Modern African Studies1, 17(4).

Cotula, L., Chauveau, J.-P., Cissé, S., \& Colin, J.-P. (2007). Changes in customary land tenure systems in Africa. Rome: FAO and IIED. Retrieved from http://dlc.dlib.indiana.edu/dlc/handle/10535/6103

Crescenzi, R., \& Rodríguez-Pose, A. (2011). Reconciling top-down and bottomup development policies. Environment and Planning A, 43(4), 773-780. https://doi.org/10.1068/a43492

Crommelinck, S., Bennett, R., Gerke, M., Nex, F., Yang, M., \& Vosselman, G. (2016). Review of Automatic Feature Extraction from High-Resolution Optical Sensor Data for UAV-Based Cadastral Mapping. Remote Sensing, 8(8), 689. https://doi.org/10.3390/rs8080689

Culas, R. J. (2012). Technological Change and Productivity Growth for Food Security: The Case of Shifting Cultivation and the REDD Policy. In M. A. Jones \& F. E. Hernandez (Eds.), Food Security, Qulaity Management, Issues and Economic Implications. Hauppauge, NY, USA: Nova Science Publishers, Inc.

Dadson, J. A. (1971). Farm-size and Modernisation of Agriculture in Ghana. In I. M. Ofori (Ed.), Factors of Agricultural Growth in West Africa (pp. 193202). Legon: University of Ghana.

Daugaliene, V. (2004). Preparation for Land Consolidation in Lithuania. In P. Van der Molen \& C. Lemmen (Eds.), Modern Land Consolidation. Fredericksberg: International Federation of Surveyors (FIG).

De Leeuw, J., Said, M., Ortegah, L., Nagda, S., Georgiadou, Y., \& DeBlois, M. (2011). An Assessment of the Accuracy of Volunteered Road Map Production in Western Kenya. Remote Sensing, 3(12), 247-256. https://doi.org/10.3390/rs3020247

De Vries, W. T., Bennett, R. M., \& Zevenbergen, J. A. (2015a). Neo-cadastres: innovative solution for land users without state based land rights, or just reflections of institutional isomorphism? Survey Review, 47(342), 220229. 
De Vries, W. T., Bennett, R. M., \& Zevenbergen, J. A. (2015b). Toward Responsible Land Administration. In J. A. Zevenbergen, R. M. Bennett, \& W. T. De Vries (Eds.), Advances in Responsible Land Administration (pp. 3-14). Boca Raton: CRC.

Deininger, K., Ali, D. A., Holden, S., \& Zevenbergen, J. (2008). Rural Land Certification in Ethiopia: Process, Initial Impact, and Implications for Other African Countries. World Development, 36(10), 1786-1812. https://doi.org/10.1016/j.worlddev.2007.09.012

Demetriou, D. (2014). The Development of an Integrated Planning and Decision Support System (IPDSS) for Land Consolidation (PhD Thesis). Leeds: University of Leeds/Springer.

Demetriou, D. (2016a). A spatially based artificial neural network mass valuation model for land consolidation. Environment and Planning B: Planning and Design. https://doi.org/10.1177/0265813516652115

Demetriou, D. (2016b). The assessment of land valuation in land consolidation schemes: The need for a new land valuation framework. Land Use Policy, 54, 487-498. https://doi.org/10.1016/j.landusepol.2016.03.008

Demetriou, D., See, L., \& Stillwell, J. (2013). A Parcel Shape Index for Use in Land Consolidation Planning. Transactions in GIS, 17(6), 861-882. https://doi.org/10.1111/j.1467-9671.2012.01371.x

Demetriou, D., Stillwell, J., \& See, L. (2012). Land consolidation in Cyprus: Why is an Integrated Planning and Decision Support System required? Land Use Policy, 29(1), 131-142.

Demetriou, D., Stillwell, J., \& See, L. (2013). A new methodology for measuring land fragmentation. Computers, Environment and Urban Systems, 39, 71-80. https://doi.org/10.1016/j.compenvurbsys.2013.02.001

Demir, H., Gur, M., \& Cagdas, V. (2002). Land Consolidation, Valuation and Cadastre. In FIG XXII International Congress. Washington, DC. Retrieved from

https://www.fig.net/resources/proceedings/fig_proceedings/fig_2002/Js 14/JS14_demir_gur_cagdas.pdf

Diao, X., Cossar, F., Houssou, N., \& Kolavalli, S. (2014). Mechanization in Ghana: Emerging demand, and the search for alternative supply models. Food Policy, 48, 168-181.

Dudzińska, M., \& Kocur-Bera, K. (2014). Land consolidation as the driving force behind ecological and economic development of rural areas. In The 9th International Conference "Environmental Engineering 2014." Vilnius, Lithuania, Lithuania: Vilnius Gediminas Technical University Press "Technika."

Dyli, J., Bennett, R. M., \& Martinez, J. A. (2016, August). Apps for Land Administration: Exploring the Needs, Options and Future Developments. GIM International, 33-35. Retrieved from https://www.giminternational.com/magazine/august-2016

Eastwood, R., Lipton, M., \& Newell, A. (2010). Farm Size. In P. Pingali \& R. E. 
Evenson (Eds.), Agricultural Economics (pp. 3324-3394). Burlington: Elsevier.

Edmead, N. (2010). Open Title - a Low Cost Tool for Inventorying Property Rights - Experiences from Ghana. In FIG Congress 2010 Facing the Challenges - Building the Capacity. Sydney: FIG. Retrieved from https://www.fig.net/resources/proceedings/fig_proceedings/fig2010/pa pers/fs04f/fs04f_edmead_4037.pdf

Ehwi, R. J., \& Asante, L. A. (2016). Ex-Post Analysis of Land Title Registration in Ghana Since 2008 Merger. SAGE Open, 6(2), 215824401664335. https://doi.org/10.1177/2158244016643351

Ekbäck, P. (2013). Institutional Design for Public Decisions on Land Use Alterations, Acquisition of Property Rights, and Compensation. In E. Hepperle, R. Dixon-Gough, V. Maliene, R. Mansberger, J. Paulsson, \& A. Pödör (Eds.), Land Management: Potential, Problems and Stumbling Blocks Landmanagement2 (pp. 67-85). Zurich: European Academy of Land Use and Development.

Elias, T. O. (1956). The Nature of African Customary Law. Manchester: Manchester United Press.

Enemark, S. (2005). Understanding the Land Management Paradigm. Innovative Technologies for Land Administration. Madison, Wisconsin, USA: FIG.

Enemark, S., Bell, K. C., Lemmen, C., \& McLaren, R. (2014). Fit for Purpose Land Administration. Copenhagen: The World Bank and the International Federation of Surveyors.

Enemark, S., McLaren, R., \& Lemmen, C. (2016). Fit-for-Purpose Land Administration - Guiding Principles for Country Implementation. Nairobi: UN-Habitat. Retrieved from http://www.gltn.net/index.php/publications/publications/download/2gltn-documents/2332-fit-for-purpose-land-administration-guidingprinciples-for-country-implementation

Ertunç, E., Çay, T., \& Haklı, H. (2018). Modeling of reallocation in land consolidation with a hybrid method. Land Use Policy, 76, 754-761. https://doi.org/10.1016/J.LANDUSEPOL.2018.03.003

Fang, Y., Shi, K., \& Niu, C. (2016). A comparison of the means and ends of rural construction land consolidation: Case studies of villagers' attitudes and behaviours in Changchun City, Jilin province, China. Journal of Rural Studies, 47, 459-473. https://doi.org/10.1016/j.jrurstud.2016.04.007

FAO. (2003). FAO Land Tenure Studies 6 - The Design of Land Consolidation Projects in Central and Eastern Europe 2003. Rome: Food and Agriculture Organization.

FAO. (2008). Opportunities to Mainstream Land Consolidation in Rural Development Programmes of the European Union (FAO Land Tenure Policy Series No. 2). Rome: Food and Agriculture Organisation.

FAO. (2012). Voluntary Guidelines on the Responsible Governance of Land, 
Fisheries, and Forests in the Context of National Food Security. Rome: Food and Agriculture Organisation.

FAO. (2017). Regional Overview of Food Security and Nutrition in Africa 2017 (The food s). Retrieved from http://www.fao.org/3/a-i7967e.pdf

FAO. (2018). The State of Food Security and Nutrition around the World. Retrieved October 11, 2018, from http://www.fao.org/state-of-foodsecurity-nutrition/en/

Fast, V., \& Rinner, C. (2014). A Systems Perspective on Volunteered Geographic Information. ISPRS International Journal of Geo-Information, 3(4), 1278-1292. https://doi.org/10.3390/ijgi3041278

Fenoaltea, S. (1976). Risk, transaction costs, and the organization of medieval agriculture. Explorations in Economic History, 13(2), 129-151.

Geiger, D., \& Schader, M. (2014). Personalized task recommendation in crowdsourcing information systems - Current state of the art. Decision Support Systems, 65, 3-16.

Genus, A., \& Iskandarova, M. (2018). Responsible innovation: its institutionalisation and a critique. Technological Forecasting and Social Change, 128, 1-9. https://doi.org/10.1016/j.techfore.2017.09.029

Ghanaweb. (2016). Paramount Chief of the Nanton Traditional Area is dead. Retrieved December 18, 2018, from https://www.ghanaweb.com/GhanaHomePage/NewsArchive/ParamountChief-of-the-Nanton-Traditional-Area-is-dead-467502

Ghawana, T., Bennett, R., Oliveira, J., Zevenbergen, J. A., Paixão, S., \& Carneiro, A. F. T. (2016). Applying the Knowledge Innovation Value Chain Model to Land Administration Research. In FIG Working Week 2016 Recovery from Disaster. Christchurch, New Zealand: International Federation of Surveyors (FIG). Retrieved from https://www.fig.net/resources/proceedings/fig_proceedings/fig2016/pa pers/ts06a/TS06A_ghawana_bennett_et_al_7969_abs.pdf

GLTN. (2017). Guide to the Valuation of Unregistered Lands - Final Draft. Nairobi. Retrieved from https://www.gltn.net/index.php/publications/publications/download/2gltn-documents/2352-final-draft-guide-to-the-valuation-ofunregistered-lands

Gómez-Barrón, J.-P., Manso-Callejo, M.-Á., Alcarria, R., \& Iturrioz, T. (2016). Volunteered Geographic Information System Design: Project and Participation Guidelines. ISPRS International Journal of Geo-Information, 5(7), 108. https://doi.org/10.3390/ijgi5070108

Gonzalez, X. P., Alvarez, C. J., Crecente, R., Gonzalez, X. P., Alvarez, C. J., \& Crecente, R. (2004). Evaluation of land distributions with joint regard to plot size and shape. Agricultural Systems, 82(1), 31-43. Retrieved from http://econpapers.repec.org/article/eeeagisys/v_3a82_3ay_3a2004_3ai _3a1_3ap_3a31-43.htm

Goodchild, M. F. (2007a). Citizens as sensors: The world of volunteered 
geography. GeoJournal, 69(4), 211-221.

Goodchild, M. F. (2007b). Citizens as voluntary sensors: spatial data infrastructure in the world of Web 2.0. International Journal of Spatial Data Infrastructures Research, 2. https://doi.org/http://citeseerx.ist.psu.edu/viewdoc/summary?doi=10.1 .1 .162 .2017

Goodfellow, T. (2014). Rwanda's Political Settlement and the Urban Transition: Expropriation, Construction and Taxation in Kigali. Journal of Eastern African Studies, 8(2), 311-329.

Grossman, M. R., \& Brussard, W. (1988). The Land Shuffle: Reallocation of Agricultural Land under the Land Development Law in the Netherlands. California Western International Law Journal, 18(2), 212-285.

Haklı, H., Uğuz, H., \& Çay, T. (2016). A new approach for automating land partitioning using binary search and Delaunay triangulation. Computers and Electronics in Agriculture, 125, 129-136. https://doi.org/10.1016/j.compag.2016.05.006

Haldrup, N. O. (2015). Agreement based land consolidation - In perspective of new modes of governance. Land Use Policy, 46, 163-177.

Hantrais, L. (1996). Comparative Research Methods. In L. Hantrais \& S. Mangen (Eds.), Cross National Research Papers (Vol. 1). Loughborough: Cross National Research Group.

Hardin, G. (1968). The Tragedy of the Commons. Science, 162, 1243-1248. https://doi.org/10.2307/1724745

Hartvigsen, M. (2013). Land Reform and Land Consolidation in Central and Eastern Europe after 1989 and its outcome in form of farm structures and land fragmentation (FAO Land Tenure Working Paper No. 24). Rome.

Hartvigsen, M. (2014). Land mobility in a central and eastern European land consolidation context. Nordic Journal of Surveying and Real Estate Research, 10(1), 23-46.

Hartvigsen, M. (2015a). Experiences with land consolidation and land banking in Central and Eastern Europe after 1989 (FAO Land Tenure Working Paper No. 26). Rome. Retrieved from http://www.fao.org/nr/tenure/infores/Ittpapers/en/

Hartvigsen, M. (2015b). Integrated Voluntary Land Consolidation - A Third Model for Land Consolidation and Land Banking in Central And Eastern Europe. Land Tenure Journal, 1. Retrieved from http://www.fao.org/3/ai5244tre.pdf

Hartvigsen, M. (2015c). Land Reform and Land Consolidation in Central and Eastern Europe after 1989 - Experiences and perspectives (PhD Thesis). Aarlborg: Aalborg University.

Headey, D., \& Jayne, T. S. (2014). Adaptation to land constraints: Is Africa different? Food Policy, 48, 18-33. https://doi.org/10.1016/j.foodpol.2014.05.005

Heide, C. van der, Silvis, H., \& Heijman, W. (2011). Agriculture in the 
Netherlands: its recent past, current state and perspectives. In Applied Studies in Agribusiness and Commerce (pp. 23-28). Budapest: Agroinform Publishing House. Retrieved from http://ageconsearch.umn.edu/bitstream/104639/2/3_Heide_Agriculture Apstract.pdf

Heisey, P. W., \& Mwangi, W. (1996). Fertilizer Use and Maize Production in Sub-Saharan Africa (CIMMYT Economics Working Paper No. 96-01). Mexico, D. F.

Heltberg, R. (1998). Rural market imperfections and the farm sizeproductivity relationship: Evidence from Pakistan. World Development, 26(10), 1807-1826. https://doi.org/10.1016/S0305-750X(98)00084-9

Hiironen, J., \& Riekkinen, K. (2016). Agricultural impacts and profitability of land consolidations. Land Use Policy, 55, 309-317. https://doi.org/10.1016/j.landusepol.2016.04.018

Holden, S. T., \& Otsuka, K. (2014). The roles of land tenure reforms and land markets in the context of population growth and land use intensification in Africa. Food Policy, 48, 88-97.

Houmy, K., Clarke, L. J., Ashburner, J. E., \& Kienzle, J. (2013). Agricultural Mechanization in Sub-Saharan Africa. Rome: FAO. Retrieved from http://www.fao.org/docrep/018/i3349e/i3349e.pdf

Houssou, N., \& Chapoto, A. (2014). The Changing Landscape of Agriculture in Ghana: Drivers of Farm Mechanization and Its Impacts on Cropland Expansion and Intensification (IFPRI Discussion Paper No. 01392). Washington, DC; Accra.

Hudson-Smith, A., Crooks, A., Gibin, M., Milton, R., \& Batty, M. (2009). NeoGeography and Web 2.0: concepts, tools and applications. Journal of Location Based Services, 3(2), 118-145.

ILRI. (1960). A Priority Scheme for Duth Land Consolidation Projects (No. 6). Wageningen.

Imam, H. A. (2015). State and Non-State Actors in Land Appropriation: Colonial Land Policy and the role of the Tindana in Northern Ghana. Research on Humanities and Social Sciences, 5(4).

Innes, J. E., \& Booher, D. E. (2004). Reframing Public Participation: Strategies for the 21st Century. Planning Theory \& Practice, 5(4), 419-436.

Jacoby, E. H. (1959). Land Consolidation in Europe. Wageningen: International Institute for Land Reclamation and Improvement.

Jones-Casey, K., \& Knox, A. (2011). Ghana's Land Administration at a Crossroads. Retrieved from https://agriknowledge.org/downloads/Or9673801

Jürgenson, E. (2016). Land reform, land fragmentation and perspectives for future land consolidation in Estonia. Land Use Policy, 57, 34-43. https://doi.org/10.1016/j.landusepol.2016.04.030

Kakraba-Ampeh, M., \& Yeboah, E. (2016). Scaling Up Community Based Tools to Secure Land Rights; Lessons from the Cocoa Belt in Ghana. Kumasi. 
Retrieved from http://Irmc-ghana.org/index.php/publications

Kalabamu, F. T. (2000). Land tenure and management reforms in East and Southern Africa - the case of Botswana. Land Use Policy, 17(4), 305319. https://doi.org/10.1016/S0264-8377(00)00037-5

Kalabamu, F. T. (2014). Divergent paths: Customary land tenure changes in Greater Gaborone, Botswana. Habitat International, 44, 474-481. https://doi.org/10.1016/j.habitatint.2014.09.007

Kapitango, D., \& Meijs, M. (2010). Land registration using aerial photography in Namibia: Costs and lessons. In K. Deininger, C. Augustinus, S. Enemark, \& P. Munro-Faure (Eds.), Innovations in Land Rights Recognition, Administration, and Governance (pp. 60-72). Washington, DC, DC: The World Bank. Retrieved from http://siteresources.worldbank.org/INTARD/Resources/3358071174581646324/InnovLandRightsRecog.pdf

Kasanga, K. R., \& Kotey, N. A. (2001). Land management in Ghana: Building on tradition and modernity.

Kathiresan, A. (2012). Farm Land Use Consolidation in Rwanda. Kigali. Retrieved http://www.minagri.gov.rw/fileadmin/user_upload/documents/agridocs/ Farm_Land_Use_Consolidation_in_Rwanda.pdf

Keenja, E., De Vries, W. T., Bennett, R. M., \& Laarakker, P. (2012). Crowd Sourcing for Land Administration: Perceptions within Netherlands Kadaster. In Knowing to manage the territory, protect the environment, evaluate the cultural heritage - FIG Working Week 2012. FIG.

Kidido, J. K., Ayitey, J. Z., Kuusaana, E. D., \& Gavu, E. K. (2015). Who is the rightful recipient of mining compensation for land use deprivation in Ghana? Resources Policy, 43, 19-27.

King, R., \& Burton, S. P. (1982). Land Fragmentation: Notes on a Fundamental Rural Spatial Problem. Progress in Human Geography, 6(4).

King, R., \& Burton, S. P. (1989). Land ownership values and rural structural change in Cyprus. Journal of Rural Studies, 5(3), 267-277.

Kludze, A. K. P. (1973). Ewe Law of Property. London: Sweet and Maxwell.

Knight, R. S. (2010). Statutory Recognition of Customary Land Rights in Africa. Rome: $\quad F A O$. Retrieved http://www.fao.org/docrep/013/i1945e/i1945e00.pdf

Kombat, E. (2016). Gunshots Rock Nanton Chief Enskinment. Retrieved December 18, 2018, from https://www.modernghana.com/news/723994/gunshots-rock-nantonchief-enskinment.html

Kuhlman, T., Koomen, E., Groen, J., \& Bouwman, A. (2003). Simulating Agricultural Land Use Change in the Netherlands. In Transition in Agriculture and Future Land Use Patterns. Wagegingen. Retrieved from http://www.feweb.vu.nl/gis/publications/docs/transition in agriculture_paper.pdf 
Kuusaana, E. D., \& Bukari, K. N. (2015). Land conflicts between smallholders and Fulani pastoralists in Ghana: Evidence from the Asante Akim North District (AAND). Journal of Rural Studies, 42, 52-62. https://doi.org/10.1016/j.jrurstud.2015.09.009

Kuusaana, E. D., \& Eledi, J. A. (2015). Customary land allocation, urbanization and land use planning in Ghana: Implications for food systems in the Wa Municipality. Land Use Policy, 48, 454-466. https://doi.org/10.1016/j.landusepol.2015.06.030

Land Title Registration Law, PNDCL 156 § (1986). Ghana.

Landmapp. (2016). Landmapp: Unlocking Land Value - Ghana. Retrieved January 25, 2017, from http://www.landmapp.net/ghana/

Lee, D. R., \& Sallee, G. T. (1970). A method of measuring shape. Geographical Review, 60, 555-63.

Lemmen, C. (2010). The Social Tenure Domain Model: A Pro Poor Land Tool (Vol. 52). Copenhagen: International Federation of Surveyors.

Lemmen, C., Jansen, L. J. M., \& Rosman, F. (2012). Informational and computational approaches to Land Consolidation. In FIG Working Week 2012 - Knowing to anage the territory, protect the environment, evaluate the cultural heritage. Rome: FIG. Retrieved from https://www.fig.net/resources/proceedings/fig_proceedings/fig2012/pa pers/ts02e/TS02E_lemmen_jansen_et_al_6049.pdf

Lemmen, C., \& Zevenbergen, J. A. (2010). First experiences with a highresolution imagery-based adjudication approach in Ethiopia. In $\mathrm{K}$. Deininger, C. Augustinus, S. Enemark, \& P. Munro-Faure (Eds.), Innovations in Land Rights Recognition, Administration, and Governance (pp. 96-104). Washington, DC, DC: The World Bank. Retrieved from http://siteresources.worldbank.org/INTARD/Resources/3358071174581646324/InnovLandRightsRecog.pdf

Lengoiboni, M., Bregt, A. K., \& Van der Molen, P. (2010). Pastoralism within land administration in Kenya-The missing link. Land Use Policy, 27(2), 579-588. https://doi.org/10.1016/j.landusepol.2009.07.013

Liedtke, C., Welfens, M. J., Rohn, H., \& Nordmann, J. (2012). LIVING LAB: user-driven innovation for sustainability. International Journal of Sustainability in Higher Education, 13(2), 106-118. https://doi.org/10.1108/14676371211211809

Lisec, A., Primožič, T., Ferlan, M., Šumrada, R., \& Drobne, S. (2014). Land owners' perception of land consolidation and their satisfaction with the results - Slovenian experiences. Land Use Policy, 38, 550-563. https://doi.org/10.1016/j.landusepol.2014.01.003

Liu, Z., Müller, M., Rommel, J., \& Feng, S. (2016). Community-based agricultural land consolidation and local elites: Survey evidence from China. Journal of Rural Studies, 47, 449-458. https://doi.org/10.1016/j.jrurstud.2016.06.021

Louwsma, M., \& Lemmen, C. (2015). Relevance of leased land in land 
consolidation. In From the Wisdom of the Ages to the Challenges of the Modern World. Sofia, Bulgaria: International Federation of Surveyors (FIG). Retrieved from https://www.fig.net/resources/proceedings/fig_proceedings/fig2015/pa pers/ts07i/TS07I_louwsma_lemmen_7597_abs.pdf

Louwsma, M., Van Beek, M., \& Hoeve, B. (2014). A New Approach: Participatory Land Consolidation. In Engaging the Challenges - Enhancing the Relevance - FIG Congress 2014. Kuala Lampur: FIG.

Mahabir, R., Stefanidis, A., Croitoru, A., Crooks, A., \& Agouris, P. (2017). Authoritative and Volunteered Geographical Information in a Developing Country: A Comparative Case Study of Road Datasets in Nairobi, Kenya. ISPRS International Journal of Geo-Information, 6(1), 24. https://doi.org/10.3390/ijgi6010024

Makana, N. E. (2009). Peasant Response to Agricultural Innovations: Land Consolidation, Agrarian Diversification and Technical Change. The Case of Bungoma District in Western Kenya, 1954-1960. Ufahamu: A Journal of African Studies, 35(1).

MASDAR. (2011). Project Appraisal Document on a Proposed Credit to the Republic of Ghana for the Land Administration Project - 2 (Vol. 58334$\mathrm{GH})$. The World Bank.

Masser, I., \& Williams, R. (1986). Learning from other countries. Norwich: Geo Books.

McLaren, R. (2011). Crowdsourcing support of land administration: a new, collaborative partnership between citizens and land professionals. RICS Research. London: RICS.

McLaren, R. (2013). Engaging the Land Sector Gatekeepers in Crowsourced Land Administration. In Conference on Land and Poverty. Washington DC: The World Bank.

McPherson, M. F. (1982). Land Fragmentation: a selected literature review. Development Discussion Papers, Harvard Institute for International Development, Harvard University, 4-8.

Migot-Adholla, S. E., Benneh, G., Place, F., \& Atsu, S. (1994). Land, Security of Tenure, and Productivity in Ghana. In J. W. Bruce \& S. Migot-Adholla (Eds.), Searching for Tenure Security in Africa (pp. 97-118). Washington, DC: The World Bank.

Migot-Adholla, S. E., Hazell, P., Blarel, B., \& Place, F. (1991). Indigenous land rights systems in sub-Saharan Africa : a constraint on productivity? The World Bank Economic Review, 5(1), 155-175.

Mills, M., van de Bunt, G. G., \& de Bruijn, J. (2006). Comparative Research Persistent Problems and Promising Solutions. International Sociology, 21(5), 619-631.

Minot, N., \& Benson, T. (2009). Fertilizer Subsidies in Africa: Are Vouchers the Answer. Washington DC.

Mireku, K. O., Kuusaana, E. D., \& Kidido, J. K. (2016). Legal implications of 
allocation papers in land transactions in Ghana-A case study of the Kumasi traditional area. Land Use Policy, 50, 148-155. https://doi.org/10.1016/j.landusepol.2015.09.015

MoFA-SRID. (2016). Agriculture in Ghana - Facts and Figures 2015. Accra: Ministry of Food and Agriculture. Retrieved from http://mofa.gov.gh/site/wp-content/uploads/2011/10/AGRICULTUREIN-GHANA-FF-2010.pdf

Molendijk, M., Morales, J., \& Lemmen, C. (2015). Light Mobile Collection Tools for Land Administration. GIM International. Retrieved from http://www.gim-international.com/content/article/light-mobilecollection-tools-for-land-administration

Mooya, M. M. (2009). Market Value without a Market: Perspectives from Transaction Cost Theory. Urban Studies, 46(3), 687-701. https://doi.org/10.1177/0042098008101002

Muchova, Z., \& Petrovic, F. (2010). Changes in the landscape due to land consolidations. Ekologia, 29(2), 140-157.

Muhinda, J. J. M., \& Dusengemungu, L. (2013). Farm Land Use Consolidationa Home Grown Solution for Food Security in Rwanda. Retrieved from http://rpfinkotanyi.org/en/IMG/pdf/Farm_Land_Use_Consolidation_in_R wanda.pdf

Mumbone, M., Bennett, R. M., Gerke, M., \& Volkmann, W. (2015). Innovations in Boundary Mapping: Namibia, Customary Lands and UAVs. In Linking Land Tenure and Use for Shared Properity. Washington DC: The World Bank.

Musahara, H., \& Huggins, C. (2005). Land Reform, Land Scarcity and PostConflict Reconstruction A Case Study of Rwanda. In J. Clover, C. Huggins, P. Kamungi-Mulemi, H. Musaraha, B. M. Ochieng, J. S. Oketch, ... K. Vlassenroot (Eds.), From the Ground Up (pp. 269-346). Pretoria: Institute for Social Studies. Retrieved from http://www.isn.ethz.ch/DigitalLibrary/Publications/Detail/?ots591=0c54e3b3-1e9c-be1e-2c24a6a8c7060233\&Ing=en\&id $=108497$

Musahara, H., Nyamulinda, B., Bizimana, C., \& Niyonzima, T. (2014). Land Use Consolidation and Poverty Reduction in Rwanda. In 2014 World Bank Conference on Land and Poverty. Washington DC: The World Bank.

Mwangi, E. (2007). Subdividing the Commons: Distributional Conflict in the Transition from Collective to Individual Property Rights in Kenya's Maasailand. World Development, 35(5), 815-834. https://doi.org/10.1016/j.worlddev.2006.09.012

Navratil, G., \& Frank, A. U. (2013). VGI for Land Administration. International Archives of the Photogrammetry, Remote Sensing and Spatial Information Sciences, $X L-2 / W 1$. Retrieved from http://www.int-archphotogramm-remote-sens-spatial-inf-sci.net/XL-2-

W1/159/2013/isprsarchives-XL-2-W1-159-2013.pdf 
NDPC. (2014). Ghana Shared Growth and Development Agenda (GSGDA), 2014-2017 (Medium-Term National Development Policy Framework No. II). Accra.

Netting, R. M. (1972). Of men and meadows: strategies of Alpine land use. Human Ecology, 4, 135-146.

Niroula, G. S., \& Thapa, G. B. (2005). Impacts and causes of land fragmentation, and lessons learned from land consolidation in South Asia. Land Use Policy, 22(4), 358-372.

North, D. C. (1990). Institutions, institutional change and economic performance. (J. Alt \& D. C. North, Eds.) (The Politi). Cambridge: Cambridge University Press.

Nothale, D. W. (1986). Land Tenure Systems and Agricultural Production in Malawi. In J. W. Arntzen, L. D. Ngcongco, \& S. D. Turner (Eds.), Land Policy and Agriculture in Eastern and Southern Africa. Tokyo: United Nations University.

Nzioki, N., Swazuri, M. A., Tracy-White, J., \& Yahya, S. (2013). Valuation of Unregistered Lands. London: Royal Institute of Chartered Surveyors (RICS). Retrieved from www.rics.org/research

Odhiambo, K. G. (2013). Land Consolidation and Settlement Reorganization The Rwandan Context. In Annual Word Bank Conference on Land and Poverty. Washington DC: The World Bank.

Ohene-Yankyera, K. (2004). Determinants of Farm Size in Land-Abundant Agrarian Communities of Northern Ghana. Journal of Science and Technology, 24(2), 45-53.

Ollennu, N. A. (1962). Principles of Customary Land Law in Ghana. London: Sweet and Maxwell.

Osei-Tutu, D., Asante, L. A., Appiah, M. N., Bendzako, T., \& Chigbu, U. E. (2016). Towards a Pro-Poor Customary Land Rights Security in Rural Ghana: Land Tenure Inventory Using Mobile Application by Local Youth. In World Bank Conference on Land and Poverty. Washington DC: The World Bank.

Ostrom, E. (1990). Governing the Commons. Cambridge: Cambridge University Press. Retrieved from http://wtf.tw/ref/ostrom_1990.pdf

Pallot, M., Trousse, B., Senach, B., \& Schaffers, H. (2011). Future internet and living lab research domain landscapes: filling the gap between technology push and application pull in the context of smart cities. EChallenges $E$ 2011. Retrieved from https://wwwsop.inria.fr/teams/axis/pages/bestpaper/2011-eChallenges-Nr-200eChallenges.pdf

Parsova, V., \& Kapostins, E. (2012). Does land consolidation fit everywhere? In Knowing to manage the territory, protect the environment, evaluate the cultural heritage. Rome: International Federation of Surveyors (FIG).

Pašakarnis, G., Morley, D., \& Maliene, V. (2012). Factors Influencing Land Consolidation Success: Lessons Learned in Lithuania. In E. Hepperle, R. 
Dixon-Gough, R. Mansberger, V. Maliene, J. Paulsson, \& A. Pödör (Eds.), Land Management: Potential, Problems and Stumbling Blocks Landmanagement (pp. 121-131). Zurich: European Academy for Land Tenure. Retrieved from http://vdf.ch/land-management-potentialproblems-and-stumbling-blocks-landmanagement-potenzialproblemfelder-und-stolpersteine-1525885909.html

Peters, M., Schneider, M., Griesshaber, T., \& Hoffmann, V. H. (2012). The impact of technology-push and demand-pull policies on technical change - Does the locus of policies matter? Research Policy, 41(8), 1296-1308. https://doi.org/10.1016/j.respol.2012.02.004

Pickett, K. (2015). Landmapp - Land Solutions as a Scalable Business. In Joint Workshop FIG Commission 3 \& 7: Crowdsourcing of Land Information. St. Julians, Malta: FIG. Retrieved from http://docs.wixstatic.com/ugd/3208e6_0097871437734f04a42249c452f 4ef39.pdf

Pingali, P. (2007). Agricultural Mechanization: Adoption Patterns and Economic Impact. In R. Evenson \& P. Pingali (Eds.), Handbook of Agricultural Economics (1st ed., Vol. 3, pp. 2779-2805). Elsevier.

Pingali, P., Bigot, Y., \& Binswanger, H. P. (1987). Agricultural Mechnization and the Evolution of Farming Systems in Sub-Saharn Africa. Baltimore and London: The Johns Hopkins University.

Pinstrup-Andersen, P. (2009). Food security: definition and measurement. Food Security, 1(1), 5-7. https://doi.org/10.1007/s12571-008-0002-y

Poorazizi, M., Hunter, A., \& Steiniger, S. (2015). A Volunteered Geographic Information Framework to Enable Bottom-Up Disaster Management Platforms. ISPRS International Journal of Geo-Information, 4(3), 13891422. https://doi.org/10.3390/ijgi4031389

Quiggin, J. (1995). Common property in agricultural production. Journal of Economic Behavior \& Organization, 26(2), 179-200. https://doi.org/10.1016/0167-2681(94)00008-3

Rahmatizadeh, S., Rajabifard, A., \& Kalantari, M. (2016). A conceptual framework for utilising VGI in land administration. Land Use Policy, 56, 81-89. https://doi.org/10.1016/j.landusepol.2016.04.027

Rajaonson, J., \& Tanguay, G. A. (2017). A sensitivity analysis to methodological variation in indicator-based urban sustainability assessment: a Quebec case study. Ecological Indicators, 83, 122-131. https://doi.org/10.1016/j.ecolind.2017.07.050

Rao, R. V. (2007). Decision Making in the Manufacturing Environment. (D. T. Pham, Ed.). London: Springer London. https://doi.org/10.1007/978-184628-819-7

Republic of Rwanda. Organic Land Law No. 08/2005 (2005).

RICS. (2017). RICS Valuation - Global Standards 2017. Royal Institute of Chartered Surveyors (RICS). Retrieved from http://www.rics.org/Global/red_book_2017_global_pgguidance_160617 
_rt.pdf

Rothstein, B. (2005). Social traps and the problem of trust. Cambridge University Press. Retrieved from http://www.cambridge.org/gb/academic/subjects/politics-internationalrelations/political-theory/social-traps-and-problem-trust?format=PB

Rubanje, I. (2016). Linking Land Use, Tenure and Consolidation. University of Twente.

Sabates-Wheeler, R. (2002). Consolidation initiatives after land reform: responses to multiple dimensions of land fragmentation in Eastern European agriculture. Journal of International Development, 14(7), 1005-1018.

Schaefer, P. F., \& Schaefer, C. (2014). An Innovative Approach to Land Registration in the Developing World Using Technology to Bypass the Bureaucracy (Policy Analysis No. 765). Washington DC.

See, L., Mooney, P., Foody, G., Bastin, L., Comber, A., Estima, J., ... Rutzinger, M. (2016). Crowdsourcing, Citizen Science or Volunteered Geographic Information? The Current State of Crowdsourced Geographic Information. ISPRS International Journal of Geo-Information, 5(5), 55. https://doi.org/10.3390/ijgi5050055

Shuai, Y., Chao-Fu, W., Xin-Yue, Y., \& You-Jin, L. (2011). The Ecological Compensation of Land Consolidation and Its Evaluation in Hilly Area of Southwest China. Energy Procedia, 5, 1192-1199.

Sims, B., \& Kienzle, J. (2016). Making Mechanization Accessible to Smallholder Farmers in Sub-Saharan Africa. Environments, 3(2), 11. https://doi.org/10.3390/environments3020011

Siriba, D. N., \& Dalyot, S. (2017). Adoption of volunteered geographic information into the formal land administration system in Kenya. Land Use Policy, 63, 279-287. https://doi.org/10.1016/j.landusepol.2017.01.036

Smith, B. (2003). Public policy and public participation engaging citizens and community in the development of public policy. Ottawa: Health Canada. Retrieved from https://atrium.lib.uoguelph.ca/xmlui/bitstream/handle/10214/3139/Smi th_Public_Policy_and_Public_Participation_Engaging_Citizens_and_Com munity_in_the_Development_of_Public_Policy_complete.pdf?sequence= 24

Soerensen, E. M. (1987). Lokal Landbrugsplanlægning - en undersøgelse af dansk jordfordelingspraksis 1979-84 og om forandring af landbrug og landskab (Serie om o). Aalborg: Aalborg Universitetsforlag. Retrieved from https://universe.ida.dk/MeetupFiles/DownloadFile?meetupNumber $=316$ 828\&fileid=5b8cb4a9-ef94-4191-8f61-08b719d53562

Song, W., \& Sun, G. (2010). The role of mobile volunteered geographic information in urban management. In 2010 18th International 
Conference on Geoinformatics (pp. 1-5). Beijing: IEEE.

Sonnenberg, J. (2002). Fundamentals of Land Consolidation as an Instrument to Abolish Fragmentation of Agricultural Holdings. In Land Consolidation: New Perspectives FIG XXII International Congress. Washington, DC: FIG.

Stefano, G. Di, Gambardella, A., \& Verona, G. (2012). Technology push and demand pull perspectives in innovation studies: Current findings and future research directions. Research Policy, 41(8), 1283-1295. https://doi.org/10.1016/j.respol.2012.03.021

Sui, D. Z. (2008). The wikification of GIS and its consequences: Or Angelina Jolie's new tattoo and the future of GIS. Computers, Environment and Urban Systems, 32(1), 1-5.

Swynnerton, R. J. M. (1955). The Swynnerton Report: A plan to intensify the development of African agriculture in Kenya. Nairobi: Government Press.

Takane, T. (2008). Customary Land Tenure, Inheritance Rules, and Smallholder Farmers in Malawi. Journal of Southern African Studies, 34(2), 269-291.

Tang, Y., Mason, R. J., \& Wang, Y. (2015). Governments' functions in the process of integrated consolidation and allocation of rural-urban construction land in China. Journal of Rural Studies, 42, 43-51. https://doi.org/10.1016/j.jrurstud.2015.09.010

Taylor, D. R. F. (1964). Changing Land Tenure and Settlement Patterns in the Fort Hall District of Kenya. Land Economics, 40(2), 234-237.

The Montpellier Panel. (2014). No Ordinary Matter: Conserving, Restoring, and Enhancing Africa's Soils. Dakar. Retrieved from https://ag4impact.org/wpcontent/uploads/2014/12/MP_0106_Soil_Report_LR1.pdf

The World Bank. (2016). Inflation, consumer prices (annual \%). Retrieved April 20, 2016 , from http://data.worldbank.org/indicator/FP.CPI.TOTL.ZG/countries/RW?displ ay= default

Thomas, J. (2006). Attempt on Systemization of Land Consolidation Approaches in Europe. Zeitschrift Für Geodisie, Geoinformation Und Landmanagement (ZfV), 131, 156-161.

Thurston, A. F. (1987). Smallholder Agriculture in Colonial Kenya: The Official Mind and the Swynnerton Plan. Cambridge: African Studies Centre.

Turner, A. (2006). Introduction to neogeography. O'Reilly Media, Inc.

Ubink, J. M., \& Quan, J. F. (2008). How to combine tradition and modernity? Regulating customary land management in Ghana. Land Use Policy, 25(2), 198-213. https://doi.org/10.1016/j.landusepol.2007.06.002

Udo, R. K. (1965). Disintegration of nucleated settlement in Eastern Nigeria. Geographical Review, 55(1), 53-67.

UN-Habitat. (2012). Handling Land - Innovative Tools for Land Governance and Secure Tenure. Nairobi: UN-Habitat/International Institute of Rural Reconstruction. 
UNECE. (2005). Social and Economic Benefits of Good Land Administration. London: HM Land Registry.

USAID. (2013). Literature Review for Land Use Consolidation and Crop Intensification in Rwanda. Kigali.

Uyan, M., Cay, T., \& Akcakaya, O. (2013). A Spatial Decision Support System design for land reallocation: A case study in Turkey. Computers and Electronics in Agriculture, 8-16. https://doi.org/10.1016/J.COMPAG.2013.07.010

Uyan, M., Cay, T., Inceyol, Y., \& Hakli, H. (2015). Comparison of designed different land reallocation models in land consolidation: A case study in Konya/Turkey. Computers and Electronics in Agriculture, 110, 249-258. https://doi.org/10.1016/j.compag.2014.11.022

Van der Molen, P. (2016). Food security, land use and land surveyors. Survey Review, 1-6. https://doi.org/10.1080/00396265.2015.1137159

Van der Molen, P., Lemmen, C., Van Dijk, T., \& Uimonen, M. (2004). Introducing the Subject of Modern Land Consolidation and Symposium report. In P. Van der Molen \& C. Lemmen (Eds.), Modern Land Consolidation (pp. 5-18). Fredericksberg: International Federation of Surveyors (FIG).

Van Dijk, T. (2002). Export of Planning Knowledge Needs Comparative Analysis: The Case of Applying Western Land Consolidation Experience in Central Europe. European Planning Studies, 10(7), 911-922.

Van Dijk, T. (2003a). Dealing with Central European land fragmentation: a critical assessment on the use of Western European instruments (PhD Thesis).

Van Dijk, T. (2003b). Scenarios of Central European land fragmentation. Land Use Policy, 20(2), 149-158.

Van Dijk, T. (2004). Land Consolidation as Central Europe's Panacea Reassessed. In P. van der Molen \& C. Lemmen (Eds.), Modern Land Consolidation2 (pp. 31-50). Fredericksberg: International Federation of Surveyors (FIG).

Van Dijk, T. (2007). Complications for traditional land consolidation in Central Europe. Geoforum, 38(3), 505-511.

Van Dijk, T., \& Kopeva, D. (2006). Land banking and Central Europe: future relevance, current initiatives, Western European past experience. Land Use Policy, 23(3), 286-301.

van Gils, H., Siegl, G., \& Bennett, R. (2014). The living commons of West Tyrol, Austria: Lessons for land policy and land administration. Land Use Policy, 38, 16-25. https://doi.org/10.1016/j.landusepol.2013.10.011

Van Huylenbroeck, G., Coelho, J. C., \& Pinto, P. A. (1996). Evaluation of land consolidation projects (LCPs): A multidisciplinary approach. Journal of Rural Studies, 12(3), 297-310. https://doi.org/10.1016/07430167(96)00024-1

Verma, N., \& Churchman, C. W. (1997). The Theory of the Firm: An 
Epistemological Analysis. Systems Practice, 10(6), 657-676.

Vitikainen, A. (2004). An Overview of Land Consolidation in Europe. Nordic Journal of Surveying and Real Estate Research, 1(1), 25-44.

Wheeler, P. T. (1973). Agriculture and agrarian land planning. In J. A. Dawson \& J. C. Doornkamp (Eds.), Evaluating the human environment: essays in applied geography, (pp. 34-56). London: Edward Arnold.

Williamson, I. P. (1985). Cadastres and Land Information Systems in Common Law Jurisdictions. Survey Review, 28.

Williamson, I. P., Enemark, S., Wallace, J., \& Rajabifard, A. (2010). Land administration for sustainable development. Redlands, California: ESRI.

Woodman, G. R. (1967). Developments in Pledges of Land in Ghanaian Customary Law. Journal of African Law, 11(1), 8-26. https://doi.org/10.2307/744465

Woodman, G. R. (1996). Customary Land Law in the Ghanaian Courts. Accra: Ghana Universities Press.

Wyatt, P. (1996). The development of a property information system for valuation using a geographical information system (GIS). Journal of Property Research, 13(4), 317-336. https://doi.org/10.1080/095999196368826

Wynn, D. C., \& Clarkson, P. J. (2018). Process models in design and development. Research in Engineering Design, 29(2), 161-202. https://doi.org/10.1007/s00163-017-0262-7

Yadlapalli, A., Rahman, S., \& Gunasekaran, A. (2018). Socially responsible governance mechanisms for manufacturing firms in apparel supply chains. International Journal of Production Economics, 196, 135-149. https://doi.org/10.1016/j.ijpe.2017.11.016

Yimer, F. (2014). Fit-for-Purpose Land Consolidation: An Innovative Tool for Re-Allotment in Rural Ethiopia (MSc Thesis). Enschede: University of Twente-ITC. Retrieved from https://www.itc.nl/library/papers_2014/msc/la/yimer.pdf

Young, M. N., Tsai, T., Wang, X., Liu, S., \& Ahlstrom, D. (2014). Strategy in emerging economies and the theory of the firm. Asia Pacific Journal of Management, 31(2), 331-354.

Yu, G., Feng, J., Che, Y., Lin, X., Hu, L., \& Yang, S. (2010). The identification and assessment of ecological risks for land consolidation based on the anticipation of ecosystem stabilization: A case study in Hubei Province, China. Land Use Policy, 27(2), 293-303. Retrieved from http://www.sciencedirect.com/science/article/pii/S0264837709000386

Zahedi-Seresht, M., Jahanshahloo, G.-R., \& Jablonsky, J. (2017). A robust data envelopment analysis model with different scenarios. Applied Mathematical Modelling, 52, 306-319. https://doi.org/10.1016/j.apm.2017.07.039

Zevenbergen, J. A. (2004). A systems approach to land registration and cadastre. Nordic Journal of Surveying and Real Estate Research, 1. 
Zevenbergen, J. A., \& Augustinus, C. (2011). Designing a pro poor land recordation system. In FIG Working Week 2011: Bridging the Gap Between Cultures. Marrakech, Morocco: FIG.

Zevenbergen, J. A., Augustinus, C., Antonio, D., \& Bennett, R. M. (2013). Propoor land administration: Principles for recording the land rights of the underrepresented. Land Use Policy, 31, 595-604.

Zhang, X., Ye, Y., Wang, M., Yu, Z., \& Luo, J. (2018). The micro administrative mechanism of land reallocation in land consolidation: A perspective from collective action. Land Use Policy, 70, 547-558. https://doi.org/10.1016/J.LANDUSEPOL.2017.09.056 


\section{Summary}

Land consolidation has been used to reduce the effects of land fragmentation in many parts of the world in order to increase food productivity and food security, amongst other benefits. However, its use on customary lands has been limited. Land fragmentation on customary lands has two main causes the nature of the customary land tenure system, and the somewhat linked agricultural system. The attempts to increase food productivity on customary lands have mostly involved fertilisation, and mechanisation. But with the small and scattered farmlands, these approaches fall short of increasing food productivity. Previous attempts at land consolidation have involved directly transferring land consolidation approaches from other regions of the world. These have failed as little consideration were given to the local conditions of customary lands. This thesis suggests the use of responsible approaches; ones that continuously consider and align technical and administrative conditions, and internal processes inherent to land consolidation, to the dynamic local societal demands, economic conditions, and cultural and legal requirements. To this end, this thesis aimed to develop a responsible land consolidation approach for customary lands. For this purpose, using Ghana as a case, four specific objectives are addressed.

First, to explore how the factors need to be addressed to develop a responsible land consolidation approach for customary lands, a comparative study was conducted between Ghana and three other countries. The factors when selecting a land consolidation strategy were identified for three countries with existing land consolidation strategies: The Netherlands, Lithuania, and Rwanda. These were set against Ghana, which has no land consolidation strategy, but has customary lands. The comparison found that certain factors in the countries with land consolidation - the government support; the prior existence of conventional land markets; an individual land tenure system; and the coverage of a functioning land information system were all absent in Ghana. The comparison concluded that these factors that differ require ways to be addressed and adapted in order to develop a responsible land consolidation strategy for Ghana's customary areas.

Second, in order get a land information to support responsible land consolidation on customary lands, the next chapter develops and assesses an approach for collecting land information to support responsible land consolidation on customary lands. The concept of Participatory Land Administration (PLA) is then developed in the context of crowdsourced, voluntary, and participatory approaches alongside newly related insights into neogeography and neo-cadastre, and fit-for-purpose and pro-poor land administration. The PLA concept is experimented in Northern Ghana, where the process was developed together with the local farming community. The 
experiment involved collecting land information relating to farms over a twoweek period, using a mobile app and a satellite image, based on PLA. The results show that PLA can potentially support land consolidation as the land information collected supports land consolidation, and the local people's involvement gave them a sense of ownership of the results.

Third, as there is no land market to provide support to land consolidation as a basis for comparison of farmland parcels, a land valuation approach to support responsible land consolidation on customary lands is developed and assessed. Using a Multiple Attribute Decision-Making (MADM) approach, the Land Value Indices is developed to assign quid pro quo land values to customary farmland parcels, based on the local people's view of land value. In a case study of Nanton, Ghana, key land value factors were identified and weighted by the local community. The weights were integrated into the framework that produced a Land Value Index for each farmland parcel. The strength of the approach is found in scenario and sensitivity analyses. However, the prime weakness of this approach is that it is more expensive to use than automatic valuation models.

The presence of the customary land tenure system limits the use of conventional land reallocation techniques available. Hence the framework of a process model for a reallocation approach to support responsible land consolidation on customary lands is developed and assessed. Using the process model approach, the key characteristics of customary land tenure and the general requirements for land re-allocation of these lands were identified; from which a land re-allocation approach is developed. This is subsequently applied to a case study in Northern Ghana. The results show that even though the approach is successful to the extent that land fragmentation (physical and legal) is significantly reduced in the study area within family lands; social land mobility, land tenure and cultural practices hinder the application of the land re-allocation between families, as this would either increase legal or physical land fragmentation.

In conclusion, land consolidation can be used to reduce land fragmentation and increase food productivity on customary lands. However, this is limited by the balance between reducing physical or land tenure fragmentation, as the reduction of the former leads to an increase in the later and vice versa. Further studies have to be conducted to overcome the balance between reducing physical land fragmentation on one hand and land tenure fragmentation on the other hand. The results of this thesis contribute to knowledge and literature, by broadening the knowledge on the transfer of land management activities to customary lands. To policy formulation and implementation, the results show that the need for land policies to consider the gap between land information collection or the building of a cadastre on the one hand and sustainable 
development on the other. In terms of food policy, the results enrich the need for a stronger link between food policy and land policy, especially in terms of food productivity. In terms of meeting societal challenges and needs, though the focus of this work is on food security, the developed land administration processes provide support for other societal needs and goals such as economic and infrastructural development, disaster risk management, climate change adaptation, and large-scale land acquisitions. 


\section{Samenvatting}

Ruilverkaveling wordt in vele delen van de wereld toegepast om de effecten van landfragmentatie te verminderen, onder andere om de voedselproductiviteit en voedselzekerheid te verhogen. Toepassing in gebieden met traditioneel grondeigendom was echter beperkt. Landfragmentatie bij traditioneel grondeigendom heeft twee belangrijke oorzaken - de aard van het gebruikelijke systeem van grondeigendom en het enigszins gekoppelde landbouwsysteem. De pogingen om de voedselproductiviteit op de traditionele gronden te verhogen, hadden voornamelijk betrekking op bemesting en mechanisatie. Maar met de kleine en verspreide landbouwpercelen schieten deze benaderingen voor het verhogen van de voedselproductiviteit tekort. Eerdere pogingen tot ruilverkaveling hadden te maken met het rechtstreeks overbrengen van de ruilverkavelingsaanpak uit andere delen van de wereld. Deze zijn mislukt omdat er weinig aandacht was voor de lokale omstandigheden van de traditionele grondeigendom systeem. Dit proefschrift beveelt het gebruik van verantwoorde benaderingen aan; benaderingen die continu technische en administratieve voorwaarden en interne processen overwegen die inherent zijn aan ruilverkaveling, en de dynamische plaatselijke maatschappelijke eisen, economische omstandigheden en culturele en wettelijke vereisten. Dit proefschrift is gericht op het ontwikkelen van een verantwoorde benadering van ruilverkaveling in gebieden met een traditioneel grondeigendom systeem. Voor dit doel, met Ghana als case studie, worden vier specifieke doelstellingen bestudeerd.

Ten eerste, om te onderzoeken welke factoren in ogenschouw moeten worden genomen om een verantwoorde ruilverkavelingaanpak voor traditioneel grondeigendom te ontwikkelen, werd een vergelijkende studie uitgevoerd tussen Ghana en drie andere landen. De factoren bij het selecteren van een ruilverkavelingstrategie werden geïdentificeerd voor drie landen met bestaande ruilverkavelingstrategieën: Nederland, Litouwen en Rwanda. Deze werden vergeleken met Ghana, dat geen strategie voor ruilverkaveling heeft, maar over traditionele landerijen beschikt. De vergelijking wees uit dat bepaalde factoren in de landen met ruilverkaveling - overheidssteun; het reeds bestaan van conventionele grondmarkten; een individueel landeigendomssysteem; en de dekking van een functionerend landinformatiesysteem - allemaal afwezig waren in Ghana. Uit deze vergelijking kan worden geconcludeerd dat deze factoren moeten worden aangepakt en aangepast om een verantwoorde ruilverkavelingsstrategie voor de traditionele landerijen van Ghana te ontwikkelen.

Ten tweede, om eigendomsinformatie te verkrijgen ter ondersteuning van een verantwoorde ruilverkaveling voor traditionele landerijen, wordt in dit proefschrift een aanpak ontwikkeld en beoordeeld voor het verzamelen van 
landinformatie ter ondersteuning van de verantwoorde ruilverkaveling voor traditionele landerijen. Het concept van Participatory Land Administration (PLA) wordt vervolgens ontwikkeld in de context van crowdsourced, vrijwillige en participatieve benaderingen naast nieuwe gerelateerde inzichten in neogeografie en neo-kadaster, en passend voor het doel (fit-for-purpose) en 'pro-poor' land administratie. Met dit PLA-concept is geëxperimenteerd in Noord-Ghana, waar het proces is ontwikkeld in samenwerking met de lokale boerengemeenschap. Het experiment bestond uit het verzamelen van eigendomsinformatie over de boerderijen gedurende een periode van twee weken op basis van PLA, met behulp van een mobiele applicatie en een satellietbeeld. De resultaten tonen aan dat PLA door middel van de verzamelde eigendomsinformatie ruilverkaveling mogelijk kan ondersteunen, waarbij de lokale bevolking een gevoel kreeg van eigenaarschap van de resultaten vanwege hun betrokkenheid.

Ten derde, aangezien er geen grondmarkt is om ondersteuning te bieden aan ruilverkaveling als basis voor de vergelijking van landbouwpercelen, is een methodiek van grondwaarderingen ter ondersteuning van verantwoorde ruilverkaveling voor traditionele landerijen ontwikkeld en beoordeeld. Met behulp van een MADM-benadering (Multiple Attribute Decision-Making), zijn de factoren voor grondwaarden (Land Value Indices) ontwikkeld om quid pro quogrondwaarden toe te wijzen aan de traditionele landbouwpercelen, op basis van de mening van de lokale bevolking over de waarde van het land. In een case studie van Nanton, Ghana, werden de belangrijkste grondwaardefactoren geïdentificeerd en gewogen door de lokale gemeenschap. De gewichten werden geïntegreerd in een methode die een landwaarde-index voor elk landbouwperceelperceel produceert. De kracht van deze aanpak is te vinden in de scenario- en gevoeligheidsanalyses. De grootste zwakte van deze aanpak is echter dat deze duurder is in gebruik in vergelijking met automatische waarderingsmodellen.

Op de vierde plaats beperkt de aanwezigheid van het traditionele grondeigendom systeem het toepassen van conventionele grondherverdelingstechnieken die beschikbaar zijn. Daarom is een raamwerk voor een procesmodel voor de aanpak van herverdeling ter ondersteuning van verantwoorde ruilverkaveling van traditionele landerijenontwikkeld en beoordeeld. Met behulp van de procesmodelbenadering zijn de belangrijkste kenmerken van het traditionele grondeigendom en de algemene vereisten voor grondherverdeling van deze gronden geïdentificeerd; van waaruit een aanpak voor grondherverdeling wordt ontwikkeld. Dit is vervolgens toegepast op een case studie in Noord-Ghana. De resultaten tonen aan dat, hoewel de aanpak succesvol is in die mate dat landfragmentatie (fysiek en juridisch) aanzienlijk wordt verminderd voor grondeigendom binnen een familie; sociale grondmobiliteit, grondbezit en culturele praktijken belemmeren de toepassing 
van de herverdeling van grond tussen families, omdat die of de juridische of fysieke landfragmentatie zou vergroten.

Tot slot kan ruilverkaveling worden gebruikt om landfragmentatie te verminderen en de voedselproductiviteit van de traditionele landerijen te verhogen. Dit wordt echter beperkt door de balans tussen de fysieke fragmentatie of fragmentatie van het grondbezit, omdat de reductie van de eerste leidt tot een toename van de laatste en omgekeerd. Nader onderzoek zal moeten worden uitgevoerd om de balans tussen het verminderen van fysieke landfragmentatie en fragmentatie van grondbezit te overbruggen. De resultaten van dit proefschrift dragen bij aan kennis en literatuur, door verbreding van de kennis over de overdracht van grondbeheeractiviteiten naar traditionele landerijen. Wat betreft de formulering en de uitvoering van het beleid tonen de resultaten aan dat er behoefte is aan grondbeleid om de kloof te verkleinen tussen de verzameling van eigendomsinformatie of de ontwikkeling van een kadaster enerzijds en duurzame ontwikkeling anderzijds. Wat het voedselbeleid betreft, verrijken de resultaten de behoefte aan een sterkere link tussen het voedselbeleid en het grondbeleid, met name wat betreft voedselproductiviteit. Alhoewel de focus van dit werk ligt op voedselzekerheid, voor het voldoen aan maatschappelijke uitdagingen en behoeften bieden de ontwikkelde landadministratieprocessen ook ondersteuning aan andere maatschappelijke behoeften en doelen zoals economische en infrastructurele ontwikkeling, rampenrisicobeheersing, aanpassing aan klimaatverandering en grootschalige grondaankopen. 


\section{About the Author}

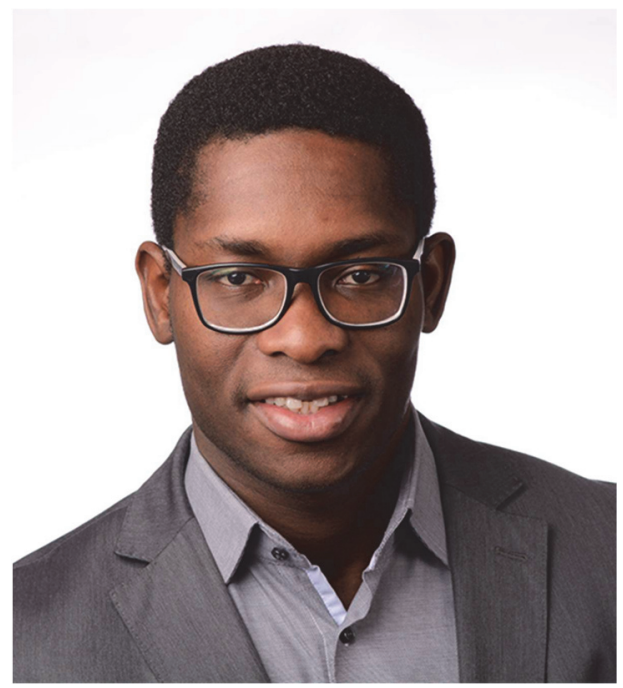

Kwabena Obeng Asiama was born on the $28^{\text {th }}$ of November, 1989 in Kumasi, Ghana. He undertook his basic education at the Kwame Nkrumah University of Science and Technology (KNUST) Basic Schools, Kumasi. He went on to Mfantsipim where he completed his senior secondary school education in 2007. He spent a year afterwards on the AFS intercultural exchange programme in Keyser, West Virginia, USA, where he attended and graduated from Keyser High School. He was awarded a Bachelor of Science degree in Land Economy from KNUST in 2012. He then undertook his mandatory national service as an assistant land management officer at Newmont Golden Ridge Limited, a subsidiary of Newmont Mining Corporation. In 2013, he furthered his studies at the University of Twente-ITC where he was awarded a Master of Science in Geo-Information Science and Earth Observation for Land Administration in 2015. In the same year, he started his four-year PhD research. As a PhD candidate, Kwabena was also involved in teaching and supervising MSc students. He received the FIG-Survey Review Prize at the XXVI FIG Congress in Istanbul for the best peer review paper of the conference in 2018. He is currently the Vice Chair of the International Federation of Surveyors Young Surveyors Network (FIG YSN), a network under the umbrella of FIG for young professionals and students of surveying, cadastre, valuation, mapping, geodesy, geospatial, and quantity surveying.

Kwabena's research interests span harnessing geo-spatial technological advances and innovative digital developments to meet and tackle the societal needs and challenges of the Global South such as food security, environmental protection, rapid urbanization, informal economies, and gender access to land, towards sustainable development. He is result-driven, with a strong capacity to lead teams and collaborate with others to achieve set all objectives, whilst ensuring smooth operations. 


\section{ISI Web of Science Publications}

Asiama, K. O., Bennett, R. M., Zevenbergen, J. A., \& Da Silva Mano, A. (2019). Responsible consolidation of customary lands: A framework for land reallocation. Land Use Policy, 83, 412-423. https://doi.org/10.1016/j.landusepol.2019.02.006

Asiama, K. O., Bennett, R., Zevenbergen, J., \& Asiama, S. O. (2018). Land valuation in support of Responsible Land Consolidation on Ghana's Rural Customary Lands. Survey Review, 1-13. https://doi.org/10.1080/00396265.2018.1467672 (FIG Paper of the Month, July, 2018)

Asiama, K. O., Bennett, R. M., \& Zevenbergen, J. A. (2017). Land consolidation on Ghana's rural customary lands: Drawing from The Dutch, Lithuanian and Rwandan experiences. Journal of Rural Studies, 56, 8799. https://doi.org/10.1016/J.JRURSTUD.2017.09.007

Asiama, K. O., Bennett, R. M., \& Zevenbergen, J. A. (2017). Participatory Land Administration on Customary Lands: A Practical VGI Experiment in Nanton, Ghana. ISPRS International Journal of Geo-Information, 6(7), 186. https://doi.org/10.3390/ijgi6070186

\section{Other Peer Reviewed Journals}

Asiama, K. O., Lengoiboni, M. N., \& van der Molen, P. (2017). In the Land of the Dammed: Assessing Governance in Resettlement of Ghana's Bui Dam Project. Land, 6(4), 80. https://doi.org/10.3390/land6040080

Asiama, K. O., Bennett, R. M., \& Zevenbergen, J. A. (2017). Land Consolidation for Sub-Saharan Africa's Customary Lands - The Need for Responsible Approaches. American Journal of Rural Development, Vol. 5, 2017, Pages 39-45, 5(2), 39-45. https://doi.org/10.12691/AJRD-5-2-2

\section{Conference Papers and Presentations}

Asiama, K. O., Bennett, R. M., Zevenbergen, J., \& Da Silva Mano, A. (2019). Responsible Consolidation of Customary Lands: A Framework for Land Reallocation. In FIG Working Week 2019: Geospatial information for a smarter life and environmental resilience. Hanoi: International Federation of Surveyors (FIG). Retrieved from http://www.fig.net/resources/proceedings/fig_proceedings/fig2019/pap ers/ts05h/TS05H_asiama_bennett_et_al_9867.pdf

Asiama, K. O., \& Asiama, S. O. (2018). Across Traditions and Modernity: The Asante Woman's Access to Land. In LANDac Annual Conference (p. 41). Utrecht: LANDac. Retrieved from http://www.landgovernance.org/annual-internationalconference/presentations/ 
Asiama, K. O., Bennett, R. M., Zevenbergen, J. A., \& Asiama, S. O. (2018). Land Valuation in support of Responsible Land Consolidation on Ghana's Rural Customary Lands. In Embracing our Smart World where the Continents Connet: Enhancing the Geospatial Maturity of Societies. Istanbul: International Federation of Surveyors (FIG). Retrieved from http://fig.net/resources/proceedings/fig_proceedings/fig2018/papers/ts1 0i/TS10I_asiama_bennett_et_al_9214_abs.pdf

Asiama, K. O., Bennett, R. M., \& Zevenbergen, J. A. (2018). Participation, Innovative Approaches and Customary Cadastres: A Practical VGI Experiment in Nanton, Ghana. In Annual Word Bank Conference on Land and Poverty. Washington, DC: The World Bank. Retrieved from https://www.conftool.com/landandpoverty2018/index.php/08-05Asiama-128_paper.pdf?page $=$ downloadPaper\&filename $=08-05-$ Asiama128_paper.pdf\&form_id=128\&form_version=final

Asiama, K. O., Bennett, R. M., \& Zevenbergen, J. A. (2017). Fitting the Needs of Customary Lands: An Experiment into Smartphone Surveys. In LANDac International Conference on Land Governance for Equitable and Sustainable Development. Utrecht: LANDac.

Kohli, D., Bennett, R. M., Lemmen, C., Asiama, K. O., Morales, A., Pinheiro, A., Wayumba, R., Zevenbergen, J. (2017). A Quantitative Comparison of Completely Visible Cadastral Parcels Using Satellite Images: A Step towards Automation. In FIG Working Week 2017 - Surveying the world of tomorrow - From digitalisation to augmented reality. Helsinki, Finland: International Federation of Surveyors (FIG).

Asiama, K. O., Bennett, R., \& Zevenbergen, J. A. (2016). Land Consolidation for Sub-Saharan Africa's Customary Lands - The Need for Responsible Approaches. In Symposium on Land Consolidation and Land Readjustment for Sustainable Development (pp. 293-305). Apeldoorn: Kadaster. Retrieved from https://www.oicrf.org/documents/40950/43224/Land+consolidation+for +sub+saharan+s+customary+lands+the+need+for+responsible+appro aches.pdf/320b8b72-28ea-3c13-9854-a0e5ebd4aafb

Rubanje, I., Bennett, R. M., Vrieling, A., \& Asiama, K. O. (2016). A Tale of Two Cases - Linking Land Use, Tenure and Consolidation in Rwanda. In LANDac International Conference on Land Governance for Equitable and Sustainable Development. Utrecht: LANDac.

Asiama, K. O., Bennett, R., \& Zevenbergen, J. A. (2015). Participatory Land Administration: A New Vista towards Responsible Land Consolidation in Customary Lands? In Joint Workshop FIG Commission 3 \& Commission 7: Crowdsourcing of Land Information. Malta: International Federation of Surveyors (FIG).

Bennett, R. M., Asiama, K. O., \& Zevenbergen, J. A. (2015). The Intelligent Cadastre. In Joint Workshop FIG Commission 3 \& Commission 7: Crowdsourcing of Land Information. St. Julians, Malta: International 
Federation of Surveyors (FIG).

Asiama, K. O., Lengoiboni, M. N., \& van der Molen, P. (2015). Compulsory Land Acquisition and Resettlement on Customary Lands in Ghana - A Governance Perspective. In LANDac International Conference on Land Governance for Equitable and Sustainable Development. Utrecht: LANDac. 